\title{
"You Can't Stop The Bell From Ringing." Protean, Unpredictable, And Persisting: The Victim Impact Statement In The Context Of Sexually Assaulted Women.
}

\author{
by \\ Karen-Lee Miller, MA, MSW \\ A thesis submitted in conformity with the requirements \\ for the degree of Doctor of Philosophy \\ Dalla Lana School of Public Health \\ University of Toronto
}

(c) Karen-Lee Miller 2015 


\title{
"You Can't Stop The Bell From Ringing." Protean, Unpredictable, And Persisting: The Victim Impact Statement In The Context of Sexually Assaulted Women.
}

\author{
Karen-Lee Miller \\ Doctor of Philosophy \\ Dalla Lana School of Public Health \\ University of Toronto \\ 2015
}

\begin{abstract}
The victim impact statement (VIS) is a victim's voluntarily written account of a range of harms experienced as a consequence of a crime. Rarely is the VIS investigated specific to sexual assault or from a theoretical perspective. This qualitative study was designed to address these gaps. Interviews were conducted with 44 participants who sought or provided VIS-related services in Canada. Findings were analyzed using insights from actor-network theory.
\end{abstract}

Findings of the overall study are presented through three distinct but interrelated papers. "Obliging Detours" (Miller, submitted) describes the development of the VIS in Canada, and its multiple, innovative, and unauthorized pathways of use. These pathways created novel opportunities, demands, and risks for sexual assault victims, particularly those who were mothers, female offenders, or had been excluded at trial. "Relational Caring" (Miller, 2014) identifies an ethic of care that underpinned use of the VIS by sexually assaulted women. Victims prioritized the well-being of others by constructing VIS narratives that privileged the harms experienced by others, protected future victims, and promoted the interests of intimate partner offenders. Victims who were mothers, 
especially those abused as minors, and those who were intimate partners of their offenders were particularly implicated. "Purposing and Repurposing Harms" (Miller, 2013) demonstrates how harm descriptions were manipulated by victims and others in keeping with, and contrary to, legislators' design of the VIS. VIS repurposing occurred through victims' practices of strategic disclosure, which was intended to effect changes in others' behaviours, and harm peddling, which was the circulation of the VIS in nonsentencing arenas by victims and nonvictims to obtain compensation, child custody, and parole delay.

Taken together, the findings revealed that the VIS has a protean nature that is produced by structural and relational factors, and lends itself to multiple uses in multiple contexts. VIS-related outcomes and the effects on victims and others could neither be wholly predicted nor prevented, and involved interactions beyond the criminal court setting. The protean, unpredictable, and persisting positive and negative effects of the VIS hold promise — and danger — for sexual assault victims. 


\section{Acknowledgements}

Sincere thanks are owed to the women who were sexually assaulted and whose experiences are represented here. My heart often ached after the interviews, but never did I cry as much as I learned. Nonvictim participants spoke earnestly, and frankly, about the merits and the dangers of the victim impact statement in the context of sexual assault; thank you.

I am also deeply appreciative of the skilled and supportive guidance offered by my thesis supervisor, Janice Du Mont, and thesis committee members Ted Myers and Dan Allman. In addition to her doctoral supervision, Jan has been a mentor since I was a graduate social work student, and provided the original research opportunities from which I launched a qualitative health research career. I have a great deal to thank her for. Thanks too to thesis defence examiners Holly Johnson and Robin Mason, both of whom I have greatly admired for many years.

Completing this dissertation would not have been possible without the insights and timely cheerleading of Dean Faye Mishna, Pia Kontos, Alkis Kontos, Ruth Croxford, Joan Eakin, Lori Ferris, Ernie Lightman, Nora Currie, and Kim Pate. Mariana Valverde deserves special mention for introducing (a reluctant) me to ANT, which continues to transform how I view social relations. Thoughtful critiques were offered by Andrea Quinlan, Julian Roberts, Marie Manikis, Susan Bandes, Amanda Konradi, Susan McDonald, and reviewers from Qualitative Health Research and Violence and Victims.

Funding was provided by the Frederick Banting and Charles Best Canada Graduate Scholarship of the Canadian Institutes of Health Research, the Policy Centre for Victim Issues of the Department of Justice Canada, and the University of Toronto. Portions of this work were presented at conferences held by End Violence Against Women (EVAWI), the Sexual Violence Research Initiative, and the International Congress of Qualitative Inquiry. Thanks to EVAWI, the Office of Research Trainees at the University Health Network, and the Ontario Ministry of Research and Innovation Trainee Program for sponsoring my dissertation-related presentation travel.

Personal thanks are extended to Gary Beauchamp (most especially), Ross Anderson, Sheila and Suzanne Marshall, John Miller, Romeo Colobong, Ada Wong, Suzanne Payne, Susan Caldwell, Molly Fitzpatrick, Lynn Davidson, Christine Dunbar, Shayne Fogle, Forbes Robertson, Jessica Babineau, Sharon Kelly, Darryl Singer, Peigi Ross, Faisal Joseph, Grace Liu, Peter Coyte, and Gail Gibbs. 
For Johnny above all, of course

and for Miki, Anila Ann, and Tovah 


\section{Contents}

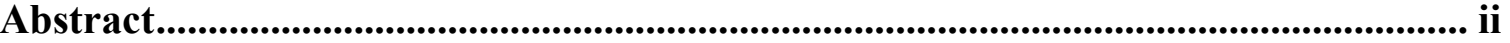

Acknowledgements ...................................................................................................................iv

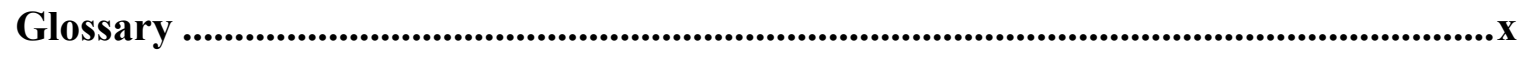

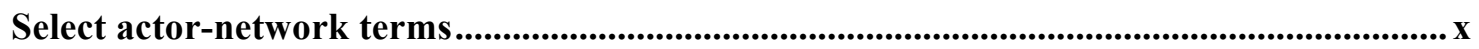

Select criminal justice system terms ................................................................................................

Introduction......................................................................................................................................1

Chapter 1-Background ............................................................................................................5

Historical Origins of the Role of Victim .........................................................................................5

The Victim Impact Statement (VIS) .............................................................................................. 7

The Canadian Context ........................................................................................................................9

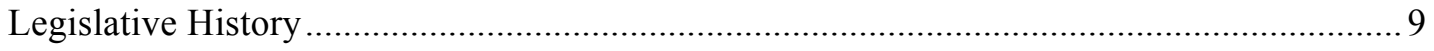

Provincial Implementation Programs …………........................................................... 12

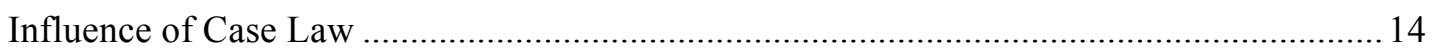

Discretionary and Proposed Considerations of the VIS ....................................................... 19

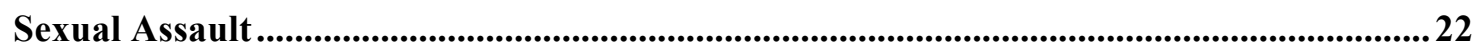

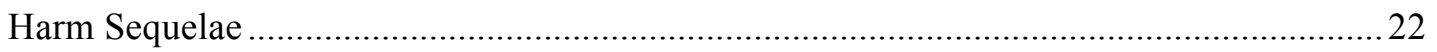

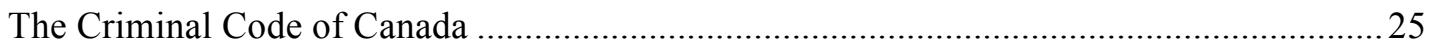

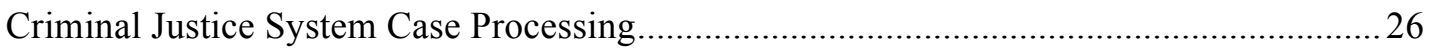

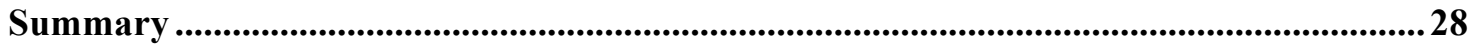

Chapter 2-Literature Review ............................................................................................29

Victim Participation and Motivation...........................................................................................29

Courtroom Workgroup ..................................................................................................................33

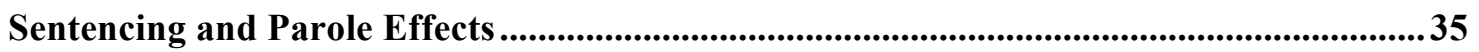

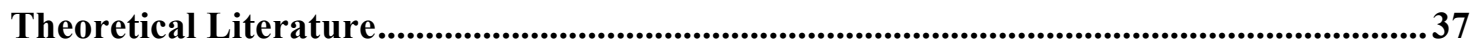

Victim Impact Statement and Sexual Assault Research...................................................43

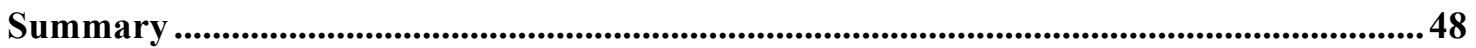

The Present Study .................................................................................................................................... 48

Chapter 3-Actor-Network Theory as a Sensitizing Lens........................................50

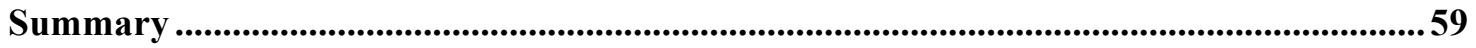

Chapter 4-Method ...........................................................................................................................61 


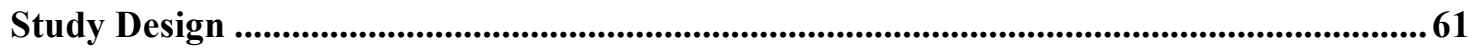

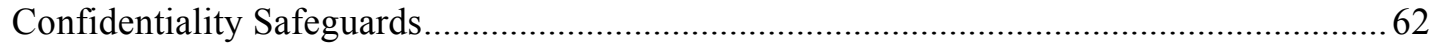

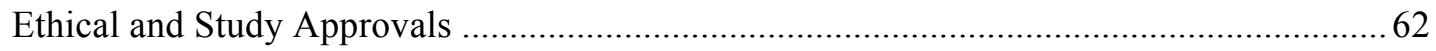

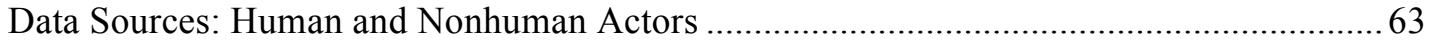

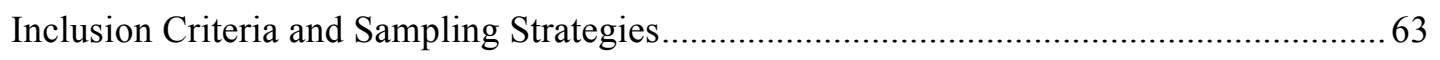

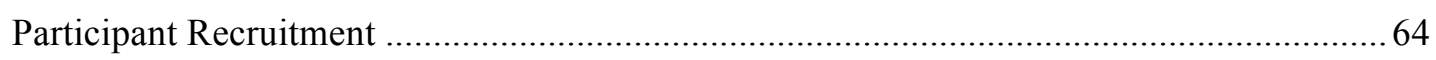

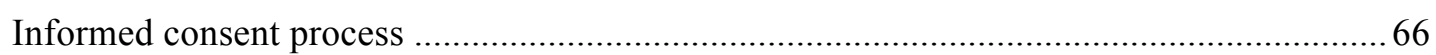

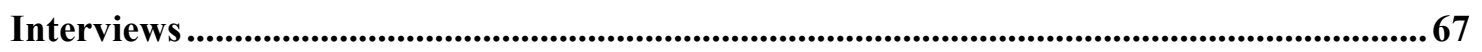

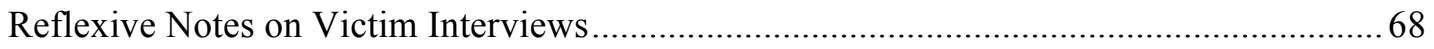

Analysis..................................................................................................................................................... 71

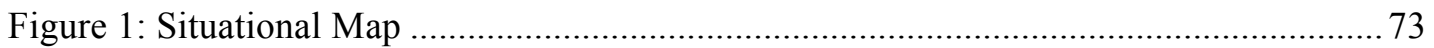

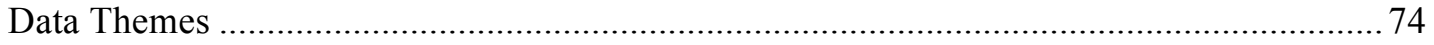

Figure 2: Analytic Development of Data Themes ............................................................. 76

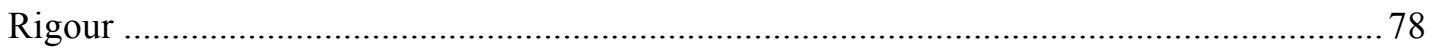

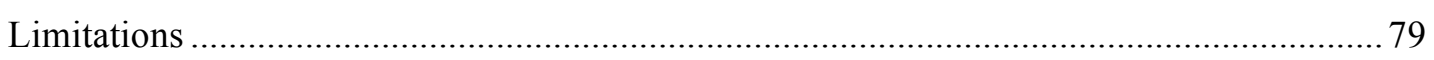

Chapter 5-Participant and Case Characteristics ....................................................81

Participant Characteristics............................................................................................................. 81

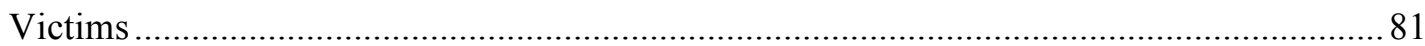

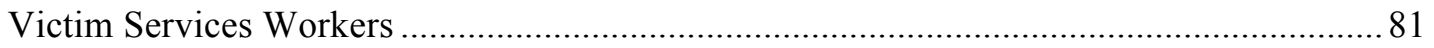

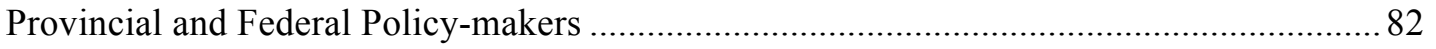

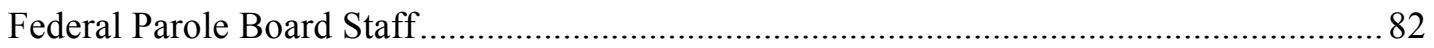

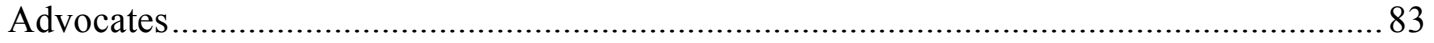

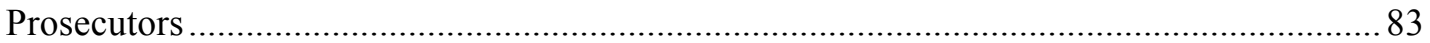

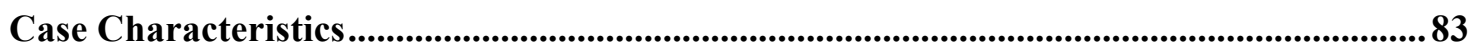

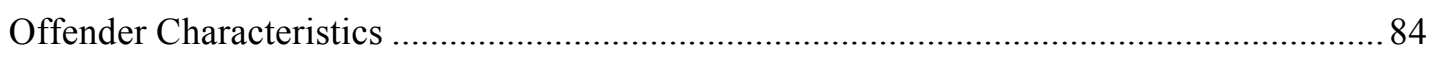

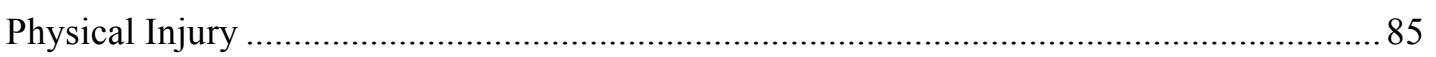

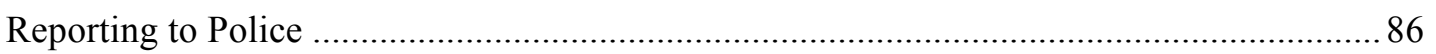

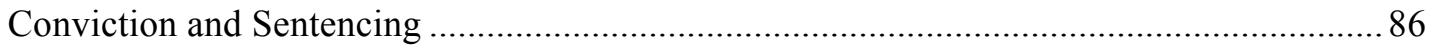

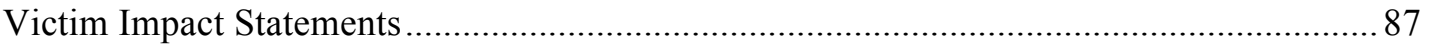

\section{Chapter 6-Obliging Detours: An Actor-Network Analysis of the Victim Impact}

Statement Involving Sexually Assaulted Women in Canada........................................88

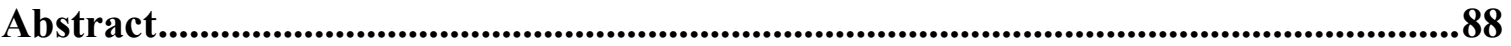

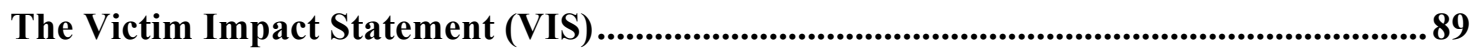

Actor-Network Theory (ANT) ….....................................................................................................91

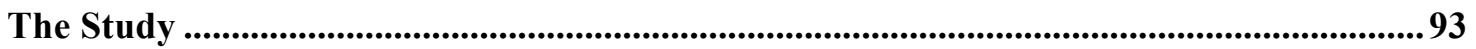


Procedure and Participants.

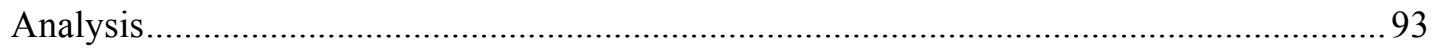

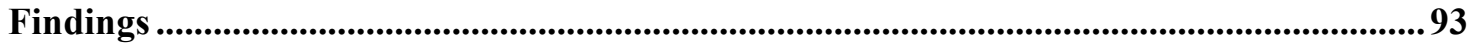

Mobilization to Multiplicity .........................................................................................99

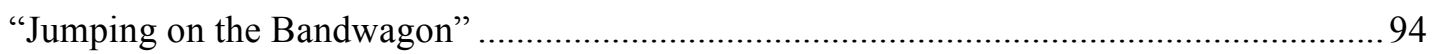

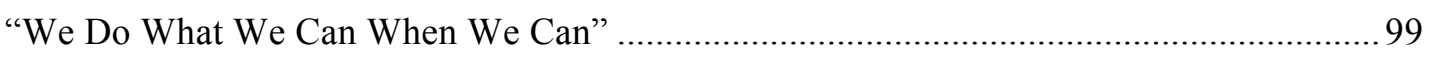

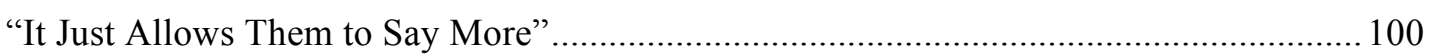

Intermediary Scripts and Injunctions to Act................................................................ 103

"You Can't Stop the Bell from Ringing" .................................................................. 103

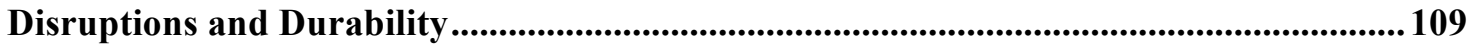

“At One Point We Obviously Loved Each Other”: Intimate Partner Sexual Assault......... 109

"Vulnerable to a Suggestion That Their Fault Continues": Victims in Conflict with the Law

Discussion

Chapter 7-Relational Caring: The Use of the Victim Impact Statement by Sexually Assaulted Women ..................................................................................................................127

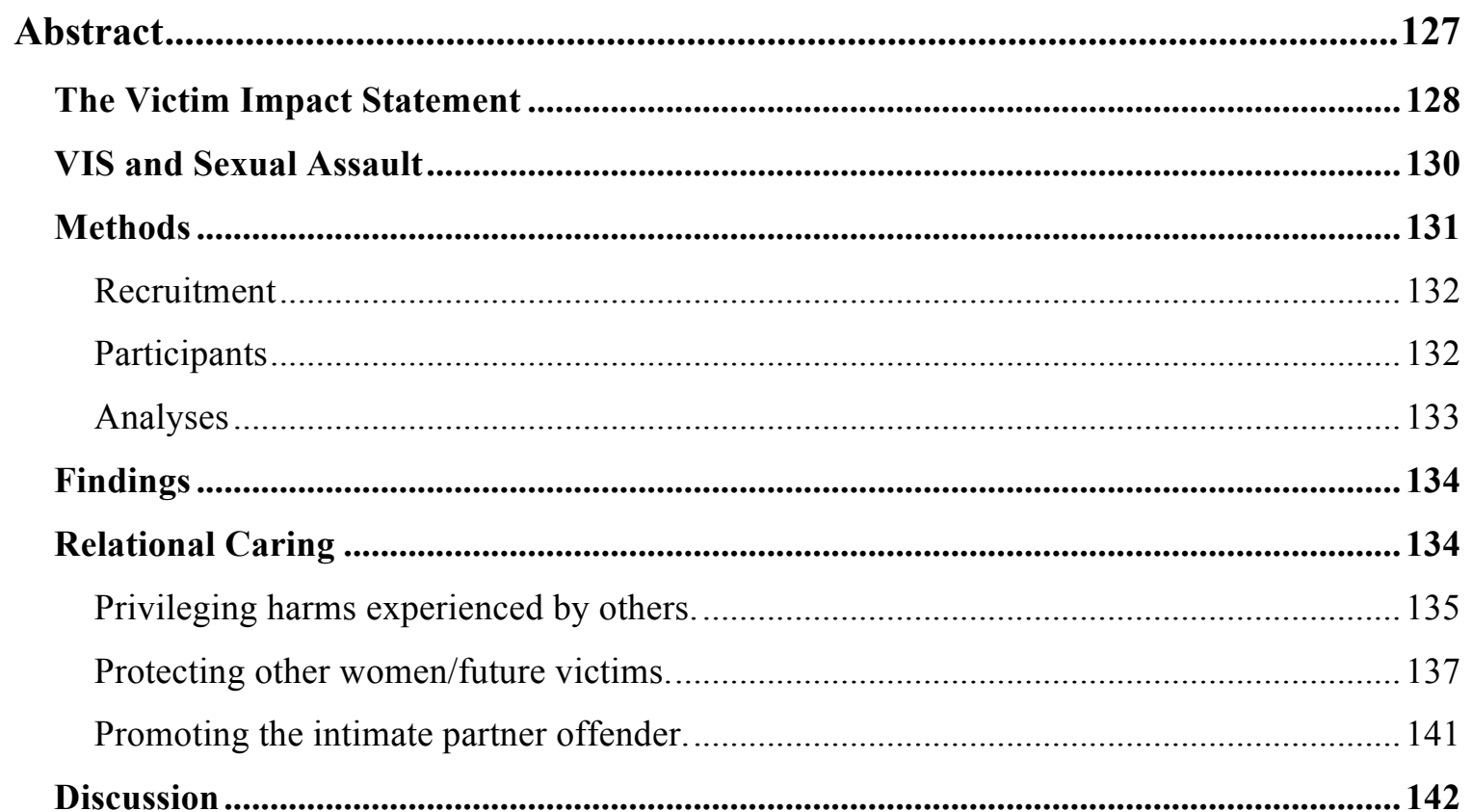

Chapter 8-Purposing and Repurposing Harms: The Victim Impact Statement and Sexual Assault ..........................................................................................................................152

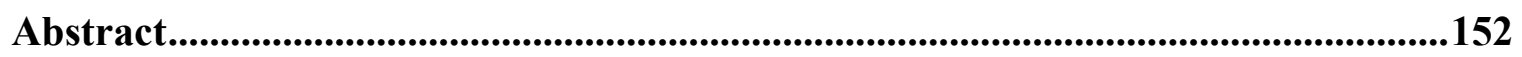

The Victim Impact Statement ……........................................................................................... 153

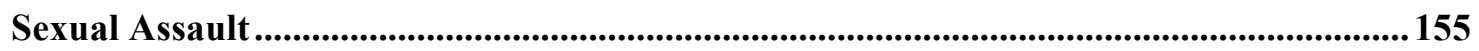

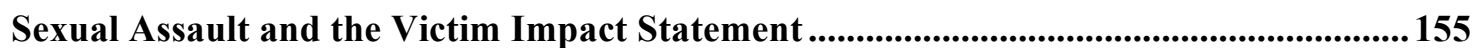


Pethods . 157

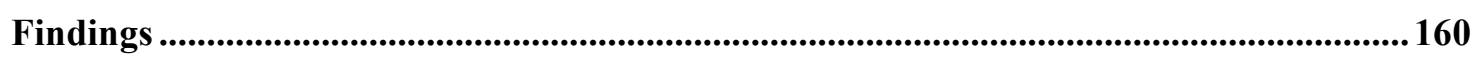

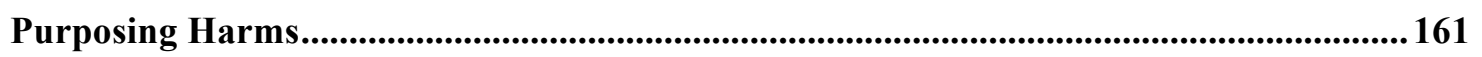

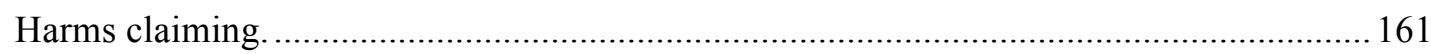

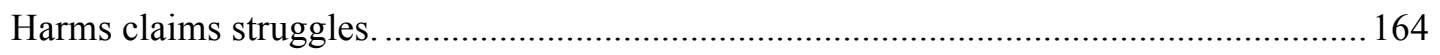

Repurposing Harms ............................................................................................................................... 168

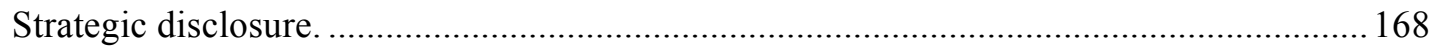

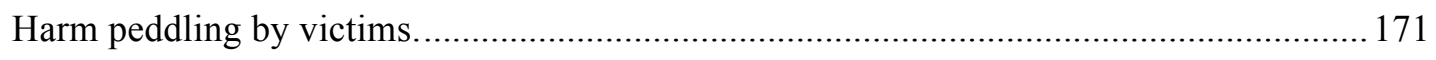

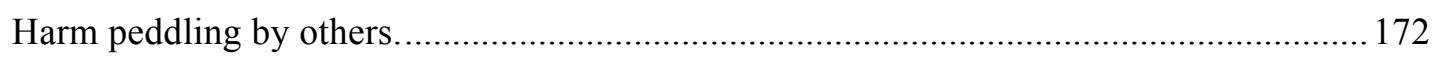

Discussion ..................................................................................................................................................... 175

Chapter 9-Concluding Remarks ...........................................................................184

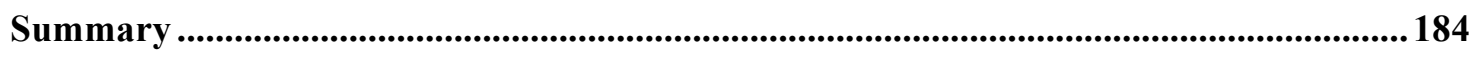

Policy, Practice, and Research: Implications and Recommendations................................. 189

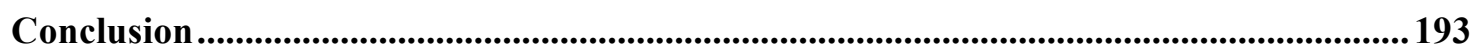

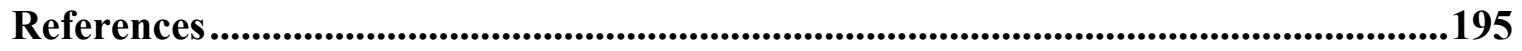

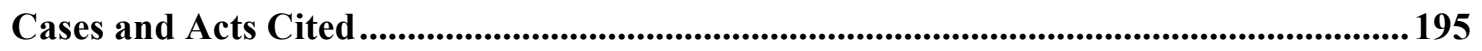

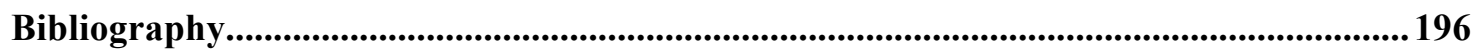

Appendix A-Victim Recruitment Script (Victim Services Eastern Canada)..........216

Appendix B —Study Information Pamphlet for Victims...............................................218

Appendix D_Information and Consent Form for Victims.........................................220

Appendix E-Information and Consent Form for Nonvictims .................................224

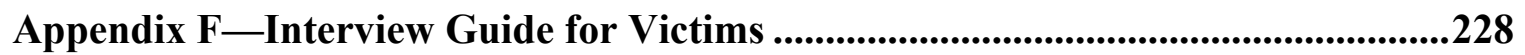

Appendix G-Interview Guide for Nonvictims ..................................................231 


\section{Glossary}

\section{Select actor-network terms}

Actor. An actor is an entity that does something and that causes some action. An actor may be human or non-human.

Inscription. Inscription is a process whereby actors embed their interests or values onto technologies or artefacts.

Intermediaries. Intermediaries carry messages and stabilize meanings across and between networks and settings. They may include laws, texts, or people.

Multiplicity. Multiplicity refers to an entity or object that is enacted in practices that produce different realities. An object that is multiple is both the same and different across and between networks without discontinuity.

Network. A network is a constellation of actors who have come together over a matter of concern.

Translation. Translation refers to processes and relations occurring amongst actors, whereby one actor's interests come to be modified into a single will in a network.

\section{Select criminal justice system terms}

Conditional sentence. An offender serving a conditional sentence serves it in the community rather than in custody. The offender is supervised by a probation officer and must comply with the conditions set out by the sentencing judge.

Crown prosecutor. A Crown prosecutor is a government lawyer who prosecutes criminal cases at the trial and appeal levels. Under Canadian law, the Crown prosecutor is not the victim's lawyer but acts on behalf of the state. For the purposes of this study, Crown prosecutor, prosecuting attorney, and prosecutor are used interchangeably. 
Federal sentence. A federal sentence is a prison term of two years or more. The adult offender serves the sentence in a federal penitentiary supervised by Correctional Service Canada.

Mandamus. A mandamus is a judicial remedy in the form of an order from a superior court to any government, subordinate court, corporation, or public authority.

Probation. Probation is a sentencing option that occurs when the judge has convicted the offender of the offence, but then suspends the sentence and releases the offender, requiring that $\mathrm{s} /$ he follow the terms of a court order for a set time that can last up to three years. Probation might be the only penalty, or it might be combined with other penalties, including a fine, a discharge, or a jail term of less than two years.

Provincial sentence. A provincial sentence is a prison term of less than two years. An adult offender serves the sentence in a provincial prison supervised by the corrections branch of the provincial government in which the institution is located.

Suspect/accused/defendant/perpetrator/offender. Criminal justice system actors use different terms to describe the person who has committed the action depending on the stage of the case in the criminal justice system. A person who has allegedly committed the action would be described as a suspect before a charge has been laid, as an accused after a charge has been laid, a defendant during trial proceedings, and a perpetrator after a finding of guilt. For the purposes of this study, the term offender is generally used to identify individuals responsible for acts of sexual assault irrespective of criminal justice system case processing status. This is in keeping with the use of the term offender by many feminist scholars to describe the responsible individual in cases where a complaint and/or charge has not been laid, or a conviction has not been registered.

Victim impact statement (VIS). A victim's written statement to the sentencing court judge describing the harm or loss suffered by the victim as a result of a crime for which a conviction has been registered. 
Victim statement (VS). A victim's written statement to the parole board describing the continuing harm or loss suffered by the victim as a result of the offender's actions.

Victim/complainant/witness. Criminal justice system actors variously identify the person against whom a crime was committed as a victim (at the point at which the act has occurred), a complainant (when the victim has laid a complaint to the police), and a witness (at the point when the act has been investigated, a charge has been laid, and the file has been passed on to the prosecutor). For the purposes of this study, the term victim is generally used, irrespective of the criminal justice system case processing status. 


\section{Introduction}

In Canada, the victim impact statement (hereafter VIS) is a written, at times also verbally presented, account of the physical, psychological, and economic harms that were experienced by a direct victim as a result of an act for which an adult or young offender has been found or has pled guilty. A VIS may also be submitted by the parent or guardian of a minor victim or the guardian, caregiver, spouse, and family member of an incompetent, incapacitated, or deceased victim. Canadian victims have the legislated right to submit a VIS at a criminal court sentencing hearing, parole board hearing, and court martial of a person found guilty of military misconduct including that of a sexual nature. The right to submit a VIS also has been legislatively extended to noncriminal proceedings such as the review board hearings, court martials, and "high risk" designation hearings of offenders considered not criminally responsible on account of a mental disorder (Criminal Code RSC, 1985 c C-46; Parole Board of Canada, 2012; Youth Criminal Justice Act, S.C., 2002).

This dissertation was a qualitative multisite examination of the VIS. The purpose of the dissertation was to understand the nature, development, use, and impact of the VIS in the context of women who have been sexually assaulted in Canada. Participants $(\mathrm{N}=$ 44) had sought or provided VIS-related services in three Canadian regions (Eastern Canada, Central Canada, and Western Canada). I present the findings of the dissertation or overall study in three independent but interconnected papers (Obliging Detours: An Actor-Network Analysis of the Victim Impact Statement Involving Sexually Assaulted Women in Canada; Relational Caring: The Use of the Victim Impact Statement by Sexually Assaulted Women; and Purposing and Repurposing Harms: The Victim Impact Statement and Sexual Assault).

Chapter 1 provides background information relevant to understanding the VIS in the context of Canadian women who had been sexually victimized. It begins with an examination of the VIS, including its historic origins, Canadian legislative history, and implementation processes. I then describe the relevant characteristics of sexual assault, including harm sequelae, Canadian legal definitions, and criminal justice case processing.

In Chapter 2, I synthesize the extant VIS literature from the vantage points of effects on victim participation and motivation, criminal justice workgroup practices, sentencing, and parole. I then describe efforts to understand the VIS from theoretical 
perspectives, as well as in the context of sexual assault. These efforts include theoretical examinations of the VIS using sociologies of emotion (Bandes, 2009; Langstraat, 2006; Schuster \& Propen, 2010; Sheley, 2012) and genre theory (Propen \& Schuster, 2010), as well as studies that exclusively or primarily examined VISs written by sexually assaulted women (Du Mont, Miller, \& White, 2008; Konradi \& Burger, 2000; Regehr \& Alaggia, 2006; Regehr, Alaggia, Lambert, \& Saini, 2008; Ruparelia, 2012; Walsh, 1986).

Chapter 3 introduces actor-network theory or ANT (Callon, 1986; Latour, 2005; Law \& Hassard, 1999), which was the conceptual and theoretical underpinning of the overall study. ANT tenets acted as sensitizing concepts (Blumer, 1954; Bowen, 2006) to assist in conceptualizing and understanding the heterogeneous (human and nonhuman) elements and relations associated with the VIS. I first provide a review of the traditional key tenets of ANT including network, translation, black box, and irreversibility (Callon, 1986; Latour, 2005; Law, 1992). I then discuss newer formulations of ANT developed by Mol (2002) and Mol and Law (1994) that promote concepts such as fluidity and the flow of relations.

Chapter 4 provides a full description of the overall study's methods. This includes information on study design such as confidentiality safeguards and informed consent processes, as well as the data collection and analysis procedures that led to the three papers. Some of these details have been published earlier (Miller, 2007a, 2007b, 2013, 2014). Chapter 5 provides demographic and descriptive information about the 44 study participants who were associated with the receipt, provision, or design of VIS services, assistance, or policy in Canada. I also describe the characteristics of each victim participant's sexual assault, case processing, and VIS-related experiences.

Chapters 6 through 8 comprise the papers that were based on the findings of the overall study. Chapter 6 is entitled Obliging Detours: An Actor-Network Analysis of the Victim Impact Statement Involving Sexually Assaulted Women in Canada (Miller, submitted), hereafter Obliging Detours. This paper examines the historical development of the VIS network in Canada, provides an indepth look at the operation of the VIS at a sentencing hearing through one case study, and illustrates the use and consequences of the VIS in the context of two rarely examined groups of women who have been sexually assaulted - intimate partners of offenders, and women in conflict with the law. Obliging Detours is explicit in its use of ANT in the articulation of the findings of network 
development and the associated relations between humans (e.g., policy-makers) and nonhuman elements (e.g., laws).

Chapter 7 is entitled Relational Caring: The Use of the Victim Impact Statement by Sexually Assaulted Women (Miller, 2014), hereafter Relational Caring. This paper examines sexual assault victims' priorities, techniques, and strategies concerning their undertaking of written and/or verbally presented VISs at criminal sentencing and parole hearings. Relational Caring also examines victims' VIS-related efforts in the context of their relationships with others, including other current or potential victims, the offender, their families, and their children. Relational Caring is implicit in its use of ANT in terms of the focus on the elements and associations that prompt victims' actions, and various actors (e.g., hypothetical victims) who are implicated in victims' decisions to act.

Chapter 8 is entitled Purposing and Repurposing Harms: The Victim Impact Statement and Sexual Assault (Miller, 2013), hereafter Purposing and Repurposing Harms. This paper first examines victims' use, or purposing, of the descriptions of harms detailed in the VIS that are in keeping with the original intent of legislators and the decisions of judges. It then examines victims' innovative uses, or repurposing, of those harm descriptions at sentencing and parole, and in other settings such as before a human rights tribunal. The purposing and repurposing of victims' harm descriptions by others such as prosecutors, judges, and offenders are also discussed. This paper is implicit in its use of ANT by focusing on multiple actors' agencies in relation to use of the VIS, and the effects of the VIS harm descriptions on individuals and relationships across multiple settings.

In Chapter 9, I provide concluding remarks. I note that the overall study has demonstrated that the VIS has a protean nature; that is, that the VIS is variable in its functions and inconstant in its consequences for victim-authors and the impact on readers/those to whom it is distributed. The VIS's protean nature is produced by structural and relational factors, which lends itself to multiple uses in multiple contexts. I summarize the findings of Obliging Detours, Relational Caring, and Purposing and Repurposing Harms that led to this conclusion. I then discuss the role that my attention to ANT played over the course of the study, focusing on its greater and lesser appearance of influence in the individual papers and how their findings were articulated. Finally, I discuss the policy and practice implications raised by the overall study findings, and 
make recommendations on how to ameliorate the more harmful aspects of VIS involvement for sexually assaulted women. 


\section{Chapter 1-Background}

This first chapter provides background information relevant to understanding the VIS within the context of sexual offences in Canada. It begins with a brief examination of the historical origins of contemporary justice and the role of the victim, as well as the development of the crime victims' movement, which led to the VIS. It then discusses the Canadian legislative history of the VIS and implementation processes. The chapter next describes the relevant characteristics of sexual assault, including harm sequelae, Canadian legal definitions, and criminal justice case processing.

\section{Historical Origins of the Role of Victim}

Criminologists and legal scholars have critically examined the historical development of the role and status of victims (Christie, 1977; Schafer, 1977; Sebba, 1996; Young, 2001). Young (2001) noted that prior to the 13th century, English society viewed wrongdoing as a private matter of concern only to the victim or their family and not to society. Resolution proceeded by way of civil action, and the obtaining of financial compensation by the injured individual should the claim succeed. The later transformation of the system from the restitution of a private injury to redress for a public wrong, that is, from the notion of tort to one of crime, was associated with the king's appropriation of the fines won by victims, jurisdictional squabbles between church and king, and the weakening of kinship ties (Schafer, 1977; Young, 2001). Young (2001) explained that from that point until the 19th century, "victim satisfaction became an irrelevancy" (p. 6) although common law still required that victims or their representatives take responsibility for prosecution.

The "inefficiency of private prosecution for a rapidly growing industrial state prompted the takeover of criminal law enforcement by agents of the state" (Young, 2001, p. 6), specifically, the development of a public police force and a public prosecutorial branch of government. These developments led to the removal of the victim from any involvement in adjudicating guilt and determining punishment (Eisenstat, 2004). Public prosecution was the "most significant development in the treatment of crime victims" (Derene, Walker, \& Stein, 2011, p. 6) because it corresponded to the enforcement of the victim's status as “evidentiary cannon fodder, or witness or claimant, not of citizen with participatory rights and obligations" (Braithwaite, 1993, p. 36). At that point in the history of the state's eclipse of the victim (Eisenstat, 2004), the seeds of controversy were 
first sown regarding whether victims were entitled to exercise some (or any) control or input into the criminal process - and if so, of what nature and to what end (Cassell, 2009; Eisenstat, 2004).

Because criminal wrongdoing under common law "engages a public interest that extends beyond any individual interest" (Young, 2001, p. 7), victims have no formal legal status and are not considered as parties to criminal proceedings (International Federation of Human Rights, 2010). For legal critics, this led to the contemporary circumstance, wherein "the one party who is represented by the state, namely the victim, is so thoroughly represented that she or he for most of the proceedings is pushed completely out of the arena, reduced to the triggerer-off of the whole thing" (Christie, 1977, p. 3). In the 1970s, growing public dissatisfaction with the victim's marginalization, coupled with increasing crime rates and the establishment of the discipline of victimology, gave rise to the conservative law-and-order movement in the United States. In turn, the organizational, cultural, and political demands and achievements of this movement, along with those that arose from contemporaneous social movements, including the civil rights movement, the anti-war movement, and the women's movement, led to the development of the American crime victims' rights movement (Derene et al., 2011; Sebba, 1996; Young, 2001). The crime victims' movement later spread to Canada through activities associated with the emotion work of parents of murdered children, the advocacy agenda of feminists, and the efforts of federal government officials who positioned themselves as experts on victims (Rock, 1986, 1988; Sebba, 1996; Stanbridge \& Kenney, 2009; Young, 2001).

The central political concern of the crime victims' movement was that the criminal justice system "had become seriously imbalanced with numerous legal rights available to defendants in criminal courts but little or no rights available to the victim of the offender's act" (Paternoster \& Deise, 2011, p. 130). As part of a "“rebalancing” strategy" (Rosebury, 2011, p. 51), the movement focused on the development of rightsbased victim-centric legislative and policy reforms such as victims' bills of rights, compensation and restitution schemes, court support services, and mechanisms such as the VIS (Rosebury, 2011). The intent was to facilitate victim engagement and satisfaction with the criminal justice system (Dubber, 2002; Englebrecht, 2008; Erez \& Laster, 1999; Kennard, 1989; Paternoster \& Deise, 2011), which has been associated with victims' 
continued cooperation as witnesses and with successful prosecution (Ash, 1972; Dawson \& Dinovitzer, 2001).

\section{The Victim Impact Statement (VIS)}

The VIS has been considered the most significant victim-oriented reform attributable to the crime victims' rights movement (Bandes, 2009). The VIS is a written statement that contains subjective details of the physical, psychological, and financial harms that a victim has experienced as a result of an act for which an adult or youth offender has been found or has pled guilty (Erez, Ibarra, \& Downs, 2011; van der Merwe \& Skelton, 2014). In Canada the right to submit a VIS is generally extended beyond the direct victim to the spouse and family of a homicide victim, the parent or guardian of a minor victim, and the guardian or representative of an incompetent or incapacitated victim (Criminal Code RSC, 1985 c C-46). Once voluntarily authored by a victim, the VIS is tendered to a sentencing court judge after conviction but before sentencing, subject to certain requirements to be admissible to the court, and eligible for cross-examination by a defence lawyer. When a judge considers the VIS, it becomes a matter of public record, and members of the public and the media may then apply for access to it. As a part of the court file, and along with other court documents, the VIS is provided to provincial or federal correctional authorities, depending on the type and length of sentence that the judge hands down (Correctional Service Canada, 2013; Government of Alberta, 2010; Public Safety Canada, 2013; Rock, 2010; Smith, 2012).

James Rowland has been credited as the creator or "Father of the VIS" (Justice Solutions, 2003, p. 1). As a chief probation officer in Fresno, California, in the mid1970s, Rowland designed the VIS in collaboration with a fellow probation officer, a public prosecutor, and a local religious minister (Seymour, 2001). Following qualitative research with primary and tertiary victims of personal and property crime, Rowland specifically designed the VIS form to collect and report a range of harms identified as important. He adapted the name from the "environmental impact statement" (Justice Solutions, 2003, p. 2), which is a document designed to inform decision-making by federal agencies by describing the positive and negative environmental effects of a proposed action (Wikipedia, 2014).

The VIS has wildly surpassed Rowland's vision of a few brief paragraphs of victim impact information in the presentence report (Justice Solutions, 2003). In less than 
40 years the VIS has become a participatory option available to victims in justice systems across common law jurisdictions such as Australia, Canada, South Africa, and England, as well as across some civil law jurisdictions including Belgium, Estonia, Finland, the Netherlands, Poland, and Romania (Project Victims in Europe, 2009; Roberts, 2009; Smith, 2012; van der Merwe \& Skelton, 2014). Each of these various schemes permits victims to articulate the harm they have experienced, although the nomenclature as well as the precise form and function of the statement vary among them (Pemberton \& Reynaers, 2011; Rosebury, 2011). For example, a VIS may be a written statement that is strictly expressive and therefore nondispositive (Edwards, 2004) in nature as it is in Canada, as well as in England where it is also known interchangeably as a victim personal statement or VPS (Roberts \& Manikis, 2011). Or a VIS may be dispositive (Edwards, 2004), and contain a victim's recommendations for sentence as is permitted in many states in the United States, where it is known as a victim statement of opinion or VSO (Lawrence, 2010). Some jurisdictions, such as Canada, now accept the VIS at the hearings of offenders who have applied for early release from prison (Bernat, Parsonage, \& Helfgott, 1994; Black, 2003; Department of Justice Canada, 2013c).

In addition to modifications of the written pro forma that Rowlands first developed, the VIS is now increasingly accepted in alternative formats by courts in some jurisdictions. An audiotaped or videotaped VIS may be accepted by a sentencing judge in New Zealand as well as in some American states, where it may also be accompanied by photos, music, or filmed images (Bandes, 2009; Leverick, Chalmers, \& Duff, 2007; Office of Justice Programs, 2014). In Canada, Australia, and many American states, a victim is now permitted to read aloud or allocute a written VIS to a sentencing court and parole board (Leverick et al., 2007; Office of Justice Programs, 2014; Parole Board of Canada, 2012). Furthermore, in Canada, the VIS is increasingly being accepted in contexts likely unimaginable to Rowlands. The VIS has been permitted at court martials, mental health review board hearings, professional disciplinary hearings, and family courts where harms arising from a convicted criminal act are not at issue (Barrett, 2008;

Roberts, 2002, 2008; Smith, 2012). 


\section{The Canadian Context}

\section{Legislative History}

The first recorded application by a Canadian victim to submit a VIS was in 1982 in R. v. Antler. The victim of childhood sexual abuse applied for-and was refused-the opportunity to submit a statement on the emotional and physical effects of the crime. Also unsuccessful was the victim's application for a writ of mandamus, which sought to compel the sentencing judge to receive the VIS. In refusing the application Madame Justice McLachlin, as she then was, noted that the existing Criminal Code of Canada did not grant victims any recognized standing and therefore the matter was best referred to Parliament.

The implications of R.v. Antler, as well as the proclamation of the Canadian Charter of Rights and Freedoms (1982) that same year, provided some of the background context for the newly formed Federal/Provincial Task Force on Justice for Victims of Crime (Barrett, 2008). In turn, the task force issued recommendations the following year that included the introduction of the VIS at sentencing (Young, 2001). In 1986, the first series of pilot projects on the VIS were initiated by the Department of Justice Canada. They were designed as "part of Canada's contribution to the international movement in this area and as an aid to federal policy formulation" (Giliberti, 1991, p. 706). In 1987, a report by the Canadian Sentencing Commission recommended that prosecutors obtain and review a VIS prior to accepting a plea deal from defence counsel (Giliberti, 1991). In 1988, Bill C-89, An Act to Amend the Criminal Code (Victims of Crime) was introduced, which provided for Criminal Code amendments regarding the VIS (Young, 2001). The proclamation of that act gave Canadian victims the legal right to submit a VIS at a sentencing hearing in adult court. Despite remaining at the court's discretion, this opportunity was considered "an unprecedented breakthrough for victims of crime" (Barrett, 2008, p. 639). The introduction of the VIS represented the first mention of the term victim in the Criminal Code (Wemmers \& Cyr, 2004). In order to be eligible to submit the VIS, a victim must have experienced a physical, sexual, or property crime; the federal government had earlier refused the federal New Democratic Party (NDP)'s request to include those victimized by corporate crime (Roach, 1999). In 1995, Bill C-37 was introduced, which amended the Young Offenders Act to allow for the consideration of the VIS in youth court for offenders between the ages of 12 and 18 years (Young, 2001). 
In 1996, the Bill C-89 provisions that had provided for the VIS were given their own section number (s. 722) in the Criminal Code, which became the statutory platform for the VIS. After that, it was mandatory for the court to consider a statement where one had been prepared in accordance with legislation (Department of Justice Canada, 2003b; Littlefield, 2004). Also in 1996, Bill C-41 included an amendment that limited a judge's discretion to disallow the use of the VIS in a "faint hope" hearing (Pilon, 1997). At a faint hope hearing, a judge reviews an application for reduced parole eligibility for an offender serving a life sentence. While the faint hope clause was repealed in December 2011, it is still available for those incarcerated prior to that date. In those cases, since the primary victim has been murdered, the written VIS is eligible for submission and allocution by a secondary victim: that is, the deceased person's legal custodian, spouse, or family member, or the individual who has been responsible for the deceased's surviving dependents (Department of Justice Canada, 2006; Pilon, 1997).

In 1999, the federal government introduced substantive statutory amendments that were specifically designed to further promote the use of the VIS at sentencing (Roberts \& Edgar, 2006). These Criminal Code amendments expanded the definition of victim from "the" person to whom harm was done to "a" person (s. 72[4][a]), and codified a victim's right to read aloud a written VIS at the sentencing hearing (s. 722[2.1]). The changes also created a duty of inquiry on sentencing courts (Barrett, 2008) because a judge was now obligated to inquire whether the victim had been informed of the opportunity to complete a VIS (s. 722.2[1]). The amendments also permitted judges, but did not require them, to adjourn a sentencing hearing to allow the victim time to prepare a VIS (s. 722.2[2]). Finally, the amendments also clarified that a copy of the VIS had to be provided to an offender "as soon as is practicable after a finding of guilt" (s. 722[1]). In 2000, the Criminal Code definition of victim was further expanded to include common law spouses (s. 722. [4][b]). These changes were intended to further enshrine victims' participation at the time of sentencing, but not to change or expand the nature of the information that was to be permitted (Brewer, 2000).

In January 2006, new provisions of the Criminal Code came into effect that affected the use of the VIS by mental health review boards (Criminal Code, s. 672.68). Review boards are independent tribunals that make dispositions about accused persons who were established to have committed the offence but, due to mental illness, lack the required intent to be considered criminally responsible for their crimes (British Columbia 
Review Board, 2010). The new provisions required a review board to consider the VIS when making their disposition, permitted them discretion to adjourn a hearing to afford a victim an opportunity to prepare a statement, and required that a victim be provided the opportunity to allocute. Prior to this, VISs were allowed before review boards in only limited circumstances (British Columbia Review Board, 2010).

These changes were the focus of considerable and ultimately ineffective objection by the Canadian Bar Association (2004), which had argued that in the absence of criminal responsibility, there was no conviction of a crime for which a submission of a VIS would be warranted. Of all the extensions beyond sentencing proceedings, the extension of the right to file and present a VIS before review boards "is the most controversial" (Barrett, 2008, p. 641). The primary issue before a review board is whether the accused poses a significant risk of future harm to public safety, rather than the acknowledgment of, and reparation for, harms that have been previously done to the victim, as is the case during a sentencing hearing (Barrett, 2008).

Until very recently, VISs have been barred from court martial proceedings in Canada (Smith, 2012). In 2013, the Strengthening Military Justice in the Defence of Canada Act (Strengthening Military Justice in the Defence of Canada Act, S.C. 2013) mandated that court martial tribunals consider VISs. In the summer of 2014, this right was also extended to victims of crimes committed by military personnel considered not criminally responsible on account of mental disorder (Department of Justice Canada, 2014b).

The Parole Board of Canada (PBC) operates within the portfolio of Public Safety Canada. The PBC is an independent administrative tribunal that is mandated under the Corrections and Conditional Release Act or CCRA (Corrections and Conditional Release Act, S.C., 1992). The PBC has exclusive authority during hearings to grant, deny, cancel, terminate, or revoke the release of offenders serving sentences of more than two years, or those sentenced to incarceral terms of less than two years in all provinces and territories other than British Columbia, Quebec, and Ontario (Parole Board of Canada, 2011a; Policy Centre for Victim Issues, 2008). In July 2001, the PBC introduced policy measures to allow a victim to read the original sentencing VIS at a federal parole review hearing and/or to update the VIS with more recent information prior to submission to board members (Department of Justice Canada, 2013b). This discretionary practice was legislatively formalized in June 2012 when the CCRA enshrined in law the right of a 
Canadian victim at a federal parole board hearing to submit and/or orally present or update the original sentencing VIS, or to present a completely new "victim statement" or VS (Corrections and Conditional Release Act, S.C., 1992, s. 140 (b)).

Victims may choose English or French as their language of choice when submitting or presenting a written or allocuted VIS or VS, or a videotaped or audiotaped VIS or VS to the federal parole board, regardless of the language of the hearing. The VIS or VS must be received in writing, and must be shared with the offender in advance of the hearing. A victim is permitted to choose when to present the VIS or VS, such as at the beginning of the hearing or following the board's interview of the offender (Smith, 2012).

In having legislatively provided for the creation of a new VS form, the CCRA expanded what is permissible as subjective victim impact or harm information. A sentencing VIS can refer to only the impacts associated with the crime for which a conviction was obtained. In contrast, a VS is permitted to refer to the impacts of current or previous offences, which may not have been successfully prosecuted. Instead, it is sufficient that written proof be provided that the victim had made a formal or informal complaint to the police or prosecutor (Parole Board of Canada, 2010a, 2010b, 2012).

Despite a victim's right to submit a VIS or VS, there are still no legislative obligations on board members to consider either one during their deliberations (Office of the Federal Ombudsman for Victims of Crime, 2011; Parole Board of Canada, 2012). Furthermore, unlike at sentencing and review board hearings, there are no obligations on parole board members to inquire whether a victim has been provided the opportunity to complete a VIS or VS. Neither are board members required to adjourn proceedings in order to have facilitated the completion of a VIS or VS (Office of the Federal Ombudsman for Victims of Crime, 2014).

\section{Provincial Implementation Programs}

While the Criminal Code of Canada is under federal jurisdiction, the provinces are responsible for the development and implementation of victim policy (Wemmers, 2008). Thus, as specifically envisioned in section 722(2)(a) of the Criminal Code, each province has its own procedures that govern the implementation of the VIS in the sentencing process, including the requirements that victims must satisfy in order to complete and submit a VIS (Manson, 2001). Variations in implementation procedures across provincial programs have resulted in VIS forms being prepared and submitted at 
different points in the criminal justice process depending upon the province in which the case was tried (Diguilio, Roberts, \& Edgar, 2002). These program variations have also given rise to debates concerning the point at which a VIS can, or must, be provided to an accused or an offender during the criminal justice process (Teasedale, 2003).

The victim services divisions associated with each of the provincial justice departments have been responsible for implementing the VIS programs in their respective provinces, providing the necessary VIS form, and offering guidance or limited assistance in the completion of the VIS (Department of Justice Canada, 2006). Irrespective of the province in which they currently reside, victims must obtain the VIS form from the victim services division in the province in which the crime against them took place (Alberta Solicitor General and Public Security, 2007). Victim services programs may be staffed by victim service officers, as occurs in the provinces of Ontario and Nova Scotia, or by welltrained volunteers under the guidance of police, as in Alberta (Alberta Justice, 2004; Nova Scotia Department of Justice, 2006; Ontario Victim Services Secretariat, 2010).

Some provincial victim services divisions have struggled to obtain sufficient funding to implement basic Criminal Code reforms associated with the VIS, for example, victim notification of the right to submit one (Department of Justice Canada, 2004). In contrast, some provinces such as Ontario have been more able to provide financial assistance to victims to attend sentencing hearings in order to verbally present a VIS (Canadian Resource Centre for Victims of Crime, 2010). In large part, insufficient funding for VIS programming reflects poor revenue gathering from, or enforcement of, the victim fine surcharge (Law \& Sulllivan, 2006).

The victim fine surcharge is a fine or financial penalty levied against a convicted offender at the time of sentencing that is subsequently collected and retained by provincial and territorial governments (Department of Justice Canada, 2013a). The surcharge was instituted in 1989. Revenues from the victim fine surcharge were intended to assist governments in funding a range of victim services (Stanbridge \& Kenney, 2009; Warrilow \& McDonald, 2008), including the implementation of VIS programs. In 2013, the Criminal Code was amended to make the victim fine surcharge mandatory by removing the judicial discretion to waive it in the presence of economic hardship to the offender or his/her dependents. The change also increased the amount offenders must pay (Casavant, Morris, \& Nicol, 2014). In July 2014, the victim fine surcharge was declared unconstitutional in R. v. Michael. The decision is currently under appeal. 
Frustrated by judges' refusals to impose the victim fine surcharge, the federal government developed alternative mechanisms for directly funding victims (Smith, 2012). One redress mechanism was the "Victims Fund," which is administered by the federal Policy Centre for Victim Issues or PCVI (Smith, 2012). The PCVI is part of the Criminal Law Policy Section within the policy sector of the Department of Justice Canada (Department of Justice Canada, 2014a). The PCVI was established in 2000 in response to a parliamentary report entitled "Victims' Rights: A Voice, Not a Veto" (Cohen, 1998), which recommended that a federal office be created to respond to victims' issues and to develop a victims of crime strategy (Hoddenbagh, Zhang, \& McDonald, 2014; Law \& Sulllivan, 2006). The PCVI administers the Victims Fund to provide direct financial assistance to victims for VIS-related expenses that are associated with attending or allocuting at hearings conducted by the PBC. Eligible expenses include travel and accommodation expenses for the victim, travel expenses for the victim's support person, and reimbursement for the victim's child care expenses (Department of Justice Canada, 2014c; Hoddenbagh et al., 2014). In 2009-2010, the latest date for which figures are available, 346 victims and 89 support people attended parole hearings to present a VIS or act as an observer with funding from the Victims Fund for a cost of $\$ 233,202$ (Hoddenbagh et al., 2014).

\section{Influence of Case Law}

In other jurisdictions, case law has determined the scope of victims' rights concerning the VIS (Konradi \& Burger, 2000); this too has been the case in Canada. Roberts (2009) noted that guidelines for the VIS's implementation have been developed by courts of first instance in Canada. This is largely because of a lack of clarity in VIS provisions in the Criminal Code, as well as the general reluctance of appellate courts to engage in VIS legislation (Roberts, 2009). Canadian judicial decisions regarding the VIS have focused on the statement's overall objectives, usefulness, and content, as well as issues of disclosure, cross-examination, and new evidence.

Criminologists (Katz, 2010; Roberts \& Edgar, 2006) have argued that the leading case in Canada regarding the use of the VIS is R. v. Gabriel (1999). In that case, Justice Hill articulated the importance of the VIS at sentencing. Specifically, the VIS was relevant to the receipt of evidence regarding the seriousness of the crime, which assists in determining victim reparation, imposing proportionate punishment, improving victim 
perception of the legitimacy of the criminal justice process, and achieving parity of identity with the offender. Justice Hill also provided guidelines for the parameters of permissible comments. He noted that a VIS should describe the harm done to, or loss suffered by, the victim that has arisen from the commission of the offence, but it must not contain criticisms of the offender or assertions about the facts of the case. Justice Hill opined that the victim should avoid recommendations on penalty (incarceration type or length), except in exceptional circumstances such as a court-authorized request, an Aboriginal sentencing circle, or as an aspect of a prosecutorial submission in which a victim had sought leniency despite offence circumstances that might suggest otherwise. Furthermore, the VIS must have been prepared in writing, in accordance with the form and procedures established by the relevant provincial victim services program.

In R. v. Bremner (2000), further guidelines were established regarding appropriate VIS commentary. The judgment emphasized that "the nature of the information that can be included in a VIS is restricted by the principle that fairness in the sentencing process is of fundamental importance" (Casavant et al., 2014, para. 2.2.43). Inappropriate material might include a victim's recommendations for sentence or the use of a diagnostic term to describe the offender, which would be more properly pronounced by an expert psychiatry witness. In R. v. Whiteman (2005), the objectives of the VIS were affirmed as assisting in determining the proper role of sentencing objectives, assessing reparation, promoting a sense of responsibility in the offender, and promoting victim participation in the criminal justice system.

In the absence of explicit guidance in the Criminal Code, case law has provided guidance for judges' use of the VIS in subsequent rulings. Thus, for example, VISs that were found to violate the R. v. Gabriel (1999) guidelines concerning criticisms of offenders, or which wished them harm, have been rejected by both trial and appeal courts (R. v. Walchuk, 2001). R. v. Gabriel guidelines have also been found to affect decisionmakers other than sentencing judges, leading to the development of policy and practice directives that have influenced the guidelines or rules that victims are expected to follow, and how prosecutors and victim services workers perform in relation to the VIS (Warrilow \& McDonald, 2008). For example, a VIS found objectionable under $R$. $v$. Gabriel guidelines prompted reactionary measures by both the Correctional Service Canada (CSC) and the PBC. The CSC denied the victim information regarding the offender, and the $\mathrm{PBC}$ threatened to revoke her status as an observer at the parole hearing 
unless she revised her VIS prior to attending, despite the fact that she was not verbally presenting (Office of the Federal Ombudsman for Victims of Crime, 2009).

The R. v. Gabriel (1999) judgment, and its implications for assessments of violations in subsequent cases, has also influenced how policy-makers have constructed the instructions and guidelines that are printed on the various provincial VIS forms. For example, the Ontario VIS instructions inform victims, "it is important not to include vengeful comments, criticisms or rumours about the accused. Such comments will not assist the judge and may detract from your statement" (Ministry of the Attorney General of Ontario, 2004b, p. 3). In Nova Scotia, the form's instructions remind victims that:

The Victim Impact Statement should not include opinions on the sentence to be given, or on the character of the offender. If the Statement contains information other than the impact of the crime on the victim writing the Statement, some or all of the Statement may not be considered by the Court. (Nova Scotia Department of Justice, 2005a, p. 1)

The links between case law decisions and VIS guidelines or printed instructions have not always been so literal. For example, in $R$. v. Shaban (2004) the court ruled that cross-examination on the VIS is not an automatic right of the defendant, and set a standard of proof for the offender that must first be met. However, existing VIS guidelines and instructions do not include this information. Instead, the information that federal and provincial governments provide has exclusively "warned" (Smith, 2012, p. 210) victims that defence counsel are eligible to cross-examine them on their statements at trial, and even at the preliminary inquiry stage. The federal Department of Justice informs victims that "the offender or his or her lawyer may cross-examine you on the information set out in the statement. It is important that the information in the statement be accurate" (cited in Smith, 2012, p. 211). In Manitoba, victims are further advised that "you may be called upon to testify in court and be asked questions about your Victim Impact Statement. If you provide any conflicting or false information, this may have a negative impact on the outcome of the case" (Manitoba Justice, n.d., p. 1). It is likely that the standard VIS warnings are included to minimize a victim's surprise at being crossexamined on his/her statement. Although uncommon, such cross-examinations have occurred (Roberts \& Edgar, 2006). It is also possible that the warnings were intended to deter a victim from writing untruthful or exaggerated claims of harm, given that case law has contradictorily opined on the VIS's evidentiary weight, which in turn has influenced 
the value and consequences of cross-examination from the perspective of defence counsel (Manikis \& Roberts, 2012; Smith, 2012).

Yet without information relating to the rarity of cross-examination, as well as the protections afforded a victim when being challenged — such as the "air of reality" burden on the offender, and the absence of an offender's right to compel a victim to attend for cross-examination when the Crown prosecutor has submitted a VIS (see for example, $R$. v. $W .[V], 2008)$ - existing guidelines may simply exacerbate the preemptory stress that victims may experience when they contemplate the prospect of being questioned about their VISs (Young \& Roberts cited in Roberts \& Edgar, 2006). What initially began as a policy recommendation that incorporated a close reading of case law might be subsequently contributing to a chilling effect, and unnecessarily deter or narrow how victims detail their harms in the VIS.

Case law has also influenced prosecutorial practices in relation to the VIS, for example, the timing of VIS disclosure to the defence counsel. In R. v. McAnespie (1993), the Ontario Court of Appeal set aside a manslaughter conviction on the grounds of the nondisclosure of fresh evidence contained in the VIS, which might have affected the verdict had it been available at trial. While the Supreme Court of Canada subsequently restored the conviction, the case later shaped two provincial prosecutorial policies in quite different ways. As a consequence of the case, prosecutors and victim services personnel with the Ontario Ministry of the Attorney General were instructed that a VIS must be immediately disclosed to defence counsel, and prosecutors were additionally required to disclose any deletions from the VIS, for example, the excise of profanity or descriptions of the facts of the case or other related events (Ministry of the Attorney General of Ontario, 2004a).

In stark contrast to the government of Ontario's focus on the potential appellate implications due to nondisclosure, the Alberta Solicitor General's office has instead emphasized the Supreme Court of Canada's restoration of the conviction in this case. The government of Alberta has since vigorously defended the right of the Crown prosecutor to decline to produce the VIS for cross-examination purposes prior to conviction (Teasedale, 2003). Moreover, a justice policy-maker candidly admitted that the lack of a unified provincial court filing system has resulted, in some areas of Alberta, in the VIS not being shared with defence counsel (Department of Justice Canada, 2003a). 
Rulings of the Alberta courts have supported the decisions made by the province's lawmakers regarding the timing of disclosure. In 2004, the Alberta Court of the Queen's Bench denied an application for disclosure of a VIS at the preliminary hearing stage in which it had been argued that the Crown prosecutor's failure to disclose the VIS prior to conviction had violated the accused's Charter rights (Fedirko v. Alberta, 2004). It was held in R. v. Schoendorfer (2004) that the disclosure of the VIS prior to conviction would have violated the privacy rights of the complainant, who had alleged sexual assault. As a consequence of these two decisions, Alberta victims have been urged to complete the VIS and personally deliver it to the courthouse as soon as police charges are laid (Alberta Solicitor General and Public Security, 2007). Alberta's police-based volunteer victim services units have been bypassed to ensure that VIS disclosure cannot occur until after conviction. Instead, victim services volunteers have been responsible for completing only a VIS notification form that alerts the clerk of the court and the Crown prosecutor that a victim wishes to file a VIS. Once the victim has filed the VIS with the clerk of the court, the clerk reserves the statement on file until a conviction is registered, whereupon it is given to the presiding judge and to defence counsel (Alberta Solicitor General and Public Security, 2006).

In jurisdictions other than Alberta, however, a victim does not directly tender a statement to the court. Instead, the VIS is submitted by a victim to the relevant victim services unit. A victim services worker who is assigned the case will forward the VIS to the Crown prosecutor who then discloses it to defence counsel and to the clerk of the court. The clerk is tasked with providing a copy to the presiding judge. Because of the required disclosure to the defence, victims in these jurisdictions have been advised to wait until after a conviction has been secured before completing and submitting their VISs to victim services staff (Nova Scotia Department of Justice, 2005b, 2006).

In other instances, narrow judicial interpretations of VIS eligibility have been counteracted by parliament through subsequent amendments to the Criminal Code. A case in point has been the expansion of the category of victim entitled to complete a VIS (Cole, 2003). In R. v. Curtis (1992) the court refused to allow the wife of an assault victim to submit a VIS because she had not been directly harmed by the offence itself, and her husband had been available to do so. Prompted by this legal precedent, the federal government introduced amendments in 1999 to the Criminal Code, which clarified for judges who might appropriately be termed a victim in the context of the VIS. Smith 
(2012) commented that, as a consequence, the current definition of victim is "quite broad and meant to include everyone, limiting VISs only if the judge finds it necessary" ( $p$. 253). A later demonstration of the court's broader interpretation of who might be called a victim was enunciated in $R$. v. Greenhalgh (2011). In that case, a Canadian border guard was convicted of sexual assault involving the illegal strip searches of young female travellers, and the court admitted VISs speaking to the crime-related psychological harms experienced by the guard's superior officer and by his former wife. In other instances, notwithstanding statutory requirements to the contrary, differences between the law-inpractice and the law-as-legislated have been reconciled in favour of judicial practice (Barrett, 2008). For example, in R. v. Tellier (2000) despite the requirements that a sentencing judge must inquire whether a victim was permitted the opportunity to provide a VIS, the failure to make the required enquiry was determined not to affect the validity of the proceedings.

Jurisprudence has also placed limits on lower court practices where the Criminal Code has been unclear. Manikis and Roberts (2012) identified instances where the courts have affirmed victim impact evidence as a source of aggravation at sentencing, such as in R. v. Cook (2009). However, limits on a trial judge's use of the VIS were rendered at the appellate level in Steeves v. R. (2010). In that case, the New Brunswick Court of Appeal ruled that the trial court judge had been overly influenced by the VIS when he rejected a joint sentencing submission by counsel, and handed the defendant a stiffer penalty. The Appeal Court cautioned that "victim impact statements have a significant role to play in the imposition of sentence, but they cannot be allowed to hijack the process" (Steeves $v$. $R, 2010$, para. 35).

\section{Discretionary and Proposed Considerations of the VIS}

Although the VIS is intended to represent the opinions and experiences of a single victim, it has been successfully used to represent the harms experienced by a group of associated individuals. In a handful of cases, judges exercised discretion to permit VISs written by individuals representing communities and organizations such as synagogue members (R. v. Truelove, 2002), a First Nations band (R. v. Bachmier, 2005), the Ontario Ministry of Health and Long-Term Care (R. v. Bogart, 2002), and the Bank of Montreal (R. v. Caporale, 2005). These cases predated the "community impact statement," which 
came into force in the context of fraud cases through Bill C-21 in November 2011 (Department of Justice Canada, 2011a, 2011b).

While a VIS "would explain the damages a victim has suffered . . . a Community Impact Statement would explain the damages a group has suffered" (Tilson, 2011, para. 5). A group is defined as a neighbourhood association, business association or seniors group that has been harmed as a result of the fraud (Department of Justice, 2011a). Unlike the VIS, the statutory language of the provision that governs the community impact statement is permissible or discretionary ("may") and there is no mandatory ("shall" or "must") duty upon judges; for example, "the court may consider a statement made by a person on a community's behalf describing the harm done to, or losses suffered by, the community arising from the commission of the offence" (Criminal Code, RSC, 1985, c C-46, s. 380.4).

The community impact statement is legislatively permitted only in cases of fraud (Tilson, 2011). However, community groups or groups representing their interests have long argued for their necessity in the context of nonfraud cases. The Office of the Federal Ombudsman for Victims of Crime (OFOVC) presented this issue at an appearance before the Inquiry Panel of the Canadian Parliamentary Coalition to Combat Anti-Semitism. They recommended that the federal government consider amending the Criminal Code to allow for "community victim impact statements" (Office of the Federal Ombudsman for Victims of Crime, 2010a, p. 24) in crimes motivated by hate.

In some quasi-judicial settings, the VIS has remained subject to discretionary and permissive consideration by authorities. For example, unlike at the federal parole board, the likelihood of a provincial parole board permitting a victim to allocute her/his VS or even to simply attend the hearing as an observer is quite variable (Barrett, 2008). In similar fashion, the acceptance of VISs in cases before the Canada Border Services Agency and Immigration Canada has remained at the discretion of board members. When an offender is released into the custody of the Canada Border Services Agency, a victim does not possess the same rights as would be triggered should the offender be released into the custody of the CSC, including the right to present and allocute a VIS (Office of the Federal Ombudsman for Victims of Crime, 2011).

Replacing these permissive/discretionary and informal mechanisms with mandatory rights, as well as including amendments to existing statutes in relation to the VIS, has been the purpose of some of the aims of the federal government's introduction 
of the Canadian Victims Bill of Rights or CVBR in April 2014 (Openparliament.ca, 2015). The CVBR contains the latest proposed amendments concerning the VIS in Canada. When enacted, the CVBR will change certain elements of the current VIS regime and provide for other rights and procedures for victims including the right to information, right to protection, right to participation, and right to restitution (Manikis, 2014; Perrin, 2014).

The CVBR is intended to clarify provisions relating to the VIS, ensure protection of the right to present a VIS and have it considered at criminal court sentencing proceedings and at hearings held by review boards, and allow for community impact statements to be considered for all offences. The CVBR calls for amendments to the Criminal Code that would expand the definition of the word victim to include those primarily or exclusively harmed by property damage or economic loss. The CVBR would require that the VIS be considered in all instances where judges or quasi-judicial adjudicators are determining the sentence to be imposed, or whether the offender should be discharge (Openparliament.ca, 2015).

The CVBR also proposes amending the Criminal Code to provide a victim or Crown prosecutor the opportunity to submit an application for a sentencing hearing adjournment to provide time for the victim to complete a VIS, whereas previously it had only been a judge who could apply for such an adjournment (Manikis, 2014; Perrin, 2014). It will also amend the court's present obligation to inquire of the prosecutor whether a victim had been apprised of the opportunity to complete a VIS; a judge would now be obligated to directly query the victim (Casavant et al., 2014).

Other new elements under the CVBR for the VIS regime include the right of allocution. A victim would also be provided the right to orally present in close proximity to a support person of his or her choosing. A victim would also be permitted to allocute outside the courtroom, or behind a screen or other device that prevents the offender from seeing him or her except by way of closed circuit television. The intent is to afford the victim support and privacy during allocution (Casavant et al., 2014). These allocutory rights would be permitted provided that the offender can communicate with her/his defence counsel during the victim's verbal presentation of the VIS. The new presentation provisions further specify that the court shall take into account those portions of the VIS that it considers relevant to sentencing, and disregard other portions, which will make up a new section of the Criminal Code (Casavant et al., 2014). The CVBR would also permit 
allocution to be accompanied by the display of a photograph of the victim taken prior to the commission of the crime (Openparliament.ca, 2015).

The CVBR also introduces a mandatory, standardized national form for the VIS and the community impact statement. The new form will explain the types of harms and losses that may be described, and will allow a victim, at the court's discretion, to include opinions or recommendations of sentence, which are not currently permitted except in exceptional circumstances (Casavant et al., 2014). At the same time as standardizing the format, the CVBR would permit more latitude for creative methods of expressing harm details: a victim would be permitted to include poetry, hand-drawn pictures, or letters.

While the CVBR proposes the creation of a complaint mechanism for a victim who believes that federal departments and agencies have not respected her or his rights, it does not envision a corresponding right to petition the court to have those rights respected. Under the proposed legislation there is no remedy or enforceability of the rights, including those that pertain to the VIS. Furthermore, discretionary variability in VIS access would persist. For example, a victim still would not be provided the automatic right to present a VIS at an immigration hearing, and to have the VIS considered in the decision to deport an offender (Office of the Federal Ombudsman for Victims of Crime, 2014). The CVBR received Royal Assent as of April 23, 2015 (Openparliament.ca, 2015).

\section{Sexual Assault}

\section{Harm Sequelae}

Although not all girls and women will identify as having experienced harms following a sexual assault, health professionals have argued that sexual violence can have such "a profound impact on physical and mental health" (Jewkes, Sen, \& Garcia-Moreno, 2002, p. 149) that "substantive changes and alterations in basic central nervous system functioning” (Burgess, Regehr, \& Roberts, 2010, p. 244) can arise. Victims' experiences of the harms of sexual assault might include immediate, short-term, and chronic physical and psychological sequelae (Martsolf et al., 2010; Yuan, Koss, \& Stone, 2006).

In Canada, the 2008 police-recorded data from the Incident-based Uniform Crime Reporting (UCR2) Survey found that in cases of sexual abuse against children and youth, minor injuries were sustained by $12 \%$ of boys and girls, although this may be an 
underestimate as the police often do not know the extent of injuries at the time of completing their reports (Ogrodnik, 2010). Girls aged 15 years to 17 years, and boys and girls under three years of age experienced the highest rates of physical injury ( $16 \%$ and $15 \%$ respectively) arising from sexual assault (Ogrodnik, 2010). In contrast to physical assault, sexual assault was less likely to result in physical injury (Ogrodnik, 2010). Abusers who exploit minors for sexual gratification often intentionally refrain from causing observable physical injury because paramount concerns are with nondiscovery and continued sexual access (Pillai, 2008).

In a review for the World Health Organization, Du Mont and White (2007) summarized the findings of 10 studies that were or could be based on all cases reported to the police, and that examined the degree of physical harms experienced by adult women arising from sexual assault or rape. Du Mont and White (2007) noted that the studies indicated that minor injury (e.g., tenderness, scratches) occurred in $24 \%$ to $72 \%$ of cases, moderate injury (e.g., lacerations requiring suturing) averaged 58\% across two studies, and severe injuries (e.g., trauma requiring surgery) occurred in $2 \%$ to $24 \%$ of cases. In addition to bruises, broken bones, and self-defence wounds, the physical harms associated with sexual assault might also include pregnancy, HIV, and sexually transmitted infections (Du Mont et al., 2005; Holmes, Resnick, Kilpatrick, \& Best, 1996; Jewkes et al., 2002). Subsequent chronic physical conditions could potentially include pelvic pain, migraines, infertility, and gastrointestinal disorders (Jewkes et al., 2002; Martsolf et al., 2010).

Coercive sexual experiences often result in girls acting out behaviourally, including in ways that cause them to be apprehended by authorities, resulting in conflict with the law (Chesney-Lind \& Sheldon, 2014). Negative neuropsychological effects in adults arising from childhood sexual abuse have also been reported; for example, increased rates of major depression and dysthymia, sexual risk taking behaviours, and physical health problems (Fergusson, McLeod, \& Horwood, 2013; Navalta, Polcari, Webster, Boghassian, \& Telcher, 2006). In adults, rape trauma syndrome (RTS), a cluster of physical and behavioral symptoms uniquely associated with the effects of sexual violence, was first identified by Burgess and Holmstrom in 1974 (Burgess et al., 2010). RTS involves behavioural, somatic, and psychological reactions in the "acute" or first phase, and lifestyle and behavioral changes (e.g., residence changes) and new psychological behaviours (e.g., nightmares, phobias) in the "reorganization" or second 
phase. While RTS preceded the terms "acute stress disorder" (ASD) or "posttraumatic stress disorder" (PTSD) (Burgess et al., 2010), RTS is now viewed as a sub-type of ASD and PTSD (Myers, 2005). The acute phase of RTS is consistent with ASD, a DSM-IV diagnostic category that describes the stress responses many victims have within the first four weeks following a traumatic event (Brewer, 2000). The ASD category is used primarily to help clinicians predict which traumatized individuals will develop PTSD (Brewer, 2000).

PTSD is the umbrella term under which the physical and psychological sequelae of various significant life threatening events (e.g., sexual assault, combat stress, natural disasters) are included (Brewer, 2000). Sexually assaulted women may develop PTSD during the long-term reorganization or second phase of RTS (Brewer, 2000). PTSD is believed a common consequence of sexual assault (Rees et al., 2011; Ullman, Townsend, Filipas, \& Starzynski, 2007). Using the U.S. National Epidemiologic Survey on Alcohol and Related Conditions (NESARC), Breslau et al. (2013) found that sexual assault victimization was associated with a much higher probability (40\%) of PTSD than was caused by other traumatic incidents such as accidents, disasters, or the unexpected death of someone close. The likelihood of a sexual assault victim developing PTSD was influenced by sexual assault severity, the victim's avoidance coping strategies, and preexisting vulnerabilities such as parental psychopathology (Breslau et al., 2013; Ullman et al., 2007).

Studies have also identified social difficulties arising from sexual assault, including new or exacerbated difficulties with close interpersonal relationships, and difficulties in social functioning at school or work (Du Mont \& White, 2007; Ullman, 1999; Winkler, 1991). For adult women, the social context of the immediate post-assault period can contribute either to the ongoing harm of the sexual assault or to the recovery from it, depending on the reactions of others when a victim discloses the sexual assault or seeks help (Campbell, Dworkin, \& Cabral, 2009b; Du Mont \& White, 2007; Ullman, 1999; Ullman, Starzynski, Long, Mason, \& Long, 2008; Ullman et al., 2007). While some studies have found that a positive social environment such as feeling supported or being believed is beneficial in aiding psychological recovery, others have found that the presence or absence of harmful reactions are more significantly associated with wellbeing (Campbell et al., 2009b; Ullman, 1999; Ullman et al., 2008; Ullman et al., 2007). Harmful reactions include intentional comments such as victim blame or disbelief, or may 
be associated with ineffective or misguided attempts to be helpful such as redirecting the victim to another topic (Ullman, 1999). Such is the effect of negative responses that even their absence may be perceived as supportive (Ullman, 1996); for some victims, no support at all is better than hurtful post-disclosure responses (Campbell, Ahrens, Sefl, Wasco, \& Barnes, 2001). Victims who respond to traumatic experiences in a manner in which observers or confidents do not expect, or which they suspect is disingenuous, or consider to exemplify poor coping (e.g., numbed or controlled self-presentation) may then also be further criticized (Silver, Wortman, \& Crofton, 1990; Winkel \& Koppelaar, 1991). Victims may then curtail additional disclosure or help-seeking due to fear of further criticism or of increased self-blame (Campbell et al., 2009b). Regardless of the confidant or supporter's intent, the experience of receiving negative or insensitive response has been found to strongly correlate with a victim's presentation of PTSD or of delayed recovery (Ullman, 1999; Ullman et al., 2007).

Sexual assault also exacts an economic toll (Greaves, Hankivsky, \& KingstonRiechers, 1995; Hoddenbagh et al., 2014). In a Department of Justice Canada (2014) examination of incidents that occurred in 2009 involving sexual assault and other sexual offences against adult women harmed by nonspouses in Canada, total tangible and intangible costs for victims, the criminal justice system, and third parties were $\$ 3,588,274,006$. Of this, female victims bore a total cost burden of $\$ 3,415,498,849$ including tangible costs (e.g., medical costs such as for counselling, and productivity costs such as lost future income) and intangible costs such as pain and suffering (Hoddenbagh et al., 2014).

\section{The Criminal Code of Canada}

In Canada, legal definitions of sexual offences have evolved in response to law reform efforts by parliamentarians and feminist advocates (Johnson, 2012; Roberts \& Grossman, 1992). The provision of legal consent (Shaffer, 2012) — or authorization for touch (Cook, Dickens, \& Thapa, 2005) - has been key to understanding acts for which criminal sanctions have been levied (Basile \& Smith, 2011; Burgess et al., 2010; Randall, 2010; Shaffer, 2012). Under the Criminal Code of Canada, sex offences currently encompass those acts associated with "sexual assault," that is, "a wide range of criminal acts ranging from unwanted touching to sexual violence including weapons," as well as those associated with "sexual offences" which refers both to the "three levels of sexual 
assault as well as other offences which are designed primarily to protect children" (Statistics Canada, 2006, p. 9).

Under Criminal Code designations for sexual assault, Level I (s. 271) is undefined, but has been determined by case law to include any sexual assaults that do not include elements of sexual assault Levels II or III. Level II (s. 272) is defined and includes sexual assault that involved the use of a weapon, threats to use a weapon, threats against a third party, or that had caused bodily harm. Level III (s. 273) is defined, and includes aggravated sexual assault that resulted in the wounding, maiming, or disfigurement of the victim, or that endangered the life of the victim (Johnson, 2012). Other sections involving sexual offences against adults include voyeurism (s. 162), obscenity (s. 163), and trafficking in persons (s. 279.01).

While children are protected under these Criminal Code provisions, Canadian minors are also protected by child-specific offences, for example, sexual interference (s. 151), invitation to sexual touching (s. 152), or incest (s. 155). Criminal Code provisions also protect children and youth by defining the "age of protection," which is the age at which a young person is legally permitted to consent to all forms of sexual activity. In 2008, Parliament raised the age of protection to 16 years of age (Department of Justice Canada, 2010). Youth under the age of 16 years are permitted to engage in consensual noncriminalized sexual activity if the minor is 12 or 13 and his/her partner is less than 2 years older, or if the minor is 14 or 15 years old and his/her partner is less than 5 years older with no relationship of trust, authority or dependency (Department of Justice Canada, 2010). Consent given by 16 and 17 year olds is rendered invalid should the sexual activity take place within a relationship of trust, authority, or dependency, or within the context of sex work or pornography. Thus, for youth involved in activity perceived to "exploit" them, or for engagement in anal sex if youth are unmarried, the age of consent in Canada is 18 years of age (Department of Justice Canada, 2010).

\section{Criminal Justice System Case Processing}

In Canada, sexual and other forms of violence against children is considered vastly underreported, both because children may not choose to disclose victimization and because younger children must rely on others in their immediate environment to report their victimization (Ogrodnik, 2010). The 2008 police-recorded data from the Incident- 
based Uniform Crime Reporting (UCR2) Survey found that the majority (80\%) of sexual offences against Canadian children and youth were classified at Level 1 (Ogrodnik, 2010).

In terms of adults, Du Mont and White (2007) noted that despite often devastating physical and psychological impacts of sexual assault upon victims, the responses of criminal justice systems worldwide have been "problematic" (p. 8). Johnson (2012) has critiqued Canadian police-recording practices, noting that classifications of sexual assault Level 1 have increased, often contrary to what would be suggested by offence details. Du Mont (2003) similarly identified troubling practices in police classification, whereby the expected charge was laid in only $40 \%$ of cases.

Plea bargaining, which is the practice in which the prosecutor and defence negotiate either charge, sentence, or fact discounts in exchange for a guilty plea by the accused (Manikis, 2012), is the norm in Canada (Wemmers, 2008) and in the United States (Koss, Bachar, Hopkins, \& Carlson, 2004). With respect to sex offences, a plea agreement has most often meant that "the offender is allowed to admit to a lesser crime, often to a nonsexual offence, with the result that he or she may not be known to the system as a sex offender" (Koss et al., 2004, p. 1438-1439). A plea agreement to a nonsexual charge results in the removal of the offender from consideration for mandatory sex offence treatment programs or inclusion in a sex offender registry (Koss et al., 2004). Nor is the offender subject to mandatory orders to provide DNA samples, which is contrary to advocates' recommendations (Koss et al., 2004; Office of the Federal Ombudsman for Victims of Crime, 2009).

Daly and Bouhours (2010) identified troublingly low conviction rates for sexual assault. Drawing on studies of five countries (Australia, Canada, England and Wales, Scotland and the United States), they concluded that the conviction rates for sexual assault have declined over the past 35 years from 18\% to $12.5 \%$. Johnson (2012) explained that if victimization surveys rather than police recorded statistics formed the basis for the examination of attrition, only $0.3 \%$ of sexual assault offenders in Canada would be convicted of sexual assault, and many at a lower level than the crime characteristics should have warranted (e.g., Level I versus Level II or III). In relation to the VIS, conviction on lesser charges limits the victim's ability to describe the impact of the original crime (Verdun-Jones \& Tijerino, 2002). In Canada, according to the Criminal Code provisions that have been upheld by case law (see for example, R. v. Talbot, 1985), 
the consequential harms described in the VIS must pertain to the crime for which a conviction has been registered.

\section{Summary}

The genesis, implementation, and enactment of the VIS is fully implicated in the historical origins of the role of the victim, the development of the crime victims' movement, and processes associated with the Criminal Code of Canada and case law decisions. With respect to the operation of the VIS in the context of sexual assault, an offence known to result in a myriad of harms, the legal definitions and criminal justice case processing of the crime influence the details that a VIS may contain. 


\section{Chapter 2-Literature Review}

As Morgan and Sanders (1999) noted 16 years ago, most of the empirical VIS literature continues to follow an atheoretical criminal policy or practice orientation. This chapter therefore provides a survey of the most commonly investigated VIS outcomes. The VIS's effects on victims' participation and motivation are discussed, as are its impacts on the working practices of criminal justice professionals, and sentencing and release decisions. The chapter then explores the very limited number of studies that have examined the VIS using a theoretical framework, and those that have focused on VIS use specifically in the context of sexual assault. It concludes with the rationale for the current study.

For this review, practice and policy examinations of the VIS that have concerned American death penalty cases were consciously excluded. While the VIS has been well studied in the United States in the context of capital sentencing (see for example Callihan, 2003), its use in those proceedings has raised unique and distinct issues of due process that are not applicable to Canada where the death penalty no longer exists (Roberts, 2009). Nonetheless, given the paucity of theoretical examinations of the VIS, those articles that included capital cases as illustrative examples (Bandes, 2009; Langstraat, 2006; Sheley, 2012) are still included. This review also excludes studies that used hypothetical or experimental research designs, whether conducted in Canada (see for example Lynett \& Rogers, 2000) or in the United States (see for example Paternoster \& Deise, 2011). It is unclear how well experimental findings can be generalized to the actual working of the VIS in the context of sexual assault in Canada (Du Mont et al., 2008).

\section{Victim Participation and Motivation}

In general, victim participation in VIS programs across all crime types has been quite low (Roberts, 2009). Only 10\% to $23 \%$ of crime victims in Canada (Giliberti, 1990; Roberts \& Edgar, 2006) and 15\% to 55\% in other common law jurisdictions (Leverick et al., 2007; Roberts \& Manikis, 2011; Sanders, 1999) submit a VIS. Canadian judges charged with sentencing have reported seeing a VIS in approximately $10 \%$ of cases, with rates varying only slightly across Canada, from a low of $8 \%$ in British Columbia to a high of 13\% in Alberta (Roberts \& Edgar, 2006). While the rates of participation have increased when the harms occurred within the context of more serious personal violence 
offences, still only a "minority" (Roberts, 2009, p. 362) of Canadian victims have utilized the VIS at sentencing. VIS use has remained rare at parole hearings in Canada (Parole Board of Canada, 2011b) and in the United States (Caplan, 2010).

Small descriptive studies have shown that most victims who completed a VIS at sentencing were women (Erez et al., 2011; Erez \& Tontodonato, 1990; Meredith \& Paquette, 2001), vulnerable (Erez \& Tontodonato, 1990), victimized at home (Erez \& Tontodonato, 1990), or harmed by known offenders (Erez \& Tontodonato, 1990; Meredith \& Paquette, 2001) or male offenders (Erez \& Tontodonato, 1990). These and similar studies have also revealed that VIS authors were more likely to have experienced a violent personal crime (Erez \& Tontodonato, 1990; Meredith \& Paquette, 2001) or personal injury (Erez \& Tontodonato, 1990), or to have had their cases proceed to trial instead of resolved through plea bargain (Cole, 2003). At a federal parole hearing, a VIS author in Canada was more likely to have been a victim of sexual assault or related to a murder victim (Department of Justice Canada, 2006).

At sentencing, victims' lack of knowledge or notification of the right to submit a VIS (Giliberti, 1991; Prairie Research Associates, 2005; Sobieski, 1992), their language or literacy difficulties (Giliberti, 1991), or their feelings of disinterest (Prairie Research Associates, 2005) or busyness (Giliberti, 1991) have been identified as important barriers to VIS submission. Victims might also have declined to complete a VIS because they wanted to put the incident behind them (Giliberti, 1991) or viewed the offence as too minor to have warranted it (Giliberti, 1991). Another barrier to VIS submission involved the time available to a prosecutor during case preparation because many lacked adequate time to ensure that a VIS was completed (Cole, 2003; Prairie Research Associates, 2005).

Studies that investigated the allocution of the VIS in court have found that fewer crime victims availed themselves of the opportunity to allocute than had chosen to submit written statements or attend the sentencing hearing (Erez and Guhlke, 1988 cited in Cole, 2003; Erez, 1989; Erez \& Tontodonato, 1992; McLeod, 1988; Prairie Research Associates, 2005; Villmoare \& Neto, 1987). In their survey of judges, Roberts and Edgar (2003) reported that $13 \%$ said they had never had a victim verbally deliver the VIS, and two thirds said that it happened only occasionally. A later survey by the same authors (Roberts \& Edgar, 2006) found a range of claims that victims had never expressed an interest in verbal delivery-from $5 \%$ of judges in Alberta to $24 \%$ of judges in British Columbia. 
In descriptive studies, victims most likely to have allocuted were identified as “angry women” (Erez et al., 2011, p. 27), White (Konradi \& Burger, 2000), or holding a higher occupational status (Villmoare \& Neto, 1987). Victims' rationales for having declined to allocute included their lack of knowledge of the right to have done so (Erez, 1989; Henley, Davis, \& Smith, 1994; McLeod, 1988; Sobieski, 1992), disinterest (Meredith \& Paquette, 2001), fear of the offender (Villmoare \& Neto, 1987), fear of public speaking (Erez and Gehlke, 1988 cited in Erez, 1989), or having already experienced testifying as too emotionally difficult (Meredith \& Paquette, 2001). Some studies found that victims had not allocuted because they had been discouraged (Konradi \& Burger, 2000; Villmoare \& Neto, 1987) or not actively encouraged by prosecutors (McLeod, 1988), or had not been permitted by judges (Meredith \& Paquette, 2001).

American victims who had allocuted indicated improved satisfaction with the criminal justice system compared with those who had not been provided the opportunity (Sobieski, 1992). Focus groups with Canadians who had submitted written VISs at sentencing, or had read them aloud, indicated widespread support for allocution (Meredith \& Paquette, 2001). These victims believed that allocution reduced the likelihood of judicial inattention to the VIS, which might have occurred had statements been provided merely in writing (Meredith \& Paquette, 2001).

Scholars have pointed out that some victims completed the VIS in the belief that it held some degree of influence on the type and severity of the sentence, which is known as instrumentality (Roberts \& Erez, 2004, 2010). Canadian research in the late 1980s found that victims across the country were most likely to have indicated that they had completed the VIS to influence the sentence, assert their rights over the offenders, or ensure justice was done (Giliberti, 1991). Similarly, Erez, Roeger, and O'Connell (1996) found that almost three quarters of surveyed Australian victims stated that they had expected the VIS to make an instrumental impact. More recently, Pemberton (2005) reported that $59 \%$ of Dutch victims said they would have welcomed the opportunity to submit a VIS even if it would not have had any impact on the sentence; this increased to $84 \%$ when they believed that instrumentality was probable (cited in Pemberton and Reynaers, 2011).

The disjuncture between victims' belief in the VIS's instrumental impact and the reality of most case dispositions has been the focus of the majority of studies that have discussed victim disillusionment and distress in relation to the VIS (Arrigo \& Williams, 2003; Cassell, 2009; Davis \& Smith, 1994b; Gewirtz, 1996; Roberts, 2003; Roberts \& Erez, 2010). Some criminologists have argued that directing a victim's attention to the 
"expressive" (Roberts \& Erez, 2004, p. 223) purpose of the VIS at the sentencing hearing would instead provide them with a more accurate understanding of its intended purpose, and thereby mitigate possible distress. The expressive purpose of the VIS is considered to be fulfilled when "the victim expresses his or her perspective about the effect of the crime, and this expression communicates messages" (Roberts \& Erez, 2010, p. 236) to the judge and offender.

Some scholars of the VIS have suggested that facilitating the expressive purpose of the VIS promotes the psychological welfare of victims (Roberts \& Erez, 2004) and assists them to achieve psychological or emotional catharsis (Erez, 1994). Emotional catharsis occurs when the mere ability to present a VIS in court, "irrespective of its ability to be actually considered in sentence, provides therapeutic benefits assisting with the emotional recovery of the victim" (Kirchengast, 2008, p. 617). Proponents argue that the therapeutic benefits associated with the expressive purpose of the VIS include “empowerment, validation, and moving on" (Erez et al., 2011, p. 24). These benefits have been particularly notable during VIS allocution when, in "a moment of expressive truth, as it were ... the victim can state for the record, in a face-to-face encounter, the extent of the harm that the offender's actions have done" (Erez et al., 2011, p. 25).

Several studies have found that victims felt validated and listened to when their VIS comments were referred to by judges during hearings because they believed this communicated that the community recognized and validated their often invisible psychological harms (Erez \& Rogers, 1999; Meredith \& Paquette, 2001; Roberts \& Edgar, 2003; Schuster \& Propen, 2006). The use of the VIS at sentencing and during the appeal process reinforces the idea that injury to an individual has occurred, which VIS supporters find particularly helpful in the context of marginalized victims such as sex workers who remain subject to significant legal and social devaluing (Savarese, 2010).

Nevertheless, contrary arguments have been strongly made against the use of the VIS for the purposes of emotional catharsis (Mosteller, 2003). Allocution, in particular, has faced therapeutic suspicion since there has been "no evidence of 'one-shot' forms of expression in the reduction/prevention of trauma" (Pemberton \& Reynaers, 2011, p. 240). Furthermore, Erez et al. (2011, p. 29) have noted that while the "giving of a VIS runs contrary to the usually adversarial nature of court proceedings," (p. 29) which suggests an unparalleled opportunity for victims, allocution "can nonetheless prove to be a difficult or unsettling experience” (p. 29). As with other forms of speaking in court such as sworn testimony, responding to direct prosecutorial examination, and undergoing defence cross- 
examination, VIS allocution might incur significant antitherapeutic effects (Erez et al., 2011). Negative therapeutic consequences in victims are seen to arise from the stress of public speaking (Erez et al., 2011), responding to defence counsel questioning intended to establish that the VIS contains embellishments or untruthfulness (Erez et al., 2011), and feeling misbelieved because the sentence imposed was not commensurate with the depths of suffering that was expressed through the VIS (Walberg-Hegan, 1997).

Increasingly, concerns have been raised about the extent to which communication with and through the VIS has been satisfying for victims (Wemmers, 2008; Wemmers \& Cyr, 2006). Wemmers and Cyr (2006) identified that up to one third of victims in Quebec believed the VIS had not allowed them to say what was important to them, and one quarter indicated that they would not complete it again, given the opportunity. In fact, the further that victims proceeded within the criminal justice system, the less important they found the VIS to be (Wemmers \& Cyr, 2006). The authors argued that this implied victims were not achieving the emotional catharsis or closure that they had anticipated by making a statement, in large part because the VIS was not satisfying their needs for meaningful participation in the criminal justice system. They and other scholars suggested that victims might have been misguidedly utilizing their participatory hearing rights - the right to complete and present a VIS — and demanding ever-increasing opportunities and services to exercise those rights simply for the want of participation that would elicit respect, restitution, and the referral to the appropriate social or mental health services (O'Hear, 2006; Pemberton \& Reynaers, 2011; Walklate, 2002; Wemmers, 2008).

\section{Courtroom Workgroup}

The "courtroom workgroup" (Eisenstein \& Jacob, 1977, p. 10) is a term used to refer to judges, prosecutors, and defence lawyers as a group. These actors have been found to informally operate as a group to serve shared goals such as courtroom efficiency, the achievement of justice, and the reduction of uncertainty (Eisenstein \& Jacob, 1977; Giblin, 2014). They also enjoy a familiarity derived from shared membership in a culture that excludes victims and other citizens (Erez et al., 2011). Unlike the police, who in an early study were found to be supportive of the VIS and believed it to be underutilized by prosecutors (Giliberti, 1991), members of the courtroom workgroup have expressed less consistent support for the VIS.

In Canada and other common law jurisdictions where VISs are permitted, studies have variously identified prosecutors and judges as hostile or resistant (Davis \& Smith, 
1994a; Erez \& Laster, 1999; Henley et al., 1994; Katz, 2010), indifferent or disinterested (Davis \& Smith, 1994a; Giliberti, 1991; Roberts, 2009; Wemmers, 2008), or as welcoming (Attorney-General's Department, 1999; Cole, 2003; Giliberti, 1991; Henley et al., 1994; Leverick et al., 2007; Roberts \& Edgar, 2006) of the VIS's incorporation in their practices. Prosecutors in different Canadian provinces were found to hold widely disparate views of the VIS. For example, prosecutors working in Ontario believed statements were useful (Giliberti, 1991), those in Saskatchewan were opposed to their use (Giliberti, 1991), and those in Quebec failed to mention them altogether when prompted to recall aspects of the criminal justice system that involved victims (Wemmers, 2008). Prosecutors' contrasting views of the VIS's usefulness caused them to utilize it quite differently at sentencing hearings (Giliberti, 1991).

Scholars have also noted shifts over time in the acceptance and use of the VIS in Canada. Prior to the 1988 codification of the VIS in the Criminal Code, judges were perceived as opposed to any form of victim participation in the sentencing process (Katz, 2010). However, in a 2003 survey of 65 Ontario Court judges, Roberts and Edgar (2003) found that most judges stated VISs were useful and could contain unique information. More than four fifths of judges in that study stated that VISs were most likely to be useful in crimes of violence, and 53\% identified sexual offences specifically. Additionally, more than two thirds of judges reported that they usually or often referred to the VIS in their sentencing deliberations. In 2006, the same authors surveyed judges in three Western Canadian provinces (Roberts \& Edgar, 2006). Their findings revealed that $47 \%$ of judges stated that VISs often or sometimes contained useful information unavailable from other sources, which had been helpful to decision-making. The authors also found that $39 \%$ of judges almost always referred to victim impact, whether or not that was gleaned from the VIS, when giving reasons for sentence (Roberts \& Edgar, 2006).

Judicial acceptance of the VIS may be a consequence of the concerted efforts of all courtroom workgroup parties to ensure that VIS details have been restricted to information already or easily incorporated by the criminal justice system, and particularly by judges. In many jurisdictions the "most persuasive arguments" (Douglas, Laster, \& Inglis, 1994, p. 96) against the introduction of the VIS were "based on the practical difficulties of implementation ... [and the] heavy workload" (p. 96) of judges and lawyers. Consequently, Erez and Laster (1999) claimed that there developed a "tacit understanding" (p. 547) among courtroom workgroup members that they would cooperate to ensure that the VIS would not "unduly tax" (p. 547) other members or the criminal 
justice system. In British Columbia prosecutors were found to be quite selective in the VISs that they submitted to court, preferring those that they perceived as helpful to judges (Roberts, 1992). Prosecutors and defence lawyers in Ontario were found to agree to withhold VISs from judges when conflicts arose between them over content (Cunningham, 1994). When surveyed in the late 1980s, Canadian judges were often unaware that a VIS had been submitted by the victim but had not been tendered to the court by the Crown prosecutor (Giliberti, 1991).

Investigations of courtroom workgroup practices have revealed that crossexamination of the VIS has been a rarity in Canada. In a survey of defence counsel in Alberta, Bateman (2002) found that they would cross-examine a VIS only "if they were positive it would not backfire on their case" (p. 25). Other research found that prosecutors and defence lawyers cited $26 \%$ and $23 \%$, respectively, as the likelihood for crossexamination of the VIS (Prairie Research Associates, 2005). Ninety-seven percent of judges in British Columbia, Manitoba, and Alberta reported that VIS cross-examination had never or almost never taken place, and $84 \%$ of judges in Ontario indicated the same (Roberts \& Edgar, 2006). However, these low rates should not be understood to indicate there was low courtroom workgroup conflict concerning the VIS; conflict was often addressed prior to the sentencing hearing. Even the concern or suggestion that a crossexamination might be conducted on the VIS has been found to prompt preemptive action by prosecutors, including the excise of contested information (Prairie Research Associates, 2005), or the withholding of the VIS from the court (Cunningham, 1994; Prairie Research Associates, 2005). A national sample of Crown prosecutors in Canada found that $18 \%$ mentioned defence counsel objections or cross-examination as an obstacle to the use of the VIS, and an undisclosed number indicated that they would withhold VISs if they believed their contents would be detrimental to prosecution (Prairie Research Associates, 2005).

\section{Sentencing and Parole Effects}

As Manikis and Roberts (2010) stated firmly, "the research record across a number of jurisdictions is clear: the introduction of VIS did not have an inflationary effect on sentencing patterns" (p. 133). Pemberton and Reynaers (2011) concluded that this lack of impact on sentencing held true even when victim statements of opinion on penalty were considered. Studies and reviews have consistently shown that with few exceptions, sentences were often negotiated with plea agreements, and the VIS was less 
important than other factors when judges decided to depart from sentencing guidelines (Cassell \& Erez, 2011; Erez \& Laster, 1999; Henley et al., 1994). Nonetheless, VISrelated sentencing discretion does appear to exist.

Erez and Tontodonato (1990) found that the presence of a written VIS in the state of Ohio was associated with an increased likelihood of incarceration rather than probation. Erez and Roeger (1995) found that the VIS was associated with increased sentencing leniency in Australia if the victims had requested it in their VISs. In an American study (Propen \& Schuster, 2008; Schuster \& Propen, 2010), despite their remarks professing that sentencing guidelines were more important than the VIS, all judges were able to recall a sentencing decision in which they had been influenced by the details contained in the VIS. In Cole's (2003) survey of 34 prosecutors in Ontario, $61.8 \%$ disclosed that they had experienced the VIS affecting sentencing in some cases. In a 2004 review of Canadian case law, the federal Department of Justice found that VISs affected sentences in some circumstances, particularly in cases of intimate partner violence (cited in Smith, 2012).

Smith (2012) identified three intimate partner sexual assault cases in Canada $(R . v$. R. (S.) [1998], R. v. S. (T.) [1996], and R. v. G. (R.) [2003]), wherein the courts had been influenced by victims' preferences regarding sentence. In R. v. S. (T.) (1996), the offender was granted a conditional sentence when the judge stated that he would have given jail time if not for the VIS. This contrasted with $R$. v. G. (R.) (2003), wherein the VIS was a significant influence in the court not granting a conditional sentence. Smith (2012) further noted that while it is "not commonly discussed," (p. 196) the outcomes of several cases in Canada have fueled speculation that VISs influence whether an offender receives a consecutive or a concurrent sentence. Cassell and Erez (2011) argued that the VIS's discretionary influence is appropriate because it facilitates judicial tailoring of individual sentences to the particular circumstances of the cases. The authors argued that this interpretation also holds true in cases where judges have used VIS harm descriptions to inform decisions that misalign with plea negotiations, for example, when the VIS is relied on to determine that prison, not probation, is instead a more suitable sentence (Erez et al., 2011).

American studies that examined the impact of written and/or verbal statements of harm at the parole level have reported mixed results (for a full review see Caplan, 2010). Caplan (2010) found that neither written nor verbal victim input was significantly related to parole denial, although verbal statements more closely approached significance. 
Similarly, in a review of the releasing and supervision decisions of authorities in all 50 U.S. states, Kinnevy and Caplan (2008) found that in-person interviews with victims were more impactful on decision-makers than victims' written statements. Canadian research has been severely limited on the impact of the VIS on provincial and federal parole boards' release decisions. While a 2006 review of practices at the federal parole board identified that submitted video or audio VISs were less likely to be reviewed by the board than written statements (Parole Board of Canada, 2006), the report left unaddressed whether the presence of written or verbal VISs had affected parole release decisions in any way.

\section{Theoretical Literature}

Rarely have VIS scholars analyzed their findings using a theoretical framework. I identified five articles that examined the VIS from the perspectives of what may be termed the sociologies of emotion (Bandes, 2009; Langstraat, 2006; Schuster \& Propen, 2010; Sheley, 2012), as well as genre theory (Propen \& Schuster, 2010). The articles were suggestive of the benefits and limitations of these particular theoretical perspectives in relation to understanding the VIS.

In her sociolegal study of American capital jurisprudence, Bandes (2009) analyzed the VIS by drawing on emotion theory stemming from Hochschild's foundational (1983) work on emotional labour. Bandes (2009) identified the effects on the capital punishment system when a nonlegal precept, in this case "closure" (p. 1), was adopted uncritically in the courtroom and by juries. She argued that the ambiguous concept of closure, which "even in the therapeutic context has no accepted clinical meaning" (p. 16) but is generally understood to be a legitimate, desired psychological state of healing from crisis, recast the capital punishment system as intended to serve therapeutic goals. The VIS, in turn, was an integral means to assist with that goal through the public sharing of a victim's private grief and recollection of loss. As Bandes (2009) critically noted, what was often overlooked was the strong role that the prosecutor's agenda played in selecting which victim was permitted to submit a VIS, and the "appropriate" (p. 15) emotions such as anger and a desire for vengeance that their statement should contain. She further explained that

to treat the victim impact statement like a private or familial expression of grief is to ignore the ways in which the survivor's message is channeled, 
translated, even transformed in light of the expression rules and role expectations of the [legal] forum. (p. 12)

Bandes (2009) noted that the imperative of closure that invited the VIS into the capital system also strongly shaped the jury response to such displays of grief, particularly in the context of a mass murder case. There, the VIS's ability to display pain and "make grief salient" (p. 22) often led to harsher punishment because "we have promised survivors that the system can give them closure, and capital punishment is now compelled by our promise" (p. 26).

Bandes's (2009) work has importantly identified the influence of sociocultural norms of emotional expression and expectations of audience sympathy that victims may rely upon when writing and submitting a VIS. She has also usefully identified the strategic value of the VIS to legal professionals, such as prosecutors arguing for harms against the state. However, Bandes (2009) explained that emotion rules operate differently in cases of sexual assault and intimate partner violence, where judges are very uncomfortable with anger and hatred, and the death of the defendant is not at stake. Consequently, she noted limitations in the applicability of her findings to noncapital cases.

Schuster and Propen (2010) qualitatively interviewed 28 judges in two districts in the state of Minnesota. Similar to Bandes (2009), the authors drew on the literature of the study of emotionology, which they defined as the emotional standards within a culture. As the authors explained:

Emotionology affects not only evaluation of emotional expressions but also affects behavior as people normalize and internalize such emotional standards. Emotionology is established by members of a culture but is highly influenced by those who are granted a widespread voice, such as the media and law, medicine, or other such powerful voices. Once emotionology is established, it affects personal and social reactions to emotions, is built into institutions, and enforces and sometimes conceals hierarchical relationships. (p. 80)

Through the lens of emotionology, Schuster and Propen (2010) examined judicial reactions to VISs in cases of intimate partner physical violence and sexual assault. They found that judges' comments reflected a belief in the separation of emotion and reason in the courtroom. This emotionology led them to elevate reason above emotion to "manage authority while at the same time not denying agency to victims" (p. 90). Judges utilized 
rhetorical strategies to facilitate this separation and manage the emotional expressions in a VIS. In order not to appear as if they had discounted victims' statements of trauma, judges first expressed to victims that they were limited in penalty options because of sentencing guidelines. Next, judges spoke in the language of certainty or inevitability to avoid the perception that they were responding to emotional VIS appeals. Finally, judges frequently attempted to control their own emotional responses when listening to VISs.

In Schuster and Propen's (2010) study, judicial emotionology in the courtroom also extended to the management of victims" "reasonable" (p. 90) expressions of grief. Judges in that study positively acknowledged evocative but restrained VISs. However, they interrupted what they perceived as unreasonable expressions of grief, such as the sprinkling of cremated human remains in the courtroom by mourning family members during VIS allocution. Schuster and Propen (2010) also found that judicial emotionology varied depending on the characteristics of the victim. Expressions of victim anger in the VIS, which judges interpreted as symptomatic of victims who were dishonest or unable to gain perspective on the crime, were unwelcome. However, judges permitted victims who had been sexually assaulted by strangers more latitude to express anger because of their “'innocence' as victims” (p. 99).

Schuster and Propen (2010) found that judges' reactions also differed to the expressions of compassion for offenders in the VISs presented by women who had been physically versus sexually assaulted. In general, compassion was highly valued since judges conflated compassion with the transcendence of personal pain and a focus on the goals of the court. The authors explained:

Compassionate victims do not seek revenge according to judges'

perceptions; they accept the limitations of sentencing guidelines and the inevitability of plea negotiations. Their requests for mercy are interpreted as cooperative, a possible indication of how plea negotiations settle for the lower end of options in sentencing guidelines grids. (p. 94)

Nonetheless, while judges valued sexually assaulted victims' expressions of compassion for stranger offenders, they were suspicious when victims of intimate partner violence expressed the same sentiment for their current or estranged partner offenders. Schuster and Propen (2010) found that victims who commented compassionately on sentencing penalties for their intimate partners faced a "truth test" (p. 96) not required of other categories of victims. Judges most often viewed their compassionate comments as evidence of trauma-induced "sickness" (p. 96). This belief was maintained unless and 
until the VIS provided information either that the victim was subsequently in the process of leaving her intimate partner, or that she now possessed insight into the cycle of abuse. Thereafter, judicial suspicion was suspended, and victims were most likely to achieve influence in mitigating the penalty. For example, the authors quoted a judge who described how "the wheels of justice [came] to a screeching halt" (p. 99) in the penalty phase of a sentencing hearing when a domestic assault victim's lengthy 15-page VIS detailed her history of sex work and drug-taking, which was perceived by the judge as insight into the physical assaults committed against her. Schuster and Propen (2010) noted that judicial standards differed for sexual assault victims. In order to affect sentencing decisions or plea negotiations, victims of sexual assault were instead often required to narratively demonstrate in the VIS that they had suffered more grievous physical harm or psychological trauma than was generally associated with serious sex offences.

The research by Schuster and Propen (2010) has contributed insight into how judicial treatment differs between victims of particular crime types, as well as the particular scrutiny under which women who are physically assaulted by their intimate partners must operate. Their work has also helpfully drawn attention to the strategic use of the VIS by victims in order to sway penalty decisions. However, their work suffers from the artificial separation between sexual assault and intimate partner violence; that is, they have apparently not considered that intimate partners might sexually assault women either in the context of a previously nonviolent relationship, or as part of ongoing physically and sexually abusive conditions. As such, their findings failed to acknowledge the complexity of sexual assault victimization. This oversight, in turn, has affected the veracity of their analysis with respect to victims' VIS-related strategies, as well as the reliability of their claims regarding the wide emotional latitude that was permitted raped women.

Sheley (2012) drew on sociological explanations of emotion, pain, and narrative to illustrate the VIS's usefulness in describing the complexity of the social experience of harm. Until the development of the VIS, harm descriptions had been the monopoly of prosecutors. Sheley (2012) discussed the VISs that were presented at the 2005 American trial of Zayd al Safarini, a perpetrator of the 1986 hijacking of Pan Am Flight 73 in Karachi, Pakistan. She showed that victims had confronted and challenged their traditional objectification in judicial proceedings through temporal and discursive narrative strategies in their VISs, including "idiosyncratic use of chronology and 
symbolic objects" (p. 55). For example, Sheley (2012) attributed the emotional impact of a son's VIS narrative concerning the return and storage of his murdered father's small, shrapnel-riddled "under the seat" (p. 29) airline suitcase to the cumulative effect of the same symbol's use in multiple other VISs. Victims who were parents had each written of their desperation as they tried to squeeze their now-deceased children into those same small "under the seat" (p. 30) spaces to shield them from the hijackers. Sheley explained that the repeated verbal reference and visual images in the VISs of the "under the seat" space demonstrated the "power of an individually significant object to serve as an access point to so many concentric realities [that] would be lost in the traditional questioning of a witness" (p. 30).

Sheley's (2012) work importantly deconstructed the narrative strategies by which victims established harm. In particular, she demonstrated how victims' loose-jointed temporal associations between the criminal act (hijacking) and their examples of continuing manifestations of harm (e.g., being psychologically unable to open the battered suitcase) had readily provided jurors with a visceral and temporal trajectory of the consequences of one criminal act. Nonetheless, the author characterized victims' narrative strategies and their effectiveness as accidental, and assessed their tactical value only insofar as they represented a challenge to the traditional monopoly of harm descriptions by prosecutors. In consequence, she neglected to examine the strategies and intentionality that might have underpinned victims' narratives. This neglect led to a poorer analysis of the purposing of harms details than might have otherwise occurred.

Langstraat (2006) also drew upon studies of emotion. She argued that the VIS represents "community rhetoric" (p. 268) that epitomizes a shift toward overt affective expression in institutionalized settings and presents a challenge to the existing hegemony of objectivity in the law. Langstraat (2006) argued that VISs "do not simply invite an explicit discourse on emotions. They require it” (p. 268). Consequently, VIS guidelines have both coaxed victims to articulate the emotional repercussions of crimes and provided pedagogical guidance on how to properly do so for the purposes of legal proceedings.

Langstraat (2006) explained that the VIS represents the legal system's first explicit acknowledgement of crime's emotional impact. Its presence is an acknowledgement that "such emotionality should—and does_-influence legal (i.e., sentencing and restitution) judgments" (p. 270). However, she noted that the emotional descriptions contained in the VIS have been "mediated by language and the demands of 
the rhetorical situation" (p. 271). She was critical of VIS forms that have been structured to "encourage 'stock narratives' that curtail emotional complexity and privilege the expression of vengeance" (p. 271). She further commented that guidelines intended to instruct victims on how to complete the statement have contained "leading' questions that represented only 'typical' traumatic response" (p. 271).

Langstraat (2006) saved her strongest critique for the ways in which the VIS “risk(s) appropriating victims' emotional expression for more traditional ends" (p. 268) while excluding others. She noted this occurred through guidelines for VIS completion that "privilege the traditional nuclear family structure," (p. 273) by inviting victims to include photographs or family portraits in the VIS. This action effectively screens out VIS narrators who do not "fit the dominant narrative of innocence," (p. 272) which is required for credibility, such as victims of intimate partner violence who have chosen to stay with their abusive partners. Langstraat (2006) also demonstrated the state's strategic appropriation of victims' particular emotional expressions in and through the VIS. She noted that in the 1997 trial of the American domestic terrorist Timothy McVeigh, prosecutors selected only those VISs that would support retributive justice and the death penalty. Langstraat (2006) concluded that VISs could affectively reeducate judges on the individual versus state consequences of criminal harm. However, she cautioned that to properly exploit the VIS's "counterhegemonic potential” (p. 273) to achieve sweeping affective change in legal culture, the current sociocultural context of emotion in which the VIS currently operates would require further investigation and critique.

Propen and Schuster (2010) applied genre and activity systems theories to the data that they had earlier analyzed using emotionology (Schuster \& Propen, 2010). They define genres as "tools-in-use" (p. 9) or artifacts that can mediate certain activities. The authors understood the VIS to be "a mediating artifact that then accomplishes meaningful advocacy work through the combined activities and interpretations of victim advocates, victims and the court system" (p. 9). Propen and Schuster (2010) suggested that the VIS exists alongside other courtroom genres such as the presentence report, sentencing guidelines, and plea negotiations. Similar to those older genres, the VIS is required to operate within existing courtroom norms and the espoused values of the legal system such as efficiency, objectivity, fairness, and justice. Unlike them, however, the VIS provides an opportunity for victim opinion, and a glimpse into the personal effects of crime. It therefore represents the possibility of system change and disruption because one VIS can 
potentially educate a judge on the broader, more general effects of crimes such as sexual assault.

Propen and Schuster (2010) reported that advocates felt pressure from judges to ensure that VISs were an acceptable genre addition to the courtroom. Advocates therefore assisted victims to achieve a suitable emotional tone and to remain within acceptable parameters of what "the judge might be interested in hearing" (p. 28), including public and personal safety concerns and the rehabilitation potential of the offender. In this regard, the authors perceived the VIS to be a genre that was influenced both by other established genres and the efforts of advocates. Propen and Schuster (2010) were ultimately concerned with examining which VIS features were those that judges and advocates believed made a VIS persuasive, and under what conditions judges would resist or welcome this new courtroom genre.

\section{Victim Impact Statement and Sexual Assault Research}

Findings from mixed-victim studies have provided evidence that sexually assaulted women are a unique population in relation to the VIS (Rogers \& Erez, 1999; Schuster \& Propen, 2006). Judges have sympathetically perceived VISs when victims were sexually assaulted by a stranger (Schuster \& Propen, 2006) and when the crime was egregious such as a "grannie rape" (Rogers \& Erez, 1999, p. 272). Judges were more likely to respond negatively when the sexual assault victim was "a prostitute compared to a respectable citizen" (Rogers \& Erez, 1999, p. 278) and when they believed the victim shared complicity in the sexual assault by dating or drinking with the offender (Schuster \& Propen, 2006). On such issues, feminists have argued that rape mythology has influenced judicial interpretations of sexual assault (Du Mont, Miller, \& Myhr, 2003; Ruparelia, 2012). Rape mythology has been identified as highly codified and deeply embedded social notions of what might be deemed a "real rape" and who might be convincingly portrayed as a "real victim" (Du Mont et al., 2003). Scholars have argued that these beliefs, in turn, have been implicated in judicial considerations of VISs written by women who were sexually assaulted (Ruparelia, 2012).

Rarely have empirical studies or legal case reviews discussed the VIS exclusively in the context of sex offences (for exceptions see Du Mont et al., 2008; Konradi \& Burger, 2000; Leichtentritt \& Arad-Davidson, 2006; Leichtentritt \& Davidson-Arad, 2002; Regehr \& Alaggia, 2006; Regehr et al., 2008; Ruparelia, 2012; Shackel, 2011; 
Walberg-Hegan, 1997; Walsh, 1986). Of these, only six investigations (Du Mont et al., 2008; Konradi \& Burger, 2000; Regehr \& Alaggia, 2006; Regehr et al., 2008; Ruparelia, 2012; Walsh, 1986) concerned or included VISs written by adult women who were sexually assaulted at some point over their lifetimes. Because such VISs are the focus of my study, I discuss these studies in more detail.

Ruparelia (2012) drew on several Canadian sexual assault cases, as well as American data on sentencing in death penalty cases, to discuss the influences of victim and offender race in Canadian judicial handling of the VIS in the context of sexual assault. She noted that given the "invidiousness of discrimination" (p. 668) inherent in the Canadian criminal justice system, the VIS was not "immune from racial, class and gender bias" (p. 668). As a result, both racialized women as victims, and racialized men as offenders, have suffered from the use of the VIS. Ruparelia (2012) concluded that VISs were "particularly dangerous" (p. 668) when used in cases of sexual assault because the statements were "more likely to be used to discredit women's claims than validate them" (p. 665).

Ruparelia (2012) drew on Razack's (2002) analysis of the gang-rape and murder of a young Aboriginal sex worker, Pamela George, to demonstrate the dangers of VIS use. The insensitive handling of George's death by the Canadian criminal justice system has been long considered an illustrative example of the systemic racism and sexism confronting Aboriginal women (Rowe, 2001). Despite this, the connections between the George trial and the inherent dangers of the VIS remain tenuous. Moreover, Ruparelia (2012) failed to attend to Razack's (2002) own finding that George's mother and sister had each undertaken a VIS to successfully challenge the defence attorney's biased characterization of George. They also used their VISs to directly complain about the misogynist treatment that George had received posthumously. They believed this poor treatment was evident in the judge's charge to jury members to keep in mind that George was a sex worker while they were considering whether she had consented to the sexual contact.

Ruparelia's (2012) neglect of the material applications of the VIS in the George case led to a conceptual failure to examine whether, and how, the statement might bear potential for a more emancipatory, strategic use by Aboriginal women. Given that Ruparelia (2012) failed to provide any empirical evidence of her own or others to demonstrate the likelihood of increased harm or lack of benefit to racialized sexually 
assaulted women as a consequence of the VIS, it remains unclear how much weight to assign to her conclusions.

Du Mont, Miller, and White (2008) interviewed 15 social workers who provided direct clinical care to female sexual assault victims through hospital-based sexual assault and domestic violence treatment centres in Ontario. Social workers overwhelmingly endorsed the VIS. They believed it to be a part of the healing process as well as legally beneficial for women. The majority of social workers also strongly believed in the communicative potential of the VIS; that is, in the context of a sexual assault case, a VIS could foster responsibility on the part of the offender, public recognition of harm, and increase the empathy and sensitivity of judges. Despite their support of the VIS, social workers consistently provided examples where victims' participation in the VIS process had resulted in ill, or nil, therapeutic effects. Moreover, when the authors prompted social workers to provide personal or anecdotal evidence in support of their beliefs that the VIS had been a beneficial adjunct legal remedy for their clients, most were unable to do so. The majority of social workers neither attended sentencing nor provided client follow-up after VIS submission. Consequently, they demonstrated confusion and uncertainty when asked whether sentences were at all influenced by the presence of VISs, or whether judges had referred to them.

The Du Mont et al. study (2008) highlighted new VIS-related activities of hospital-based social workers, which had not been previously explored. In this regard, the study could be considered to have identified a new VIS-implicated therapeutic-legal borderland, although the authors did not pursue those implications. Instead, because court and sentencing hearing accompaniments were generally outside social workers' practice, the authors simply emphasized that the professionals had struggled, unsuccessfully, to make sense of the processes and outcomes of the VIS. Ultimately the findings provided evidence that social workers' role, unlike the increasingly liminal status of victim advocates and victim services workers to the courtroom work group (Englebrecht, 2008), has remained that of an outsider to the criminal justice system. While the study helpfully highlighted the expansion of VIS-related activities into clinical care, it remained unable to further explicate the operations and effects of the VIS beyond an exploratory description of its nascent impact on hospital-based social work practice.

Regehr and colleagues (2008) qualitatively interviewed 31 victims of sexual assault who were involved in the criminal justice system. Victims were predominantly women ( 28 women, two men, and one transgendered person). While half of the victims 
completed VISs, the reasons for participation or decline remained unknown. The authors noted enthusiastically that the VIS "was repeatedly referred to by participants as an important and positive aspect of the court process" (p. 107). However, it was unclear whether the sentiments were expressed by victims with successfully concluded cases who had submitted and/or allocuted a VIS, or whether these were merely general statements by victims who had wished to but were unable to present in court. For example, the authors commented that one victim had prepared a statement but was prevented from allocuting the VIS when the offender had pled guilty, which then led her to feel that "she had been cheated out of her day in court" (p. 107).

Regehr and colleagues (2008) provided scant additional details on the VIS, and neglected to mention it altogether in their findings. This lacuna was perhaps a consequence of their overall finding that "victim experience was shaped by the attitudes and behaviours of specific people within the system demonstrating the importance each individual plays in their official capacity" (p. 99). Thus, the authors perceived the VIS as a simple textual document produced exclusively by a victim, which was less important than other influences when accounting for victim experience and satisfaction with the criminal justice system. Consequently, their findings shed limited light on the use or the effect of the VIS, particularly on the interactions between victims and members of the broader VIS network.

Regehr and Alaggia (2006) examined the involvement of female sexual assault victims in the Canadian criminal justice system from the perspectives of 14 key legal and therapeutic informants. The authors found that therapists and advocates viewed the VIS as "opportunities [for victims] to tell their story which allowed them to take control over their victimization" (p. 38), particularly when judges referred to the VIS in sentencing. However, they cautioned that a VIS might be counterproductive to healing. Providing a victim with the opportunity to complete a VIS appeared to incorrectly imply that it was her healing, rather than due process and a fair trial for the alleged offender, that was the legal system's primary consideration. While important, Regehr and Alaggia's (2006) work is of limited assistance here because the authors touched only briefly on the VIS, and did not distinguish the VIS from other forms of criminal justice participation. It was often unclear whether informants' discussions of their clients' experiences of disappointment or revictimization were related specifically to the VIS, or to the more general negative effects of participation in the criminal justice system. 
Konradi and Burger (2000) qualitatively interviewed 37 female victims of completed or attempted rape who participated or intended to participate in the sentencing phase of a trial. Participation was defined as attending/observing sentencing, presenting a written VIS, or presenting an oral VIS. Victims attended hearings (68.9\%), allocuted (27.6\%), and submitted written statements (34.4\%). Characteristics of the rapist (e.g., relationship to the victim), sexual assault (e.g., presence of injuries), or victim (e.g., education) were not predictive of choosing a particular type of participation and eschewing others. The authors found that fewer women exercised their right to present a VIS orally than provided written statements or only attended hearings. Positive external encouragement by prosecutors and victim-witness personnel was predictive of participation. Age, race, and ethnicity were also found to be important factors associated with the type of participation. The study is directly relevant to issues of motivation, rationale, and experience that have been brought to bear on victims' sentencing participation decisions. However, the authors' findings remain difficult to directly apply because the type of participation (e.g., hearing observation or written VIS commentary) to which their discussion pertained was often unclear. Consequently, the study failed to fully illuminate the strategies, purposes, and experiences exclusive to the VIS.

In a much earlier study, Walsh (1986) examined sentencing dispositions in 417 sexual assault cases in the state of Ohio from 1980 to 1983 . Walsh found that the similarities between actual sentencing outcomes and victims' sentencing recommendations in the VIS gave rise to the belief "that something is being done" ( $p$. 1139) to appease the victims' wishes. However, he explained that victims were unaware that the agreement was "almost entirely mediated by legally relevant variables" (p. 1139). Consequently, he argued that VISs were "a mere genuflection to ritualistic legalism" (p. 1139) of victim participation. The author also noted that when victims desired probation over imprisonment, VISs were more likely to be ignored, which later led some VIS scholars to suggest that Walsh had demonstrated the courts were more punitive than victims of sexual assault were (Erez \& Roberts, 2007). Walsh's findings are of limited use in understanding the contemporary uses and experiences of the VIS because of their datedness, as well as the focus on victim sentence recommendation, which is not legislatively permitted in Canada. 


\section{Summary}

Most VIS research has not exclusively focused on sexual assault. Despite their importance, the six studies that focused on adult VIS authors in the context of sexual offences (Du Mont et al., 2008; Konradi \& Burger, 2000; Regehr \& Alaggia, 2006; Regehr et al., 2008; Ruparelia, 2012; Walsh, 1986) have suffered from a range of methodological limitations that restrict their utility for this study. These shortcomings include being outdated (Walsh, 1986), lacking empirical data from victims (Du Mont et al., 2008; Regehr \& Alaggia, 2006; Ruparelia, 2012), or the failure to distinguish the use of the VIS from other forms of criminal justice participation (Konradi \& Burger, 2000; Regehr et al., 2008), which has made meaningful interpretation difficult. Additionally, none of these studies examined the increasing eligibility and use of the VIS outside of the sentencing hearing.

Theoretical works on the VIS have been rare. The handful of studies that have theoretically examined the VIS have helpfully established links with the sociologies of emotion and with genre theory (Bandes, 2009; Langstraat, 2006; Propen \& Schuster, 2010; Schuster \& Propen, 2010; Sheley, 2012). However, their neglect of an exclusive focus on sexual assault, and in some cases their heavy reliance on American capital cases (Bandes, 2009; Langstraat, 2006; Sheley, 2012), have limited their applicability. Moreover, for the most part, they have all narrowly conceptualized victim agency to VIS completion/noncompletion or unstrategized descriptions of harm. In so doing, they have failed to investigate the complexity, ambiguity, or agency associated with victims' use of the VIS. These failures have limited the insights provided into victims' real-world decision-making processes regarding the submission of the VIS, and who or what else might influence those processes.

\section{The Present Study}

The VIS is a victim's voluntarily written account of a range of harms experienced as a consequence of a crime. Rarely has the VIS been investigated specific to sexual assault, an offense known to frequently involve potentially serious harms to the victim. Nor has the VIS been examined from a theoretical perspective. Much remains to be learned about the deliberate purposes and strategies to which sexually assaulted women apply harms descriptions contained in the VIS, and how others may also make use of 
them, including in nonsentencing arenas. This dissertation was designed to address these gaps. Interviews were conducted with 44 participants who sought or provided VIS-related services in Canada. Findings were analyzed using insights from ANT because the exploration of macro and micro stakeholders and negotiative practices is a strength of ANT (Bergquist, Ihlstralm, Ljungberg, \& Kesson, 2008), which may assist in illuminating how and why the VIS performs, otherwise and unexpectedly, in multiple contexts. 


\section{Chapter 3-Actor-Network Theory as a Sensitizing Lens}

This chapter reviews the key tenets of actor-network theory or ANT (Callon, 1986; Latour, 2005; Law \& Hassard, 1999) which have been used in this study as sensitizing concepts (Blumer, 1954; Bowen, 2006). This study represents the first application of ANT to the VIS. In so doing, this study departs from the largely descriptive and atheoretical stance present in most VIS studies (for exceptions see Bandes, 2009; Langstraat, 2006; Propen \& Schuster, 2010; Schuster \& Propen, 2010; Sheley, 2012).

The foundations of ANT are associated with the works of Michel Callon, John Law, and Bruno Latour (Callon, 1986; Latour, 2005; Law \& Hassard, 1999). ANT scholars are concerned with the enactment and circulation of power, which is performed by processes of delegation and discipline across networks of heterogeneous actors who may be human or nonhuman. ANT is grounded in empirical case study (Law, 2009). To date, applications of ANT in the area of medical sociology have examined health conditions including blindness (Schillmeier, 2007), autism (Hendricks, 1997), Alzheimer's disease (Moser, 2008), lower limb atherosclerosis (Mol, 2002), and anemia (Mol \& Law, 1994); health care practices such as diagnosing (Gardner, Dew, Stubbe, Dowell, \& Macdonald, 2011) and therapeutic texting (Haxell, 2008); and health technologies such as the metered dose inhaler (Prout, 1996), computerized medical record system (Lehoux, Sicotte, \& Denis, 1999), and genetic technology (Williams-Jones \& Graham, 2003).

ANT theorists explicitly endorse the symmetric empirical treatment of humans and nonhumans (Latour, 1993). Humans and nonhumans are viewed as possessing equal ontological status as actors. As Latour (1996b) explained:

An "actor" in ANT is a semiotic definition — an actant — that is something that acts or to which activity is granted by another. It implies no special motivation of human individual actors, nor of humans in general. . . An actant can literally be anything provided it is granted to be the source of action. (p. 373, original emphasis)

Clarke (2009) further elaborated that nonhuman actors or actants might include: cultural objects, technologies, animals, media, nonhuman animate and inanimate pieces of material culture, and ... lively discourses ... [that] are products of human action (and we can study the production processes); 
[or] constructed as "natural" (and we can study how they have been constructed as such). (p. 201)

Hartt and colleagues (2014) succinctly summarized that at "the core of an actor or actant ... is the ability to change an experience" (p. 300). Yet understanding the interactive nature of the agency of actors is critical: "by themselves, things don't act" (Callon \& Law, 1995, p. 485). Interaction is action "shared with other kinds of actants dispersed in other spatio-temporal frameworks and who exhibit other kinds of ontology" (Latour, 1996c, p. 239, original emphasis). ANT posits that human and nonhuman actors must be simultaneously considered when accounting for social interaction because they are "co-constitutive - together constitute the world and each other" (Clarke, 2009, p. 209). Thus, the interactionist agency of a human or nonhuman actor includes others who are the same or different, and who may be physically or discursively co-present, and extra local or at a distance in time or space. Interaction involves human and nonhuman actors who are central to the issue, as well as those who are "implicated" (Clarke, 2005, p. 46), that is, less powerful and often ignored.

Like human actors, nonhuman actors have agency and "their agency is everywhere" (Clarke, 2009, p. 203). Nonhuman actors structurally condition interactions (both with human actors and with other nonhuman actors) through material properties and requirements (Clarke, 2009). When a nonhuman imposes behaviour onto human actors, it is known as prescription (Latour, 1992); an example would be a "sleeping policeman" (Latour, 1999, p. 186) or speed bump, which forces drivers to slow down.

Actors achieve their form, meanings, and attributes as a consequence of their relations with other actors and entities in an actor-network- a cluster of human and nonhuman actors who have come together over a matter of concern (Latour, 1999). In other words, an actor-network is "an ad hoc constellation of people, things, ideas, resources etc. ... that went into making object X or theory Y" (Valverde, 2004, p. 3). Networks are productive and performative. In order to stabilize and become durable, they must be constantly enacted or they will dissolve (Latour, 1986). Network performativity relies on relational activities and entities shared among actors.

The relational association of actors across an actor-network is called the process of translation (Callon, 1986; Latour, 1987). ANT has often been referred to as the "sociology of translation" (Law, 1992, p. 380) because its primary focus is on identifying relations among actors that have resulted from the processes of "all the negotiations, calculations, acts of persuasion and violence" (Callon \& Latour, 1981, p. 279) that take 
place when an actor's interests have been transformed, modified, and aligned with others into "a single will” (Callon \& Latour, 1981, p. 279). Consequently, ANT scholars understand power as consequential to actions, arising from and implicated in the construction and maintenance of networks.

Power is not an inherent possession of actors, but instead has to be "made" (Latour, 1986, p. 273) through activities such as convincing and enlisting other actors in the network. An act of persuasion or translation in which one actor gains the authority to speak or act on behalf of another actor "is a process before it is a result" (Callon, 1986, p. 224). Translation is the means through which some actors have succeeded in "obliging" (Usher \& Edwards, 2007, p. 114) all other actors to travel along the same path. Translation processes, through ordering struggles, "generate ordering effects such as devices, agents, institutions, or organizations" (Law, 1992, p. 386). Because the purpose of examining translation is to determine how and when ordering relations take place (Munro, 2009), Callon (1986) noted that translation may be viewed through four "moments" (p. 203) or ordering struggles: problematization, interessement, enrolment, and the mobilization of allies. Documenting the activities and relations that occur during these four moments enables researchers to reveal the development and maintenance of stable networks, and to determine how and where networks have failed to become established.

Problematization involves the activities through which particular actors articulate an issue as important, and establish what is to be perceived as the legitimate and uncontroversial solution (Callon, 1986). Primary actors accomplish problematization by defining a set or lack of conditions as a problem, and by situating themselves as the “obligatory passage point" (Callon, 1986, p. 204) or "narrative bottlenecks" (Singleton \& Michael, 1993, p. 229) for other actors, so that they become indispensable to solving the problem they have defined. Primary actors also accomplish problematization by circumscribing the identities and authorities of other actors in relation to that problem, as well as their interrelationships or links with one another (Callon, 1986).

Interessement is defined as "the process of translating the images and concerns of one world into that of another, and then disciplining or maintaining that translation in order to stabilize a powerful network" (Star, 1991, p. 32). More simply put, interessement consists of the activities and devices that are involved in how "allies are locked into place" (Callon, 1986, p. 206), specifically through catering to their "explicit interests" (Latour, 1987, p. 108). Latour (1987) explained that "as the name 'inter-esse' indicates, 
'interests' are what lie in between actors and their goals, thus creating a tension that will make actors select only what, in their own eyes, helps them reach these goals amongst many possibilities" (pp.108-109). Interessement establishes the concrete ways in which participation by interested actors is facilitated or impeded (Usher \& Edwards, 2007), and negotiates the terms of their involvement or roles. Interessement inevitably results in the establishment of devices or definitions that are intended to weaken and undermine conflicting formulations of the entity or problem in question (Gardner, 2009).

Interessement sets the barriers to participation, while enrolment, the third moment of translation, fashions the alliance within the network (Usher \& Edwards, 2007). Enrolment is achieved only when the "multilateral negotiations, trials of strength and tricks that accompany the interessements" (Callon, 1986, p. 211) are successful, at which point actors accept the new roles ascribed to them. Enrolment fashions the alliances within the network (Usher \& Edwards, 2007) when some actors yield to the will of others (Singleton \& Michael, 1993), and others make mutual concessions (Callon, 1986).

The mobilization of allies represents the fourth moment of translation, at which point "a constraining network of relationships has been built" (Callon, 1986, p. 218). Mobilization is accomplished through the establishment and acceptance of key spokesagents who claim to represent the state-of-affairs of the problem on behalf of the actors who have been mobilized in the network (Gardner, 2009). If the mobilization of allies is successful, "only voices speaking in unison will be heard" (Callon, 1986, p. 223). Closure occurs through the subsequent conclusion of the "negotiable hypotheses on identity, relationships and goals of different actors" (Callon, 1986, p. 218) that were first articulated by problematization.

A consequence of an actor-network's self-interested striving for stabilization is black boxing (Stalder, 1997). In ANT, a "black box is that which no longer needs to be considered, those things whose contents have become a matter of indifference" (Callon \& Latour, 1981, p. 285). The more elements that an actor-network can place into a black box, such as "thoughts, habits, forces, and objects" (Callon \& Latour, 1981, p. 285), the stronger an actor-network is. An actor-network takes on the characteristics of a black box once it is successfully stabilized (Latour, 1987). A black-boxed network "may then link itself to one or more 'external' actor-networks with which it exchanges intermediaries" (Callon, 1991, p. 152). When black-boxed networks enter as a single point or node into another larger actor-network, the process is known as punctualization (Callon, 1991; Law, 1992). Law (1992) explained: 
This, then, is the core of the actor-network approach: a concern with how actors and organizations mobilize, juxtapose and hold together the bits and pieces out of which they are composed; how they are sometimes able to prevent those bits and pieces from following their own inclinations and making off; and how they manage, as a result, to conceal for a time the process of translation itself and so turn a network from a heterogeneous set of bits and pieces each with its own inclinations, into something that passes as a punctualized actor. (p. 386)

Callon (1991) commented that punctualized actors may subsequently behave either as actors or intermediaries. Punctualized actors or nodes can also be "juxtaposed with other punctualized nodes in successive translations" (p. 153). He further explained that "networks of punctualized networks may themselves be folded up into points. And, as such points are clustered together, so one moves from the micro-social to the macrosocial" (p. 153). Macro actors are simply "micro actors seated on top of many (leaky) black boxes" (Callon \& Latour, 1981, p. 286).

Punctualization represents "a process or an effect, rather than something that can be achieved once and for all" (Law, 1992, p. 385). Punctualization is "always precarious, it faces resistance, and may degenerate into a failing network" (Law, 1992, p. 385). At the same time, however, punctualization is implicated in generating ordering practices and effects intended to act as if permanence has been achieved. Such practices and effects include irreversibility, normalization, and inscription. Irreversibility is a concept that "captures the accumulated resistance of an actor-network against change" (Rodon, Pastor, Sesé, \& Christiaanse, 2008, p. 100). Callon (1991) noted that the degree of irreversibility of a translation "is a relational matter" (p. 150) that concerns durability and robustness. He explained that the extent to which a translation is irreversible depends on two factors:

(a) the extent to which it is subsequently impossible to go back to a point where that translation was only one amongst others; and

(b) the extent to which it shapes and determines subsequent translations. (p. 150)

Callon (1991) explained that normalization "accompanies and measures the irreversibility of translation" (p. 151). Normalization "standardizes and constrains actors and intermediaries" (p. 151). The effect of normalization on the actornetwork is one of predictability. Callon (1991) elaborated that "a network whose interfaces have all been standardized transforms its actors into docile agents and its 
intermediaries into stimuli which automatically evoke certain kinds of responses" (p. 151). Normalization stabilizes the relationship between human and nonhuman actors through the establishment of institutionalized practices, which embody social relations through inscription (Usher \& Edwards, 2007).

Through the process of inscription, actors embed their agendas or interests into various artifacts or technologies. Once an inscription device is available, "all the intermediary steps which made its production possible are forgotten" (Latour \& Woolgar, 1986, p. 63). Inscriptions often become stable and routinized, "an aspect of 'frozen discourse"” (Usher \& Edwards, 2007, p. 115) and capable of rebuffing competing translations. Inscriptions may operate as intermediaries or actors (Callon, 1991; Usher \& Edwards, 2007). The difference between these categories is not ontological, but rather empirical (Callon, 1991).

Intermediaries, which may include laws and regulations, texts, artifacts, or human beings, "tirelessly carry messages which describe (in both senses of the word) the networks in which they are inscribed" (Callon, 1991, p. 140). An intermediary represents the actor who constituted it "in the double sense of 'standing for' and 'acting on behalf of' it" (Gherardi \& Nicolini, 2005, p. 4). Callon (1991) noted that actors are able to "define one another by means of the intermediaries that they put into circulation" (p. 140). In so doing, intermediaries also define the relationship between actors because they determine, and stabilize, actors' social and technological roles and responsibilities (Akrich, 1992). Intermediaries “with special qualities” (Gherardi \& Nicolini, 2005, p. 288) are distinguished by specific terms. Members in this category of intermediaries would include, for example, boundary objects (Star \& Griesemer, 1989). Star and Griesemer (1989) explained that boundary objects are "entities both adaptable to different viewpoints and robust enough to maintain identity across them" (p. 387). Boundary objects "act as anchors or bridges, however temporary" (p. 424) between different social worlds. Examples of different types of boundary objects include coincident boundaries and standardized methods (Star \& Griesemer, 1989).

Coincident boundaries are "common objects which have the same boundaries but different internal contents" (Star \& Griesemer, 1989, p. 410). Star and Griesemer (1989) noted that coincident boundaries arise under unique conditions involving aggregated data, and autonomous and distinct work that is distributed across large geographical scales that requires "a common referent" (p. 411) to ensure continued collaboration and the resolution of different goals. The authors provided an example of the territorial state of 
California as a coincident boundary because it enabled conservationists, professional biologists, and museum administrators to understand how their disparate work dealt with the same object. Boundary objects also include standardized methods, which are defined as "methods of common communication across dispersed work groups" (Star \& Griesemer, 1989, p. 411). Star and Griesemer (1989) commented that "method standardization both makes information compatible and allows for a longer 'reach' across divergent worlds" (p. 407) because methods provide "a useful lingua franca between amateurs and professionals ... future generations . . . or for researchers at a distance" ( $p$. 407).

Intermediaries that occur in text or device form, including the results of boundary objects such as standardized forms (Star \& Griesemer, 1989), maps, lines of credit, and photographs, are known as immutable mobiles (Latour, 1986b, 1987). Mol and Law (1994) explained that an entity "is immutable when its elements do not change and the relationship between them is not altered. It holds itself stable wherever it goes" (p. 649). An immutable mobile enables stability in meaning or durability across distance and time; for example, "specimens are chloroformed, microbian colonies are stuck into gelatin, even exploding stars are kept on graph papers in each phase of their explosion" (Latour, 1986b, p. 21). The immutability of intermediaries is not simply about the state or perception of sameness, but about the mobilization of allies: "the 'things' you gathered and displaced have to be presentable all at once to those you want to convince and who did not go there" (Latour, 1986b, p. 7).

Intermediary scripts are an embedded set of instructions that determine how a technology or intermediary will function (Akrich, 1992; Williams-Jones \& Graham, 2003). These instructions, or first-level protocols of control (Galloway, 2004), contain technical and normative values (Prout, 1996) that actively shape some uses while prohibiting others, and therefore also purposively configure human and nonhuman users through "injunctions to act" (Callon, 1991, p. 141). When this happens, intermediaries begin to function as actors. According to Callon (1991), "an actor is an intermediary that puts other intermediaries into circulation ... that takes the last generation of intermediaries and transforms (combines, mixes, concatenates, degrades, computes and anticipates) these to create the next generation" (p. 141). It is "purely practical" (Callon, 1991, p. 141) and empirical conditions that determine the division between intermediaries and actors, including those known as mediators. 
Enrolled actors, whether human or nonhuman, who behave unexpectedly or who “make others do unexpected things" (Latour, 2005, p. 106, original emphasis), are known as mediators. Latour (2005) explicated the distinction between mediators and intermediaries like this:

An intermediary . . . is what transports meaning or force without transformation: defining its inputs is enough to define its outputs. For all practical purposes, an intermediary can be taken not only as a black box, but also as a black box counting for one, even if it is internally made of many parts. Mediators, on the other hand ... their input is never a good predictor of their output; their specificity has to be taken into account every time. Mediators transform, translate, distort, and modify their meaning or the elements they are supposed to carry. (p. 39, original emphasis)

Latour (2005) noted that mediators function differently depending on whether they are human or nonhuman. Nonhumans such as objects may "mutate" (Latour, 2005, p. 202) or move more quickly and recursively between their roles as mediators and intermediaries than humans might. Mutations occur through encounters marked by "know-how, habituation, or disuse" (p. 80), as well as occasions "offered by accidents, breakdowns, and strikes" (p. 81).

Actors such as mediators and dissidents might disrupt irreversibility by transforming or modifying vulnerable translations. Latour (1986) commented that the transmission or "spread in time and space of anything - claims, orders, artifacts, goods" (p. 267) - is vulnerable because it remains in the hands of others beyond the originator. These other actors, Latour (1986) explained, may act in many different ways, letting the token drop, or modifying it, or deflecting it, or betraying it, or adding to it, or appropriating it. ... When no one is there to take up the statement or the token then it simply stops. (p. 267)

Moreover, as Callon (1991) reminded, "all translations, however apparently secure, are in principle reversible" (p. 150). Translation, whether between humans or between humans and nonhumans, remains "contingent, local, and variable" (Law, 1992, p. 387). While embodying relations through inscriptions "is a good ordering strategy, durability is still a relational effect and not simply the nature of things" (Law, 1992, p. 387). For example, inscriptions embedded in technology—as well as the technology itself — may be 
translated by other human and nonhuman actors in ways that were not at all intended by the original designers (Latour, 1996a; Williams-Jones \& Graham, 2003).

These early ANT works have been contested on several fronts. Some authors criticized the use of "war metaphors" (Jensen \& Winthereik, 2005, p. 266) in key concepts such as allies, enrolment, and mobilization. Other scholars, including Star and Griesemer (1989), Fujimura (1995, 1997), Gherardi and Nicolini (2005), and Vickers and Fox (2005), disputed some characterizations of actor-network stability, such as the implied requirement of a primary actor's heroic success. Star and Griesemer (1989) also challenged the classic concept of interessement, which requires the "funnelling" (p. 390) of a single successful obligatory point of passage, and the puppeteer-like control of a “manager, entrepreneur, or scientist" (p. 390). Their own work, in contrast, identified a "many-to-many mapping, where several obligatory points of passage are negotiated with several kinds of allies" (p. 390). In her study of the molecular genetic research network, Fujimura (1997) continued the critique of ANT's classic vision of a singular powerful actor. Her work uncovered the practices of "co-enrollment" (p. 206), "distributed authority" (p. 17), and "traces of continuity" (p. 16) in the production and stabilization of the "oncogene bandwagon" (p. 2), which was a network's collective commitment to a particular representational practice.

Vickers and Fox (2005) challenged the necessity of enrolled micro actors' obedience in maintaining actor-network stasis. Instead, micro actors could simply appear to enact their scripted roles and, without derailing the network, strategically alter the intended plans of a macro actor to better suit themselves. Gherardi and Nicolini (2005) criticized ANT's traditional definition of enrolment for failing to regard the influence of “dissidents" (p. 5) and "unenrolled actors" (p. 5) in the achievement of actor-network stability. They recommended a more expansive approach to conceiving agency. The authors noted that while agency could be focused, it could also be dispersed, which posits a "less heroic and more quotidian" (pp. 21-22) take on the emergence of macro actors than Callon and Latour (1981) first proposed.

Classical ANT also has been critiqued for its emphasis on durability (Munro, 2009). Later ANT works undertaken by Mol and her colleagues (de Laet \& Mol, 2000; 2001; Mol, 2002; Mol \& Law, 1994) have stood as important advancements. These authors developed concepts such as "fluid spatiality" (Mol \& Law, 1994, p. 641) and the flow of relations. In so doing, they extended the understanding of how power is exercised by associations and demonstrated how entities may transform themselves without 
creating discord or discontinuity. What would have been called a failed or failing actornetwork by older ANT scholarship, that is, once immutable mobiles are no longer able to maintain consistent identity and links between different spaces, have become for Law and Mol (2001) "mutable mobiles" (p. 613), or objects of fluid spaces that do not easily collapse. When the focus is on fluid space "there is no single strongpoint to be defended in order to preserve continuity" (Mol and Law, 1994, p. 662). As such, the object or nonhuman actor can transform itself into another arrangement that is both the "same" and "different" without discontinuity. An example of this is Mol's (2002) ethnography of lower limb atherosclerosis. She found the disease was enacted differently through various practices in different hospital departments. For the pathologist, atherosclerosis was intelligible only under a microscope where it was enacted by evidence of calcification; for a physician in the examination room, atherosclerosis was enacted by a patient's inability to walk without pain; and in the vascular clinic, atherosclerosis was enacted by ultrasound and a pressure cuff. Each practice generated its own material reality of the disease known as atherosclerosis. Rather than viewing these as different perspectives on a singular disease, Mol noted that these were multiple diseases. At the same time, the contradictions between the multiple enactments or versions of atherosclerosis were ignored. Thus, alongside the practices that generated multiplicity were those that strove for overall coherence by approaching atherosclerosis as a "patchwork singularity" (p. 71).

This concept of multiple enactments moves the emphasis away from actornetwork durability. Instead, in Law's (2009) words, it works analytically to wash away a single crucial assumption: that successful translation generates a single coordinated network and a single coherent reality. . . . Most of the time and for most purposes practices produce chronic multiplicity. They may dovetail together, but equally they may be held apart, contradict, or include one another in complex ways. (p. 143, original emphasis)

This later ANT work has significant implications for our understandings of durability, resistance, and relational effects of network actors and intermediaries.

\section{Summary}

Taken together, ANT scholars' understandings regarding network organization, the roles of mediators and intermediaries, and entity multiplicity are suggestive of new 
and fruitful avenues of investigation that could be applied to the VIS. By encouraging the examination and interactions of humans and nonhumans, the application of ANT to the VIS network problematizes who or what may be perceived to be a VIS author, utilizer, target, or audience. An ANT perspective also prompts a broadening of the investigative scope concerning the nature and make-up of the VIS and the function(s) it performs, including its influence on, and engagement with, a range of human and nonhuman actors. This could be particularly helpful in illuminating criminal justice policy and outcomes associated with the VIS, particularly in the context of sexual assault, where little knowledge exists to date. 


\section{Chapter 4-Method}

This chapter provides descriptions of the study's method. It begins with study design including confidentiality safeguards, ethical and study site approvals, informed consent process, sampling strategies, and recruitment activities. Data collection and analysis procedures are then outlined.

\section{Study Design}

The study was intentionally structured to address two key concerns: (a) the protection of the ethical and legal vulnerabilities of the sexually assaulted women who chose to directly participate in the study, and others who might have been referred to during interviews with nonvictim respondents; and (b) the theory-methods compatibility with an ANT-inspired approach to examining the VIS.

My first concern, protecting the ethical and legal vulnerabilities of sexually assaulted women, was addressed by designing research protocols in anticipation of a request for disclosure from defence lawyers or other interested parties such as police (Palys \& Lowman, 2000). The anticipation of negative consequences of study participation is an ethical responsibility of feminist researchers who work with women who have been sexually assaulted (Bergen, 1993). While the risk of court-ordered disclosure is extremely slim in this and similar research, a priori precautions to minimize these risks were necessary to fulfill the legal requirements of a privileged communication, which is a private statement that must be kept in confidence for the communicator's benefit (Lowman \& Palys, 1999; Palys \& Lowman, 2000). The precautions were also necessary to comply with best practice guidelines regarding the anticipation of possible future uses of research data (Interagency Advisory Panel on Research Ethics, 2006, 2009).

The second concern involved ensuring the study was ANT theory-methods compatible. I addressed this concern through sampling strategies such as the purposive, broad sampling of human actors, the inclusion of multiple nonhuman actors, and multiple data collection methods (i.e., interviews; reviews of documents such as VISs, criminal justice policies, and case law decisions). 


\section{Confidentiality Safeguards}

In keeping with recommendations of the Tri-Council Policy Statement (Interagency Advisory Panel on Research Ethics, 2006, 2009), I ensured participant anonymity and confidentiality during data collection and analysis by collecting only nonidentifying information, and using password-protected electronic file storage. In this dissertation, and in the three peer-reviewed published or submitted papers that report its data, study participants are identified only by their role or relationship to the criminal justice system (e.g., victim, prosecutor). Further participant identifiers and descriptors (e.g., victim 1, prosecutor 2) have not been included with quotes because they would permit readers to "track" multiple comments from a particular participant, which might jeopardize participant anonymity and confidentiality (Morse \& Coulehan, 2015).

I also took special precautions to ensure that confidentiality risks associated with disclosure and the third-party request of records could not occur under any circumstances because of participation in this study. The work involved in the identification of these risks, and the development of precautionary measures, followed the efforts of Ted Palys and John Lowman of the Centre of Criminology at the University of British Columbia (Lowman \& Palys, 1999; Palys \& Lowman, 2000). These special precautions included (a) requiring only verbal confirmation of informed consent to participate and (b) removal of the standard notification that is typically provided in consent forms of the potential disclosure of data upon demand by legal authorities. These precautions involved no additional risks to participants and were in keeping with the gold standard of ethical practice involving vulnerable populations such as victims and women in conflict with the law (Academy of Criminal Justice Sciences, 2000; Palys \& Lowman, 2000).

\section{Ethical and Study Approvals}

The Research Ethics Board of the University of Toronto granted ethical approval for the study. Additional study approvals were granted by the provincial ministry or department responsible for victim services in the two participating study sites (Eastern Canada and Central Canada). The provincial ministry or department responsible for victim services (Eastern Canada) granted approval for the conduct of interviews with victims and victim services staff. The Central Canada ministry/department responsible for victim services granted approval for the access to victim services workers only. 


\section{Data Sources: Human and Nonhuman Actors}

The purpose of the study was to understand the nature, development, use, and impact of the VIS in the context of women who have been sexually assaulted in Canada. Consequently, data sources associated with the actors, events, and settings associated with the "key processes" (Miles \& Huberman, 1994, p. 33) of the VIS were sampled. In keeping with ANT, actors included humans and nonhumans.

Human actors included "primary actors" (Miles \& Huberman, 1994, p. 33) of the VIS network, including victims, victim services workers, and prosecutors. Participants also included those individuals in the criminal justice system who would be considered to work at "the peripheries ... people not central to the phenomena but neighbours to it ... [and] dissidents and renegades" (Miles \& Huberman, 1994, p. 34). Peripheral participants in this study included advocates for female victims and/or female offenders, and federal parole board services staff. The benefit of peripheral participants includes access to information that might stand in contrast with the perspectives offered by primary actors. Nonhuman actors and entities included participants' VISs, as well as those primary and peripheral processes, mechanisms, and tools associated with the VIS such as case law, policies, or other courtroom genres (Propen \& Schuster, 2010) that may be used to relay or manage subjective victim harm information.

\section{Inclusion Criteria and Sampling Strategies}

All interview participants were required to communicate in fluent English. Additional inclusion criteria for victim participants were that they (a) were adult females, (b) had been sexually assaulted, (c) had submitted a VIS that articulated harms incurred as a consequence of sexual assault, and (d) had obtained judicial conclusion of the case for which the VIS had been submitted with neither pending nor ongoing appeal. The additional inclusion criteria for nonvictim participants were (a) being an adult, and having possessed either (b) experience providing VIS-related assistance to adult females who had been sexually assaulted, or (c) extensive knowledge of, or involvement in, VIS-related policy, administration, and/or case law analysis.

At the beginning of the study, interview participant selection was guided by purposeful sampling (Patton, 1990) using criterion-based selection (Le Compte \& Preissle, 1993) and by theoretical sampling (Denzin \& Lincoln, 2000; Glaser \& Strauss, 1967). I derived a criterion-based selection from the findings of an extensive literature 
review that identified primary VIS actors as those who operated within the primary VIS settings of system-based or court-based victim services that are charged with implementing VIS schemes (see for example Burgess et al., 2010; Department of Justice Canada, 2009; Meredith \& Paquette, 2001; Nova Scotia Department of Justice, 1998; Roberts, 2009) such as victims, victim services workers, and prosecutors. Theoretical sampling occurs when the objective of developing a theory or explanation determines the specific criteria by which a sample is selected (Denzin \& Lincoln, 2000; Glaser \& Strauss, 1967). In keeping with ANT's attention to discursive formations (Clarke, 2009), theoretical sampling pointed to the necessity of including peripheral actors such as VIS policy-makers.

Secondarily, I utilized conceptually driven sequential sampling (Miles \& Huberman, 1994, p. 27), a strategy wherein sampling criteria evolves once initial fieldwork reveals facets of the phenomenon that warrant further investigation (Miles \& Huberman, 1994). This strategy precipitated the inclusion of peripheral actors such as staff of not-for-profit feminist organizations that provided counselling or legal advocacy to female victims or federally-sentenced offenders. It also triggered the inclusion of frontline and policy staff involved with victims and federally-sentenced offenders at the point of parole.

In addition to the inclusion of human participants, theoretical sampling in an ANT-inspired VIS study requires including actors or artifacts associated with the "policy archaeology" (Scheurich, 1994, p. 297) of the VIS, specifically its manufacture and management at federal and provincial levels. Thus, this study also included as data collection sources: (a) VISs written by victim participants; (b) administrative VIS processing practices, including memoranda, forms, and manuals associated with provincial VIS programs; and (c) artifacts associated with the judicial use, interpretation, and management of the VIS in Canada, including provisions in the Criminal Code of Canada (Criminal Code, 1985) and the Corrections and Conditional Release Act (Corrections and Conditional Release Act, S.C., 1992), along with relevant case law.

\section{Participant Recruitment}

Forty-four $(\mathrm{N}=44)$ participants from six positions relevant to the operation of the VIS in Canada were recruited: (a) victims, (b) victim services staff, (c) prosecutors, (d) 
federal parole board staff, (e) provincial and federal policy-makers, and (f) advocates who had worked with female victims and female offenders who had been sexually assaulted.

For assistance with the recruitment of participants for this study, I approached two provincial ministries (Central Canada and Eastern Canada) responsible for victim services, and a national association of not-for-profit sexual assault crisis centres.

Citing privacy laws and policy directives, respectively, the Central Canada ministry and the sexual assault association declined to actively or passively assist with victim recruitment (e.g., refused permission for access to the database of victims who had accessed their services and did not permit study flyers in their offices). The Eastern Canada ministry agreed to assist with victim recruitment. They instituted a process whereby victim services workers identified sexual assault victims in their caseloads who had completed a VIS. Victim services managers contacted the victims and read a standardized script that described the study and asked for permission to release contact information to the researcher (Appendix A). They also provided victims with a study brochure (Appendix B). They recorded this contact-for-research-purposes in the victim's case file, and forwarded to me the names of 11 interested victims. Once I contacted the victims to provide further study information, one victim declined to speak further.

The sexual assault association declined to assist with recruitment of their staff or volunteers. The Central Canada ministry and the Eastern Canada ministry both agreed to assist with staff recruitment. They circulated the nonvictim study brochure (Appendix C) and invited staff to email victim services managers if they were interested in participating. Managers then forwarded to me the names of interested staff (Central Canada, $\mathrm{n}=9$; Eastern Canada, $\mathrm{n}=11$ ).

Word-of-mouth recommendations through my academic, work, and personal contacts, as well as snowball sampling, was used to recruit one victim (Central Canada), four advocates (Western and Central Canada), two Crown prosecutors (Western and Central Canada), five policy-makers (federal, Eastern, and Western Canada) and two federal parole board staff (federal and Central Canada).

Recruitment, interviews, and analysis proceeded in an iterative fashion. Recruitment ceased once theoretical saturation of the data had been reached. Theoretical saturation occurs when no new theoretical insights emerge from new data; rather, data confirm what has already been found (Punch, 1998). 


\section{Informed consent process}

The process for obtaining the consent of interview participants met all requirements for free and informed consent in accordance with section 2 of the TriCouncil Policy Statement (Interagency Advisory Panel on Research Ethics, 2009).

Victim and nonvictim participants were provided a detailed information letter and consent form (see Appendix D for victims and see Appendix E for nonvictims) and were asked to read it or I read aloud the form to them. The consent form was written in plain language that detailed the purpose and methodology of the study, the range of topics that might be covered during the interview, the voluntary nature of participation, the protection of confidentiality, the option to withdraw from the study without penalty, assurance that neither study participation nor withdrawal could affect the legal and social services they received (if VIS completers) or their employment (if nonvictims), assurance that individual interviews would not be shared with the criminal justice system institutions or community-based organizations to which they belonged or which were associated with any services received, and contact information to obtain further details about the study or their participation in it. The consent form did not contain the oftenstandard warning that the data might be subject to being disclosed by law (Interagency Advisory Panel on Research Ethics, 2006; Jackson \& MacCrimmon, 1999). That common a priori warning to study participants was omitted in this study to avoid the possibility that a future court could interpret the consent statement as a waiver of privilege, which would result in the possibility of disclosure of confidential information (Jackson \& MacCrimmon, 1999; Palys \& Lowman, 2000).

Following review of the consent form, participants were asked for verbal consent to participate in the study, which was then documented before the interview proceeded. The Tri-Council Policy Statement (Interagency Advisory Panel on Research Ethics, 2009) has instructed that informed consent should generally be recorded in writing unless there are valid reasons for not doing so. In this study, the collection of signed consent documents would have created a written record that could have connected a participant to the data $\mathrm{s} /$ he provided and/or to other cases involving sexual assault complainants. The sensitive nature of this study was such that participants required absolute confidence that no identifying information would be maintained, and their identities were protected from disclosure. Signed consent forms were therefore not appropriate. 


\section{Interviews}

Qualitative, audiotaped, semi-structured interviews ranging from approximately 60 to 90 minutes in length were conducted with the 44 participants from October 2006 to June 2008. Interviews loosely followed prepared guides that used open-ended questions to elicit information on the key processes and experiences of the VIS (see Appendix F for the victim interview guide and see Appendix $G$ for the nonvictim interview guide) and provided the flexibility to explore new topic areas that participants raised. Audiotaped interviews were transcribed verbatim by professional transcribers.

Due to budgetary constraints, two different interview modes were used: in-person $(\mathrm{n}=25)$ and telephone $(\mathrm{n}=19)$. Nearly all victims $(10$ of the 11$)$ and all but one of the Eastern Canada staff members (10 of the 11) were interviewed in-person. Although interactional (interviewer-participant) differences between the two modes have elsewhere elicited concerns (see for example Irvine, Drew, \& Sainsbury, 2010), in this study I observed no differences in either richness or in type of detail. In three cases involving victims, the in-person interviews occurred in the presence of adult family members for support, and/or infants/very young children due to victims' mothering responsibilities. In all but one case, in-person victim interviews were conducted in participants' own homes or the homes of family members; the lone exception took place in my hotel room at the victim's request because her children and neighbours were unaware of the assault. Inperson and telephone interviews with nonvictims took place at the participants' place of work during work hours, with the exception of two advocates who were interviewed inperson or by telephone when at home.

Two victims (one each in Eastern and Central Canada) completed two interviews. The Eastern Canada victim recontacted me to provide an audiotape of the sentencing hearing concerning the trial of the offender who had harmed her. I had the audiotape professionally transcribed and returned her original audiotape along with a copy of the sentencing hearing transcript. I then reinterviewed her to clarify her understandings of the transcribed VIS-related discussion that had been recorded between the judge, defence counsel, and prosecutor. I reinterviewed the Central Canada victim after she had contacted me several months following her interview regarding new matters related to the secondary use of her VIS. Following their interviews, three Central Canada victim services workers initiated renewed contact to provide additional information by e-mail 
and telephone (see also Denzin \& Lincoln, 2000; Eakin \& Mykhalovskiy, 2003; Frost et al., 2010).

\section{Reflexive Notes on Victim Interviews}

Each victim participant appeared to take seriously her participation in the study and to place high personal value on the interview (see also Campbell, Adams, Wasco, Ahrens, \& Sefl, 2009a, 2010). In many cases, victims appeared to have gone to a great deal of effort to clean their homes and make me feel personally welcome through the provision of refreshments and home-baked snacks (similar to Bergen, 1993; Finch, 1984). The psychological benefit of the role of hostess believed to accrue to sexually assaulted women when interviews take place in their private dwellings has been noted in other sexual assault studies (Bergen, 1993).

In order to be available to participate, several victims took unpaid or holiday time away from work (similar to Campbell, 2002) and/or hired babysitters or enlisted the help of friends and relatives for the care of older children. The $\$ 25$ honorarium paid to victim participants to offset child care and transportation costs and to compensate them for their time often seemed starkly inadequate when contrasted with the work necessitated by interview participation: that is, juggling work and volunteer schedules, altering school drop-off and pick-up routines, requesting assistance from friends and relatives who were aware of the sexual assault or hiding interview-related activities from those who were not, and scheduling early or late family dinners.

The interviews were clearly emotionally difficult for victim participants. In all but one case, victim participants at times cried or became visibly or audibly upset as interpreted through unsteady voice or breath patterns, repetitive rocking, or hand wringing. In three cases due to the degree of upset, I asked participants whether they would like to terminate the interview; all chose to continue. Once women expressed an interest in continuing, I chose to continue since previous research has shown that distress during an interview does not preclude participants with trauma experience from deriving benefit, catharsis, or validation from participation (Bergen, 1993; Collogan, Tuma, Dolan-Sewell, Borja, \& Fleischman, 2004; Drauker, 1999; Walker, Newman, Koss, \& Bernstein, 1997). Further, while describing events within the research context may be distressing to some, it is different from (re)experiencing the original trauma (Collogan et al., 2004). For example, in two large post-physical and sexual victimization studies, the 
small number of women who found the interviews more upsetting than they anticipated stated that they still would have consented had they known how they would react (Brabin \& Berah, 1995; Walker et al., 1997). Benefits to research participation in similar studies have included feelings of empowerment, altruism, personal worth, and meaning making (Campbell et al., 2009a; Collogan et al., 2004; Drauker, 1999; Levine, 2004).

In seven of the victim interviews, I lingered between one and two and a half hours following the completion of the interview. Unprompted, several victim participants showed me scrapbooks, art work, family photographs, and/or diplomas or certificates proudly hard-won after their sexual assaults (see also Dickson-Swift, James, Kippen, \& Liamputtong, 2006). A few participants further detailed the assault and its impact on their lives on topics unrelated to the VIS. These discussions remained private. I did not include these conversations as data since these details were related more to the trauma of the event or to overcoming it than I had anticipated in my research protocol or believed necessary to document in relation to the VIS. Drauker (1999) noted that participants in sexual violence studies will find ways, irrespective of researchers' protocols, intent, or foci to tell stories of their sexual assaults in ways that are meaningful to themsometimes by starting at the "beginning" (p. 169). Since the VIS does not come at the "beginning," that is, before or at the time of the assault(s), an interview designed to focus only on the VIS in cases of sexual assault appeared insufficient for the majority of women whom I interviewed.

While ethics protocols call generally for distressed participants to be provided with a written list of local resources (Interagency Advisory Panel on Research Ethics, 2009), which I had compiled for purposes of the university research ethics board submission for this dissertation, such a response does not fit the reality of the paucity of psychological or social services in rural areas. Rural areas are often characterized by inadequate or no services, as well as long wait lists and a lack of public transportation, which hampers access even to those services that are available (American Psychological Association, 2000). Before I began the Eastern Canada victim interviews, I called each of the relevant community agencies near the interviewees' homes. My conversations with agency staff confirmed the existence of very long wait lists, and/or the absence of free services or programming to sexually assaulted women who were not current clients of their agencies, irrespective of whether victims might be in crisis. Consequently, I had chosen in advance to provide victim participants with the prepared list of services as well as to additionally refer them to the victim services office that had originally handled their 
cases. I had earlier established with victim services managers that their staff would be able to respond immediately, as well as to fast-track community social services and mental health services at no cost to study participants should they require it. This protocol had been agreed to in advance by victim services.

The issue of urgent post-interview referral services arose in one case. At the conclusion of that interview, as I turned in the doorway to leave, the victim queried her post-sexual assault mental health functioning. She disclosed thoughts of self-harm and indicated concern over her current provision of care for her children due to post-sexual assault traumatic sequelae. These specific concerns had not arisen during the interview. Following her disclosure, I assessed her immediate risk for self-harm, determined to the best of my ability that it was safe for me to leave her, and with her knowledge and permission contacted the victim services office that had first handled her case. I obtained assurance from victim services that she would be immediately contacted and provided support. Subsequent to my initial call to victim services, I later followed up with the manager to ensure that contact with the victim had taken place.

During or following each interview, each victim also asked me questions of a personal nature, including my academic and personal experiences regarding sexual assault, whether I had children, a partner, or pets, and how I coped emotionally with hearing stories of sexual assault. These types of questions are not unfamiliar to feminist researchers engaged in work of this nature (Bergen, 1993, 1996). Personal interaction and the facilitation - and expectation — of intimacy may be enhanced when interviews of a personal nature take place in participants' homes (Finch, 1984). In addition, these questions may have helped participants situate me structurally and personally as a woman with similar experiences and/or embodying gendered empathy and understanding (Finch, 1984). My responses to the questions reflected both feminist admonitions of the reflexive, vulnerable personal work that is necessarily involved in making research as dialogic and non-hierarchical as is possible (Finch, 1984; Oakley, 2003; Stanley \& Wise, 1983, 1993), and methodological concerns that the emphasis needed to remain on participants and not divert from their own stories (Patton, 1990). These discussions also remained private and are not included as data.

As a qualitative health researcher, I found the emotion work (Dickson-Swift, James, Kippen, \& Liamputtong, 2009; Kontos, Miller, Colantonio, \& Cott, 2014; Miller et al., 2008) involved in interviewing women who have been sexually assaulted to be humbling, rewarding, and taxing. These reactions have been noted by other researchers 
(Campbell, 2002). Bearing witness to stories of sexual assault is difficult, and sometimes, researchers are not equal to the task (Martin, 2005). There is often a personal price to pay for involvement in "rape work" (Martin, 2005, p. 4), of which this research is a part, including short-term sleeplessness, jumpiness, and what in some contexts has been called "useful pain" (Campbell, 2002, p. 156), and in others, "vicarious trauma" (Baird \& Jenkins, 2003, p. 71). Certainly, my post-interview emotional reactions were not dissimilar to those I had experienced as a rape crisis centre volunteer over the course of six years in two centres not involved in this research, which has also been noted by other researchers (Campbell, 2002).

There are, however, distinct differences between rape work of a research nature and that undertaken as an advocate. The first difference is that of a collegial therapeutic network to debrief post-interview. The absence of a collegial network to process the emotion work demands experienced during academic rape work has been elsewhere identified as problematic, and in some follow-up studies has been subsequently rectified as part of research design (Campbell, 2002). The second difference concerns my personal experiences of differences in status accorded to academics and advocates undertaking rape work in their respective spheres. Unlike community advocacy support work, studying and writing about sexual assault carries increasingly valuable academic cache (Campbell, 2002); in this instance, professional development legitimacy such as the acquiring of a $\mathrm{PhD}$.

\section{Analysis}

Verbatim transcribed interviews were entered and coded in Nvivo qualitative data analysis software (QSR International Pty Ltd., 2006). In keeping with accepted contemporary modified grounded theory approaches (Goldkuhl \& Cronholm, 2010), coding occurred within a context of combined inductive and deductive approaches in which themes emerged from the data and were analyzed within the context of theory. Situational maps (Clarke, 2005) were also used in the analysis.

First, data were read line by line (Strauss, 1987) and sorted using a combination of a "start list" (Miles \& Huberman, 1994, p. 58) of codes that had been derived from the literature review. This step isolated the processes and actors of the VIS involved in the most obvious and discrete situations in which the VIS was involved or invoked (e.g., writing, court submission, allocution at sentencing). During interviews, participants 
discussed 85 different human and nonhuman actors involved directly or peripherally in VIS-related interactions, some of whom had not been identified through the literature review (e.g., sexually assaulted female offenders, Memoranda to Cabinet, family court judges); these were further analyzed. The results formed the basis for substantive coding. I devised a situational map to gain a fuller understanding of the human and nonhuman actors, artifacts, and activities associated with the VIS network.

Data gleaned from the interviews and documents of study participants were analyzed inductively. My focus was on the conditions of enrolment in the VIS network; participants' and others' interactions, strategies, and tactics; and the consequences of actions (Strauss, 1987). I also distinguished nonhumans (e.g., the victim fine surcharge, Criminal Code provisions, policy manuals) as actors or mediators when they exerted influence on other documents, processes, and people, and/or as intermediaries when they functioned as technological or bureaucratic tools and carried meaning or instruction between settings or actors. These steps revealed examples of interactionist agency and processes of translation, and were used to revise my situational map.

My revised situational map (see Figure 1) decentred the traditional understanding of the VIS, which has consisted of the victim-VIS-sentencing court triad. Instead, it illustrated the inclusion of broader micro-, macro-, and mezzo-level relations and interactions throughout an extended network. I drew lines and directional arrows between human and nonhuman actors to map their routes and hierarchies of influence, and to indicate where and how VIS-associated human and nonhuman actors and mediators might interact - for example, the reuse of VISs in multiple contexts by victims to obtain compensation, or the application of case law to shape whether and which victims are permitted by authorities to use the VIS. Noting the relations among the various human and nonhuman actors present is key in a situational map, and relational analyses work well to determine which stories/which relations should then be pursued (Clarke, 2005). 
Figure 1: Situational Map

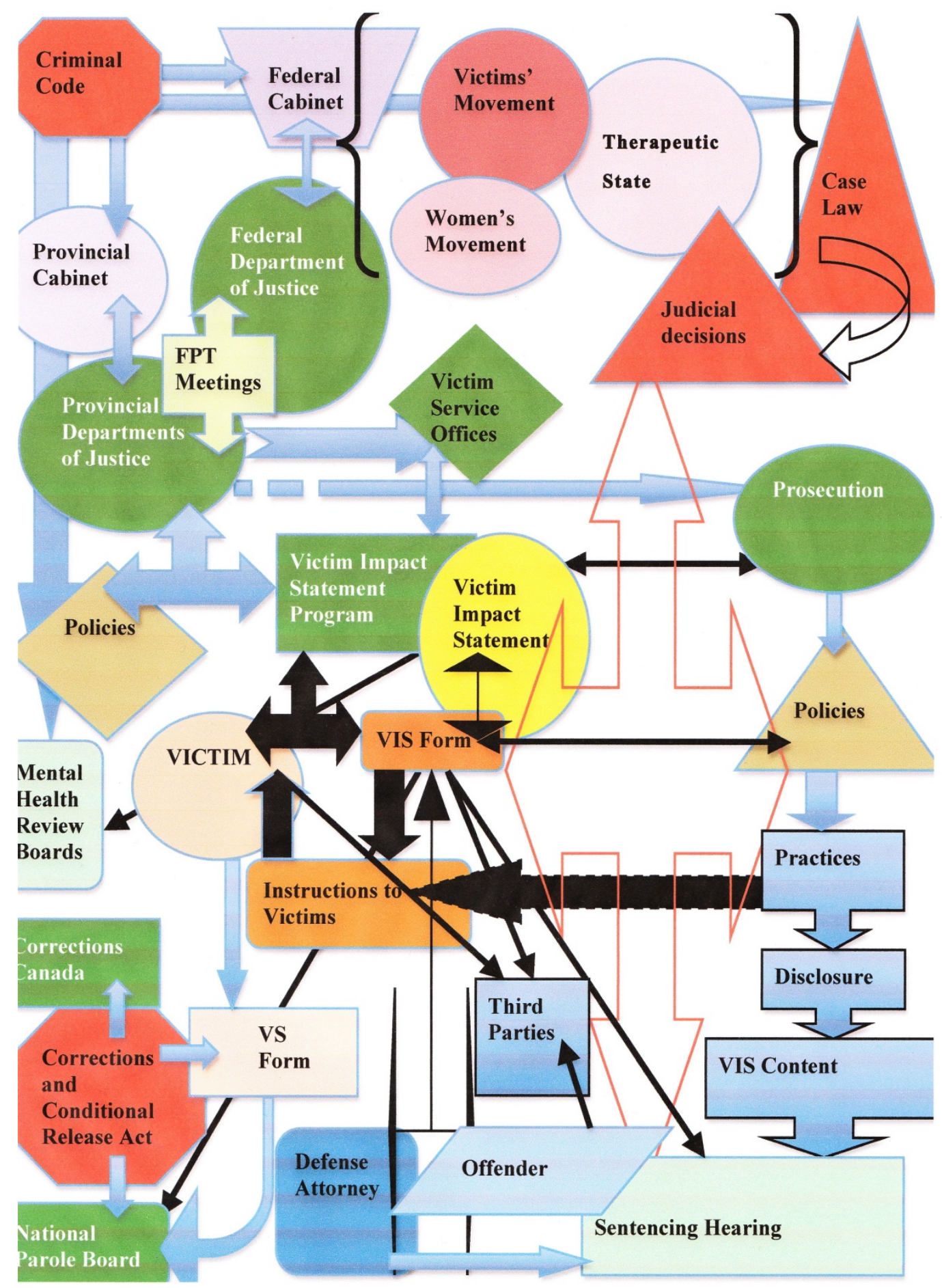




\section{Data Themes}

Situational and relational analyses provided the basis to group moments of network translation and interactionist human and nonhuman agency. These moments were then condensed, investigated for interrelationships, and abstracted, moving from lower-order (e.g., problematization of the VIS) to higher-order themes (e.g., VIS circulating practices by third parties) as analysis progressed. These data themes also informed the development of the three papers included in this dissertation (Miller submitted, 2013, 2014).

At first my analysis was heavily guided by ANT tenets such as interessement, and a focus on the presence and impact of nonhuman actors such as the Criminal Code or appellate rulings. I singled out the influences on the VIS form and narrative of successive political negotiations, discursive and relational orientations, and technological drifts. In so doing, I examined processes of VIS production and circulation, along with their resultant macro and micro consequences for how the VIS was used, distributed, and received. These consequences, in turn, were identified as creating the conditions for novel opportunities and risks for particular categories of sexual assault victims, including those who had been excluded at trial and who were mothers or offenders. There were findings of increasingly patterned VIS use and receipt such as family court use by abusive men, voluntary and coerced false recanting by intimate partner victims, and penitential receipt by criminalized victims. These findings are reported in Chapter 6, entitled An ActorNetwork Analysis of the Victim Impact Statement Involving Sexually Assaulted Women in Canada (Miller, submitted).

A subsequent closer examination of victim utilization of the VIS focused thematically on motivation behaviours. Victims were reported by both victim and nonvictim participants to consistently demonstrate a strong moral sense of responsibility for the safety and emotional well-being of others, and a desire to protect them from physical and psychological harm through their VIS activities. Advocates and victim service workers also noted that these behaviours occurred among clients to whom they provided VIS-related advice or assistance. I examined these behaviours vis-à-vis interactions with others, which revealed victim practices such as audience targeting and the purposive embedding of messages in the VIS to kin and community members. The multiple settings in which these practices were undertaken were next identified. This confirmed that the behaviours were part of an overarching orientation to the VIS that played out in sentencing as well as nonsentencing arenas. This further analysis resulted in 
Chapter 7, Relational Caring: The Use of the Victim Impact Statement by Sexually Assaulted Women (Miller, 2014).

Next, I examined textual descriptions of harms more closely vis-à-vis interactionist agency. This analytic activity built on earlier analysis regarding motivation behaviours that had led me, unexpectedly, to insights regarding new settings where VISs were submitted. For example, VISs mentioned by study participants had been submitted to a human rights tribunal and to family court. Novelties in setting were then iteratively examined vis-à-vis original legislative objectives, the range of actors who authored and/or submitted VISs, and the uses to which VIS harms claims were put. These setting-agency interactions were then conceptualized as the purposing of VIS harms descriptions. I further examined, refined, and elaborated the purposes to which harm details were applied, as well as the tactics involved in the multiple enactments of the VIS's reuse and repurposing by victims and by those antagonistic to their needs (e.g., offenders). This further analysis resulted in Chapter 8, Purposing and Repurposing Harms: The Victim Impact Statement and Sexual Assault (Miller, 2013). Figure 2 represents the analytic development of data themes that informed my findings for all three papers. 


\section{Figure 2: Analytic Development of Data Themes}

\section{The Black Box of the VIS}

A black box is "that which no longer needs to be considered,

those things whose contents have become a matter of indifference" (Callon \& Latour, 1981, p. 285).

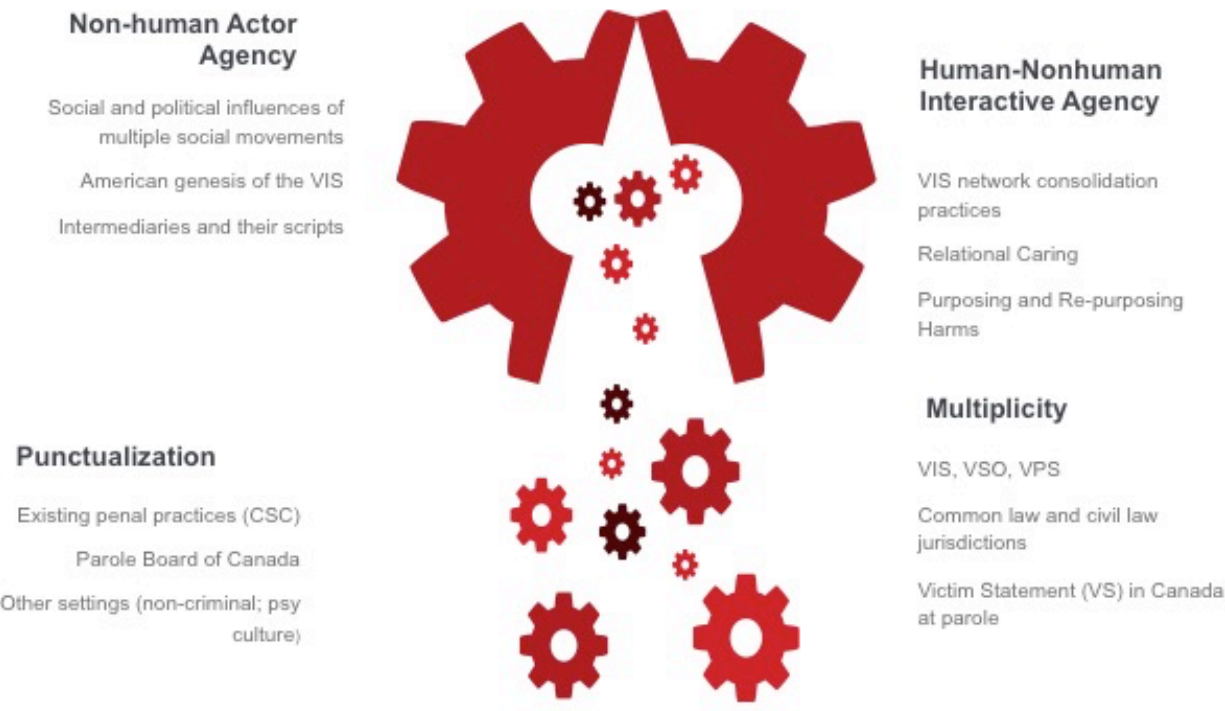

Victim Impact Statement Actor-Network

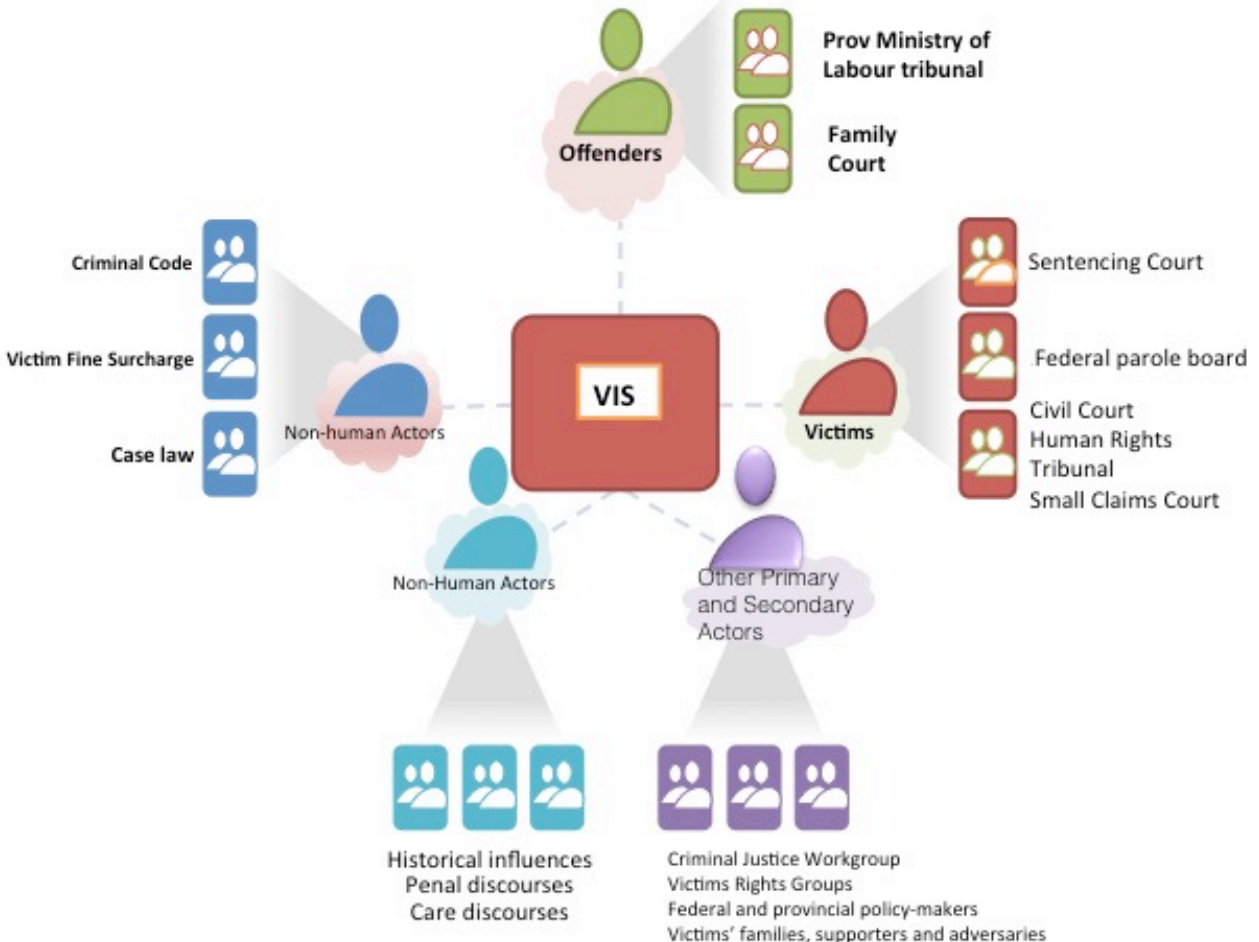


The development, functioning, and

effects of the VIS and its actor-

network in the context of sexually

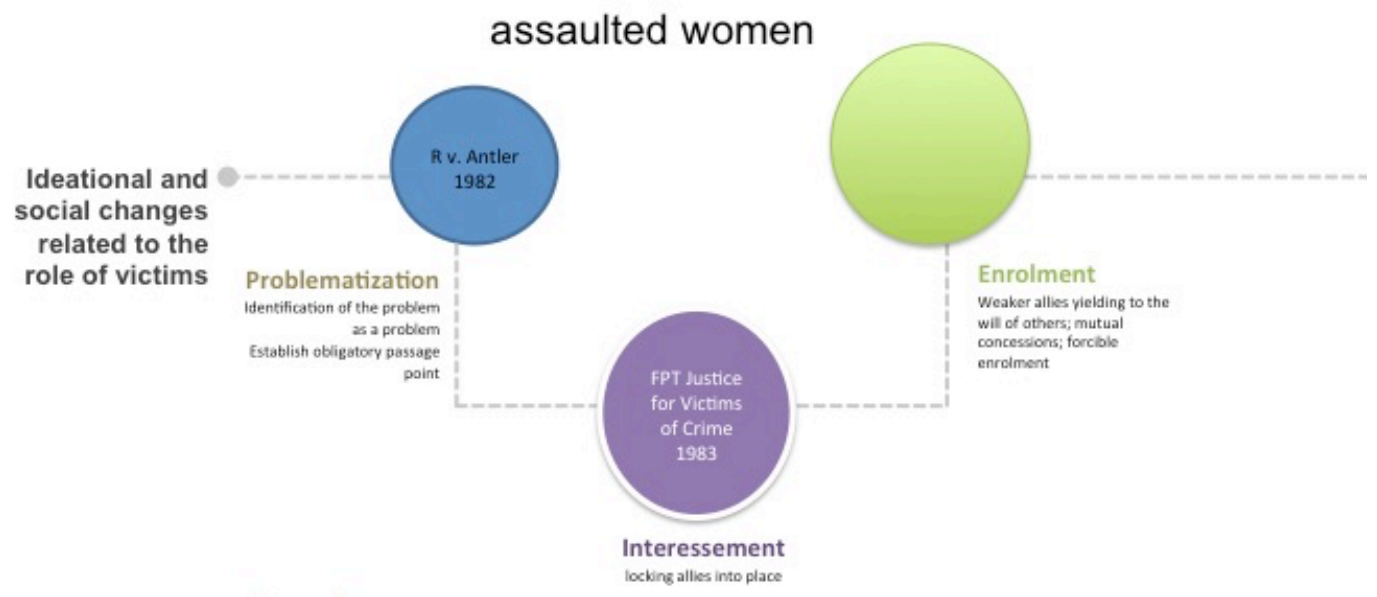

Development

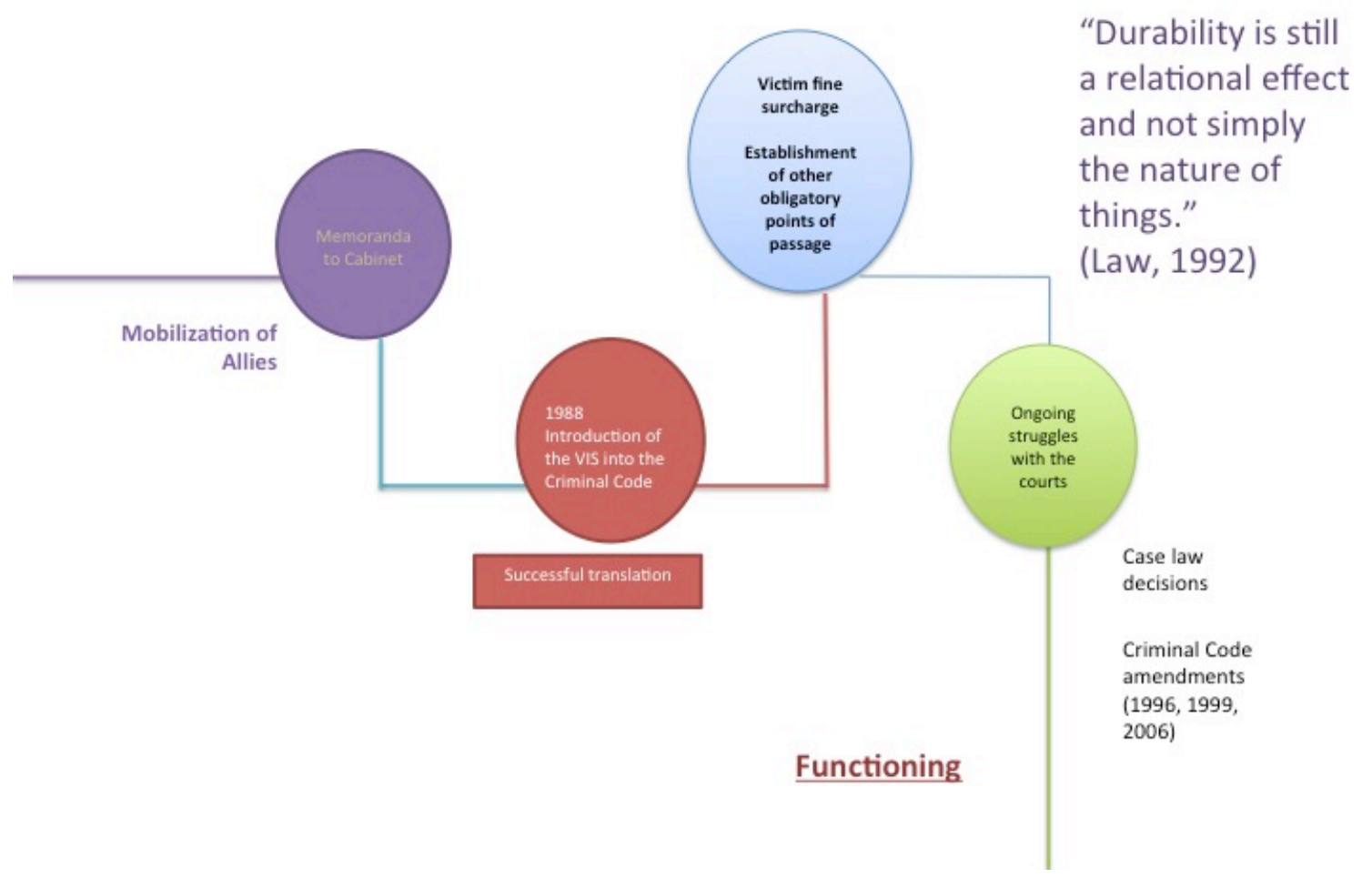




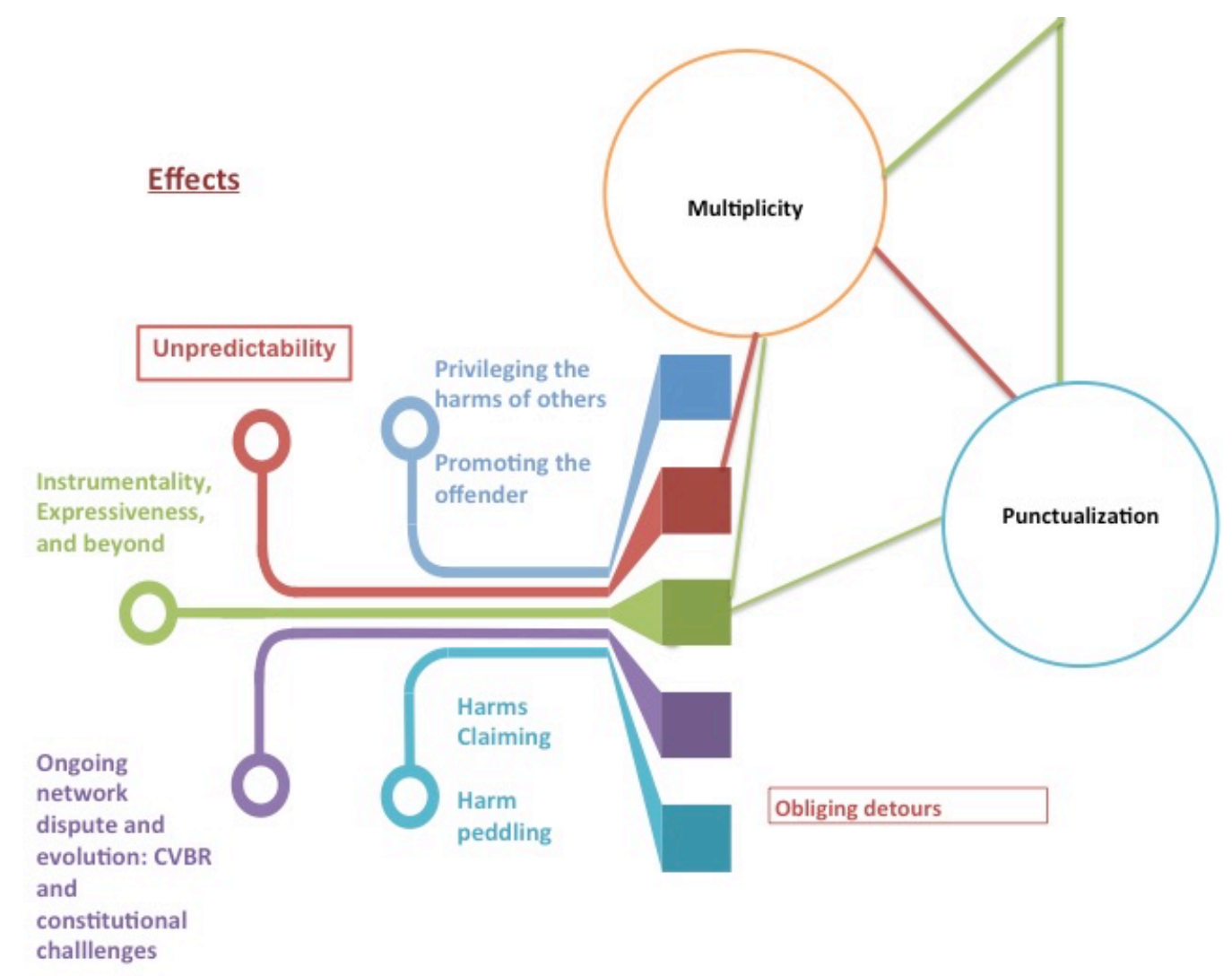

\section{Rigour}

There is currently no consensus for how best to specify quality in qualitative research (Mays \& Pope, 2000; Miller \& Kontos, 2013). I relied upon Lincoln and Guba's (1985a) four-point criterion of trustworthiness: credibility, dependability, confirmability, and transferability. Their approach to trustworthiness emphasized the establishment of clarity regarding judgments and methodological decisions made throughout the study. Here, the transparency of methodological and theoretical design was intended to address credibility. Dependability was established in this dissertation through source triangulation, which is the inclusion of different actors' perspectives regarding similar events, and through method triangulation, which involves interview and document analysis, as well as the use of theoretical sampling (Goldkuhl \& Cronholm, 2010). I established confirmability by the provision of interview quotes in published findings to demonstrate that my analysis was grounded in the data (Regehr et al., 2008), and that the methods and process of the research were transparent (Miyata \& Kai, 2009). Transferability in a qualitative context means having provided a sufficient degree of detail to potential implementers or evaluators (Miyata \& Kai, 2009) that the fittingness, or 
degree of concurrence, between sending and receiving contexts has been made clear (Lincoln \& Guba, 1985b). Therefore, I presented evidence of the potential for extrapolating study findings to inform transferability judgments (Miyata \& Kai, 2009) in the form of sufficient detail about the key VIS processes, as well as the sampling and analysis of multiple situations, humans, and nonhumans throughout the VIS network.

\section{Limitations}

This study has several important limitations. First, undertaking a VIS is an uncommon experience for most sexual assault victims in Canada because the majority of cases do not end in conviction (Du Mont, 2003; Du Mont, McGregor, Myhr, \& Miller, 2000; Du Mont \& Myhr, 2000), which is the disposition that triggers a victim's eligibility to complete a VIS.

Second, this qualitative exploratory study focuses on the experiences of female survivors of sexual assault, and those who have directly or indirectly assisted them. As such, the examination is clearly sex specific. A meta-review of research related to sexual assault found the preponderance of female subjects to be endemic to the field of sexual assault research more generally (Martsolf et al., 2010). It is unknown whether VIS-related experiences may differ for male sexual assault victims or those who have assisted men with the preparation or submission of a VIS.

Third, this study focuses specifically on the VIS network across several (Eastern, Central, and Western) Canadian provinces. The majority of interviewed victims were selected from the client database of the department responsible for victim services in one province in Eastern Canada, which may not be representative of sexual assault victims in general or those seeking assistance in other provinces. Furthermore, since the victim services workers with whom they had prior dealings were the first point of contact for this study, clients in the Eastern province who were dissatisfied with either the services or the information they had received in relation to the VIS may be overrepresented in either passive or active refusals to participate.

Although advocates who represented national, Central, and Western Canada organizations discussed victims who had sought their VIS-related assistance, other nonvictim respondents restricted their comments to victims who had been clients of victim services units in Eastern, Central, and Western Canada. Such a sampling strategy likely largely excluded the experiences of female victims who belong to groups that limit their use of formal victim services (e.g., Aboriginal women, see for example Brennan, 
2011). It may also have overrepresented the experiences of victims who were perceived by themselves or others to have experienced particularly egregious assaults (e.g., by parental figures or strangers, see for example Ritter, 2011). The association between the access of formal support services and the degree of real or perceived injury has been noted in other sexual assault studies (Gavey \& Schmidt, 2011).

Finally, all interviewed victims (the 10 who had agreed to participate after their names were forwarded by the department responsible for victim services in a province in Eastern Canada, and the one victim from Central Canada who had self-selected) were White, and fluent English-speakers. This excluded Francophone women, as well as those who were not fluent in English or for whom that was not their first language. Aboriginal women and women of colour who had been sexually assaulted were also not represented in the overall study, which is particularly detrimental to understanding the full breadth of victims' experiences. Given widespread racism throughout the criminal justice system and in mythologies surrounding sexual assault, racialized women may have alternate perspectives on the value of the VIS in the context of sexual assault (Ruparelia, 2012). These perspectives were not present here, and would be a valuable project in future research. 


\section{Chapter 5-Participant and Case Characteristics}

This chapter provides demographic and descriptive information on the 44 individuals who participated in interviews. Eleven were sexual assault victims, 20 were victim services workers, two were prosecutors, two were parole board services staff, five were policymakers, and four were advocates providing counselling and/or legal advocacy or advice to female victims and/or female offenders. Participants were overwhelmingly female $(n=42$ female; $n=2$ male), which reflects the gendered workplace patterns of victim services and feminist organizations generally (Maier, 2008), as well as this study's restriction to female victims.

\section{Participant Characteristics}

\section{Victims}

Eleven victims were interviewed: 10 from Eastern Canada and one from Central Canada. Each victim participant was a White, adult woman who was born in Canada and spoke English as a first language. Victims ranged in age from 25 to 52 years, with an average of 41 years at the time of interview. All but four had some postsecondary education; two had attended Grades nine or 10; two had obtained a highschool diploma; two had taken some college courses; four had graduated from college and one of the college graduates was currently attending university; and one had graduated from university. Seven worked full time and two worked part time. Of the two part-time workers, one received partial injured worker's compensation. Two victims were not working due to temporary unemployment or permanent psychiatric disability.

\section{Victim Services Workers}

Twenty victim services workers (VSW) in two provinces (Eastern Canada [n = 11] and Central Canada [ $\mathrm{n}=9]$ ) were interviewed. In general, staff in Eastern Canada were older and more educated and had longer employment tenure with victim services than those in Central Canada. 
In Eastern Canada, 11 staff members of four regional offices of the ministry or department responsible for victim services were interviewed. All but one of the staff was a woman. Staff ranged in ages from 31 to 60 years with an average of close to 46 years. Nine staff held university degrees; three staff held more than one degree. Staff had worked in victim services from two and a half to 15 years, with an average of nine years. Timing of the last VIS assistance provision in the context of sexual assault ranged from less than 24 hours to six months prior to the interview, with an average of 75 days.

Nine staff members of four regional offices of the ministry/department responsible for victim services in Central Canada were interviewed. Staff ranged in age from 27 to 51 with an average of 37 years. Five held college diplomas, and four held Bachelor of Arts degrees. Staff had worked in victim services from one to 10 years, with an average of five years. Timing of participants' last provision of VIS assistance in the context of sexual assault ranged from two days to one year, with an average of 100 days.

\section{Provincial and Federal Policy-makers}

Five policy-makers were interviewed. Policy-makers worked in federal as well as the Eastern and Western provincial departments or ministries responsible for victim services. Policy-makers ranged in age from 40 to 60 years, with an average age of 53 years for those who responded to the question about their age. Four policy-makers were women, the other was a man. All held university or law degrees. Policy-makers had been employed in their positions from four to 20 years with an average length of just over 12 years. They were involved in VIS-related activities such as assisting with protocols, participating on committees and federal-provincial-territorial working groups, giving presentations or workshops on the VIS, or assisting provincial counterparts with VIS-related aspects or protocols. Date of last involvement in any VIS activity ranged from the day of the interview to three months prior to the interview.

\section{Federal Parole Board Staff}

Two federal parole board staff members were interviewed. One was a regional communications officer who provided direct information to victims in Central Canada. The other was a policy-maker with experience providing VS and VIS policy information to all provincial and territorial departments of justice, and participating on intergovernmental and 
federal-provincial-territorial working groups. One was 44 years of age, the other was 62 years. Both held university degrees. One had been employed seven years, the other did not answer the question. Date of last involvement ranged from the day of the interview to just over one month prior to the interview.

\section{Advocates}

Four participants were advocates from organizations that identified as feminist in orientation, and that provided services to, or on behalf of, women who had been victimized; this included one organization that specifically dealt with women who are in conflict with the law. The advocates worked in organizations that operated in Central and Western Canada, and were provincial $(n=2)$ or national $(n=2)$ in scope. Advocates ranged in age from 48 to 61 years old; one advocate declined to answer the question. Three held university degrees. Employment in the position ranged from two months to 34 years. Advocates provided direct legal advice/assistance and counselling support, and workshops and presentations on the VIS. The dates of last VIS assistance in the context of sexual assault from time of interview ranged from two days to one year.

\section{Prosecutors}

Two female prosecutors participated in the study; one was from the provincial ministry/department responsible for prosecution services in Central Canada, the other was from the provincial ministry/department responsible for prosecution services in Western Canada. One was 35 years of age, the other declined to answer the question. One had five years of experience as a prosecutor, the other had 20 years of experience. Both held university degrees. One prosecutor had last been involved with a sexual assault VIS two weeks prior to the interview. The other prosecutor was unable to clearly recall the date of her last involvement in a sexual assault VIS but noted that her last nonsexual VIS involvement had occurred on the day of her interview.

\section{Case Characteristics}

Seven of 11 victims had been sexually assaulted as adults, and four had been sexually assaulted as minors. Six of the sexual assaults of adult victims occurred in 2002 or 
more recently, and one took place in the mid-1980s. The sexual assaults of the four minors took place during the late 1960 s or the 1970 s.

Three victims experienced nonpenetrative sexual assault (e.g., grabbing, fondling) and eight victims were vaginally, anally, and/or orally sexually penetrated (e.g., fellatio or cunnilingus). Four victims were repeatedly sexually assaulted over the course of one sexual assault episode that lasted several hours. One victim was repeatedly sexually assaulted during multiple brief episodes on the same day. Three victims were sexually assaulted on multiple occasions across periods of between two and a half and nine years.

Of the sexual assaults on adult victims, two had taken place out of doors in public locations, four were committed in the victim's home and/or backyard, and one was committed at the victim's workplace. In two cases, children were present or nearby while their mothers were sexually assaulted by their fathers. Child or adolescent victims were sexually assaulted out of doors, indoors, or a combination of indoors and outdoors.

Sexual assaults were perpetrated through one or more of the following tactics: misuse of positions of trust or authority $(n=4)$, unlawful entry $(n=3)$, surprise or ambush $(n=2)$, weapon use $(n=2)$, infliction of physical injury $(n=2)$, explicit or implied threats to children who were present or nearby $(n=2)$, threat of death to victim $(n=2)$, and covert administration of a prescription drug $(n=1)$.

\section{Offender Characteristics}

Eight victims were sexually assaulted by men known to them: one was an employer; three were current or previous intimate partners; three were fathers or those acting in that role; and one was related by marriage. Strangers sexually assaulted three victims.

Six victims were sexually assaulted by offenders who had previously sexually assaulted other adult women or children. Of the three offenders who had sexually assaulted other adult women, two were prosecuted and convicted of these other sexual offences at the same time as the victim's trial, and one was convicted in an earlier, unrelated case and was in custody at the time of the victim's trial. In the cases of the offenders who had harmed other adults in addition to the victims, prosecutors had contemplated applying for a dangerous offender designation but had chosen not to. In one case, the offender's change to a plea of guilty was contingent on the prosecutor's agreement not to proceed with the dangerous offender application. Of the three victims sexually assaulted as children, their offenders were 
charged with or convicted of one or more sexual assaults or drug-facilitated sexual assaults against the victim's child-aged younger siblings, younger sibling's child-aged friend, childaged neighbour, or adolescent-aged friend, or the offender's child-aged younger sibling.

\section{Physical Injury}

Victim injuries have been classified using a sexual assault physical injury scale used by McGregor, Du Mont, and Myhr (2002). Mild injuries are defined as soreness with no expected effect on physical functioning. Moderate injuries are expected to have some effect on function of the genitalia and/or more than redness and tenderness (including lacerations, bruising, abrasions, anal-rectal injuries), and/or were injuries that require treatment (lacerations requiring suturing, wounds requiring dressings), and/or consist of bruising of the head and neck that can be expected to result in significant headache. Severe injuries include head injury with concussion and/or evidence of attempted strangulation and/or other major injuries (e.g., limb fracture, internal organ contusion).

In this study, none of the four victims whose sexual assaults occurred or began in childhood or adolescence were brought to the attention of a health professional. However, drawing on data from the sexual assault descriptions disclosed during interviews and harm descriptions contained in the VISs, it might be reasonably presumed that one victim each experienced mild injuries and severe injuries, and two victims experienced moderate injuries.

Of the seven victims sexually assaulted as adults, two reported having incurred no physical injuries, one victim reported mild physical injuries, two reported moderate physical injuries, and two reported severe physical injuries. All five adult victims who reported having suffered physical injuries presented to health professionals. Of these, three victims presented immediately or within the same day to health professionals; one presented more than 24 but less than 48 hours after the sexual assault; and one presented approximately 72 hours after the sexual assault. Testing and treatment consisted of one or more of the following: physical examinations $(n=5)$, forensic evidence collection/completion of a sexual assault evidence kit $(\mathrm{n}=2)$, HIV testing $(\mathrm{n}=2)$, x-rays $(\mathrm{n}=1)$, emergency referral for mental health consultation $(\mathrm{n}=1)$, and sexually transmitted infections and HIV prophylaxis provision $(\mathrm{n}=2)$. Two victims who were released from a hospital emergency department without further treatment were later readmitted to hospital for assault-related physical injuries (i.e., broken nose, 
sprained back). Health professionals denied forensic evidence collection to two victims who specifically requested it.

\section{Reporting to Police}

Victims sexually assaulted as adults reported to the police on the same day that the sexual assault occurred in five cases, within 14 days in one case, and within a month in one case. Victims sexually assaulted as children reported the sexual assault(s) 24, 28, 30, and 31 years after they occurred. Time between reporting and conviction ranged from 4 months to 1.5 years for victims sexually assaulted as adults, and from 1 to 5 years for those sexually assaulted as children.

\section{Conviction and Sentencing}

Six offenders originally pled not guilty; of these, four changed their pleas to guilty. One offender changed his plea to guilty of simple physical assault in exchange for the dropped charge of sexual assault; the case remained in the study because the details in the VIS about the harm associated with the victim's sexual assault were not altered in any way as a consequence of the plea. One offender agreed to plead guilty to a lower sexual assault charge. One offender pled guilty in exchange for the sexual offender designation application being dropped by prosecutors. One offender pled guilty in exchange for a shorter sentence. The remaining five offenders entered a plea of guilty to sexual assault.

Of seven offenders who had committed crimes against adult women, convictions were for Level 1 sexual assault $(\mathrm{n}=3)$, Level 1 sexual assault and overcoming resistance $(\mathrm{n}=$ 1), Level 2 sexual assault $(\mathrm{n}=1)$, Level 2 sexual assault, physical assault, and uttering threats $(\mathrm{n}=1)$, and physical assault $(\mathrm{n}=1)$. The four offenders who had committed crimes against girls or adolescents were convicted under historical (1969-1978) charges in the Criminal Code, including indecent assault, acts of gross indecency, rape, attempted rape, and sexual contact.

Of the 10 offenders declared guilty of sexual offences, four were given federal sentences ( 4.5 years, 5 years, 8 years, 20 years); one was given a provincial sentence and probation ( 2 years and 4 months custody, 3 years probation); two were given a conditional sentence ( 2 years less a day house arrest); two were given a conditional sentence followed by probation (9 months house arrest and 15 months probation; 12 months house arrest and 6 
months probation); and one was given probation ( 2 years less a day). The offender who was convicted of simple physical assault was given an unspecified length of probation.

\section{Victim Impact Statements}

Of eleven submitted VISs, six were read aloud. An additional three victims desired to allocute but were prevented by the judge or not apprised of the opportunity at the time. Three allocuted VISs were reported in the local media. One VIS that had not been read aloud because the victim had been unaware of her right to do so was quoted verbatim by the judge in his sentencing remarks; these remarks were later reported in the local media.

Three of four eligible VISs were subsequently submitted to the federal parole board. Of these, only one was purposefully updated by the victim to include harms that had occurred after the original offence (e.g., harassing phone calls from prison; death threats). Of the two original VISs that the board reviewed, one victim had declined the opportunity to update it but was pleased to have it reviewed. In the other case, the federal parole board had requested an update but the victim declined; her wish to have the board refrain from reviewing her VIS during their deliberations was refused.

In seven instances, VISs were purposefully used by victims in contexts other than the criminal sentencing hearing. These contexts included: a successful criminal compensation application in another province where the victim also had been assaulted by the offender, a civil trial that was later withdrawn, a successful civil trial where the victim defended herself against a harassment claim initiated by the offender, a successful Small Claims Court application, a successful application for damages to a provincial Human Rights Commission, a book detailing the victim's sexual assault experiences, and a successful application for publicly funded mental health counselling.

One VIS was used by an offender. The victim's VIS from the sentencing hearing was submitted by her offender to a provincial department responsible for labour issues, where she had lodged a complaint against him subsequent to the criminal trial. The offender had added his own handwritten, pejorative commentary in the margins of her VIS in an attempt to discredit her. 


\title{
Chapter 6-Obliging Detours: An Actor-Network Analysis of the Victim Impact Statement Involving Sexually Assaulted Women in Canada
}

\begin{abstract}
The victim impact statement (VIS) is a subjective written statement to the court that describes crime-related harms. Interviews with 44 Canadian sexual assault victims, criminal justice professionals, and advocates were analyzed using actor-network theory as a sensitizing lens. Findings revealed innovative, unauthorized, and multiple pathways of VIS use. These pathways, termed "obliging detours" because of the double meaning of obligethat is, to do a service or favour, as well as to compel or require-created novel opportunities, demands, and risks for victims who had been excluded at trial, or were mothers or in conflict with the law. Discussed are the policy and practice implications of increasingly patterned VIS use by abusive men, voluntary and coerced false recanting through the VIS by intimate partner victims, and the penitential receipt of the VIS by victims who have come into conflict with the law. ${ }^{1}$
\end{abstract}

The victim impact statement (VIS) is a victim's voluntary written statement to a sentencing judge that details the physical, psychological, social, and financial harms that have been experienced as a result of an act for which a defendant has been found or has pled guilty (Du Mont, Miller, \& White, 2008). Although it has captured popular imagination, the VIS has been declared by some critics as too great a risk to the due process and procedural fairness rights of offenders, while others have lamented its often inconclusive therapeutic benefits to victims (Erez, Ibarra, \& Downs, 2011; Lens, Pemberton, \& Bogaerts, 2013; Roberts, 2009; Sheley, 2012). In general, the VIS has been viewed as a victim's simple, singular, and sometimes vindictively written grocery list of harms. Missing from scholarly

\footnotetext{
${ }^{1}$ Submitted manuscript
} 
examination thus far has been the range of actors - human, discursive, and textual — that have gone into making the VIS, in actor-network theory (ANT) terms, a "matter of concern" (Latour, 2004, p. 232). ANT is an ideal methods-analysis package with which to investigate organizing practices, relations, and outcomes (Latour, 2005). It is used here as a sensitizing lens to examine the VIS in the specific empirical context of women who have been sexually assaulted by men.

The paper begins with a brief sociohistorical overview of the VIS, and a review of the major tenets of ANT. Next, data is analyzed from a qualitative exploratory study on the use of the VIS in the context of sexually assaulted women in Canada. The policy archaeology and development of the VIS is discussed, as is its operation-in-practice and consequences; specifically, how its use and reuse creates opportunities and obligations for multiple individuals across a range of settings. The paper concludes with thoughts on the implications of increasingly patterned VIS use and receipt, which departs from original legislative intent and displaces sentencing judges as the end-users of the VIS (contra Henley, Davis, \& Smith, 1994).

\section{The Victim Impact Statement (VIS)}

The VIS is a voluntarily written statement of the subjective harms of crime that is tendered to a sentencing court judge after conviction but before sentencing. It is the most significant reform to arise from the American crime victims' movement of the 1970s (Bandes, 2009). Over the course of approximately 40 years, the VIS has become a participatory option available to victims in justice systems across common law jurisdictions such as Canada, South Africa, and the United Kingdom, as well as across a few civil law jurisdictions including the Netherlands, Belgium, and Poland (Project Victims in Europe, 2009; van der Merwe \& Skelton, 2014).

Each of the various VIS schemes permits victims to articulate the harms they have experienced, although their nomenclature as well as their precise form and function vary (Pemberton \& Reynaers, 2011; Rosebury, 2011). A VIS may be a statement that is strictly expressive and therefore nondispositive (Edwards, 2004) as occurs in England, where it is also known interchangeably as a victim personal statement or VPS (Roberts \& Manikis, 
2011). Alternately a VIS may be dispositive (Edwards, 2004) and contain a victim's recommendations for sentence as is permitted in many American states, where it is known as a victim opinion statement or VSO (Lawrence, 2010). Some jurisdictions also now accept the VIS at parole (Black, 2003; Department of Justice Canada, 2013).

Despite the VIS's increasing availability, it is not typically undertaken by victims. Only $10 \%$ to $23 \%$ of crime victims in Canada (Giliberti, 1990; Roberts \& Edgar, 2006) and $15 \%$ to $55 \%$ in other common law jurisdictions (Leverick, Chalmers, \& Duff, 2007; Roberts \& Manikis, 2011; Sanders, 1999) submit a VIS. Small descriptive studies have identified that those who do are most often female, vulnerable (e.g., pregnant or elderly), a victim of violent crime or personal injury, victimized at home, harmed by a known or male offender, or have had the case proceed to trial versus plea bargain (Cole, 2003; Erez \& Tontodonato, 1990; Lens et al., 2013; Meredith \& Paquette, 2001; Roberts \& Manikis, 2011). Victims most likely to have read aloud a VIS have been identified as "angry women" (Erez et al., 2011, p. 27), White (Konradi \& Burger, 2000), or holding a higher occupational status (Villmoare \& Neto, 1987). Even fewer victims submit a VIS during parole proceedings in Canada (Parole Board of Canada, 2011) and the United States (Caplan, 2010); those who do are most often a sexual assault victim or a relative of a homicide victim (Department of Justice Canada, 2006). Many victims have completed a VIS in the hope that it held some degree of influence on the type and severity of the sentence (Roberts \& Erez, 2010). However, there has been no evidence to suggest systemic instrumental influence at sentencing, although findings are mixed on whether it delays release from prison (Roberts, 2009).

The therapeutic potential of the VIS is also contested. Some research has found that when VIS use was facilitated or validated by legal personnel, undertaking one was associated with some degree of victim satisfaction, emotional catharsis, and psychological healing (Du Mont et al., 2008; Roberts \& Erez, 2010). However, the VIS also has been criticized for the anxiety, confusion, and emotional anguish that it has provoked in victims, primarily due to the difficulties of writing such a personal piece, and its unsympathetic reception by offenders and some judges (Arrigo \& Williams, 2003; Gewirtz, 1996).

Given its legal genesis, it is perhaps unsurprising that most VIS literature follows a criminal policy or practice orientation (Morgan \& Sanders, 1999). A handful of studies have analyzed the VIS using emotionology perspectives (Bandes, 2009; Langstraat, 2006; 
Schuster \& Propen, 2010; Sheley, 2012). These studies have importantly identified the influence of sociocultural norms of emotional conduct that guide victims' expressions of harms in their VISs, their expectations of audience sympathy and redress, and the responses of criminal justice actors. Yet as Bandes (2009) argued, emotionology is best suited to examining VIS use in cases concerning the death penalty rather than sexual assault, because strong victim emotion such as vindictiveness and the necessity of the management of victim emotions by prosecutors and decision-makers are at their most obvious. Moreover, emotionology as a discipline is disinterested in issues concerning the sociohistorical development of the VIS, and the influence of social and institutional stakeholders, which may influence an individual victim's VIS narrative.

\section{Actor-Network Theory (ANT)}

Despite its name, ANT is not a prescriptive theory but rather, in Law's (2007) words, a "toolkit" that enables users to tell "stories about 'how' relations assemble or don't . . . a sensibility to the messy practices of relationality and materiality" (p. 2) among humans and nonhumans. Here, it is first used to help tell the story about the development and operation of the VIS network, which is defined as the assemblages of individuals (e.g., victims, offenders, judges), organizations (e.g., justice departments, parole boards), and nonhuman entities (e.g., laws, discourses, policies) across time and place that are implicated in the fashioning/refashioning and use/reuse of the VIS. It is then used to draw attention to the performativity and multiplicity of the VIS itself.

Network development, including that of the VIS, can be helpfully examined through Callon's (1986) "four moments" of association: problematization, interessement, enrolment, and the mobilization of allies. Problematization involves the activities through which primary actors articulate an issue as important, and establish themselves much like gatekeepers as an “obligatory passage point" (Callon, 1986, p. 204) which other actors must pass through in order to remain involved in the network. Interessement includes the activities and devices that are involved in how "allies are locked into place" (Callon, 1986, p. 206). Enrolment fashions the alliances within the network (Usher \& Edwards, 2007) through some actors yielding to the will of others (Singleton \& Michael, 1993) or making mutual concessions 
(Callon, 1986). Mobilization is the establishment and acceptance of key spokes-agents such that only a single perspective on the issue is accepted (Callon, 1986).

A successfully stabilized network takes on the characteristics of a "black box" (Latour, 1987, p. 131). When black-boxed networks enter as a single point or node into another actor-network, they become "punctualized" (Callon, 1991). Punctualization is always precarious (Law, 1992, p. 385) despite being implicated in generating ordering practices intended to act as if permanence has been achieved. Such practices include inscription, whereby actors embed their agendas or interests onto various artifacts or technologies, even when users are unaware of the underlying agenda. For example, concerns about injuries to pedestrians is translated onto a speed bump or "sleeping policeman" (Latour, 1999, p. 186), which causes drivers to slow down to avoid impairing the suspension on their cars. Practices also include use of intermediaries which "tirelessly carry" (Callon, 1991, p. 140) messages or likenesses between settings and actors. Intermediaries that are devices or texts are known as "immutable mobiles" (Law, 1992, p. 388) and can include a wide variety of entities including money, formulae, and laws.

These early "actor-network 1990" (Law, 2007, p. 7) core preoccupations with how networks develop and achieve durability later gave way to a focus on how the products or concerns of networks may transform themselves from one site to another without creating discord or discontinuity. What would have been called a failed or failing network by earlier ANT scholarship, that is, once immutable mobiles are no longer able to maintain consistent identity and meanings across different regions, became for Law and Mol (2001) "mutable mobiles" (p. 613) across fluid space. Mol and Law (1994) used the example of anemia. In the Netherlands, anemia is diagnosed when laboratory-measured hemoglobin levels fall below a certain threshold. In other places, such as Africa, physicians diagnose anemia through the clinical gaze and presence of pale nail beds. Rather than view this as an example of two networks - the laboratory and clinic - each with its own version of anemia, Mol and Law (1994) proposed that anemia transforms itself into another arrangement that is both the same and different, without discontinuity. This work importantly rebuts the notion that successful translation - actors moving a set of ideas or artifacts from one place to another-generates a single coordinated network and a single coordinated reality (Law, 2007). 


\section{The Study}

\section{Procedure and Participants}

Ethical approval was granted by the researcher's university, and two provincial ministries responsible for victim services in Central and Eastern Canada. In-depth, audiotaped, transcribed qualitative interviews (60 to 90 minutes each) were conducted with 44 participants across Canada: 11 female victims of childhood and adult sexual victimization (Eastern and Central Canada); 29 criminal justice professionals serving in different capacities (20 court-based victim services workers [Eastern and Central Canada]); five policy-makers [federal, and Western and Eastern Canada]; two federal parole board staff [federal and Central Canada]; and two prosecutors [Central and Western Canada]); and four advocates who worked with female victims and/or female offenders (Central and Western Canada). Study details have been earlier published (Miller, 2013, 2014). Data were also elicited from VISs, victim services policies, and judicial decisions.

\section{Analysis}

Interview and documents were first inductively analyzed to focus on negotiative interactions and outcomes (Strauss, 1987), including the strategies, tactics, and "often wild innovations" (Latour, 2005, p. 12) undertaken by participants and those whom they explicitly invoked. Next, insights gleaned from ANT, such as Callon's (1986) four moments and the importance of nonhumans (e.g., immutable mobiles such as laws, or discourses of rape) were applied. The focus remained on participants' descriptions of their own and others' performativity and enactment of the VIS, in order to identify the hows of the VIS network and the implications for sexually assaulted women.

\section{Findings}

Findings demonstrated the presence and effect of secondary pathways of VIS use, which introduced novel possibilities and consequences of VIS use for victims and others, as well as new emotional and legal demands and constraints placed upon victims. I have termed these new pathways "obliging detours" because of the double meaning of oblige; that is, to do a service or favour but also to compel or require. 
Findings are organized in three sections as follows. In "Mobilization to Multiplicity," several stages of VIS network organization are described, drawing on classical ANT tenets such as enrolment. In "Intermediary scripts and Injunctions to Act," the implications of obliging detours arising from micro practices are illustrated in a case study entitled, "You Can't Stop The Bell From Ringing." The final section, "Disruptions and Durability" reveals the complex influence of victim self-blame on VIS performativity and obliging detours, specifically, women sexually assaulted by their current or previous intimate male partners, and those who are in conflict with the law.

Actors are identified as victim (V), victim services worker (VSW), advocate (A), prosecutor (P), policy-maker (PM), and parole board staff (PBS). Data derive from interviews, unless specified as a VIS or sentencing transcript (ST).

\section{Mobilization to Multiplicity}

\section{"Jumping on the Bandwagon"}

The VIS was a nascent but ascending entity in the American criminal justice system, and still virtually unheard of in Canada, when the first recorded application by a Canadian victim to submit one was made in 1982 in $R$. v. Antler. The victim of childhood sexual abuse applied for-and was refused - the opportunity to submit a statement on the emotional and physical effects of the crime. The judge noted that the existing Criminal Code did not grant victims any recognized standing, and therefore the matter was best referred to parliament. The case prompted the federal government to establish a Federal/Provincial Task Force on Justice for Victims of Crime (Barrett, 2008), which represented the earliest stages of problematization (Callon, 1986) for the VIS network in Canada. A policy-maker described the government's very early thinking around the VIS:

Well, it wasn't so much that we saw a VIS model in the United States that we thought would be a good one for Canadians. It was more like jumping on the [VIS] bandwagon, if you know what I mean? . . There was a sense, as I think there still is, that if it's happening in the U.S. it's good just because it's happening there, without a lot of critical analysis of whether [the VIS] really is a benefit, or how [the VIS] is impacting on the justice system, or anything of that sort. 
The task force recommended the introduction of the VIS at sentencing, and the development of provincial victim services divisions (Department of Justice Canada, 2003). The federal department of justice consequently began to examine a range of VIS options:

Some of my [justice department] research colleagues were doing these pilot projects, testing models of [VISs]. From there it became an issue of, only some judges were allowing [VISs] . . . could it be legislated? What were the pros and cons? (PM)

Interessement, or the activities and devices involved in securing allies (Callon, 1986), occurred through the development and circulation of a key policy instrument —or intermediary — known as the Memoranda to Cabinet (Privy Council Office, 2001):

Like any other Criminal Code amendment, [the VIS involved] a Cabinet process, [requiring a] "Memoranda to Cabinet" that set out various options for what couldn't and could be included, and then sub-options in terms of various models on the [VIS]. (PM)

The Memoranda to Cabinet is “a Minister's vehicle for submitting and explaining a proposal to Cabinet and for obtaining its approval" (Privy Council Office, 2001, p. 65) and contains recommendations, options analysis, and a communications plan. In ANT-speak, each component of the Memoranda to Cabinet concerning the VIS acted as an immutable mobile of decisions from multiple sites. In relation to the VIS, these included the resolutions and negotiations involving the positioning of federal justice officials as experts on victims, data ambiguity from the field research conducted on the VIS, tensions during federal and provincial strategy-implementation discussions, and power struggles with established victim's rights advocates, such as the parents of murdered children who held long-standing grievances against the Canadian criminal justice system and for whom VISs were hugely symbolically significant (see also Rock, 1986; Sebba, 1996; Stanbridge \& Kenney, 2009; Young, 2001). The Memoranda to Cabinet culminated in detailed plans outlining how the federal justice minister (in ANT terms, the spokes agent) intended to explain the proposed VIS legislation to the public.

It has been suggested elsewhere that the division of powers between the government and the courts has created an ongoing "invitation to struggle" (Randazo \& Waterman, 2014, p. 26) over the meaning of the law. A legislative principal, such as the Parliament of Canada 
or the U.S. Congress, develops contracts in order to effectively bind the actions of bureaucratic and judicial agents (Randazo \& Waterman, 2014). Legislative statutes serve as effective contracts because they stipulate the preferences of the legislature a priori and, if written properly, that is, with enough specific detail, they influence judges to decide accordingly (Randazo \& Waterman, 2014); for example, compelling judges to accept the VIS. Proscriptive legislative statutes, like the one that created and defined the VIS following approval of the Memoranda to Cabinet and a subsequent draft bill, acted as the obligatory passage point (Callon, 1986) that determined how, and under which conditions, victim impact information might be solicited, submitted, and used.

Political values, and wariness, are built into artifacts (Winner, 1980) including legislative statues. VanSickle-Ward (2014) demonstrated that "statutory ambiguity is more likely under conditions of political and institutional fragmentation, particularly when the policy in question is high profile" (p. 12). The extent of ambiguity, in turn, influences the extent of policy delegation and the degree of discretion permitted bureaucratic and judicial actors (VanSickle-Ward, 2014). The introduction of the VIS in the Criminal Code of Canada (Criminal Code RSC, 1985 c C-46) in 1988 was crafted carefully, with vagueness and permissiveness, to make the VIS palatable to necessary allies, while disregarding the disgruntlement of those who would be later forcibly enrolled:

Sort of baby steps. The first [VIS] provision was just, judges "may [emphasis] consider a [VIS]," and so nobody was too concerned about it. Well, I shouldn't say nobody; certainly defence counsel were quite concerned ... And I can't recall, ever, the [feminist] equality-seeking groups that we were working with to develop some of the sexual assault reforms ever being keen on the [VIS] . . But, generally, our provincial [justice] colleagues were thinking that the [legislative scheme of the VIS] would progress at sort of an acceptable pace. It wouldn't be an overnight change in the way sentencing is done because it was permissive. And that gave the provinces [time] to jump on board the bandwagon ... It took a fair bit of time for each provincial jurisdiction to develop their [VIS] program. (PM) 
Because the administration of justice in Canada is a provincial responsibility, federal justice-makers "can't get much done" if provinces "are not on side" (PM). While the federal department of justice needed allies to share the responsibility for VIS survival, provincial justice actors needed stable funding to transform the VIS from an idea into a procedure and artifact that could be introduced into courtrooms around the country. The federal government addressed this barrier to network enrolment by introducing the victim fine surcharge, which is a financial penalty levied against a convicted offender at the time of sentencing that is subsequently collected and retained by provincial and territorial governments (Warrilow \& McDonald, 2008).

Revenues from the victim fine surcharge were intended to assist governments in funding the implementation of a number of victim services programs, not exclusively the VIS (Warrilow \& McDonald, 2008). Yet with its presence black boxed in the Criminal Code, the VIS readily lent itself to being favoured for the new funds. Once the victim fine surcharge began to be collected, it both provided the means, and increased the pressure, for the provinces to establish stand-alone VIS programs in accordance with federal legislation. In several provinces, a collective of human and nonhuman allies was assembled in similar processes of problematization and enrolment as had occurred at the federal level:

In 1990 in [name of province], there was a coordinator of victim services, a secretary, and a [provincial] Act. Nothing else, no programming [slight chuckle]. Money through the victim fine surcharge was beginning to accumulate, so there was real pressure to get some programming out there. So, one of the things that we looked at early on was the [VIS]. We saw it could be a major part of our direct service component. I was very cognizant of the new provisions in the Criminal Code allowing for [the VIS], and allowing for a designated [VIS] program, for the development of forms and procedures of [the VIS]. So I developed forms and procedures for [the VIS], wrote a Memoranda to Cabinet, and ended up with the Order-in-Council [a legislative order originating from the provincial Cabinet], which is how the [name of province] VIS program came about. (PM) 
Similar to Star and Griesemer's (1989) identification of multiple obligatory passage points that may develop in a single network, several provinces instituted their own legislative schemes to establish and maintain control of the VIS process. As one policy-maker explained,

Because [of] [victims'] lack of [legal] sophistication, and because there's no legal guidance available to victims in [the Criminal Code for] writing their [VIS], we were very concerned that [the VIS] could end up putting victims in jeopardy ... That was one of the major reasons why we determined that the only route to get a [VIS] before the courts would be through our offices. [VIS] forms are only available from us, and can only be submitted to the court through us. (PM)

The mobilization of allies does not always go smoothly, even in successful networks. In one province, a few defence lawyers and a provincial judge challenged the role of victim services as a second obligatory passage point for VIS submission. A policy-maker noted, Early on when we were developing the [VIS] program, our staff were in fact [twice] subpoenaed to speak to [VIS] content and our role, and the specific [complaint] that [victim services staff] had influenced [VIS] content . . . [in terms of] contamination and suggestibility.

In consequence, victim services in that province now appends a written notice to each VIS that indicates to the judge that the victim has been provided advice on how to comply with the Criminal Code, and is solely responsible for its content. Despite use of this inscription device to forestall future criticism, inadmissible content continues to be blamed on victim services. One policy-maker complained,

There continues to be [pause] confusion [sarcastic emphasis] by the courts in terms of the role of victim services. It is not the role of victim services to determine what will, and what will not be, submitted [in a VIS]; that's up to the victim of crime. It's our role to advise victims. To determine whether or not the content is acceptable or unacceptable, we view as a role for the courts.

Because developers and policy-makers are unable to precisely determine how an artifact or entity will be used, they must engage in "ongoing feedback and interaction with 
the end-user or consumer" (Williams-Jones \& Graham, 2003, p. 289) to retain their influence. Consequently, the federal justice department has "provided the funding for all the major [academic] research on the [VIS]" in Canada, and has also provided funding to the director of victim services of each provincial and territorial jurisdiction to attend a thrice yearly meeting on victims' issues (PM). A policy-maker admitted, "[before the funding was given] the directors wouldn't attend." The meetings are important from the perspective of the federal primary actor because the directors provide on-the-ground VIS-related horizon scanning: "what's working, what's not working, what the emerging issues are" (PM).

\section{"We Do What We Can When We Can"}

The VIS has undergone a number of legislative changes in Canada since its introduction in 1988. These have included, among others, the expansion of victim eligibility criteria to include common law spouses, the imposition of a duty of inquiry on sentencing courts, permitting but not requiring judges to adjourn a sentencing hearing to allow the victim time to prepare a VIS, and the expansion of use to youth and military courts and mental health review boards (Smith, 2012). Interviews confirmed that network squabbles occurred during the design, drafting, and introduction of each of these legislative changes. Some of these changes, like sentencing reforms designed to restrict judicial discretion (Tonry $\&$ Coffee, 1992), were a response by the federal department of justice to case law decisions they opposed, for example, decisions associated with how many VISs might be accepted in one case, and whether victims were permitted to allocute. Comments included:

We were surprised with some of the case law decisions in the early days in terms of the definition of victim. You know, that a court would find and this has been corrected [by subsequent legislation] — that there could only be one victim to an offence. (PM)

In Regina v. Jackson (2002) the court was, yet again, placing limitations on how victim impact evidence was going to be considered by a court . . . Judges . . . construed the [VIS] provisions [in the Criminal Code] in a very limiting and mean-spirited way, you know, that it's not permissible to consider victim impact information other than in a form according to the provisions of the Criminal Code ... It was a bad decision, and I believe 
that was probably the reason why [the federal government] brought in that [Criminal Code] section afterwards which permitted the victim to read a statement. (P)

Another policy-maker commented on the incremental nature of the changes undertaken by the federal government. She cast doubt on an often unproblematized article of faith of ANT scholars, that is, that primary actors proceed by way of conscious deliberation during the consolidation and expansion of the network. She noted,

I'm quite pleased that we've come as far as we have in the criminal law [related to the VIS]. I don't think we could have done it any other way except in the sort of the three incremental [Criminal Code] amendments and had any sort of acceptance ... I don't think at the time the senior [justice] people were looking at it as incremental - they were just sort of reacting to the situation that they had at that time. In hindsight you could say, yes, we did it deliberately incrementally, but really, we do what we can when we can, when the [political] climate is right, and when you know that you're going to have success on the law reform because there's wide support in the government.

\section{"It Just Allows Them to Say More"}

Once the VIS was successfully black boxed in the Criminal Code as the only permissible form of victim involvement at sentencing, politicized victim advocates were successful in inserting it into the existing parole network; a process known in ANT as punctualization. The federal parole board, which conducts hearings into the release of offenders serving sentences of more than two years, introduced policy measures in 2001 to allow presentation of a VIS that had been presented at sentencing or had been subsequently updated (Department of Justice Canada, 2013). A policy-maker noted,

Victim advocates [were] pushing for [the VIS at parole hearings] . . Victims wanted to be able to say what impact it would have on them if the parole was granted, concerns about their safety and so on, that they felt was totally missed and that nobody else was bringing to the attention of the parole board on their behalf . . I I don't really think that was the case ... but they were quite successful. 
So persistent were victim advocates that the policy was legislatively formalized in amendments to the Corrections and Conditional Release Act (Corrections and Conditional Release Act, S.C., 1992). Since 2012, Canadian victims have had the right to submit and/or orally present or update the original sentencing VIS, or to present a new "victim statement" or VS, to the parole board.

The process of being freed from the strictures associated with the criminal sentencing trial appears to have radically altered the VIS as an entity, including its parameters and its relations to others and to the crime. At sentencing, a VIS is permitted only to refer to the impact associated with the crime for which a conviction was obtained. When it is presented at parole, however, conviction is no longer necessary. The harm-related information unrelated to a conviction that might appear in an updated VIS at parole might concern harms that have occurred since sentencing (e.g., harassing phone calls made while the offender is in prison). Or it might concern the "withdrawn charges, things that were part of a plea bargain, you know, what probably didn't become part of the record in the past because it was bargained out" (PBS). Thus, the initial, and deceptively simple, material effect for victims of the VIS presence at parole was that "it just allows them to say more" (PBS).

Yet the expansion of the VIS to the parole network also contained a surprise detour. The corresponding network detour enacted a new category of victim, and along with it, a new obliging path. As one parole board respondent explained,

So, those individuals are called "recognized victims" ... and what we have to have is two things. We have to have documentation that proves there has been some kind of report made to the police, a complaint made. Then that person has to put something in writing that says how they've been harmed, and then [parole board staff] has the authority to approve, or not approve, that person as a recognized victim . . . and then they're entitled to submit [a VIS or VS].

Once an individual has fulfilled the demands asked of them by the obliging detour, they are enfolded fully into the network. A parole board staff member explained at this point the victim can "write about anything" in an updated VIS or VS:

The thing about parole board hearings is that it's not a retrial, and it's not a reconsideration of evidence, so the victims whether they're considered 
"recognized" or actual "direct" victims, regardless of what we have grouped them under ... we don't really edit things [unless it] impede[s] . .

. the offender's right to fair hearing . . . like "you're a monster, you deserve to die."

In some widely publicized cases, this new obliging detour has greatly benefitted sexual assault victims who were excluded at criminal trial:

Larry Takahashi, who was known as the "Garneau Rapist," was convicted of seven rapes. But there were actually over 100 victims. So, what these [other] victims chose to do is to complete [VISs] for the parole hearing. Because [the other victims] didn't go through the court process-I'm assuming that there wasn't enough evidence, or they didn't want to testify, or whatever - they couldn't complete VISs at sentencing ... I don't know how many of the 100 [other victims] submitted [VISs to the parole board] but there were a significant number ... It provided some [emotional] closure in that they were heard, and they were able to have input. (PM)

The expansion of the VIS network to include enrolment of the parole board remains, however, unsettled and incomplete. First, there is no official body responsible for informing victims of their right to complete a VIS or VS at parole. A parole board respondent commented that, "By law, we can't be proactive in notifying the victims that they can complete a VIS ... and the Correctional Service [of Canada] can't either. We have to wait for [victims] to come to us." Next, despite a victim's right to submit a VIS or VS, parole board members are not under any duty to inquire whether a victim has been apprised of their right to complete one, nor are they under any obligation to consider it during deliberations (Office of the Federal Ombudsman for Victims of Crime, 2010). At the same time, the expansion of the VIS to the parole network represents an obliging detour that some victims cannot evade. Victims who are no longer interested in participating in processes involving the offender are unable to prevent the ongoing use of their VIS. In this study, a victim was significantly distressed at having her original sentencing VIS forwarded by correctional authorities to the parole board. Against her wishes it was also used as part of a peace bond application to monitor the offender after warrant expiry. She explained, "the VIS was a very personal piece that I wrote, and I don't want anyone to have it . . I want to get it back.” 


\section{Intermediary Scripts and Injunctions to Act}

\section{"You Can't Stop the Bell from Ringing"}

The provision of legal consent (Shaffer, 2012) — or authorization for touch (Cook, Dickens, \& Thapa, 2005) - is key to understanding acts for which criminal sanctions might be levied. Pilon (2001) noted, "the history of age of consent laws in Canada has evolved considerably in the past century so that the existing Criminal Code prohibitions against sexual contact with children bear scant resemblance to those that were in place as recently as 20 years ago" (p. 1). In Canada, the current age of consent is 16 years of age with limitedconsent peer-group exceptions for 14 and 15 year olds, although those younger than 18 are not permitted to consent to sexual activities that exploit them such as prostitution or pornography, or to engage in anal intercourse (Department of Justice Canada, 2010).

Legal definitions of consent were different in Canada in 1977 when a participant in this study was a 15 year old who had been verbally and physically coerced into having intercourse with a man almost twice her age who was related to her by marriage. At the time of the assault, the age of consent was 14 years of age so the victim was not considered a minor, although girls under 16 were still considered vulnerable and enjoyed some limited legal protections (Pilon, 2001).

In order to avoid a trial, the prosecutor and defence negotiated a plea. Plea bargaining, which is the practice in which the prosecutor and defence negotiate either charge, sentence, or fact discounts in exchange for a guilty plea by the accused (Manikis, 2012), is the norm in Canada (Wemmers, 2008) and in the United States (Koss, Bachar, Hopkins, \& Carlson, 2004). With respect to sexual offences, a plea agreement often means that an offender is convicted of a nonsexual offence (Koss et al., 2004). When the prosecutor first telephoned the victim to explain that the offender was willing to plead guilty to a lesser charge, the victim reiterated the sex was nonconsensual. She emphasized her lack of blame by evoking images of sexual inexperience and blood and body evidence, which the offender had dismissed at the time. The victim recalled,

I said to [prosecutor], "Whatever he is pleading down to, he's going to have to say that I was a virgin." Because after he raped me, and there was blood and everything ... he said, "Oh well. [Vaginal tearing/bleeding] happens a lot because I'm [penis size is] so big." 
The offender agreed to plead guilty to the lesser offence of "having sexual intercourse with a girl of previously chaste character between the ages of 14-16 years." Legal analyst Pilon (2001) noted that historically "few charges had been laid under this provision" prior to its repeal in 1988 because of the "kind of scrutiny that a complainant might face in testing the proof of her chaste character" (p. 2). While lack of consent was not a component of the charge, "failure to prove that the accused was more to blame [for the sex act] than the female person could result in acquittal" (p. 2).

In the agreed-upon-facts at court, the incident was described by the prosecutor as an out-of-doors incident wherein the

[Accused] had [victim] take only one leg out of her jeans, and she proceeded to lay there while [accused] had sexual intercourse with her . . . [Accused] had some trouble maintaining an erection and would masturbate for a short period of time before continuing. Once [he] had finished and, in fact, ejaculated, he got up and left her there to get herself dressed and walk back to the car. (ST)

Values and beliefs, like pre-existing ideas or memes, are noncorporeal actors (Hartt, Mills, Mills, \& Corrigan, 2014). When they are a property of a human actor, they act to shape and constrain decision-making, including how the person may relate to others as well as to artifacts, onto whom the values also may be inscribed. In this case, the victim's support for the plea agreement was prompted by a relational care ethic (Miller, 2014), which is a sexual assault victim's protective orientation toward possible future victims. Relational caring had first directed her to lay a complaint with police. Later, at the plea stage, relational caring caused her to place the protection of others above her own psychological need for a sexual assault conviction, which would have left no legal doubt that she had not desired the sexual activity. She inscribed the relational caring ethic onto her VIS narrative:

I have come forward to ensure the prevention of further abuse of girls, adolescents or young women, by [offender] . . I am not willing to risk other young girls' safety, by persuing the sexual assault charge \& having the evidence weigh in at less than a conviction, allowing him to walk away without a record. (VIS; verbatim spelling) Akin to "performances of disempowerment" (Erez, Globokar, \& Ibarra, 2014, p. 180) 
whereby victims use depictions or claims of vulnerability as a source of action against defendants, the victim fashioned her harm claim of nonconsensuality through the discourse of the innocent victim:

[Offender] misused \& abused his position of authority and trust, given to him that day, by my mother ... He could have ... encouraged ... healthy curiosity \& obvious innocent wonder . . Instead . . . [offender] chose to instill fear, betrayal, powerlessness ... I was a girl of chaste character. (VIS)

Because the historical sexual offence charge meant "just sexual intercourse, yeah, basically" (V) and consent was not at issue (ST), the victim purposed the VIS to articulate her harm claim that the sexual activity was unwanted. To do so, she repeatedly characterized the experience as "rape" in her VIS:

For the two weeks immediately following the rape I was an emotionally scarred basket case . . . I would disassociate from my body the way I did when [offender] raped me ... to cope with the rape I became withdrawn . . . [offender]'s lack of responsibility for raping me ... I am appalled that [offender] still denies that he raped me. (VIS)

In relation to the VIS, a plea bargain to lesser charges limits the victim's ability to describe the impact of the original crime (Verdun-Jones \& Tijerino, 2002). Under the Criminal Code, the consequential harms described in the VIS must pertain to the crime for which a conviction was registered. This has been confirmed by case law precedent in $R v$. Talbot (1985), where the VIS of the deceased victim's aunt was permitted only on the offence for which a conviction was registered (indignity to a dead body), and not on the charge for which there was an acquittal (manslaughter). Here, because the VIS was in conflict with the pled-down charge, the prosecutor and victim services worker briefly argued:

[Prosecutor and victim services worker] had disagreements on me using the word rape [in the VIS] . . Their conversation was not directed towards me. It didn't involve me ... They weren't questioning me. They were questioning the [VIS], and each other. [Victim services worker] was saying, "I don't think that [the term rape] should be in [the VIS] . . Please, make her take [the word rape] out . . . I don't think that the judge is going to like that". . . [Victim services worker] was trying to say what 
could happen [if the word rape stayed in the VIS]. [Prosecutor] was

shutting her down, and saying, "No! It will be okay!" [Victim services

worker] looked a little strained in her face. You could tell her worry. (V)

With hindsight, the victim commented during interview, "I do believe that [prosecutor] knew that the judge was not going to like [the word rape] but that she might be able to keep it in there." The prosecutor's actions were an example of what Randazzo (2014) has called a "disjuncture" (p. 26) in the unfolding of legislative ends, which is caused by "information asymmetry and knowledge expertise developed by the agents . . . which provides agents with incentives to shirk the principal's wishes and act accordingly to the agent's preferences" ( $p$. 26). This disjuncture was accomplished by the prosecutor submitting the unedited VIS to the court, which in Latour's (2005) terms, enabled the VIS to "mutate" (p. 202) from intermediary to mediator. Mediators are actors who behave unexpectedly or who "make others do unexpected things" (p. 106).

As Mol (1999) noted, "objects that are performed do not come alone: they carry modes and modulations of other objects with them" (p. 81). Evoking "the traces (and traces of traces)" (Carter \& Michael, 2003, p. 232) of three nonhuman actors/intermediaries implicated in the VIS - the Criminal Code, and the legal concepts of consent and rape - the judge declared the VIS was partially invalid:

There are repeated references in the [VIS] to rape; in other words, an offence which occurred absent consent. The difficulty I have with that is that the [VIS] in that sense bespeaks of, and in essence asks me to sentence the accused for, an offence to which he has not been convicted [which] is a primary consideration or primary aspect of the [VIS]. (ST) The prosecutor argued against the rejection of the term rape in the VIS, "Absent a joint recommendation on sentence I . . could perhaps see that as more of an issue. I would also note that I've indicated to [the defence] that we're not conceding it wasn't consensual" (ST). The judge disagreed: "But you're asking me to sentence him for something in which the issue of consent is not an aspect of the offence" (ST). Defence counsel agreed, and invoked the proceduralizing statutes that regulated the VIS: "I had the same concerns [about the VIS] ... The fundamental law of what your Lordship has stated [about the VIS] is correct" (ST). 
Prout (1996) has commented on "inscriptions of user competence" (p. 209), which are the requirements or use instructions embedded in devices that deliberately elicit, or demand, specific and learned user abilities to ensure effective use. In this case, the victim unintentionally violated configuring inscriptions. In using the term rape to distinguish her experience as sexual assault and not seduction in social terms, the victim instituted a harm claim that violated the case law precedents that had informed the instructions on the VIS form, which were to speak only of impact and not to describe the crime. Only through continued dialogue between the judge, defence, and prosecutor did she come to understand the nature of the legal conflict, and what she could have done to avoid it: "It was the way I had phrased it: 'the way the rape [emphasis] affected me.' I could have put 'incident,' instead."

The judge then offered the prosecutor (and the victim) a compromise. Her VIS could remain, as is, only if she declined to allocute:

Instead of having [the VIS] completely rewritten, I'm prepared to consider the [VIS], deleting myself, any reference to the issue of consent or a suggestion that it was rape. ... Otherwise, if she wishes to submit another [VIS] deleting that reference [in order to allocute], I would consider it. . . .

But I'm prepared to self-edit. (ST)

The judge's acceptance of the technically inadmissible VIS was an obliging detour. It created conditions of possibilities but with a price; it demanded obedience not only of the victim but others who would not otherwise have been involved. While the victim was required to forgo allocution, the extralocal and asynchronous implications of the judicial self-editing included that correctional authorities (in this case, the offender's probation officer) were now to be provided an unedited VIS claiming harms of rape as if that claim was a legally admissible fact. In this regard, the effects of self-editing were similar to other negotiation tactics undertaken by nondocile actors as they engage with intermediary and user-competence scripts during artifact use. The negotiations then influence, in the words of ANT scholar Akrich (1992), the extent to which actors "are able to reshape the object, and the various ways in which the object may be used" (p. 206) by others, and at a later date. 
Although the victim wanted very much to read aloud her VIS, she agreed to the judge's concession. Her decision was undertaken at the prosecutor's quiet, but insistent, urging. She recalled:

The judge said, "Now, if she wants to continue with reading it out loud, she would have to go back and take these things out, or [strong emphasis] I can just delete them in my mind." And I was thinking, what a funny thing to say, "delete them in my head." That's when the [prosecutor] whispered in my ear, "You can’t stop the bell from ringing." And I said, “Ohhhh [indicating sudden understanding]. Okay. Just leave [the term rape] in then."

Avoidance of direct conflict is still a form of negotiation (Miller \& Kontos, 2013), and an indication that the "interactional course may not have been totally finished" (Strauss, 1993, p. 38). The victim believed the prosecutor's strategy ensured that ideas of lack of consent and therefore blamelessness remained foremost in the judge's mind while he determined crime seriousness:

[Prosecutor] was encouraging me [not to modify the VIS wording]. She definitely wanted [the word rape] kept in there. And it worked!! [emphasis, excited laughter] [Because then] the judge said, "I don't want you to ever, ever think back on this and think you were responsible for what happened, because you were a child."

Confirming this recollection of events, a review of the sentencing transcript revealed that the judge had commented to her:

I have read the [VIS], and made my comments as regards to what was appropriately [submitted in the VIS] before the Court ... This is not an offence for which you share any blame ... The Court acknowledges as well that this offence has had a very substantial, long-lasting impact on you. And, in fact, it robbed you of your childhood, deprived you of many things that you could have enjoyed as an adult in terms of your family, your husband . . . I accept the pain and suffering [as stated in the VIS] that you endured, as a result of that day of events. 
As with the prosecutor's strategizing concerning her unedited VIS, the victim suggested that the judge, too, had been particularly strategic in how he applied it:

The judge [made] a 180-degree turn. It seemed like he was going against the [VIS], [but] then he was so supportive ... He was doing it by the "letter of the law" [a phrase that connotes, in a negative way, the act of following the literal interpretation of the law but not the spirit or intent of legislatures] ... The [prosecutor] told me later, "What the judge said [about the VIS] is very calculated. You can almost hear it in his voice.

He's saying things very specifically, so they can't come back and appeal [his use of the VIS] in any way."

Following his comments to the victim, the judge further determined that the nature and circumstances of the assault, which had been gleaned from the VIS, indicated that a DNA sample from the offender for the National Databank (Royal Canadian Mountain Police, 2011) would be warranted, as had been recommended by the prosecutor. A DNA sample was ordered, as would be customary for sexual assault offences, despite the defence attorney's objections that the impact on the privacy and liberty of the offender that the order implied was not justified when consent was not at issue.

\section{Disruptions and Durability}

\section{“At One Point We Obviously Loved Each Other”: Intimate Partner Sexual Assault}

While the physical forms of intimate partner violence get "the lion's share" (Cattaneo, DeLoveh, \& Zweig, 2008, p. 152) of attention from practitioners and researchers, rates of intimate partner sexual assault in Canada have increased in recent years (Sinha, 2013). In the U.S., nearly one in 10 women has been sexually assaulted by an intimate partner during her lifetime (Breiding et al., 2014). Some women who are sexually assaulted by their partners do not experience other forms of violence, while others experience sexual assault alongside chronic or episodic physical or emotional abuse. Still others are sexually assaulted as retaliation for leaving the relationship (DeKeseredy, 2007). Three victim participants in this study were sexually assaulted by current or previous intimate partners. One victim recalled: 
We were together for a long time and at one point we obviously loved each other; it's just we hadn't for a while ... He kept talking about getting back together, and he knew I didn't want to ... He shut all the curtains and the blinds so nobody could see in the house and it was not good ... He just kept going [acts of penetrative sexual assault] and going ... When he fell asleep, I took [our baby] . . . and I grabbed the phone, and ran outside [to call for help].

Victim services staff and advocates reported that many victims who have experienced intimate partner sexual assault are resistant to completing a VIS:

They are scared to piss [intimate partner] off . . They don't want to ... give him reason to come after them by telling him what they really think [in the VIS] ... Women are still trying to keep the peace, even at that point. (VSW)

Advocates and victim services workers noted that for those who did complete a VIS, selfblame for the assault was often inscribed by victims in their VIS narratives:

So [victims of intimate partner sexual or physical assault] weave some self-blame or self-responsibility [into VIS] and that's, I think, from always having to justify to their families, like, "why do you stay?" (VSW)

[intimate partner sexual assault victims] on a whole tend to blame themselves ... I had one victim describe how ... she was throwing up into the toilet and [partner] decided that he wanted to have [emotophilic] sex [sex with someone who is vomiting]. So, she's vomiting, and he's [sexually assaulting her], and she's crying - and she somehow blames herself for that ... [Self-blame] will kind of weave its way into the way [victims] word things [in the VIS] . . She wrote in her VIS, "I didn't really tell him to get off." (VSW)

Victims of intimate partner sexual assault who are mothers are at risk of unique negative sequelae when their VISs are used against them during custody disputes. Despite that family court has often been experienced as secondary victimization for assaulted women (Rivera, 
Sullivan, \& Zeoli, 2012), the third-party use of the VIS by offending partners had not been envisaged by legislators:

[Policy-makers have] heard of examples where a [VIS] has described a harm on a person to such an extent that it appears that they have less ability to cope with certain things, and then that arises in family proceedings to be used against them to challenge their parenting abilities and so on. That would not have been foreseen at the time [the VIS was legislated]. I'm sure [the victim] just wanted to describe that the violence against them had destroyed their confidence in themselves, and had a far greater impact than one would imagine - and then it comes back to haunt them later because [the court is] saying, "well, you're damaged goods now, we can't let you keep your children.” (PM)

Victims who chose to remain in relationships with the men who assaulted them were often described as emotionally labile, and prone to using their VISs in strategic, resistive, and often unapproved ways. Several respondents reported that many victims used their VISs to recant or undermine their complaint, and to support the offender:

[intimate partner sexual and physical assault] victims change their minds about everything ... At the very beginning they hate him and want him strung by his toes, and at the end they love him and want him back. Or, vice versa. [laughter] (VSW)

We have had a few cases where ... the [intimate partner sexual assault] victim has chosen to write a VIS that significantly underestimates the impact ... The [prosecutors] haven't been real happy with those victims! [laughter] (PM)

Victim services staff also described several cases where victims who had chosen to leave their partners experienced pressure from others to use the VIS to recant. One VSW recalled: The accused's family were pressuring her on what to write in her [VIS]. They were telling her what to write. They were asking her to fax it to them for their approval. Basically asking her to censor her words, and provide a [VIS] that actually was in favour of the accused. 
KLM: Was the family's pressure specifically focused around her comments in the VIS?

VSW: Yes-when they had exhausted all other avenues. You know, first it was pressuring her around testifying, and trying to persuade her against testifying at the trial. Then telling her to tell the [prosecutor] that she was too traumatized to proceed. Then telling her that she would get the house if she didn't testify! When that didn't work, they tried with the guilt, and they said he's going to go to jail, he's going to get deported, he's going to lose his job. Then, when that didn't work they went on to the VIS process . .. They thought [a favourable VIS] would keep him out of jail.

\section{"Vulnerable to a Suggestion That Their Fault Continues": Victims in Conflict with the Law}

Women and girls may come into conflict with the law as a result of experiences of nonfamilial or familial sexual victimization as well as intimate partner sexual assault. Coercive sexual experiences often result in girls acting out behaviourally, including in ways that cause them to be apprehended by authorities (Chesney-Lind \& Sheldon, 2014). A study participant who had been sexually abused as a child described in her VIS, "I was in a reformatory for a while... My parents were always having to confine me or notify the police I was gone again." Adult women in conflict with the law have been noted to have extraordinarily high rates of sexual victimization in childhood and adulthood. In Canada, $80 \%$ of nonAboriginal women and $90 \%$ of Aboriginal women who have received federal sentences have been previously victimized (Canadian Human Rights Commission, 2003). Of Canadian women serving incarcerative sentences for violent offences, $62 \%$ have committed low-level or common assault. The majority of these have committed the crime against a spouse or partner by whom they were physically or sexually assaulted (Elizabeth Fry Society of Manitoba, 2007).

Over the course of her 20 years of experience working with male and female offenders convicted of violent crimes, an advocate participant noted the women displayed entrenched patterns of self-blame arising from sexual and physical victimization histories. "In all of the cases I would say the VIS has a profound effect on women [offenders], more so 
than I ever saw in the men, because [women] are very vulnerable to a suggestion that their fault continues." These patterns of self-blame, in turn, imbued female offenders' reception of information about how they had victimized others.

The advocate spoke specifically of her VIS-related experience with nine federallysentenced female offenders who had been previous victims of adult or childhood sexual assault, and convicted of violent nonsexual offences. The VISs written by these offenders' victims had been submitted in various settings including sentencing, deportation, parole hearings, and life-imprisonment sentence reviews. The advocate repeatedly described how female offenders with sexual and/or physical victimization histories would become overly emotional or penitential when presented with the VIS at or after their own criminal trials. Female offenders subsequently demonstrated a pronounced tendency to engage in behaviours that were not in their best legal interests. The advocate shared a particularly poignant case of a sexually and physically abused offender who became suicidal after reading a VIS by her victim's family. She subsequently failed to fully pursue the legal remedies available to her:

[Offender] had passed by all her parole eligibility dates because she didn't feel she deserved another chance ... So, we had just managed to get to the point of agreeing to start working on temporary passes. I had even been trying to work on her agreeing to have her case reviewed for wrongful conviction. She got the [VIS] because one of the things I said is, "we should ask [Correctional Service Canada] if there is anything out there involving you and victims or community members." I had asked for [the VIS] to come to me but they sent it directly to her. She was devastated, and was on suicide watch for several days. She was right back to where she was, and probably even worse, because she was reading what the reaction of the victims was at the time of sentencing . . Even though I tried to talk to her about it, she has not agreed to go back to starting her work to get released, or to have her case reviewed. So, that's a pretty severe impact of the [VIS]. (A)

Sexually assaulted female offenders who are not Canadian citizens may be at enhanced legal risk when they respond penitentially to the VIS. In a case the advocate discussed, a victim convicted of killing her sexually and physically abusive mate failed to 
adequately defend her interests within the context of a deportation hearing. When her in-laws submitted VISs that described the emotional harms that they had suffered as a consequence of her murdering their son, the female offender became "paralyzed with guilt":

Once she saw their [VISs] she refused to defend herself, and basically accepted that she will be deported. She probably would have been deported anyway without the [VISs] but at least she may have worked on [her legal defence]. (A)

The advocate also described an example involving the strategic use of the VIS by a sexually and physically assaulted female offender. In order for her children to obtain financial support while she was incarcerated, she had encouraged them to submit a VIS to the parole board that would claim that they had been emotionally harmed by her murder of her abusive common law partner, who had acted as their stepfather. The intent was then to reuse the VIS in a later criminal compensation application as evidence that their claims of emotional distress had been accepted, and hence legitimated, by correctional authorities. Her efforts were unsuccessful. The parole board refused to grant the children standing as "recognized victims," which is required before being permitted to submit a VIS. The advocate noted,

[Offender] wanted her kids recognized as victims [in order to write a VIS] in the hope that they could get some kind of compensation ... The parole board refused to accept it ... [but] they allowed [VISs] from the ex-wife's kids.

\section{Discussion}

The VIS network is an association of practices, sites, and actors that can act to fashion, equip, and govern sexually assaulted women in a myriad of empowering, surprising, and sometimes unfortunate ways. The use of ANT gave insight into the continuing durability and expansion of the VIS network in Canada despite innovations of use both unanticipated, and frowned upon, by the legislators and policy-makers who had proposed and implemented the VIS.

Across jurisdictions, the VIS functions under different legislative regimes, is called by different names, and is held to different evidentiary standards. Yet it still is identified and 
recognized as a VIS. Multiplicity is not the same as pluralism (Mol \& Law, 1994), and the "most surprising" detail of multiplicity is that "one may include the other . . what is 'other' is also within" (p. 85). It is the VIS's use at parole in Canada that most clearly establishes its unique status as something that in ANT terms, "keeps on differing but also stays the same" (Mol \& Law, 1994, p. 664), and illuminates the implications of its obliging detours. There, the content admissibility criteria of the VIS, which is defined as the presence of a criminal conviction for which the harms details contained in the VIS must refer, no longer applied. The original obligatory point of passage or "narrative bottleneck" (Singleton \& Michael, 1993, p. 229) was no longer relevant. This unmoored the VIS from its established relationship with judges, as well as with other nonhuman actors such as the charge at conviction. Once the VIS took on the shape and function of a parole-centric VS, it remained like, and yet unlike itself. The VIS, to use Mol and Law's (1994) words, "transform[ed] itself from one arrangement into another without discontinuity" (p. 664) and managed to thrive after evading the legislative and case law requirements that had both birthed and constrained it at sentencing. The VIS's mutable facility may be a hitherto unrecognized reason for its increasing march across common and civil law jurisdictions, and its continued survival.

Yet multiplicity can have negative impacts on enrolled actors in a network, which ANT scholars have yet to document. In the case of the VIS, its multiplicity suggests that enrolled or reluctant allies who have, in the words of a policy-maker participant, "jumped on the VIS bandwagon," might utilize and enact an entity-actor that is not (only, or fully) what they presumed, with sometimes unsettling results. In this study, the parole board refused to accept a VIS by the children of an abused woman who had murdered their stepfather, while at the same time accepting VISs from their half-siblings by another (nonoffending) mother. This provides some evidence that the successful use of artifact multiplicity depends upon the facility or approval provided by other actors, and whether potential users can successfully negotiate the new obliging detours. Thus, "many-to-many mapping, where several obligatory points of passage are negotiated with several kinds of allies" (Star \& Griesemer, 1989, p. 390 ) is less benign than supposed, and may prove a greater barrier than its properties on the performance and successful use and reuse of an object. Potential users, and ANT scholars, might be better advised to (re)attend to the organizing and potentially oppressive practices of what Callon (1991) calls the "translation regime" (p. 147) of an actor-network, which is 
intended to reduce potentiality and permit only certain courses of action (Gardner, 2009), rather than the lure of possibility presented by multiplicity's new-old wine in new-old bottles. In this case, VIS multiplicity institutionalized an obliging detour that, true to its name, some victims were unable to avoid. The introduction of the VIS at parole meant that VIS authors are unable to prevent its use in a manner and in a temporal-spatial setting to which they might be opposed, as occurred here.

William-Jones and Graham (2003) developed the concept of "drift" (p. 276) to characterize the use of a technology that is unanticipated because it differs from the designer's original intent. Drift may be influenced, or exacerbated, by gender considerations. Frissen's (1995) examination of the gendered uses of the telephone identified that, contrary to its designers' intent, women used the technology to facilitate sociability and relationality. Telecommunication technology use was not only shaped by sociocultural arrangements - the pre-existing gendered responsibility of maintaining close social relationships - but was an active agent in shaping them as well (Frissen, 1995). Here, similarly, the VIS both enabled the expression of relational caring (Miller, 2014) and additionally shaped its activities and material effects.

Because of her use of the word rape in her VIS, the victim described in the case study was prevented from reading aloud the statement in open court, which she had desired for purposes of communicative expressiveness, long considered a laudable goal of the statement (Manikis, in-press). Yet relational caring, and her concern for other or future victims, provided a much stronger "injunction to act" (Callon, 1991, p. 141) in ANT terms than her desire to communicate to the offender. As an actor, relational caring directly shaped her participation at the sentencing hearing. Her VIS, in turn, set in motion judicial fact finding that structured an obliging detour that demanded the subsequent involvement of extralocal human and nonhuman others, including those acting at-a-distance and in potentia. Influenced by the presence of the term rape in her VIS, which contradicted the agreed-upon facts and the charge at conviction, the court instituted an order for DNA evidence collection. The DNA sample, the collection of which signalled the offender's troubled status as a sex offender, was to be housed in a national databank repository, and could one day be used to confirm, or exonerate, his relationship to other crime scene evidence (Royal Canadian Mountain Police, 2011). 
When intersectionality - the intensification of conditions of social inequality through multiple matrices of gender and race (Siltanen \& Doucet, 2008) which can include status or vulnerability before the law (Grabham, Cooper, Krishnadas, \& Herman, 2008) - is taken into account in relation to the VIS, the evidence and effect of technology or artifact drift appears particularly stark. Intimate partner sexual assault victims' use of the VIS as a novel form of complaint recanting, as well as abusive men's VIS practices that introduced victims' narratives into family court, are suggestive of drifts so profound that they appear to constitute new formal patterns of use. Drift has important, and far-reaching practical and policy implications (Williams-Jones \& Graham, 2003). Loss of custody or changes in parenting time arrangements not only affects a woman's relationship with her child(ren), but also increases her abuser's access to her. Highly involved parenting by men who are, or were, abusive to their partners may indicate a desire for continued control, not an overriding interest in co-parenting (Hardesty \& Ganong, 2006). The effects of the reuse of the VIS by offenders in family court may therefore have significant and ongoing personal safety implications for victimized mothers, which should be attended to by family lawyers, mediators, and social service providers. Aside from this study, however, it would appear that the VIS continues to be overlooked as a site of concern in cases involving simultaneous criminal and family law disputes (see for example Neilson, 2014).

Sexual assault within the context of current or previous intimate relations adds a layer of complexity to our understanding of the operation and the experiences of the VIS (Schuster \& Propen, 2006), particularly in cases involving the use of the VIS as a novel form of both voluntary and coerced complaint recanting. Here, the VIS functions to undermine progressive dominant aggressor charging policies and mandatory charge-laying procedures that have been implemented to relieve victims from responsibility for charge laying, and reduce their risks of offender retaliation or being criminalized for resistance violence (Neilson, 2014). Rates of recanting are very high in cases involving intimate partner violence, and the majority of these are false and intended to assist the offender (Neilson, 2014). The use of the VIS to contribute to false victim-recanting efforts is an issue that urgently requires further examination. Many women are motivated to seek criminal justice intervention for reasons unrelated to punishing their intimate partners, and for which more flexible post-sexual assault approaches by police and prosecutors are more helpful (Brown, 
2000). In those cases, any efforts to inhibit the strategic use of the VIS for recanting purposes could be considered a failure to recognize unconventional forms of resilience (Walklate, 2011) and may lead to sexually assaulted women's further disempowerment. In other cases, however, coercive pressure to submit VISs that are favourable to the offender represents a continuation of abuse that requires intervention.

The notion of victim is a "categorization device that is reflexive, indexical and rhetorical" (Holstein \& Miller, 1990, p. 105), which advises others how they should classify and respond to those harmed. Whether someone believes they may rightfully claim victim status or has that claim approved or denied by others is often a reflection of the structural locations of gender, race, and class of the claims-maker, which is influenced by social power relations (Savarese, 2010; Walklate, 2011). In relation to sexual assault and the VIS, the structural location of the victim has been shown to affect the attribution of both harm and blameworthiness that she and her statement can expect to receive. Earlier studies have demonstrated that offending women such as sex workers have experienced a particularly poor reception by the criminal justice system, including having their VISs treated with suspicion (Rogers \& Erez, 1999; Ruparelia, 2012). It is uncommon that the experiences of offender-victims, particularly those convicted of violent offences, are included in sexual assault victimization or VIS studies alongside those of nonoffender victims. Their stories have been included here deliberately as a means of "thinking otherwise" (Walklate, 2011, p. 187) about victimization and offending. Such inclusion importantly rejects the troubling division between victims perceived as blameless and those dismissed as having mismanaged lives (McAlinden, 2014; Pratt, 2005). The presence of female offenders contributes to further critical theorizing about the range of identities and experiences of women who have been sexually victimized and their relationship to the VIS network. The work here suggests the VIS has a disproportionate gendered impact on due process interests of female offenders because of extreme emotional distress arising from victimization sequelae. It is a novel finding that requires further investigation.

Mol (2010) argued that the purpose of ANT "is to make specific, surprising, so far unspoken events and situations visible, audible, sensible" (p. 255) as a starting means of having "other kinds of conversations" (p. 266) about particular phenomena and the activities of human and nonhuman actors. ANT has been used here to examine the VIS network, and 
reveal the implications of new pathways or obliging detours of VIS use for sexual assault victims, including those who are offenders.

\section{Author's Note}

This work is a component of the author's doctoral dissertation at the University of Toronto.

\section{Acknowledgments}

I am grateful to the victims who so generously shared their experiences. Criminal justice participants prioritized interviews in spite of heavy workloads: thank you. Janice Du Mont, Ted Myers, Dan Allman, Andrea Quinlan, Marie Manikis, Susan Bandes, and Amanda Konradi provided insightful comments on earlier drafts.

\section{Declaration of Conflicting Interests}

The author declared no potential conflicts of interest with respect to the research, authorship, and/or publication of this article.

\section{Funding}

The author disclosed receipt of the following financial support for the research, authorship, and/or publication of this article: Support was received from the Frederick Banting and Charles Best Canada Graduate Scholarship of the Canadian Institutes of Health Research, and the Policy Centre for Victim Issues, Department of Justice Canada. The views expressed do not necessarily reflect those of supporters or funders.

\section{References}

Akrich, M. (1992). De-scription of technical objects. In W. E. Bijker \& J. Law (Eds.), Shaping technology/building society: Studies in sociological change (pp. 205-224). Cambridge, MA: MIT Press.

Arrigo, B. A., \& Williams, C. R. (2003). Victim vices, victim voices, and impact statements: On the place of emotion and the role of restorative justice in capital sentencing. Crime \& Delinquency, 49(4), 603-626. doi: 10.1177/0011128703252408

Bandes, S. (2009). Victims, "closure," and the sociology of emotion. Law \& Contemporary Problems, 72(1), 1-25. 
Barrett, J. (2008). Expanding victims' rights in the Charter era and beyond. Supreme Court Law Review, 40, 627-653.

Bergquist, M., Ihlstralm, C., Ljungberg, J., \& Kesson, M. A. (2008). Combing actor network theory and genre theory to understand the evolution of digital genres. Sprouts: Working Papers on Information Systems, 8(20). http://sprouts.aisnet.org/8-20

Black, M. (2003). Victim submissions to parole boards: The agenda for research. Australian Institute of Criminology: Trends and issues in crime and criminal justice(May), 1-6.

Breiding, M. J., Smith, S. G., Basile, K. C., Walters, M. L., Chen, J., \& Merrick, M. T. (2014). Prevalence and characteristics of sexual violence, stalking, and intimate partner violence victimization - National Intimate Partner and Sexual Violence Survey, United States, 2011. Surveillance Summaries, 63(SS08), 1-8.

Brown, T. (2000). Charging and prosecution policies in cases of spousal assault: A synethesis of research, academic and judicial responses. (rr2000-5e). Ottawa: Department of Justice Canada.

Callon, M. (1986). Some elements of a sociology of translation: Domestication of the scallops and the fishermen of St. Brieuc Bay. In J. Law (Ed.), Power, action, and belief: A new sociology of knowledge? (pp. 196-233). London: Routledge \& Kegan Paul.

Callon, M. (1991). Techno-economic networks and irreversibility. In J. Law (Ed.), $A$ sociology of monsters: Essays on power, technology and domination (pp. 132-164). London: Routledge.

Canadian Human Rights Commission. (2003). Protecting their rights: A systematic review of human rights in correctional services for federally sentenced women. Ottawa: Canadian Human Rights Commission.

Caplan, J. M. (2010). Parole release decisions: Impact of victim input on a representative sample of inmates. Journal of Criminal Justice, 38(3), 291-300. doi: 10.1016/j.jcrimjus.2010.02.012

Carter, S., \& Michael, M. (2003). Signifying across time and space: A case study of biomedical educational texts. Sociology of Health and Illness, 25(2), 232-259.

Cattaneo, L., DeLoveh, H., \& Zweig, J. (2008). Sexual assault within intimate partner violence: Impact on help-seeking in a national sample. Journal of Prevention and Intervention in the Community, 26(1-2), 137-153. doi: 10.1080/10852350802022415

Chesney-Lind, M., \& Sheldon, R. (2014). Girls, deliquency, and juvenile justice. Malden: Wiley Blackwell.

Cole, M. A. (2003). Perceptions of the use of victim impact statements in Canada: A survey of Crown counsel in Ontario. (Unpublished master's thesis), University of Ottawa, Ottawa.

Cook, R. J., Dickens, B. M., \& Thapa, S. (2005). Caring for victims of sexual abuse. International Journal of Gynaecology and Obstetrics, 91(2), 194-199. doi: 10.1016/j.ijgo.2005.08.001

Corrections and Conditional Release Act, S.C., Minister of Justice (1992).

Criminal Code RSC, 1985 c C-46, Minister of Justice.

DeKeseredy, W. (2007). Sexual assault during and after separation/divorce: An exploratory study. Washington, DC: National Institute of Justice.

Department of Justice Canada. (2003). Victims of crime initiative mid-term evaluation: Technical report. Ottawa. 
Department of Justice Canada. (2006). Victim impact statement. Ottawa: Author Retrieved from http://publications.gc.ca/collections/Collection/J2-285-1999E.pdf.

Department of Justice Canada. (2010). Age of consent to sexual activity. Retrieved August 15, 2011, from http://www.justice.gc.ca/eng/dept-min/clp/faq.html

Department of Justice Canada. (2013). Use of victim impact statements at sentencing and parole. Retrieved October 1, 2013, from http://www.victimsweek.gc.ca/res/r58.html

Du Mont, J., Miller, K.-L., \& White, D. (2008). Social workers' perspectives on the victim impact statements in cases of sexual assault in Canada. Women \& Criminal Justice, 18(3), 1-23. doi: 10.1300/J012v18n03_01

Edwards, I. (2004). An ambiguous participant: The crime victim and criminal justice decision-making. British Journal of Criminology, 44(6), 967-982. doi: 10.1093/bjc/azh050

Elizabeth Fry Society of Manitoba. (2007). Human and fiscal costs of prison. Winnipeg: Elizabeth Fry Society of Manitoba.

Erez, E., Globokar, J. L., \& Ibarra, P. R. (2014). Outsiders inside: Victim management in an era of participatory reforms. International Review of Victimology, 20(1), 169-188. doi: $10.1177 / 0269758013510809$

Erez, E., Ibarra, P. R., \& Downs, D. M. (2011). Victim welfare and participation reforms in the United States: A therapeutic jurisprudence perspective. In E. Erez, M. Kichling \& J. Wemmers (Eds.), Therapeutic jurisprudenc and victim participation in justice: International perspectives (pp. 15-39). Durham, NC: Carolina Academic Press.

Erez, E., \& Tontodonato, P. (1990). The effect of victim participation in sentencing on sentence outcomes. Criminology, 28, 451-474. doi: 10.1111/j.17459125.1990.tb01334.x

Frissen, V. (1995). Gender is calling: Uses of the telephone. In K. Grint \& R. Gill (Eds.), The gender-technology relation: Contemporary theory and research (pp. 79-94). London: Taylor \& Francis.

Gardner, J. (2009). The ordering of medical things: Medical practices and complexity. (Master's), Victoria University of Wellington, New Zealand. Retrieved from http://researcharchive.vuw.ac.nz/xmlui/bitstream/handle/10063/1178/thesis.pdf?seque nce $=1$

Gewirtz, P. (1996). Victims and voyeurs at the criminal trial. Northwestern University Law Review, 90(3), 863-897.

Giliberti, C. (1990). Victim impact statements in Canada. Volume 7. A summary of the findings. Ottawa, ON: Department of Justice Canada.

Grabham, E., Cooper, D., Krishnadas, J., \& Herman, D. (Eds.). (2008). Intersectionality and beyond: Law, power and the politics of location. Abingdon: Routledge-Cavendish.

Hardesty, J. L., \& Ganong, L. H. (2006). How women make custody decisions and manage co-parenting with abusive former husbands. Journal of Social and Personal Relationships, 23(4), 543-563. doi: 10.1177/0265407506065983

Hartt, C. M., Mills, A. J., Mills, J. H., \& Corrigan, L. T. (2014). Sense-making and actor networks: The non-corporeal actant and the making of an Air Canada history. Management \& Organizational History, 9(3), 288-304. doi: 10.1080/17449359.2014.920260 
Henley, M., Davis, R. C., \& Smith, B. E. (1994). The reactions of prosecutors and judges to victim impact statements. International Review of Victimology, 3, 83-93. doi: $10.1177 / 026975809400300206$

Holstein, J. A., \& Miller, G. (1990). Rethinking victimization: An interactional approach. Symbolic Interaction, 13(1), 103-122.

Konradi, A., \& Burger, T. (2000). Having the last word: An examination of rape survivors' participation in sentencing. Violence Against Women, 6(4), 351-395. doi: $10.1177 / 10778010022181895$

Koss, M. P., Bachar, K. J., Hopkins, C. Q., \& Carlson, C. (2004). Expanding a community's justice response to sex crimes through advocacy, prosecutorial, and public health collaboration: Introducing the RESTORE program. Journal of Interpersonal Violence, 19(12), 1435-1463. doi: 10.1177/0886260504269703

Langstraat, L. (2006). Emotion and community rhetorics: Victim impact statements as cultural pedagogy. In P. Bizzell (Ed.), Rhetorical agendas: Political, ethical, spiritual (pp. 267-274). Mahwah, NJ: Lawrence Erlbaum Associates.

Latour, B. (1987). Science in action: How to follow scientists and engineers through society. Cambridge, MA: Harvard University Press.

Latour, B. (1999). Pandora's hope: Essays on the reality of science studies. Cambridge, MA: Harvard University Press.

Latour, B. (2004). Why has critique run out of steam? From matters of fact to matters of concern. Critical Inquiry, 30, 225-248. doi: 093-1896/04/3002-0020

Latour, B. (2005). Reassembling the social: An introduction to actor-network-theory. Oxford: Oxford University Press.

Law, J. (1992). Notes on the theory of the actor-network: Ordering, strategy, and heterogeneity. Systems Practice, 5(4), 379-393.

Law, J. (2007). Actor network theory and material semiotics. http://hwww.heterogeneities.net/publications/Law2007ANTandMaterialSemiotics.pdf

Law, J., \& Mol, A. (2001). Situating technoscience: an inquiry into spatialities. Environment and Planning D: Society and Space, 19(5), 609-621. doi: 10.1068/d243t

Lawrence, E. (2010). Victim opinion statements: Providing justice for grieving families. Journal of Law and Family Studies, 12(2), 511-522.

Lens, K. M. E., Pemberton, A., \& Bogaerts, S. (2013). Heterogeneity in victim participation: A new perspective on delivering a victim impact statement. European Journal of Criminology, 10(4), 479-495. doi: 10.1177/1477370812469859

Leverick, F., Chalmers, J., \& Duff, P. (2007). An evaluation of the pilot victim statements schemes in Scotland. Aberdeen, SCT: University of Aberdeen Law School.

Manikis, M. (2012). Recognizing victims' role and rights during plea bargaining: A fair deal for victims of crime. Criminal Law Quarterly, 58(3-4), 411-441.

Manikis, M. (in-press). Victim impact at sentencing: Towards a clearer understanding of their aims. University of Toronto Law Journal. doi: 10.3138/UTLJ.2717

McAlinden, A.-M. (2014). Deconstructing victim and offender identites in discourses on child sexual abuse: Hierarchies, blame and the good/evil dialectic. British Journal of Criminology, 54(2), 180-198. doi: 10.1093/bjc/azt070

Meredith, C., \& Paquette, C. (2001). Summary report on victim impact statement focus groups. Ottawa, ON: Department of Justice Canada Retrieved from http://publications.gc.ca/collections/Collection/J3-3-2-2001E.pdf. 
Miller, K.-L. (2013). Purposing and re-purposing harms: The victim impact statement and sexual assault. Qualitative Health Research, 23(11), 1445-1458. doi: $10.1177 / 1049732313507753$

Miller, K.-L. (2014). Relational caring: The use of the victim impact statement by sexually assaulted women. Violence \& Victims, 28(5), 797-813. doi: 10.1891/0886-6708.VVD-13-00056

Miller, K.-L., \& Kontos, P. (2013). The intraprofessional and interprofessional relations of neurorehabilitation nurses: A negotiated order perspective. Journal of Advanced Nursing, 69(8), 1797-1807. doi: 0.1111/jan.12041

Mol, A. (1999). Ontological politics: A word and some questions. In J. Law \& J. Hassard (Eds.), Actor network theory and after (pp. 74-89). Oxford: Blackwell/The Sociological Review.

Mol, A. (2010). Actor-network theory: Sensitive terms and enduring tensions. Kölner Zeitschrift für Soziologie und Sozialpsychologie, 50, 253-269.

Mol, A., \& Law, J. (1994). Regions, networks and fluids: Anaemia and social topography. Social Studies of Science, 24(4), 641-671.

Morgan, R., \& Sanders, A. (1999). The uses of victim statements. London: University of Bristol, Department of Law.

Neilson, L. C. (2014). Enhancing safety: When domestic violence cases are in multiple legal systems (criminal, family, child protection). A family law, domestic violence perspective. (J2-395/2014E-PDF). Ottawa: Department of Justice Canada.

Office of the Federal Ombudsman for Victims of Crime. (2010). Towards a greater respect for victims in the Corrections and Conditional Release Act. (J84-2/2010E-PDF). Ottawa: Office of the Federal Ombudsman for Victims of Crime Retrieved from Website: http://www.victimsfirst.gc.ca.

Parole Board of Canada. (2011). PBC QuickStats: Parole, pardons and clemency. Retrieved September 16, 2013, from http://pbc-clcc.gc.ca/infocntr/factsh/parole_stats-eng.shtml $-10$

Pemberton, A., \& Reynaers, S. (2011). The controversial nature of victim participation: Therapeutic benefits in victim impact statements. In E. Erez, M. Kichling \& J. Wemmers (Eds.), Therapeutic jurisprudence and victim participation in justice (pp. 229-248). Durham: Carolina Academic Press.

Pilon, M. (2001). Canada's legal age of consent to sexual activity. (PRB-99-3E). Ottawa: Library of Parliament Retrieved from http://www.parl.gc.ca/Content/LOP/researchpublications/prb993-e.pdf.

Pratt, G. (2005). Abandoned women and spaces of exception. Antipode, 37(5), 1052-1078.

Privy Council Office. (2001). Guide to making Federal acts and regulations. Ottawa: Government of Canada.

Project Victims in Europe. (2009). Implementation of the EU framework decision on the standing of victims in the criminal proceedings in the member states of the European Union. Lisboa, Portugal.

Propen, A., \& Schuster, M. L. (2010). Understanding genre through the lens of advocacy: The rhetorical work of the victim impact statement. Written Communication, 27(1), 335. doi: $10.1177 / 0741088309351479$

Prout, A. (1996). Actor-network theory, technology and medical sociology: An illustrative analysis of the metered dose inhaler. Sociology of Health \& Illness, 18(2), 198-219. 
R. v. Antler (B.C.J. No. 1705, 69 C.C.C. (2d) 480 (BC SC) 1982).

(1985).

Randazo, K. A., \& Waterman, R. W. (2014). Checking the courts: Law, ideology, and contingent discretion. Albany: State University of New York Press.

Rivera, E. A., Sullivan, C. M., \& Zeoli, A. M. (2012). Secondary Victimization of Abused Mothers by Family Court Mediators. Feminist Criminology, 7(3), 234-252. doi: $10.1177 / 1557085111430827$

Roberts, J. (2009). Listening to the crime victim: Evaluating victim input at sentencing and parole. In M. Tonry (Ed.), Crime and Justice: A review of research (pp. 347-412). Chicago: University of Chicago Press.

Roberts, J., \& Edgar, A. (2006). Victim impact statements at sentencing: Judicial experiences and perceptions. A survey of three jurisdictions. (rr06-vic3). Ottawa, ON: Department of Justice Canada.

Roberts, J., \& Erez, E. (2010). Communication at sentencing: The expressive function of victim impact statements. In A. Bottoms \& J. V. Roberts (Eds.), Hearing the victim: Adversarial justice, crime victims and the state (pp. 232-254). Devon, UK: Willan Publishing.

Roberts, J. V., \& Manikis, M. (2011). Victim personal statements: A review of empirical research. Report for the Commissioner for Victims and Witnesses in England and Wales. University of Oxford: University of Oxford.

Rock, P. (1986). A view from the shadows: The Ministry of the Attorney General of Canada and the making of the Justice for Victims of Crime Initiative. Don Mills: Oxford University Press.

Rogers, L., \& Erez, E. (1999). The contextuality of objectivity in sentencing among legal professionals in South Australia. International Journal of Sociology, 27, 267-286. doi: 10.1006/ijsl.1999.0092

Rosebury, B. (2011). The political logic of victim impact statements. Criminal Justice Ethics, 30(1), 39-67. doi: 10.1080/0731129x.2011.559061

Royal Canadian Mountain Police. (2011). The National DNA Data Bank of Canada Annual Report 2010-2011. Ottawa: Royal Canadian Mounted Police.

Ruparelia, R. (2012). All that glitters is not gold: The false promise of victim impact statements. In E. A. Sheehy (Ed.), Sexual assault in Canada: Law, legal practice and women's activism (pp. 665-700). Ottawa, ON: University of Ottawa Press.

Sanders, A. (1999) Taking account of victims in the criminal justice system: A review of the literature. Social Work Research Findings: Vol. 32. Edinburgh: The Scottish Office Central Research Unit.

Savarese, J. L. (2010). "Doing no violence to the sentence imposed": Racialized sex worker complainants, racialized offenders, and the feminization of the Homo Sacer in Two Sexual Assault Cases. Canadian Journal of Women and the Law, 22(2), 365-395. doi: 10.3138/cjwl.22.2.365

Schuster, M. L., \& Propen, A. (2006). 2006 WATCH victim impact statement study. Minneapolis, MN: University of Minnesota.

Schuster, M. L., \& Propen, A. (2010). Degrees of emotion: Judicial responses to victim impact statements. Law, Culture and the Humanities, 6(1), 75-104. doi: $10.1177 / 1743872109349104$ 
Sebba, L. (1996). Third parties: Victims and the criminal justice system. Columbus: Ohio State University Press.

Shaffer, M. (2012). The impact of the Charter on the law of sexual assault: Plus ça change, plus c'est la même chose. Supreme Court Law Review, 57(2), 337-354.

Sheley, E. L. (2012). Reverberations of the victim's "voice": Victim impact statements and the cultural project of punishment. Indiana Law Journal, 87.

Siltanen, J., \& Doucet, A. (2008). Gender relations in Canada: Intersectionality and beyond. Don Mills: Oxford University Press.

Singleton, V., \& Michael, M. (1993). Actor-networks and ambivalence: General practitioners in the UK cervical screening programme. Social Studies of Science, 23(2), 227-264.

Sinha, M. (2013). Measuring violence against women: Statistical trends. Ottawa, ON: Statistics Canada.

Smith, A. M. (2012). Victim impact statements: Past, present and a look to the future. Toronto: Thomson Reuters Canada Limited.

Stanbridge, K., \& Kenney, J. S. (2009). Emotions and the Campaign for Victims' Rights in Canada. Canadian Journal of Criminology and Criminal Justice/La Revue canadienne de criminologie et de justice pénale, 51(4), 473-509. doi: $10.3138 /$ cjccj.51.4.473

Star, S. L., \& Griesemer, J. R. (1989). Institutional ecology, "translations" and boundary objects: Amateurs and professionals in Berkeley's Museum of Vertebrate Zoology, 1907-1939. Social Studies of Science, 19, 387-420.

Strauss, A. (1993). Negotiation: Varieties, contexts, processes, and social order. San Francisco: Jossey-Bass.

Strauss, A. L. (1987). Qualitative analysis for social scientists. Cambridge, MA: Cambridge University Press.

Tonry, M., \& Coffee, J. C. (1992). Plea bargaining and enforcement of sentencing guidelines. In A. von Hirsch \& A. Ashworth (Eds.), Principled sentencing (pp. 308-322). Boston, MA: Northeastern University Press.

Usher, R., \& Edwards, R. (2007). Lifelong learning - signs, discourses, practices. Dordrecht, Netherlands: Springer.

van der Merwe, A., \& Skelton, A. (2014). Victims' mitigating views in sentencing decisions: A comparative analysis. Oxford Journal of Legal Studies. doi: 10.1093/ojls/gqu026

VanSickle-Ward, R. (2014). The devil is in the details: Understanding the causes of policy specificity and ambiguity. New York: Suny Press.

Verdun-Jones, S. N., \& Tijerino, A. A. (2002). Victim participation in the plea negotiation process in Canada: A review of the literature and four models of law reform. (rr20025e). Ottawa, ON: Department of Justice Canada.

Villmoare, E., \& Neto, V. V. (1987). Victim appearances at sentencing hearings under the California Victims' Bill of Rights - Final Report. Rockville, MD.

Walklate, S. (2011). Reframing criminal victimization: Finding a place for vulnerability and resilience. Theoretical Criminology, 15(2), 179-194. doi: $10.1177 / 1362480610383452$

Warrilow, L., \& McDonald, S. (2008). A Summary of Research into the Federal Victim Surcharge in New Brunswick and the Northwest Territories. Victims of Crime Research Digest, 1(1), 21-23. 
Wemmers, J. (2008). Victim participation and therapeutic jurisprudence. Victims and Offenders, 3, 165-191. doi: 10.1080/15564880801938318

Williams-Jones, B., \& Graham, J. (2003). Actor-Network Theory: a tool to support ethical analysis of commercial genetic testing. New Genetics and Society, 22(3), 271-296. doi: $10.1080 / 1463677032000147225$

Winner, L. (1980). Do artifacts have politics? Daedalus, 109(1), 121-136.

Young, A. N. (2001). The role of the victim in the criminal process: A literature review 1989-1999. Ottawa: Policy Centre for Victim Issues, Research and Statistics Division Retrieved from http://www.justice.gc.ca/eng/rp-pr/cjjp/victim/rr00_vic20/rr00_vic20.pdf. 


\title{
Chapter 7-Relational Caring: The Use of the Victim Impact Statement by Sexually Assaulted Women
}

\begin{abstract}
The victim impact statement (VIS) is a written account of harms experienced as a result of crime. This study investigates VIS use by sexually assaulted women through interviews with Canadian victims, victim services workers, and feminist advocates $(\mathrm{N}=35)$. Findings suggest that victims use the VIS to express relational caring. Relational caring is an ethic of care that prioritizes others through privileging the harms experienced by others because of witnessing the sexual assault or coping with the victim's post-sexual assault sequelae, protecting future or hypothetical victims, and promoting the interests of intimate partner offenders. Relational caring challenges traditional conceptions of victim agency and VIS use for instrumental purposes, as well as the targets and temporalities of sexual assault harms that are detailed in the statement. Relational caring has unique implications for victims who are mothers, especially those abused as minors, and for intimate partners. Legal, therapeutic, and social service consequences are discussed. ${ }^{1}$
\end{abstract}

The victim impact statement (VIS) as it is referred to in Canada and the United States is also known as the victim personal statement (VPS) in England and Wales (Erez \& Roberts, 2007). It is a victim's written account to the court of the physical, psychological, and financial harms experienced as a result of an act for which a defendant has been found or has pled guilty. Of all reforms initiated by the victims' rights movement, the VIS is considered the most significant (Bandes, 2009). It is simultaneously and contradictorily praised as a tool of voice and empowerment for victims and the proceduralizing of opportunity for their vengeance and continued helplessness (Sheley, 2012).

Despite increasing interest in the particularities of the VIS, most examinations include sexually assaulted women as only one of several groups under consideration (e.g., Erez \& Tontodonato, 1992; Lens, Pemberton, \& Bogaerts, 2013; Leverick, Chalmers, \& Duff, 2007).

\footnotetext{
${ }^{1}$ Miller, Karen-Lee (2014). Relational caring: The use of the victim impact statement by sexually assaulted women. Violence and Victims, 29(5), p. 797-813. doi: 10.1891/0886-6708.vv-d-13-00056
} 
Yet differently crimed victims' experiences may vary throughout the criminal justice system, which may influence VIS motivation and use (Konradi \& Burger, 2000). Only rarely has the VIS been examined exclusively in the context of sex crimes (Du Mont, Miller, \& White, 2008; Konradi \& Burger, 2000; Leichtentritt \& Davidson-Arad, 2002, 2006; Miller, 2013; Regehr \& Alaggia, 2006; Ruparelia, 2012; Walsh, 1986). Although important, these studies generally suffer from shortcomings that limit their usefulness in understanding the lived experiences of sexually assaulted women such as the focus on statements written by professionals for sexually abused boys and girls (Leichtentritt \& Davidson-Arad, 2002) or a failure to include empirical data to support their claims (Ruparelia, 2012).

Much remains unknown about the unique motivations, strategies, and experiences of sexually assaulted women who have completed a VIS. This article is designed to address these issues. It begins with a canvass of VIS research. It next discusses findings drawn from interviews with victims, victim services workers, and feminist advocates $(\mathrm{N}=35)$ across Canada. It concludes with a discussion of the broader social, legal, and therapeutic implications of an ethic of care, which prompts victims to use the VIS to prioritize the harms and the needs of others.

\section{The Victim Impact Statement}

In Canada, where this study took place, the 1988 introduction of the VIS represented the first mention of the word victim in the Criminal Code (Wemmers, 2005). Following conviction and before sentencing, a Canadian victim is eligible to submit a VIS. It must be completed by the victim on a specific form obtained only from a provincial or territorial victim services office, although others such as victim services workers or social workers may provide limited assistance in its preparation (Du Mont et al., 2008). Although procedures for VIS submission vary slightly across the country, typically a victim services officer will, following a finding of guilt, obtain a completed VIS from the victim and forward it to the prosecutor who then provides copies to the judge and defence attorney. At this point, the victim may be cross-examined on the content of the VIS or may be permitted to read it aloud during the sentencing hearing.

Judges in adult and youth courts are required to ask whether a victim has been advised of the opportunity to prepare a VIS and to consider it during deliberations where one 
has been submitted. A victim also has the legislated right to have the VIS considered during a review hearing for an offender considered not criminally responsible on account of mental disorder and at a parole hearing for an offender serving more than two years (Corrections and Conditional Release Act, S.C. 1992; Criminal Code R.S.C., 1985 c C-46). In principle, this is how the VIS should operate. In practice, the failure of sentencing courts to make the required inquiry does not affect the validity of the proceedings (Barrett, 2008), and contrary to law, judges do not always open or read victims' statements (Alberta Justice, 2006; Miller, 2013).

Submission rates for the VIS remain quite low across all crime types. Statements appear in approximately $10 \%$ to $23 \%$ of cases in Canada and between $15 \%$ and $30 \%$ internationally (Giliberti, 1990; Leverick et al., 2007; Roberts \& Edgar, 2006; Sanders, 1999). A VIS author is most often female, vulnerable, a victim of violent crime or personal injury, victimized at home, harmed by a known or male offender, or has had the case proceed to trial versus plea bargain (Cole, 2003; Erez \& Tontodonato, 1990; Lens et al., 2013; Meredith \& Paquette, 2001). Fewer victims choose to verbally present than to submit written VISs or attend sentencing (Cole, 2003; Konradi \& Burger, 2000). Those who read VISs aloud in court are most often White or hold higher occupational status (Konradi \& Burger, 2000; Villmoare \& Neto, 1987). Many victims expect the VIS to have an instrumental effect, that is, to influence the quantum and severity of the sentence (Erez, Roeger, \& O'Connell, 1996). However, no evidence exists to suggest systemic instrumental influence in Canada or internationally (Roberts, 2009). The disjuncture between instrumental beliefs and the reality of most case dispositions often causes victims considerable distress (Arrigo \& Williams, 2003; Roberts, 2009).

The use of the VIS at parole is infrequent in Canada (Parole Board of Canada, 2011) and the United States (Caplan, 2010). Many victims are uninformed they may do so (Kilpatrick et al., 1989). In Canada, sexual assault victims or families of murder victims are the most likely to submit a VIS for parole board consideration (Department of Justice Canada, 2013). Unlike the clear absence of instrumental impact at sentencing, research is mixed on whether the presence of a written or verbally delivered VIS delays release from prison (Caplan, 2010). 


\section{VIS and Sexual Assault}

The uniqueness of VISs written by women in the context of sex crimes has been suggested by the few published studies (Du Mont et al., 2008; Miller, 2013; Walsh, 1986) and reports of empirical findings (Du Mont, Forte, \& Miller, 2004; Du Mont \& Miller, 2004, 2007; Miller, 2005, 2007; Walberg-Hegan, 1997) that specifically focus on this victim population. Qualitative examinations of sexually assaulted women's broader participation in the criminal justice system (Konradi \& Burger, 2000; Regehr \& Alaggia, 2006) and some multi-crime VIS studies (Rogers \& Erez, 1999; Schuster \& Propen, 2006, 2010) also support this perspective.

Multiple authors have found that rape mythology — those highly codified and deeply embedded stereotypes of what may be deemed a "real rape" and who may be convincingly portrayed as a "real victim" (Du Mont, Miller, \& Myhr, 2003)—-has influenced to some degree how judges interpret or use the VIS. Rogers and Erez (1999) found judicial valuations of harms in Australia were dependent on whether the VIS author was "a prostitute compared to a respectable citizen" (p. 278) or whether her sexual assault was seen as particularly egregious such as in a "grannie rape" (p. 271). Similarly, an American study (Schuster \& Propen, 2006, 2010) found that judges continued to evaluate VISs against notions of victim "complicity" and blameworthiness. Victims who were sexually assaulted by men they were dating, or who had been drinking prior to the sexual assault, were considered less innocent of the sexual assault than those victimized by strangers. In Canada, Ruparelia (2012) argued the VIS is "more likely to be used to discredit women's claims than validate them when it comes to sexual assault” (p. 665). In another study (Du Mont \& Miller, 2007; Du Mont et al., 2008), the VIS-related guidance offered by Canadian sexual assault care social workers was influenced by concern with the justice system's continued acceptance of rape myths. Although social workers strongly believed that victims derived therapeutic benefits from narrating experiences of harm for court purposes, they were preoccupied with ensuring that victims did not submit angrily worded or overly detailed VISs, which might provoke judicial ire or cross-examination (Du Mont et al., 2008).

Feminists continue to be troubled by concerns that the potential risks of secondary trauma or legal jeopardy that VIS submission poses outweigh its possible therapeutic benefits (Du Mont \& Miller, 2007; Miller, 2005; Regehr \& Alaggia, 2006). Regehr and Alaggia 
(2006) cautioned that feminist therapists' recommendations to clients that the VIS is a possible conduit of emotional healing might be counterproductive because the legal system's primary consideration is with due process for offenders, not the needs of victims.

Nevertheless, despite negative experiences such as defence challenges to the crime details contained in the VIS, or distress upon learning that judges would not permit the VIS to be read aloud, sexually assaulted women indicated that they would still recommend the VIS to other victims (Miller, 2007).

Recently, Miller (2013) found that sexual assault victims were at risk of legal and emotional harm when their own statements were used against them in nonsentencing contexts. Several former intimate partner offenders submitted VISs prepared for trial court as a means of introducing in family court evidence of victims' psychological instability. Victims' evocative, narrative descriptions of post-sexual assault emotional sequelae prompted some family court judges to limit or revoke their custody rights. Nonetheless, Miller (2013) stopped short of cautioning against VIS use because victims also demonstrated success at leveraging their sentencing VISs in other proceedings, for example, at a human rights tribunal and in small claims court.

These studies are important first steps toward identifying the nature and extent of the uniqueness of the VIS in the context of sex crimes against women. Yet their rarity, combined with the methodological shortcomings of many of the studies, including datedness of findings (Walsh, 1986) or the absence of the perspectives of adult authors of the VIS (Du Mont et al., 2008; Leichtentritt \& Davidson-Arad, 2002; Walberg-Hegan, 1997), warrants further research.

\section{Methods}

Data were collected during an exploratory study (2006-2009) on the use of VISs written by women who had been sexually assaulted in Canada. For the purposes of this article, data were restricted to qualitative interviews conducted with 35 participants $(\mathrm{N}=35)$ : victims $(n=11)$, victim services workers $(n=20)$, and feminist advocates $(n=4)$. Audiotaped, semistructured interviews each lasted 60-90 minutes in length. Two victims completed two interviews after recontacting the researcher to provide further details. Participants also shared VISs, trial transcripts, and policy and practice manuals. 


\section{Recruitment}

The author's academic institution and two participating provincial government ministries responsible for victim services in Central and in Eastern Canada granted ethical and study approvals. Recruitment was guided by purposeful sampling (Patton, 1990) using criterion-based selection (Le Compte \& Preissle, 1993) which identified victims and victim services staff as among those most likely to have VIS experience, and by theoretical sampling (Glaser \& Strauss, 1967) which suggested that advocates could provide novel insight. Participants were required to communicate in fluent English. Victim inclusion criteria also included (a) adult woman, (b) sexually assaulted as a minor or adult, (c) VIS submission, and (d) case conclusion with neither ongoing nor pending appeal. Nonvictim inclusion criteria were (a) adult and experience either in (b) VIS support or (c) VIS policy, administration, or case law.

The author approached a national network of not-for-profit sexual assault crisis centres and two provincial ministries (Central Canada, Eastern Canada) responsible for victim services for assistance with the recruitment of victims. Citing policy directives and privacy laws, respectively, two declined. Only the Eastern Canada ministry agreed to assist, and after applying study inclusion criteria, identified and contacted 11 victims who agreed to the release of their information. Following researcher contact, 10 chose to participate in this study. One victim from Central Canada self-referred after she learned of the study through her colleague.

Both provincial ministries agreed to assist with staff recruitment. Managers advertised the study and forwarded the names of interested staff who fit study criteria. All those who expressed interest agreed to participate in the study (Eastern Canada, $n=11$; Central Canada, $n=9$ ). Four advocates in Western and Central Canada were recruited by the researcher through outreach to feminist organizations and snowball sampling (Warren, 2001).

All participants provided verbal informed consent. They were neither required to sign written consent forms nor provided with standard research disclosures, which could place interviews at risk of subpoena (Lowman \& Palys, 1999; Palys \& Lowman, 2000).

\section{Participants}

At interview, victims were $25-52$ years of age, with an average of 41 years. All were White. Eight victims experienced penetrative (oral, anal, and/or vaginal) assaults; three 
experienced nonpenetrative assaults (fondling, grabbing). In eight cases, victims knew their offenders: three were current or previous partners, three were fathers or men who acted in that role, one was related by marriage, and one was the victim's employer. Three offenders were strangers. In three cases, children or siblings of victims witnessed or were within hearing distance while the sexual assaults took place.

Six victims were assaulted as adults in 2002 or more recently, and one was assaulted in the mid-1980s. Four victims were assaulted as minors during the late 1960s or the 1970s. Victims assaulted as adults reported to the police immediately or up to one month after the assault. Victims assaulted as minors reported to police 24 to 31 years after the assault. The time between police reporting and trial conclusions ranged from 4 months to 1.5 years for victims assaulted as adults and from 1 year to 5 years for those assaulted as minors.

Ten offenders were convicted of sexual offences; one was convicted of nonsexual assault. VISs described post-sexual assault harms from the time of the assaults to the sentencing hearings. Six victims also read aloud their VISs. An additional three victims desired to allocute but were prevented by the judge or not apprised of the opportunity at the time. Three of four eligible VISs were subsequently submitted to the federal parole board.

Twenty victim services workers who provided VIS information and assistance were interviewed. Eastern Canada staff $(n=11)$ ranged in age from 31 to 60 years, with an average of 46 years; one was a man, and the others were women. Staff had worked in victim services from 2.5 to 15 years, with an average of 9 years. Central Canada staff $(n=9)$ ranged in age from 27 to 51 years, with an average of 37 years; all were women. Staff had worked in victim services from 1 to 10 years, with an average of 5 years.

Four feminist advocates were interviewed. Advocates provided VIS-associated legal advice or frontline counselling to victimized women including those who had been sexually assaulted and those who had come in conflict with the law. All were women ranging from 48 to 61 years of age; one woman declined to provide the information. Employment in current position ranged from 2 months to 34 years.

\section{Analyses}

Verbatim transcribed interviews were analyzed inductively to focus on VIS-related conditions, interactions among actors, strategies and tactics, and consequences (Strauss, 1987). Using a qualitative analysis software (QSR International Pty Ltd., Doncaster, 
Australia), preliminary codes were developed and applied, which were later condensed, investigated for interrelationships, and organized according to thematic content moving from lower-order to higher-order themes. For example, examination of victims' decision-making processes involving the details of VIS narratives revealed motivation aspects, which went beyond documenting personally experienced harms. These motivation aspects were next examined vis-à-vis interactions with others to reveal deliberate strategies including the protection of others and tactics such as information embeddedness. From the intersections among multiple practices, strategies, and consequences, an overarching ethic of care associated with VIS content, submission, and presentation was identified. This ethic of care was termed "relational caring" because it prioritized concern for others in a manner suggestive of protectiveness, care, and commitment, irrespective of whether the other individual was kin, stranger, or hypothetical.

\section{Findings}

Participants are identified by their roles as victim (V), victim services worker (VSW), and advocate (A). Findings are drawn predominantly from interviews, with supporting evidence drawn from VISs where noted.

\section{Relational Caring}

Victim participants consistently demonstrated a strong moral sense of responsibility for the safety and emotional well-being of others and a desire to protect them from physical, psychological, or other harms. This behavior was also noted by advocates and victim services staff to occur among victims to whom they provided advice or assistance.

Relational caring was enacted through the VIS in three distinct ways: (a) at sentencing, by privileging or prioritizing the harms experienced by others as a result of witnessing the sexual assault and/or of coping with women's post-sexual assault sequelae; (b) at sentencing and parole, by protecting other women/future victims through VIS submission and verbal delivery; and (c) at sentencing, by promoting the interests of the intimate partner offender. Each of these components is individually discussed in the following texts. 
Privileging harms experienced by others. An intrinsic component of relational caring was victims' privileging or prioritizing the harms experienced by others as a direct consequence of the sexual assault or of coping with victims' negative responses. Victims considered the individual and unique harms experienced by others to be an important consideration, which the court should hear. In the following example, a victim describes how she wanted the court to know that her post-sexual assault reactions, including coming in conflict with the law as a juvenile, were experienced as significant emotional harms by her loved ones:

I wanted to write about how [multiple sexual assaults] affected not just me but the rest of my family. You know, by the time I was 13, I was running away from home. I was sent to [another province] to live with an uncle for a while. I was in a reformatory for a while. . . . It put strain on my whole family. . . . It's a domino effect. [Sexual assault] doesn't just stop with you; it affects others. (V)

Women who were mothers at the time of their sexual assaults were particularly concerned about articulating the negative post-sexual assault sequelae experienced by their children:

How did I want my life portrayed [in the VIS] as a result of this assault? ... Like it affected me, but when I come home and cry in front of my kids, it affects my kids 'cause they see me upset. I can't explain to them what happened. At this age, they don't understand. (V)

Women who had been assaulted as children or adolescents reflected that despite the long lapse of time between the sexual assault and their roles as mothers, their children often bore the brunt of post-sexual assault sequelae. One victim suggested that the full ramifications of the sexual assault were only evident after she became a mother, and constituted ongoing harm to her relationship with her son:

To actually say [in the VIS], how [sexual assault] impacted my life would be much harder to write when you're young. Because for me, back then, it only affected that day, that couple of years. School was terrible, my grades were terrible ... but that was just little stuff . . Until you enter certain life experiences, you don't know how the rape affected you. ... When you have your first child, it all comes up again ... Then, when [son] started 
going through puberty, I was different towards him. If he walked around with his top off at [age] 13, which is so innocent, just to walk from the bedroom to the kitchen, it would really bother me ... I was moody with him. (V)

All victim participants felt stymied by the rules explained to them by victim services staff regarding permissible VIS content at sentencing. These rules were adapted from policy directives derived from Canadian case law on the VIS (Roberts, 2009). They prohibited recommendations on sentence, pejorative or prejudicial commentary, and inclusion of details pertaining to crimes for which the defendant had not been found guilty. Several victims also believed that the rules restricted commentary to their own experiences and would not permit any mention of the harms experienced by their children as a result of victims' reactions:

[The VIS] is just how it impacts on you [emphasis added], which limits what you want to say. I found it really hard to put how it impacted [on] my family . . . but [assault] was stressful for [daughters] because they thought their mother was going to go bananas [crazy] afterwards. (V)

Victims dealt with their desire to include the effects on children by overtly or covertly embedding this information in their VISs. Some emphasized in their VIS the additional emotion work (Kontos, Miller, Colantonio, \& Cott, 2014) or mothering work required to manage children distressed by news of the sexual assault. One victim wrote,

My daughters had to be told what occurred by phone. I had to find a way to be strong for them so that they wouldn't get too upset. This has been really hard on them ... they feel angry and hurt, that he could have injured their Mother in such a manner. I'm trying to help them work out their emotions, but it is very hard to do when I haven't worked out mine yet. (VIS)

Others described the negative effects experienced by their families vis-à-vis victims' social roles as wives and mothers:

Through each new developmental stage, such as wife, mother, empty nest syndrome ... I would again experience the impact of not having dealt with the rape and its destructiveness. (VIS) 
Some mothers felt forced to leave out mention altogether of children, often to lingering regret:

I was led to believe that a [VIS] is, like, what impact it had on me and how I felt because I was the victim, not [toddler] . . Because he was there [witnessed the assault], I was more concerned with him than I was with myself. I would have liked to have said more [in the VIS] about how it would impact my little one later on. But I was told [the VIS] is how I felt. So, what I wrote is mostly about me . . . But I think [the VIS] would have served a better purpose if he had had more part in it. (V)

Protecting other women/future victims. The protection of other women and future victims was a strong impetus for the written and verbal presentation of the VIS for most of the victims in this study as well as for many other victims as described by advocates and victim services workers. An advocate noted,

Sometimes, women pressure themselves to complete a statement because they feel they hadn't taken action during the process of their violation. And this is the way to fill that gap because they didn't fight back at the time ... [Victims say] "I need [emphasis added] to do this for other women." (A)

Victims' protective practices toward others were perceived by victims and by victim services workers to originate from an essential nurturing female nature:

I just seen [the VIS] as something I needed to do. I had to do it. It was my responsibility as a woman to make sure that other women are safe. That's how I seen it. And being a mother and protecting my daughters, this was a way I could help and protect other people's daughters. (V)

For women who have female children, they write [the VIS] for them, I find. (VSW) For many victims, the effectiveness of the VIS in facilitating their desire for the safety of others was linked to an instrumental understanding of the VIS. Participants reported that many victims believed that the VIS had an overall positive causal effect on imprisonment at 
the sentencing stage and that longer periods of incarceration would enable stronger protection for loved ones or potential victims. A victim commented,

[Offender] wouldn't have served time. He would have got a slap on the wrist and got away with it so that's why I made the [VIS]. To make sure he never touches a neighbour's kid or another child again, especially my sister. (V)

Several victims erroneously believed that the instructions which accompanied the VIS form specifically called for them to consider the needs of other or future victims. One victim used belief in this directive to help guide her VIS decision-making:

It took me a long time to get my head around whether or not I wanted to [complete a VIS]. I didn't want to 'cause I'm a private person, and I was fine [after the sexual assault] . . . But I kept thinking, well, if not for yourself, is it good for anybody else? And the [the VIS] instructions did say that. The [instruction] form said, you know, "If this doesn't benefit you, it may benefit other people." I knew that in the back of my mind. So in the end, I did [the VIS] because I thought if it helps to keep him behind bars, or get him there, then I'll do it . . You know, you've got to do what you've got to do. (V)

The responsibility of protecting others through use of the VIS was also extended to those who might be harmed or slighted professionally by the comments it contained. One victim edited her VIS to protect the police officers involved in the investigation:

What I did do [in the VIS], in addition to the [physical, psychological, and social] areas, I did write an extra piece ... which went into some details about my experience of the police investigation, which I couldn't separate from what happened to me ... Shortly before I was supposed to [verbally] deliver it, the [prosecutor] and one of the investigating officers took me aside ... [They] did convince me to alter my VIS and to take [criticism of police] out. They said if I went ahead and said that, that would become the focus in the media, and all the good work they'd done would be for nothing ... And I caved. (V) 
When evaluating how the VIS might best assist in the protection of others, victims often believed it crucial that they read it aloud in open court. Verbal presentation of the VIS meant that the attending public could hear their accounts of harm. Furthermore, these details could be then reported by the local media, which would widen the cast of the VIS's protective net in terms of potentially protecting others who might be at risk once the offender returned to the community:

To me [the VIS] was one of the key things to get things done. Yeah, 'cause it tells it like it was. [My sister and I] wanted to make sure everybody knew that this happened to us, and he's, you know, possible to do this to somebody else. So we wanted to prevent that from happening. We thought by reading [the VIS] in court, it was going to make a bigger difference to the community. (V)

Victims received positive reinforcement of their beliefs that reading aloud the VIS was an effective means of promoting the well-being and safety of other victims. In smaller communities, sentencing hearings were often well attended by local residents. Attendees frequently approached victims afterward to commend them for their bravery and to comment that the VIS represented an important community service:

One of my math teachers was at [verbal presentation of the VIS] and I said, "Thank you Mr. [X] for coming." And then he said, "No, no, no. Don't you thank me. We're going to thank you because you brought this up. And now it's going to help the community for other people to come forward. The same thing is probably happening to them." (V) Two victims, whose VISs were either read aloud by them or repeated in part by judges and subsequently quoted verbatim or summarized in local newspapers, believed that they had direct evidence of the helpfulness of their VISs for other victims. They believed that the media attention focused on their VISs, in particular their descriptions of lifelong self-blame for the abuse and how emotionally liberated they felt following conviction, had or were about to influence other victims to come forward:

From what I heard from someone else, another victim did [report sexual assault to police] after they heard my [VIS]. I'm going to help womenand I have-by doing this. (V) 
Just to see the [newspaper] article and to see it separate from the court news and in larger headings so that it was more noticeable. I thought, there, now the people in the area know. They know who he is, and they know what he's done. There's no hiding it any more. That made me feel really good because I do believe there are other kids around here that he has molested ... Also, the [relative of a suspected victim] . . came to me and said she knows that something has to be said about him, and I don't think it's going to take too much longer before she says something [to police]. (V)

Relational caring was also implicated in decisions regarding VIS submission at parole hearings. At the parole stage, victims were crucially concerned with the safety of loved ones or of future or hypothetical victims. One victim explained that her fearfulness over her family's safety prompted her to forward her VIS to the parole board:

It's different if you're with a boyfriend and you break up and he assaults you and says, "Bang, I'm going to kill you." Well, okay, this is your mistake and your damage, and if he kills me, he kills me. But when he says he's going to kill your mother? And you know he means it? And he's capable of it? Well, then you think again, why should she have to die for my mistakes? So then, you've got to do what you can do. (V)

Relational caring was also involved in an evaluation of the risk to others should victims decline to submit a VIS to parole authorities. In the following exchange, an advocate justified her advice on the implications of not submitting a VIS given the victim's protectiveness toward possible future victims:

[Victim] did want to see if there was any use in her being involved in the parole board [VIS] process in terms of protecting herself and other women whom her former partner might be a potential threat to in the future. She wanted some advice on what she should say, or whether she should even do [a VIS] . . . In my experience ... the offender is evaluated by different standards than if there was no [VIS] submitted. I advised her, if she was truly concerned about him being a threat to other people besides her, that 
by not making a [VIS] that she needed to think about whether that would have an impact as well. (A)

Promoting the intimate partner offender. In this study, three victims were sexually assaulted by current or previous common law partners. Although none chose to deploy the VIS to promote and protect the interests of offenders, this practice was often described by victim services staff and advocates. Nonvictim participants commented on the frequency with which victims of sexual assault by husbands or boyfriends frequently undertook the VIS to publicize the offender's good character or to minimize the harms they experienced during and after the assault. The use of the VIS to promote the interests of intimate partner offenders often stemmed from victims' self-blame for their sexual assaults:

Victims feel that if they provided a [VIS] that accurately detailed the effects of the crime, it would be used as an excuse to put or keep [their partners] in jail. Women don't want to take that responsibility because they feel that somehow they have a partial responsibility for what happened. It's some of that whole notion of "blame the victim." (A) Victim services workers noted that victims who were hoping that the VIS could assist their intimate partners were typically upfront with their intentions. Victims often requested information from victim services on how to better achieve this end:

I have had victims [of intimate partner sexual assault] where they are hoping that the [VIS] will lessen his sentence by telling the judge things to minimize the emotional impact. They actually will say that right out, you know. When I tell them, "You have a right to do a [VIS]," they'll say, "Will that help him? ... If I put this in, will that help him so he won't get as much jail?" (VSW)

Victims have said to me that, "I would like to talk [in the VIS] about what sentence he gets because I didn't want this charge to proceed," or "I did want him charged at first but now we're working on our relationship and [jail] is going to harm his employment." . . Usually at that point, there is communication between them and the defence lawyer. (VSW) 
Advocates and victim services workers understood that victims often had valid, complex, and multiple reasons for using the VIS to promote or to protect the offender:

They don't want him to go to jail. Why? Because they love him. Because they're afraid of him. Because he's their paycheque. Because a jail sentence means he would be deported. Very good reasons. (A)

[Victim is] feeling responsible for her baby. Because if [offender] is deported, then he's not here. [Baby is] not going to be able to see who dad is, even though he's an abuser. (A)

Despite this broader contextual understanding, however, most victim services staff experienced discomfort regarding victims leveraging of the VIS to persuade the courts to be lenient toward abusive current or former intimate partners. This discomfort appeared most often resolved through the exclusive focus on their clients' status as victims:

The purpose of the [VIS] is not to get him a lighter sentence. But she's the victim and she has a right to do what she needs to do. I didn't walk in her shoes. Really, I don't like to see it used that way. But if somehow in her mind that helps, then it's still about her. (VSW)

\section{Discussion}

Relational caring is an orientation toward the care and protection of others, which is not dependent on kinship or familiarity, and may include hypothetical or future others. It is enacted at multiple decision points related to the written and verbal submission of the VIS at sentencing and parole. Relational caring is a novel finding unique to VIS research. This study is the first to identify an externally focused care orientation as overwhelmingly guiding victims' motivations for, and constructions of, the VIS.

Relational caring conceptually bridges understandings of sexually assaulted victims' decision-making practices concerning the VIS with those involving other stages of their justice system involvement or other forms of post-sexual assault participation. Concerns regarding the safety of others have been identified as one of several reasons women choose to report a sexual assault (Hattem, 2000) and as sometimes informing their negotiations with prosecutors regarding plea arrangements (Konradi, 2007). In one study, more than a third of 
victims justified their involvement in sexual assault research by citing a desire to help other victims (Ahrens \& Campbell, 2000). During such activities, acts of caring for others provided the means for some women to resolve the emotional impact of the rape event (Konradi, 2010). Victims reported personal or therapeutic benefits even when they experienced negative emotional reactions arising from various forms of rape crime narration (Edwards, Kearns, Calhoun, \& Gidycz, 2009; Miller, 2007).

In this study, however, a difference was detected in terms of the degree to which care for others provided the impetus for decision-making. It is argued here that the similarities between victims' concerns regarding impacts on loved ones, as well as their focus on the interests of intimate partner offenders and the needs of hypothetical victims, reveal an overarching ethic of care that guided VIS submission and content. It is possible that this broader ethic of care has, to date, been compartmentalized by researchers into discrete activities by sexually assaulted women at other moments of criminal justice involvement, which has obscured its coherence. Or it may be that there is something fundamentally unique to the type of participation that the VIS invites that prompts sexual assault victims to overwhelmingly think of others during its undertaking. This is an important analytical distinction that requires further investigation.

Relational caring was first evinced in victims' privileging of the harms experienced by others as a direct consequence of witnessing the sexual assault or of secondarily responding to victims" post-sexual assault sequelae or coping mechanisms such as "go[ing] bananas," hard weeping in front of small children, or coming in conflict with the law. Such privileging effectively enabled women to broaden the definition of who may be considered a victim in relation to the consequences of assault. This is an important integrative strategy that belies a common misperception that the effects of sexual assault are of an intimate personal nature and do not inflict harm on others in the community (Ahrens \& Campbell, 2000). Furthermore, victims with a lengthy passage of time between the assaults committed against them as minors and the writing of their VISs as adults were able to broaden the definition of secondary harms. They included, even if sometimes covertly, the harms experienced by their own children. In so doing, they articulated a belief in a complex temporal link between the original sexual assault and their children's suffering, as well as additionally defined this as a contemporary source of their own distress. Until now, temporality has not been examined as 
an important feature influencing VIS details or the manner through which sexual assault harms are construed in relation to secondary victims. This identifies an important area for future investigation by VIS scholars.

Privileging the harms of others may also have other benefits. It may, for example, be an effective strategy for communicating with judges and gaining their approval. Schuster and Propen (2006) noted that judges were more "impressed" with VISs from sexual assault victims who were able to demonstrate that they could "think beyond the personal effects of crime" (p. 13). Certainly, victims in this study worded their VISs in anticipation of the potential for broader social significance through presentations in open court and subsequent reporting by local media. In turn, they also derived personal therapeutic benefit from the positive responses of community members, which included praise as well as indications of other victims coming forward.

Some victims erroneously believed the instructions on the VIS form suggested that they consider others' well-being when deciding to complete a VIS. Although this finding differs from the common emphasis on the link between unclear instructions and inappropriate VIS commentary found in other studies (see for example Roberts, 2009), it does confirm that victim input is shaped by what they believe is required to comply with authorities. Victims struggled with whether or how to include their children's or families' harms given their interpretations of instructions. Elsewhere, information processing and cognitive impairment have been highlighted as concerns when working with traumatized women (McDonald, 2000, 2010). Together, these results highlight the importance of systemic improvements in print and verbal instructions on the VIS.

Relational caring was also expressed as desire to exploit the VIS's presumed instrumental potential to protect loved ones or future victims. Viewed this way, relational caring inverts traditional understandings of victims' engagement in instrumentalism as an expression of vengefulness (Arrigo \& Williams, 2003). Instead, the attempt to use the VIS to ensure that others are protected through harsher sentences is an act of caring and often a brave and desperate one. Moreover, despite the general pattern of an absence of effect, victims may be correct in keeping alive hopes that the VIS will influence outcomes. In isolated instances, it has (Cassell \& Erez, 2011; Cole, 2003). 
The protection of future victims through the use of the VIS at parole is suggestive of an integral preemptive aspect of relational caring. That is, it incorporates an ongoing subjective assessment of risk. For criminologists such as Roberts (2009), however, the change from using the VIS to catalogue harms at sentencing to presenting it before authorities who assess risk of re-offence is without merit because "there is no expressive function being served" (p. 384). Expressiveness is believed to occur when the victim expresses her perspective about the effects of the crime to the sentencing judge and offender (Roberts \& Erez, 2010). However, this fails to recognize relational caring, in which the victim's object of VIS expression and communication concerns the ongoing protection of a vulnerable or at-risk other. It may be unrealistic, moreover, to expect victims who have expressed relational caring at other points of VIS involvement to simply cease at paroleparticularly when some evidence of instrumentality exists (Caplan, 2010).

Several respondents suggested that the care impetus underpinning victims' approach to the VIS arises from an essential female nature. Certainly, feminist theory has grappled with the problematic of gendered moral development and caring (Gilligan, 1982; Noddings, 1984); engaging further in this debate is beyond the scope of this article. Nevertheless, given the clear evidence identified here of relational caring, it behooves frontline service providers and justice personnel to ensure that victims are advised on how best to protect their own legal and social interests as they engage in activities designed to support and assist others. This is particularly crucial for those using the VIS to protect intimate partner offenders.

Sexual assault within the context of current or previous intimate relations adds a layer of complexity to our understanding of the VIS (Schuster \& Propen, 2006). This is acutely so in the cases of women who have chosen not to leave their abusers, because as Langstraat (2006) notes, they “do not 'fit' the category of innocence” (p. 272) often required of VIS narrators to be perceived as credible. Here, victim services staff and advocates actively mitigated against presumptions of victims" "false consciousness" or internalized oppression as abused women (Littleton, 1989). Instead, they perceived a range of valid reasons why victims would use the VIS to protect their partners. Although this is suggestive of progressive change, ambivalence best described their acceptance of the practice. Staff often relied on notions of women as victims within a consumerist discourse that accords them satisfaction of a range of rights (Dubber, 2002). Yet, the failure to view victims as agential 
decision-makers capable of seizing an opportunity to wield the VIS as a legal tool in a manner not envisioned by policymakers or frontline staff may lead to the further disempowerment of assaulted women. This is an important and contentious issue for further examination by those who provide services to victims.

The use of the VIS to leverage leniency has been noted elsewhere. Leverick et al. (2007) found that some victims used the VIS to indicate an absence of impact, whereas others expressed positive views or concern for the accused. In one study, similar tactics were found to be effective because the VIS led to greater leniency in compliance with victims' wishes (Erez \& Roeger, 1995). Canadian courts have signalled willingness, under certain circumstances, to consider probation or house arrest when informed through the VIS that incarcerating the offender would cause undue hardship to the victim (Roberts, 2009) or when the sexually assaulted partner victim wishes it (Balfour \& Du Mont, 2012). Thus, it may be hypothesized that the courts are fueling the paradox of the use of the VIS to encourage the punishment, as well as the protection, of intimate offenders.

Although protection of intimate partners through the VIS was a dominant theme in staff and advocate interviews, victims did not raise it. It is possible that this is a consequence of recruitment method. Because victim services managers selected almost all victims, they may have shared their staff's ambivalence surrounding the practice of using the VIS to support offending intimate partners and chose not to include such victims. Another possible interpretation is that the victims in this study who were sexually assaulted by current or former intimate partners suffered such egregious assaults (i.e., weapon use, drug facilitation, presence of children) that the protection of others became paramount. This deserves further study, particularly given the paucity of research on intimate partner sexual assault (DeKeseredy, 2007).

Relational caring challenges the ongoing perception that the victims of violent crime, and sexual violence victims in particular, are more likely to use the VIS to "heap abuse upon the defendant or (utter) a wish for severe punishment" (Lens et al., 2013, p. 492) because of feelings of hostility, revenge, and retaliation. Such conceptions tiredly recycle stereotypes regarding the general nature of sexual assault complainants, which legislative and victims' rights reforms have failed, to date, to remediate (Barrett, 2008; Shaffer, 2012). At the same time, however, caution must be sounded against interpreting relational caring vis-à-vis the 
criminal justice system's tendency to insist on, or efforts of well-intended advocates and victim services staff to assist with, the portrayal of sexual assault victims as "nice, good victims," in VIS narratives (Du Mont et al., 2008, p. 11). Although relational caring is an ethic of care in which the concern for and responsibility of others is prioritized and enacted through the VIS, it is not a passive approach. Consequently, it should be recognized for the ways in which it enables novel, strategic outcomes, which challenge traditional conceptions of victim agency, and presumptions regarding the targets and temporalities of the harms of sexual assault.

\section{Acknowledgements}

Support was received from the Frederick Banting and Charles Best Canada Graduate Scholarship of the Canadian Institutes of Health Research, and the Policy Centre for Victim Issues, Department of Justice Canada. The views expressed do not necessarily reflect those of supporters or funders. I am grateful to the victims who so generously shared their experiences. Victim services workers and advocates prioritized interviews in spite of heavy caseloads; thank you. Janice Du Mont, Susan McDonald, Ruth Croxford, Pia Kontos, and the anonymous reviewers provided insightful comments. This work is a component of my doctoral dissertation at the University of Toronto.

\section{References}

Ahrens, C. E., \& Campbell, R. (2000). Assisting rape victims as they recover from rape: The impact on friends. Journal of Interpersonal Violence, 15(9), 959-986. http://dx.doi.org/ $10.1177 / 088626000015009004$

Alberta Justice. (2006). Court services statistics for victim impact statements filed with the court but not considered. Edmonton, AB: Alberta Justice, Solicitor General.

Arrigo, B. A., \& Williams, C. R. (2003). Victim vices, victim voices, and impact statements: On the place of emotion and the role of restorative justice in capital sentencing. Crime \& Delinquency, 49(4), 603-626. http://dx.doi.org/10.1177/0011128703252408

Balfour, G., \& Du Mont, J. (2012). Confronting restorative justice in neo-liberal times: Legal and rape narratives in conditional sentencing. In E. Sheehy (Ed.), Sexual assault in Canada: Law, legal practice, and women's activism (pp. 701-724). Ottawa, ON: University of Ottawa Press.

Bandes, S. (2009). Victims, "closure," and the sociology of emotion. Law \& Contemporary Problems, 72(1), 2-25. 
Barrett, J. (2008). Expanding victims' rights in the Charter era and beyond. Supreme Court Law Review, 40, 627-653.

Caplan, J. M. (2010). Parole release decisions: Impact of victim input on a representative sample of inmates. Journal of Criminal Justice, 38(3), 291-300. http://dx.doi.org/10.1016/j.jcrimjus.2010.02.012

Cassell, P. G., \& Erez, E. (2011). Victim impact statements and ancillary harm: The American perspective. Canadian Criminal Law Review, 15(2), 149-196.

Cole, M. A. (2003). Perceptions of the use of victim impact statements in Canada: A survey of Crown counsel in Ontario (Unpublished master's thesis). University of Ottawa, Ottawa.

Corrections and Conditional Release Act, S.C. 1992. c. 20.

Criminal Code, R.S.C. 1985, c. C-46, s. 722.

DeKeseredy, W. (2007). Sexual assault during and after separation/divorce: An exploratory study. Washington, DC: National Institute of Justice.

Department of Justice Canada. (2013). Use of victim impact statements at sentencing and parole. Retrieved from http://www.victimsweek.gc.ca/res/r58.html

Du Mont, J., Forte, T., \& Miller, K.-L. (2004, November). Evaluating the use and usefulness of victim impact statements in sexual assault cases. Paper presented at the Intimate Partner Violence: Effective Interventions, the 132nd Annual Meeting of the American Public Health Association, Washington, DC. Retrieved from https://apha.confex.com/apha/132am/techpro-gram/paper_89668.htm

Du Mont, J., \& Miller, K.-L. (2004, April). Victim impact statements in the context of sexual assault: Narratives of empowerment or entrapment? Some preliminary findings. Paper presented at the 2004 International Research \& Action Conference: Innovations in Understanding Violence Against Women, Wellesley, MA.

Du Mont, J., \& Miller, K.-L. (2007). Victim impact statements: Do they help, hinder or harm? Preliminary findings on the views of social workers who work with women who have been sexually assaulted. In L. Elit \& J. C. Froese (Eds.), Women's health in the majority world: Issues and initiatives (p. 217). New York, NY: Nova Science.

Du Mont, J., Miller, K.-L., \& Myhr, T. L. (2003). The role of "real rape" and "real victim" stereotypes in the police reporting practices of sexually assaulted women. Violence Against Women, 9(4), 466-486. http://dx.doi.org/10.1177/1077801202250960

Du Mont, J., Miller, K.-L., \& White, D. (2008). Social workers' perspectives on the victim impact statements in cases of sexual assault in Canada. Women \& Criminal Justice, 18(3), 1-23. http:// dx.doi.org/10.1300/J012v18n03_01

Dubber, M. (2002). Victims in the war on crime: The use and abuse of victims' rights. New York: New York University Press.

Edwards, K. M., Kearns, M. C., Calhoun, K. S., \& Gidycz, C. A. (2009). College women's reactions to sexual assault research participation: Is it distressing? Psychology of Women Quarterly, 33, 225-234. http://dx.doi.org/10.1037/a0034339

Erez, E., \& Roberts, J. (2007). Victim participation in the criminal justice system. In R. C. Davies, A. J. Lurigio, \& S. Herman (Eds.), Victims of crime (pp. 277-297). Los Angeles, CA: Sage.

Erez, E., \& Roeger, L. (1995). The effect of victim impact statements on sentencing patterns and outcomes: The Australian experience. Journal of Criminal Justice, 23(4), 363-375. 
Erez, E., Roeger, L., \& O’Connell, M. (1996). Victim impact statements in South Australia. In C. Sumner, M. Israel, M. O’Connell, \& R. Sarre (Eds.), International victimology: Selected papers from the 8th International Symposium on Victimology (pp. 205-216). Canberra, Australia: Australian Institute of Criminology.

Erez, E., \& Tontodonato, P. (1990). The effect of victim participation in sentencing on sentence outcomes. Criminology, 28, 451-474. http://dx.doi.org/10.1111/j.17459125.1990.tb01334.x

Erez, E., \& Tontodonato, P. (1992). Victim participation in sentencing and satisfaction with justice. Justice Quarterly, 9(3), 393-418.

Giliberti, C. (1990). Victim impact statements in Canada. Volume 7. A summary of the findings (WD 1990-11a). Ottawa: Department of Justice Canada.

Gilligan, C. (1982). In a different voice: Psychological theory and women's development. Cambridge, MA: Harvard University Press.

Glaser, B., \& Strauss, A. (1967). The discovery of grounded theory: Strategies for qualitative research. Chicago, IL: Aldine.

Hattem, T. (2000). Survey of sex assault survivors. Ottawa, Canada: Department of Justice Canada.

Kilpatrick, D. G., Tidwell, R. P., Walker, E., Resnick, H. S., Saunders, B. E., Paduhovich, J., \& Lipovsky, J. A. (1989). Victims' rights and services in South Carolina: The dream, the law, the reality. Final report. Charleston, SC: Crime Victims Research and Treatment Center, Medical University of South Carolina.

Konradi, A. (2007). Taking the stand: Rape survivors and the prosecution of rapists. Westport, CT: Greenwood Press.

Konradi, A. (2010). Creating victim-centred criminal justice practices for rape prosecution. In S. L. Burns \& M. Peyrot (Eds.), New approaches to social problems treatment research in social problems and public policy (pp. 43-73). Bingley, UK: Emerald Group.

Konradi, A., \& Burger, T. (2000). Having the last word: An examination of rape survivors' participation in sentencing. Violence Against Women, 6(4), 351-395. http://dx.doi.org/101177/10778010022181895

Kontos, P., Miller, K.-L., Colantonio, A., \& Cott, C. (2014). Grief, anger, and relationality: The impact of a research-based theater intervention on emotion work practices in brain injury rehabilitation. Evaluation Review, 38(1), 29-67. http://dx.doi.org/10.1177/0193841X14531260

Langstraat, L. (2006). Emotion and community rhetorics: Victim impact statements as cultural pedagogy. Mahwah, NJ: Lawrence Erlbaum Associates.

Le Compte, M. D., \& Preissle, J. (1993). Ethnographic and qualitative design in educational research. San Diego, CA: San Diego Academic Press.

Leichtentritt, R. D., \& Davidson-Arad, B. (2002). Construction of the victim impact statement for sexually abused minors: A dramaturgy approach. British Journal of Social Work, 32(8), 1067-1087.

Leichtentritt, R. D., \& Davidson-Arad, B. (2006). The impact of sexual abuse as portrayed by Israeli social workers through the victim impact statement. Families in Society, 87(1), 123-132. http:// dx.doi.org/10.1606/1044-3894.3492 
Lens, K. M. E., Pemberton, A., \& Bogaerts, S. (2013). Heterogeneity in victim participation: A new perspective on delivering a victim impact statement. European Journal of Criminology, 10(4), 479-495. http://dx.doi.org/10.1177/1477370812469859

Leverick, F., Chalmers, J., \& Duff, P. (2007). An evaluation of the pilot victim statements schemes in Scotland. Aberdeen, SC: University of Aberdeen Law School.

Littleton, C. A. (1989). Women's experience and the problem of transition: Perspectives on male battering of women. University of Chicago Legal Forum, 23, 23-57.

Lowman, J., \& Palys, T. (1999). Going the distance: Lessons for researchers from jurisprudence on privilege. A third submission to the SFU Research Ethics Policy Revision Task Force. Burnaby, BC: Simon Fraser University.

McDonald, S. (2000). The right to know: Women, ethnicity, violence and learning about the law (Unpublished doctoral dissertation). Ontario Institute for Studies in Education of the University of Toronto.

McDonald, S. (2010). "Explain, please!” Working with victims and restitution. Victims of Crime Research Digest, 3, 9-14.

Meredith, C., \& Paquette, C. (2001). Summary report on victim impact statement focus groups. Ottawa, Canada: Department of Justice Canada.

Miller, K.-L. (2005, February). The victim impact statement and therapeutic jurisprudence: Implications for women who have been sexually assaulted. Paper presented at the Western Society of Criminology 32nd Annual Conference, Honolulu, HI.

Miller, K.-L. (2007). Empowering victims: The use of the victim impact statement in the case of sexual assault in Nova Scotia. The perspectives of victims and victim services staff. Ottawa, ON: Department of Justice.

Miller, K.-L. (2013). Purposing and repurposing harms: The victim impact statement and sexual assault. Qualitative Health Research, 23(11), 1445-1458. http://dx.doi.org/10.1177/1049732313507753

Noddings, N. (1984). Caring: A feminist approach to ethics and moral education. Los Angeles, CA: University of California Press.

Palys, T., \& Lowman, J. (2000). Ethical and legal strategies for protecting confidential research information. Canadian Journal of Law and Society, 15(1), 39-80.

Parole Board of Canada. (2011). PBC QuickStats: Parole, pardons and clemency. Retrieved from http://pbc-clcc.gc.ca/infocntr/factsh/parole_stats-eng.shtml\#10

Patton, M. Q. (1990). Qualitative evaluation and research methods. Newbury Park, CA: Sage.

QSR International Pty Ltd. (2006). NVivo qualitative data analysis software, Version 7. Doncaster, Australia: Author.

Regehr, C., \& Alaggia, R. (2006). Perspectives of justice for victims of sexual violence. Victims \& Offenders, 1(1), 33-46. http://dx.doi.org/10.1080/15564880500498721

Roberts, J. (2009). Listening to the crime victim: Evaluating victim input at sentencing and parole. In M. Tonry (Ed.), Crime and justice: A review of research (pp. 347-412). Chicago, IL: University of Chicago Press.

Roberts, J., \& Edgar, A. (2006). Victim impact statements at sentencing: Judicial experiences and perceptions. A survey of three jurisdictions. Ottawa, ON: Department of Justice Canada. 
Roberts, J., \& Erez, E. (2010). Communication at sentencing: The expressive function of victim impact statements. In A. Bottoms \& J. V. Roberts (Eds.), Hearing the victim: Adversarial justice, crime victims and the state (pp. 232-254). Devon, UK: Willan.

Rogers, L., \& Erez, E. (1999). The contextuality of objectivity in sentencing among legal professionals in South Australia. International Journal of Sociology, 27, 267-286. http://dx.doi.org/10.1006/ijsl.1999.0092

Ruparelia, R. (2012). All that glitters is not gold: The false promise of victim impact statements. In E. A. Sheehy (Ed.), Sexual assault in Canada: Law, legal practice and women's activism (pp. 665-700). Ottawa, ON: University of Ottawa Press.

Sanders, A. (1999). Taking account of victims in the criminal justice system: A review of the literature. Social work research findings (Vol. 32). Edinburgh: The Scottish Office Central Research Unit.

Schuster, M. L., \& Propen, A. (2006). 2006 WATCH victim impact statement study. Minneapolis, MN: University of Minnesota.

Schuster, M. L., \& Propen, A. (2010). Degrees of emotion: Judicial responses to victim impact statements. Law, Culture and the Humanities, 6(1), 75-104. http://dx.doi. org/10.1177/1743872109349104

Shaffer, M. (2012). The impact of the Charter on the law of sexual assault: Plus ça change, plus c'est la même chose. Supreme Court Law Review, 57(2d), 337-354.

Sheley, E. L. (2012). Reverberations of the victim's "voice": Victim impact statements and the cultural project of punishment. Indiana Law Journal, 87(3), 1246-1286.

Strauss, A. L. (1987). Qualitative analysis for social scientists. New York: Cambridge University Press.

Villmoare, E., \& Neto, V. V. (1987). Victim appearances at sentencing hearings under the California Victims' Bill of Rights-Final report. Washington, DC: Government Printing Office.

Walberg-Hegan, L. M. (1997). Voices of victims: The experience of preparing a victim impact statement for use in court, as described by adolescent sexual abuse survivors (Unpublished doctoral dissertation). Ontario Institute for Studies in Education of the University of Toronto.

Walsh, A. (1986). Placebo justice: Victim recommendations and offender sentences in sexual assault cases. Journal of Criminal Law and Criminology, 77, 1126-1141.

Warren, C. A. B. (2001). Qualitative interviewing. In J. F. Gubrium \& J. A. Holstein (Eds.), Handbook of interview research: Context \& method (pp. 83-102). Thousand Oaks, CA: Sage.

Wemmers, J. A. (2005). Victim policy transfer: Learning from each other. European Journal on Criminal Policy and Research, 11(1), 121-133. http://dx.doi.org/10.1007/s10610005-3624-z 


\title{
Chapter 8-Purposing and Repurposing Harms: The Victim Impact Statement and Sexual Assault
}

\begin{abstract}
The purpose of the victim impact statement (VIS) is to inform judges of victims' crimerelated physical, psychological, and financial harms. Findings from interviews with Canadian sexual assault victims, advocates, victim services workers, and prosecutors $(\mathrm{N}=37)$ demonstrated that harm descriptions were manipulated by victims and others in keeping with, and contrary to, VIS design. Victims and prosecutors purposed the VIS to inform court outcomes through harms claims and struggles over those claims. The repurposing of harms claims occurred through practices of strategic disclosure, intended to effect changes in others' behaviors, and harm peddling, the circulation of the VIS in nonsentencing arenas. Victims, adversaries, and criminal justice professionals engaged in harm peddling to obtain compensation, child custody, and parole delay. Implications of purposing and repurposing harms claims include novel opportunities and legal pitfalls for victims, varied responses by judges, and an expansion of social control over victims and offenders.
\end{abstract}

This article is an examination of victim impact statements (VISs) written by sexually assaulted women in Canada. ${ }^{1}$ The VIS is a narrative account submitted to the court that details the physical, psychological, and financial harms experienced as a result of an act for which a defendant has been found or has pled guilty. Submitted after conviction but before sentencing, the VIS must be provided to defence counsel and is eligible for crossexamination (Du Mont, Miller, \& White, 2008). Since its inception, scholars have debated the intent of legislators in introducing the VIS. It has generally been agreed that rationales for VIS use have included beliefs that the statement can or should fulfill "instrumental" (i.e., influencing the duration or severity of the custodial sentence) or "expressive" (i.e., providing emotional closure to the victim) purposes (Roberts \& Erez, 2010). Because of these dual and

\footnotetext{
${ }^{1}$ Miller, Karen-Lee (2013). Purposing and re-purposing harms: The victim impact statement and sexual assault. Qualitative Health Research, 23(11), p. 1445-1458. doi: 10.1177/1049732313507753
} 
conflicting purposes, scholars have been simultaneously concerned with the impacts of the VIS on procedural fairness for offenders and the extent of therapeutic benefit for victims (Roberts, 2009).

At present, little is known about how sexually assaulted women have utilized the VIS. Most VIS study populations have included sexually assaulted women with other victim groups (Rogers \& Erez, 1999; Schuster \& Propen, 2006), a research practice that has failed to recognize that the type of crime might have influenced victims' motivations, usage, and experiences of the VIS (Konradi \& Burger, 2000). The few studies that were designed to specifically examine VIS use by sexually assaulted women are now outdated (Walsh, 1986), did not originally include empirical data from victims (Du Mont et al., 2008; Regehr \& Alaggia, 2006; Ruparelia, 2012), or combined victims' use of the VIS with other forms of criminal justice participation (Konradi \& Burger; Regehr \& Alaggia), which made meaningful interpretation difficult. Additionally, scholars neither critically examined VIS harms descriptions nor examined their use outside of sentencing.

Much remains to be learned about the deliberate purposes, strategies, and arenas to which sexually assaulted women apply harms descriptions contained in the VIS, and how others make use of them. This article is designed to address these issues. I begin with an overview of the literature on the VIS, sexual assault, and the reports of studies that discussed the use of the VIS in that context. Second, I discuss findings collected from interviews with victims, feminist advocates, victim services workers, and prosecuting attorneys $(\mathrm{N}=37)$ across Canada. I conclude with discussion of the implications of the varied uses and interpretations of harms claims by victims and others, including offenders and judges.

\section{The Victim Impact Statement}

The VIS emerged from the crime victims' rights movement of the 1970s in the United States and is considered its most significant reform (Bandes, 2009). The VIS is now a recognized component of most common law jurisdictions such as the United States, the United Kingdom, Australia, and Canada (Roberts, 2009). In Canada, where this study took place, the introduction of the VIS in 1988 marked the first mention of the word victim in the Criminal Code of Canada (Wemmers, 2005). 
It is mandatory that Canadian judges in adult or youth court inquire whether a victim has been advised of the opportunity to complete a VIS, and consider the statement during sentencing deliberations. Victims also have the legislated right to have their VIS considered during applications for judicial review of parole eligibility reduction in cases of life sentences for murder and at review hearings for offenders considered not criminally responsible on account of mental disorder. Recently, victims have been afforded the legislative opportunity to submit a VIS at parole hearings of offenders serving sentences longer than 2 years. Nevertheless, there are no corresponding requirements that the statements be read, or considered, by parole decision-makers (Corrections and Conditional Release Act, 1992; Criminal Code, 1985; Department of Justice Canada, 2013b; Parole Board of Canada, 2012).

Victims have seldom participated in VIS schemes at sentencing (Roberts, 2009). Estimates of the number of victims who have submitted a VIS have ranged between $10 \%$ and 23\% in Canada (Giliberti, 1990; Roberts \& Edgar, 2006) and between 15\% and 30\% internationally (Leverick, Chalmers, \& Duff, 2007; Sanders, 1999). Characteristics of a victim most likely to have submitted a VIS at sentencing have included being a woman and/or vulnerable (elderly, a minor, pregnant), victimized at home, or harmed by a known offender or male offender (Erez \& Tontodonato, 1990; Meredith \& Paquette, 2001). A VIS author was more likely to have experienced a violent personal crime or personal injury, or to have had the case proceed to trial compared to plea bargain (Cole, 2003; Erez \& Tontodonato; Meredith \& Paquette).

The oral delivery or allocution of the VIS in sentencing court has occurred less commonly than written submission (Prairie Research Associates, 2005). Those who allocuted were most likely White or of higher occupational status (Konradi \& Burger, 2000). VIS submission rates were even lower during parole proceedings than at sentencing in Canada (Parole Board of Canada, 2011) and the United States (Caplan, 2010). At parole eligibility hearings, VIS authors were most often sexual assault victims or related to murder victims (Department of Justice Canada, 2013a).

Erez, Roeger, and O'Connell (1996) found that almost three quarters of Australian victims stated that they expected the VIS to have an instrumental impact. Victims' beliefs in instrumentality were unfounded; findings from multiple studies have shown no systemic influence on sentencing in Canada or internationally (Roberts, 2009). Research findings have 
remained inconclusive on whether written or orally delivered VISs have negatively impacted early release (Caplan, 2010). The disjuncture between belief in instrumentality and case outcome has been characterized as responsible for a significant amount of victim disillusionment and distress associated with the VIS (Roberts \& Erez, 2010).

\section{Sexual Assault}

Studies have demonstrated that sexual violence has often led to such "profound impact on physical and mental health" (Jewkes, Sen, \& Garcia-Moreno, 2002, p. 149) that "substantive changes and alterations in basic central nervous system functioning" (Burgess, Regehr, \& Roberts, 2010, p. 244) have been noted to occur. Immediate, short-term, and chronic physical and psychological sequelae have been reported. The range of immediate physical harms has included genital and other injuries, pregnancy, and sexually transmitted infections, as well as injuries associated with restraint, struggle, or escape such as bruises, self-defensive wounds, and broken bones. In some victims, subsequent chronic conditions have arisen such as pelvic pain, migraine headaches, infertility, and gastrointestinal disorders (Jewkes et al., 2002).

Psychological harms that have resulted from sexual assault have included fatigue, anxiety, depression, eating disorders, new or aggravated substance abuse, poorer positive health-related behaviors, and an increased likelihood of experiencing subsequent genderbased violence (Basile \& Smith, 2011; Rees et al., 2011); posttraumatic stress disorder has also commonly been experienced (Rees et al.). Economic harms have also been reported. These have included lost days of work because of the sexual assault or court appearances, out-of-pocket expenses for health care, medication, crisis or longer-term psychotherapy, and replacement of damaged property or clothing. Intangible costs such as pain and suffering and lost quality of life have also been incurred by victims (Zhang, 2008).

\section{Sexual Assault and the Victim Impact Statement}

Findings from international victimization studies have suggested that lifetime prevalence rates for sexual assault range from $8 \%$ to $18 \%$ (Black et al., 2011; Perreault \& Brennan, 2010). Sexual assault has remained one of the most unreported crimes (Du Mont, 
Miller, \& Myhr, 2003). In Britain, only $11 \%$ of victims have reported to police (Smith, Coleman, Eder, \& Hall, 2011). Internationally, conviction rates have ranged from $5.6 \%$ to $12.5 \%$, with evidence of decline (Jordan, 2011).

Johnson (2012) likened the attrition or "winnowing" (Koss, Bachar, Hopkins, \& Carlson, 2004, p. 1438) of sexual assault to a pyramid. The broad base of the pyramid represented the total prevalence of sexual victimization, and the peak indicated the incidence of conviction. Applying Johnson's stark imagery, the VIS, which is eligible for judicial consideration only after conviction, and is a voluntary practice undertaken by a minority of victims, would be seen as existing at the uppermost tip of the pyramid's peak. Despite such relative rarity, many feminists and criminal justice professionals have believed that completing a VIS, or having the opportunity to do so, was essential to sexually assaulted women's therapeutic well-being because it remained the only active input afforded them, whether or not they testified (Du Mont et al., 2008; Regehr \& Alaggia, 2006).

Evidence that sexually assaulted women are a unique population in relation to the VIS has been drawn from findings of mixed-victim studies (Rogers \& Erez, 1999; Schuster \& Propen, 2006). It was reported that judges often perceived VISs more sympathetically when victims had been sexually assaulted by a stranger (Schuster \& Propen, 2006), or when the crime was egregious, such as a "grannie rape" (Rogers \& Erez, p. 272). A judge was more likely to respond negatively when the sexual assault victim was "a prostitute compared to a respectable citizen" (Rogers \& Erez, p. 278), or when it was believed the victim shared complicity in the sexual assault by dating or drinking with the offender (Schuster \& Propen, 2006). In this regard, feminists have argued that rape mythology has influenced judicial interpretations of sexual assault. Rape mythology has been characterized as highly codified and deeply embedded social notions of what might be deemed a "real rape" and who might be convincingly portrayed as a "real victim" (Du Mont et al., 2003). In turn, these beliefs have been implicated in judicial considerations of VISs written by women who have been sexually assaulted (Ruparelia, 2012).

Only a handful of previous studies were designed to specifically examine the VIS in the context of sexual assault (Du Mont et al., 2008; Konradi \& Burger, 2000; Regehr \& Alaggia, 2006; Ruparelia, 2012; Walsh, 1986). On the whole, findings from these studies were used to support a rather simplistic view of the harm details that might be contained in a 
VIS. Scholars generally described VIS harms descriptions as cathartic expressions by victims (Du Mont et al., 2008; Konradi \& Burger; Regehr \& Alaggia, 2006). VISs were perceived as having been helpful to healing when they were promoted by or validated by legal personnel (Du Mont et al., 2008; Konradi \& Burger; Regehr \& Alaggia, 2006), or as having been a source of further harm when their contents were unfairly regarded with suspicion by defence attorneys and victim-blaming judges (Ruparelia, 2012).

Irrespective of whether the experiences of writing or submitting VISs were perceived as positive or negative, harms descriptions have been viewed by scholars as objective statements of injury rather than purposefully constructed accounts that warranted critical analysis (Du Mont et al., 2008; Konradi \& Burger, 2000; Regehr \& Alaggia, 2006). Furthermore, scholars have examined neither the use of VIS harms descriptions outside of sentencing nor their use by nonvictims. These issues warrant further inquiry into the ways in which VIS harms descriptions might be used by, and against, sexually assaulted women.

\section{Methods}

In this article, I draw on data collected during an exploratory qualitative study (2006 to 2009) on the use of VISs written by women who had been sexually assaulted in Canada. Qualitative, audiotaped, semi-structured interviews between 60 and 90 minutes in duration were conducted with 37 participants: victims who had been sexually assaulted $(n=11)$, victim services workers $(n=20)$, feminist advocates $(n=4)$, and prosecuting attorneys $(n=$ 2). Two victims completed two interviews after contacting the researcher to provide additional details. Victims also provided copies of their VISs, trial transcripts, or newspaper clippings associated with the sexual assault. Nonvictim participants also provided prosecuting attorney memoranda, as well as victim services memoranda, policy manuals, and VIS information packages.

\section{Procedure}

Ethical and study approvals were granted by the University of Toronto and two participating provincial ministries responsible for victim services in Central and Eastern Canada. Participants were required to communicate in fluent English. Inclusion criteria for victim participants included (a) adult woman, (b) sexually assaulted as a minor or adult, (c) submitted a VIS, and (d) judicial conclusion of the case with neither ongoing nor pending 
appeal. Inclusion criteria for nonvictim participants were (a) adult, and either (b) VIS experience or (c) extensive knowledge of, or involvement in, VIS policy, administration, or case law. Participant selection was guided first by purposeful sampling (Patton, 1990) in which criterion-based selection (Le Compte \& Preissle, 1993) was used based on a literature review that identified victims, victim services workers, and prosecuting attorneys as those most likely to have VIS experience. Participant selection was next guided by concepts of theoretical sampling (Strauss, 1987) that suggested feminist advocates who worked with victims and offenders in noncourt settings might provide additional insight into alternative experiences of the VIS.

Ten victims were recruited from the database of the participating Eastern provincial ministry. Victim services managers identified and contacted eligible victims using a prepared script that explained the study. If victims expressed an interest in participating, managers requested permission to release contact information to the researcher. One victim from central Canada learned of the study from a colleague and initiated contact. Twenty victim services workers were recruited from the two participating ministries by managers who used a prepared script and released the names of interested staff. Four feminist advocates and two prosecuting attorneys were recruited through snowball sampling (Warren, 2001). Participants were not required to sign written consent forms, nor were they provided with standard research disclosures that might place interviews at risk of subpoena (Palys \& Lowman, 2000).

\section{Participants}

At time of interview, victims $(\mathrm{N}=11)$ ranged in age from 25 to 52 years (average 41 years). Seven were assaulted as adults; four were assaulted as minors. Six adult victims were assaulted in 2002 or more recently; one was assaulted in the mid-1980s. Four victims were assaulted as minors during the late 1960s or during the 1970s. Eight victims were assaulted by men known to them: three by current or previous partners, three by fathers or men who had acted in that role, one by an employer, and one related by marriage. Three offenders were strangers. Three victims experienced nonpenetrative sexual assault (e.g., grabbing, fondling) and 8 victims experienced vaginal, anal, and/or oral penetrative sexual assault (e.g., fellatio or cunnilingus). 
To perpetrate the assault, offenders used one or more the following tactics: four misused positions of trust or authority, three engaged in unlawful entry, two surprised or ambushed their victims, two used weapons, two deliberately inflicted physical injuries, two made explicit or implied threats to children who were present or nearby, two threatened to murder their victims, and one covertly plied his victim with prescription drugs. Four victims were repeatedly assaulted over the course of several hours. One victim was assaulted more than once during single episodes on the same day; three were assaulted across periods of 2.5 to 9 years. Ten offenders were convicted of sexual assault; one offender was convicted of nonsexual assault.

Twenty victim services workers (Eastern Canada, $n=11$; Central Canada, $n=9$ ) were interviewed. Eastern Canada staff ranged in age from 31 to 60 years with an average of 46 years; one was a man, the others were women. Staff had worked in victim services from 2.5 to 15 years, with an average of 9 years. Central Canada staff ranged in age from 27 to 51 with an average of 37 years; all were women. Staff had worked in victim services from 1 to 10 years, with an average of 5 years.

Four feminist advocates who worked in not-for-profit organizations that served victimized and/or criminalized women were interviewed - one from Western Canada and three from Central Canada; all were women. Advocates ranged in age from 48 to 61 years; one advocate declined to respond. Employment in current position ranged from two months to 34 years. Two prosecuting attorneys who worked with provincial ministries responsible for prosecutions were interviewed - one from Western Canada and one from Central Canada. Both were women; one was 36 years of age, the other declined to respond. One had five years of experience as a prosecutor; the other had 20 years of experience.

\section{Rigour}

The requirements needed to establish quality in qualitative research remain under debate (Mays \& Pope, 2000; Tracy, 2010). I adopted Lincoln and Guba’s (1985) four-point trustworthiness criterion (credibility, dependability, confirmability, and transferability), given its emphasis on the establishment of clarity regarding methodological decisions. The elicitation of the perspectives of individuals with different roles and experiences of the VIS regarding similar issues and events ensured credibility. A dependability audit (Miyata \& Kai, 2009) that involved a methodologically self-critical account of research conduct was used to 
establish dependability and confirmability. Transferability was addressed through sufficient detail such that evaluators might assess applicability of findings (Miyata \& Kai) vis-à-vis fittingness or degree of concurrence between sending and receiving contexts (Lincoln \& Guba, 1985).

\section{Analysis}

Verbatim transcribed interviews and written materials provided by participants were entered and coded using NVivo (QSR International, 2006). For the purposes of this article, analysis was restricted to data on VIS harms descriptions. Following Strauss (1987), I first inductively analyzed data to focus on conditions, interactions among actors, strategies and tactics, and consequences. Next, I grouped examples into categories and identified salient subcategories. These were then condensed, investigated for interrelationships, and organized according to thematic content, moving from lower-order to higher-order themes.

Through an iterative process, higher-order themes were developed that captured examples of the nexus between textual descriptions of harms and interactionist agency. To illustrate, first sweep analysis of the conditions of VIS submission led to insight regarding novelties in sites of presentation. Setting novelties were then iteratively examined vis-à-vis original legislative objectives, the range of actors who authored and/or submitted VISs, and the uses to which VIS harms claims were put. These setting-agency interactions were then conceptualized as the theme of repurposing VIS harms descriptions. This theme was further refined and elaborated, and the tactic of harm peddling by victims and by adversaries was identified as a subtheme or component.

\section{Findings}

Within the article participants are identified by their roles as victim (V), victim services worker (VSW), prosecuting attorney (P), and advocate (A). Findings are drawn predominantly from interviews, with supporting evidence provided by written materials. They are organized thematically. "Purposing harms" refers to the use of harms at sentencing to fulfill the original instrumental and expressive purposes of the VIS. It was accomplished through "harms claiming," which was victims' articulations of a broad range of subjective experiences of harms that they attributed to their sexual assaults. Purposing harms was also accomplished through "harms claims struggles," which were covert and overt disagreements 
over the legitimacy of victims' harms claims, or the manner in which other actors were deploying them.

"Repurposing harms" refers to the use of harms claims beyond the VIS's dual rationales of purpose, that is, instrumentality or expressiveness. It was accomplished by "strategic disclosure," which was the targeting of specific information to particular individuals to prompt changes in behaviors or understandings. Repurposing harms was also accomplished by "harm peddling," which was the submission of VIS harms claims by victims, adversaries, and criminal justice professionals in nonsentencing arenas.

\section{Purposing Harms}

Harms claiming. Victim services workers and feminist advocates perceived that the use of the VIS represented a novel means of harms claiming. The statement could be used by a victim to describe crime impact as well as to achieve recognition by others of her status as victim. A victim services worker commented,

Prior to [the VIS], there wasn't really any opportunity for the victim to express in any formal way, or way that would be considered by the courts and other justice officials, the impact of the offence on them. So the [VIS] changes that. It gives them that opportunity for that expression, an outlet, and it legitimizes, I think, their role as not just witnesses but as victims in the justice system. (VSW)

The opportunity to be recognized as victims by the courts was particularly important given that many sexually assaulted women experienced marginality and stigma. These factors exacerbated the emotional distress that arose from the sexual assault as well as the trial. A prosecutor explained,

Complainants are so often women that are easily victimized, and it's because these women are, in some way, marginalized. Whether it's a drug addiction or poverty, mental illness, mental disability, or a prostitute, which means by the time someone is a prostitute often they have so many of those things in their background. ... I don't have many witnesses who are university educated or who were sober at the time of the offence. It makes prosecution difficult. It also means I deal with victims who carry 
around a lot of grief and a lot of blame and self-esteem issues resulting from their attack. $(\mathrm{P})$

The effects of emotional and personal vulnerabilities also presented significant barriers to the completion of a VIS. Victims might have been unable to compellingly describe crime impacts or to write statements at all. Two respondents noted the following:

I can have victims who've been sexually assaulted in the most vile ways who are very basic about their [VISs]. . . . Very brief, like, I'm talking a couple of sentences. . . . They don't want to go there. First of all, it may be sometimes they don't want the offender to know how much it has impacted them because they don't want to open that door. Other times they're keeping things very much at surface level because that's safe for them, that's their coping. (VSW)

I did not want it to happen this way but it went down that I had a prostitute complainant not show up for court, and I had her arrested on the street that night where she worked so that she could come and testify. She sure as hell wasn't sticking around to file a [VIS] afterwards. (P)

Criminal justice professionals have often held perceptions of the "average" rape. Researchers have found that expected sexual assault sequelae have included nightmares, depression, fear of strangers, and relationship difficulties (Erez \& Laster, 1999; Schuster \& Propen, 2006). VISs in this study frequently contained details such as the following: "Following the assault, I had some depression and lack of concentration for some months." "I have fewer relationships now than I used to because I'm afraid to let my guard down." "I monitor footsteps behind me or glances from men or sexualized comments directed by men." "My husband endured 17 years of sexual relations devoid of any intimacy. For [name], my husband, having sex with me was like the lights were on but nobody's home."

Victims also claimed a range of harms that, surprisingly, were well beyond the physical or psychological traumas that would be typically expected by the courts. They claimed harms as varied as chronic illnesses, drug use, severe financial burden, criminal behavior, education and career limitations, and secondary harms to loved ones and animals. Verbatim VIS quotes included: "I have also been advised that my background of abuse 
created a fertile ground for the illnesses I now have: [irritable bowel syndrome], Fibromyalgia, Chronic Fatigue Syndrome, Multiple Chemical Sensitivity, and Permanent Nerve Damage." "I lost my two jobs as a result of the assault . . . and ended up going into Bankruptcy. With us just getting pre-approved for our first home, my dreams had been crushed." "I spent nine months in reform school which was the loss of my freedom and time away from my family and traditions." "If I had more self-esteem I would have gone to college and had a career earning a better income for my family instead of working in a factory." "All of this created distance between my sister, \& brother, and myself." "I have been verbally abusive to the puppy, because my mind keeps centering on that night and the why."

Victims made use of, or purposed, harm claims. They did so in keeping with the original instrumental and expressive purposes that were credited as the raison d'être of the VIS. Victims explained:

At the very first that I heard about [the VIS], I thought that it would help with my case. And then, when I actually received the [VIS information] package . . . I was like, no, this is more for me. But still, at that time I thought it would help with my case as well . . . maybe swing the judge a little.

I think definitely reading [the VIS] and letting [the judge] know exactly how it felt, how it affected my marriage, how it affected my kids, I think definitely it made a big difference in sentencing.

Prosecutors also effectively purposed victims' harms claims. A prosecuting attorney explained her protocol for the use of harms claims at the appeal level:

[The VIS] has to be opened. It has to be made an exhibit. . . . Usually the first exhibit on sentence is the criminal record and the second exhibit on sentence from the prosecuting attorney would be the [VIS]. That . . is when you elaborate even more, because you've had some involvement with the victim and you make known what's in that statement and you also elaborate on it, the detail, you know. 
Prosecutors utilized VISs for instrumental ends. In some instances, prosecutors used the statements to "highlight the aggravating factors of the case to suggest a higher starting range for sentence" (P). Should the victim have been unable or unwilling to allocute, prosecutors might also have chosen "to read the [VIS] because there are certain things in it that they want to make sure they emphasize in regards to their sentencing recommendations" (VSW). Prosecutors also made use of the VIS at the court-of-appeal level to justify the sentence that was imposed.

Prosecutors and victim services workers noted that victims' harms claims were often written in colloquial or informal language. Victims' unsophisticated descriptions of harms often actively hindered their usefulness to prosecutors. A prosecutor commented, I have to say I'm not all that impressed; it doesn't give [prosecutors] a lot to work with. Just to give you a recent example. ... We are talking [about a case involving] anal intercourse and fondling, [and the VIS states], "[Sex] brings back too much memories. And then if I do have sex, I can't sleep at night at all. I'm awake all night. Then for the next couple of days I'm real bitchy." That's it! That's all we get in the VIS. . . Whereas a good prosecutor would have put questions to the witness [to prompt elaboration of harms], like, "Why is it you can't sleep at night?" "I have nightmares about what [offender] did to me." ... So, that's something, okay, but there's more you know, like, "For how long? Did you see a doctor about it? Did you have to take counselling about it?" . . It's obvious that we're not getting, in many cases, the most complete evidence of victim impact coming across from [VISs].

Harms claims struggles. Struggles arose when professionals in the criminal justice system dismissed a victim's right to claim harms or disagreed with either the claims made or the way they were being used by others. Struggles occurred at pivotal moments of VIS processing, including notification of the victim's right to articulate harms in the VIS, acceptance of the harms claims by prosecuting and defence attorneys, and judicial receipt. Harms struggles were often, but not always, resolved by denying victims' claims. The first moment of struggle occurred covertly, when some prosecutors refrained from seeking VISs. 
This occurred because of prosecutors' concerns with court efficiency or their beliefs that the seriousness of the sex crimes did not warrant it. A victim services worker explained,

[Prosecutors] say they didn't get a VIS because "We needed to get the docket moving," or "Oh, it was low end," which drives me insanemeaning it was not as serious a sexual assault as some. And I said, "That was her only sexual assault." No violence, no penetration, but if that's the only thing she's ever had, it's major.

Court efficiency concerns also sometimes prompted prosecutors to covertly decline to seek a VIS at the plea-bargaining stage. However, contrary to the earlier attribution of "low-end" dismissals, prosecutors might also have decided not to actively seek a VIS because of concerns the claims were more serious than the agreed on facts. A prosecutor commented,

[Prosecutors] want to clean up the case, get it out of the system. . . It's unusual to be able to get somebody who is going to come in and plea to a very serious kind of sexual assault. So when you do get the opportunity, you grab it as a prosecutor even though a joint submission means that regardless of the victim impact, you're bound. . . . If you get the [VIS] and it demonstrates maybe a more serious offence, you're not really going to be able to resile from the position that you took because it's going to really bring the administration of justice into disrepute.

The second moment of struggle arose when prosecuting and defence attorneys assessed the utility and permissibility of the harms claims. In some instances, overt struggles resulted from early disclosures of the VIS. When submitted prior to conviction, a defence attorney was able to use the VIS to capitalize on discrepancies in testimony:

In accordance with the rules of disclosure, [VISs] were being disclosed and then used [by defence attorneys] to cross-examine the victim on . . . minor things. In my experience it was, "Oh well, she said that she went to the doctor twice, and [in the VIS] she's saying she went once," that sort of thing. . . . It was the use of the [VIS] really to ... test the complainant's credibility ... [and] to defeat the ability of the prosecutor to obtain a conviction on the evidence. $(\mathrm{P})$ 
In other instances, overt struggles involved the procedural parameters of victims' harms claims under legislation that pertained to the VIS. Prosecutors were often disadvantaged during these struggles:

The defence has been allowed to put parameters on the introduction of impact evidence [in the VIS], you know, by arguments such as, "You have to make sure it accords with the [VIS] provisions of the Criminal Code," and "This isn't strictly permissible," and sort of niggling things. Whereas the strictures of a trial are not supposed to be observed at the sentencing phase. There has to be a little bit more latitude given, that has been recognized by the Supreme Court [of Canada]. But what has happened is latitude has been reserved for the defence whereas the prosecutor has to jump over quite a few technical hurdles, still, in the calling of victim impact evidence. $(\mathrm{P})$

Disputes over harms claims did not always instigate harm struggles. To conclude cases, prosecutors often cooperated with defence attorneys to alter or deny the claims. Victims were requested to rewrite their VISs without the offending portions, or prosecutors independently struck or removed the portions before they were presented to judges. Despite the possible relevance of these actions to the offence's gravity, victims varied in their reactions to requests related to rewriting or striking. In one case, a victim was unperturbed:

A sex-trade worker that I was working with who was sexually assaulted by her john [wrote as] the first sentence of her [VIS], "I knew something was wrong when he locked the door of the vehicle." That is problematic from a legal perspective because that denotes forcible confinement. . . It's not what he was convicted on. ... The prosecutor came back to me ... it had to be taken out. When I spoke to [victim] about it, it wasn't a big deal for her [to remove it]. . . . She was just trying to impart to the judge that her intuition had told her all along this guy was a bad john. (VSW)

In another case, the denial of harms claims caused great distress. When a plea agreement resulted in a conviction on a historical charge that focused on the victim's age and virginity but removed the issue of lack of consent, the victim's claims of "rape" and "unwanted sexual violence" were rendered inadmissible as harms: 
Of course consent is an issue, it's an issue to me. . . How many times I told him, "I don't want to do this.". . . I wish I had understood more of what ... [offender was] pleading guilty to. But I understood as much as the [prosecutor] wanted me to.... They're trying to win. ... [ [Prosecutor] certainly never lied but she knew what not to talk about [removing consent as an issue of charge] so that I would . . . accept his plea to a lesser charge.

... So I agreed to have ... the [sections struck] from [the VIS]. (V)

The third moment of harms claims struggle occurred between prosecutors and judges at the point of judicial receipt and interpretations of the harms claims contained in the statements. Some judges believed that the details written in the VIS offered no new harms information than might be gleaned during testimony. Another judge, in contrast, insisted the VIS contained such important claims that its absence indicated no harms had occurred. Respondents commented:

The judge was handed the [VIS] . . . He just took the envelope and waved it at me and said, "Is there anything in here that the complainant hasn't already told me?" . . . And I said, "I couldn't say, your Honor," and he said, "Oh, I'm sure it's all the same," and he just put it back in the file, unread. ... That was the end of it. (P)

It was a penetrative sexual assault on a virtually unconscious woman. . . . I was arguing for a sentence beginning at three years. ... The judge ... wanted to get it under two years so that this accused, who had no prior criminal record, could get a conditional sentence order. So we were having quite a tug of war. ... The complainant had chosen not to file a [VIS]. . . . She could not face talking about it again. She just wanted to finish with her testimony, and get it over with, and she could not emotionally deal with writing out a [VIS]. . . . And the judge said, "Well, where's the [VIS]? Where is the aggravation of harm? There's no allegation of harm done." And I said, "It can be presumed. You saw the complainant testify. You saw how upset she was. You heard everyone describe how she was crying through the night." ... And she said, "Well, without a [VIS] I'm 
going to consider that there was no harm done, and that's a mitigating factor." (P)

In contrast, other judges were credited with having actively supported victims' harms claims. For example, an offender who had harmed a victim participant in this study was convicted of nonsexual assault, yet the victim was not required to remove from her VIS the harms claims particular to the sexual aspect of the assault. In another case, the absence of a VIS from a sex-trade worker who was unable to complete one had no effect on the judge's interpretation of the existence of harms:

The judge took it that yes, harm is presumed in sexual assault: "I saw this woman testify. I heard what she said, and the harm was serious. I don't need her to tell me again [by submitting a VIS] that it was serious." (P) Whether or not to actively engage in harms claims struggles with a judge was, at times, a subjective decision made by the prosecutor on the basis of extralegal factors. These factors included workplace jockeying or the avoidance of judicial ire:

Well, depending on the case, and depending on the judge that they are arguing this in front of, they have their own reputation as prosecuting attorneys to uphold, and there are bigger hills [than the VIS] to die on. ... Some [victims] can really make a lot of out something that might be viewed as a minor sexual assault, and for this person to go pages about something [minor], then it may turn the judge off. And if the prosecutor is arguing some other important pieces, he's not going to want to piss the judge off. (VSW)

\section{Repurposing Harms}

Strategic disclosure. Criminologists have long emphasized that the use of the VIS has enabled a vastly different "communicative dynamic" between victims and offenders than might be achieved by a prosecutor (Roberts, 2009). Allocution in court of the VIS fostered a safe, direct forum for the expression of harms:

[Victims] have told me that they finally felt the accused had to listen to them because, of course, the courtroom is a very safe environment with [court security]... . They'll say, "He had to sit and listen to me. He 
couldn't get up, he couldn't come after me, he couldn't hurt me, he couldn't put a gun to me, and he couldn't leave," and they really appreciate that opportunity. (VSW)

For many victims, however, the simple expression of harms was insufficient. They repurposed harm descriptions by strategically disclosing information to obtain particular outcomes from others. In relation to offenders, "[Victims] are hoping their words are going to be powerful enough to make change in the accused" (VSW). In one victim's case, her VIS was intended to clearly convey her intention to protect others from additional harm. She believed her efforts were successful, and that the early disclosure of her VIS led to the offender's plea change:

V: $\quad$ My dad read my [VIS]. He read it, and then he went back in the courtroom and pled guilty.

Researcher (R): So, you think your statement influenced his pleading guilty?

$\mathrm{V}$ : $\quad$ Oh, yes! Yes. When he read it, he knew for once in my life I wasn't going to stand back and take it.

Victims also strategically disclosed harms to effect changes in offenders' concepts concerning the acceptable treatment of women. For example, one victim believed that her sexual assault was, in large part, attributable to the offender's cultural background. Her VIS was written in such a way as to underscore this belief and to assert that his behavior was amenable to change. At the time of sentencing, she believed her VIS was interpreted by the offender in such a way that he arrived at a new understanding of the impact of his actions. She thought his new reflections would effect concrete change in his behavior:

[Offender's] culture believes in being married, having the kids, raising a family, but they also believe in having their girlfriends on the side kind of deal, and I was telling him that's not the way most Canadian families believe. We believe in marriage, and sticking together, and not having affairs, and [having] a commitment. I mean, that's what the [wedding] ring symbolizes. . . . And I read [the VIS] to him, and about half way through when I started talking about me and my husband, how it affected our 
marriage, I remember looking directly into his eyes and there was just a real look [emphasis] in him that I think it finally sunk in.

Participants also reported a great many cases when women's strategic disclosures appeared wholly ineffective with offenders. Offenders were described as inattentive, fidgety, and disinterested during VIS allocutions or the repeating of VIS details by judges. Advocates and victim services workers were unsurprised by these reactions:

Men don't make the mistake of raping. It's a conscious, intentional, purposeful act. For some men it is to terrorize. For some men it's just to get what they want. But I don't believe that for most men who commit those transgressions that being told the other person hurts makes much difference. (A)

In some cases, victims strategically disclosed harms to effect changes in perceptions in others beyond offenders. A victim explained that she wrote the VIS because "I wanted the public to know that I wasn't at fault." In several cases, victims strategically used harms descriptions in their VIS to correct faulty family histories and the mischaracterizations held by family members. For example, one victim used her VIS to disclose details her estranged family could not have otherwise known:

I wrote how I was raped over and over. They didn't know that [father] wanted me to take over my mother's role as wife when she passed away. Things like that. That he took all my family away from me because he had them convinced I was on drugs - but, how could I be a good mother if I was on drugs? You tell me. ... So, I put that in.

Victims also used their VIS to strategically disclose harms outside of sentencing hearings. One victim strategically shared her VIS as a means to reassure her husband, who had remained distraught yet uncommunicative over her sexual assault by a stranger:

[Husband] is the type that doesn't talk a lot about feelings, so I think I shared [the VIS] with him just to let him know how I was feeling about [the sexual assault], even way after the fact. I think for me sharing [the VIS] is kind of a protection too. I don't want him worrying or being concerned when I can handle it, or him being upset, so I just said, "Here you go, if you want to read it." 
Another victim strategically disclosed her VIS harms details to a new boyfriend. She did so to provide background details that would rationalize behaviors that she attributed to the assaults, such as mistrust of men and difficulties with sexual intimacy. She explained, "[The VIS] is the worst thing, but the reason I wanted [boyfriend] to read it was because so that he could understand why I was moody or whatever, eh?" Even when the strategic disclosure of harms appeared to effect new knowledge or behavior changes in others, for some victims these results were unsatisfactory:

V: I thought that [VIS allocution in front of family] would make me feel better, but it doesn't.

R: How come?

V: $\quad$ Because they [had] disowned me... . They always said to me, "There's something wrong with you." But now after hearing the VIS, the family tries to talk to me. If I'm out at the grocery store, and if I see any of my aunts, they'll come up and hug me and say, "How are you doing?

Hope you're doing better." . . . But I don't feel anything when they do that because they weren't there to help me. . . They stopped talking to me for years.

In another case, a victim noted that her ex-partner's family had accurately interpreted her strategic disclosure of harms. Because of the VIS, she believed that they more fully comprehended the pain and inconvenience she experienced because of forensic evidence collection and HIV testing. Their reactions, however, were not the sympathies she had sought: "His parents knew that I wasn't lying. They knew I was telling the truth [in the VIS]. But he's their little boy. They just looked embarrassed."

Harm peddling by victims. Some victims suggested that the acceptance of the VIS by a judge in a successfully concluded criminal trial accorded it a type of tangible - and transferable - status and authority. They believed others viewed it as objective evidence of the court's recognition that they had been wronged, and therefore that it would aid them in obtaining additional redress. Thus, among victim respondents, the VISs submitted at sentencing were harm peddled in multiple legal, quasilegal, and public arenas. These novel sites for submission of the VIS included a successfully concluded criminal compensation 
application in another province where the victim also had been assaulted by the offender, a civil trial for damages that was voluntarily discontinued, a civil trial at which the victim successfully defended herself against a harassment claim initiated by the offender, a successful small claims court application, a successful application for damages to a provincial human rights commission, a book detailing the victim's sexual assault experiences, and a successful application for publicly funded mental health counselling. A victim explained:

I provided [the human rights commission] with all the evidence that I thought might help my case, so I brought [the VIS] . . . I also brought [the VIS] into [small claims court] when [offender] tried to take my cars away [in lien of] borrowed money.

One victim harm peddled her VIS by including it in a book that chronicled the entirety of her sexual assault experience. Accompanying a photocopied excerpt of the typed VIS that she had submitted and allocuted at sentencing was a narrative history of the creation of her VIS. She first explained how her VIS had been edited by police without her permission. She next expressed regret that she had complied with investigators' requests to remove from the VIS her claims of harms that had arisen because of poor police handling of the investigation. Finally, she advised other victims of the difficulties of VIS allocution and warned of the stress of cross-examination. Another victim was coerced by police to harm peddle her VIS. Investigating officers had claimed, erroneously, that if she failed to produce a VIS that she would be unable to obtain publicly funded counselling services. When asked how she felt about this, she replied, “I didn't care. I wanted to get the help, so I did anything that I had to. ... And I did. Ever since, I've been getting help all along."

Harm peddling by others. Six participants reported instances in which victims' harms claims in the VIS were used by adversaries in nonsentencing contexts. Venues included family court, a provincial labour board hearing, and the Parole Board of Canada. In family court, advocates and victim services staff recounted several examples in which VIS harms claims such as post-sexual assault crying fits, general depressive malaise, or benzodiazepine use for anxiety were used to justify the revocation or limitation of victims' parental rights. An advocate discussed a case in which the victim's harms claims in the VIS 
were described so "vividly" that "child protection concerns arose" in two separate proceedings several years apart:

A: $\quad$ This was a woman whose ex-partner had been charged with multiple forms of assault, including sexual assault. She was asked right at the beginning of the process to complete the [VIS], so it'd be in the file. ... It was disclosed to the defence and the lawyer made it available to her ex-partner. So the criminal trial proceeded. Meanwhile, she was proceeding with family court measures, to resolve custody. . . . At the end of the criminal proceeding, he was not convicted of anything. So her [VIS] was never even used in criminal court. ... She was continuing with her family court matters and he is fighting for custody. So in one of his affidavits, he attached her [VIS] . . to say, "Look what she wrote in here. Obviously, she's unstable" ... and the judge was influenced by that in the custody order that was made. [Ex-partner] got full custody. . . . But, it got worse! . . [Victim] remarried someone with two children of his own ... [with] an existing shared parenting regime in place. The [victim's] first husband provided her new partner's ex-wife with a copy of her [VIS]. And [new partner] lost the joint custody of his children.

R: And do you believe that these outcomes were directly attributable to the use of her [VIS]?

A: Mm-hmm. [affirmative sound; nods head yes]

R: Okay. And what gave you that indication?

A: In both cases, the judges made reference to the [VISs] and what was in them, and [linked those to] their concerns about whether or not this woman could provide stable care to the children.

A victim services worker recalled another case in which a victim's ex-husband successfully used her VIS in family court. Because of the custodial consequences that occurred, she was always mindful to alert other victims that their VIS might be used against them: 
I want to make sure that they understand that [the VIS] can get into other courts.... We have seen someone put in there that they now have posttraumatic stress disorder . . . and then it got used against them in family court as evidence she was an unfit mother, not capable of looking after their child. [Victim] was absolutely shocked. She phoned here, crying ... "How could that happen? How could that be that it got into family court and they have my [VIS]?" We always make sure that they are aware that it's a court document, it's filed, the defence have a copy, the accused gets to see it. It's not private. It's not just between you and the judge. It really is out there.

In some instances, it was not clear whether harm peddling by adversaries negatively impacted victims' interests. To illustrate, one victim complained to a provincial labor board that her employer had fired her because she reported his sexual assault. During the hearing, the offender submitted a copy of her VIS as part of the package of materials organized by his lawyer to rebut her complaint. In the margins of the VIS, the offender had penned a handwritten note, in grammatically incorrect language, to undermine her credibility. Because the victim had represented herself at the hearing, she had not thought to review the materials disclosed by her offender's lawyer. She was taken aback:

Until I'd actually taken [the VIS] out for [researcher] to look at today, I thought it was my copy. And when I saw [offender's] handwriting I thought, "What? Oh noooo!" [emphasis; loud groan] ... He wrote here, "This statement can proof that [victim] did all these are just looking for money. As soon as [offender] plea guilty, [victim] called the [labour board] on the same day to asking for money. This is her plan. Step by step.” This just brings back a lot of anger!

Transcripts of the hearing showed that board members commented that they had received her VIS, but failed to mention its source or the handwritten comments. Because she was awarded damages, it remains unclear whether the case was negatively impacted by the harm peddling of her VIS by the offender.

One victim had her VIS harm peddled by criminal justice professionals at the parole hearing for the offender. This occurred despite her clearly expressed wishes to the contrary. It 
was also suggested to her that they had harm peddled her VIS as supporting documentation in a peace bond application to monitor the offender after warrant expiry. She found it emotionally stressful that her VIS had been harm peddled as part of an examination of risk assessment related to the offender's release to society, as well as to potentially impose additional criminal sanctions. She was particularly distraught given that these were punitive activities that she neither philosophically nor politically supported:

I have problems that [the VIS] remains this kind of living document twenty years later that is still referred to ... in terms of the parole or life of the man who raped me. . . Because I am not that woman anymore. The impact has changed significantly. And again, it's using me and what I said twenty years ago as a way of shoring up a system that does not benefit me as a woman who has been raped. ... And I resent that I have been used and manipulated and co-opted within that, and that there is no mechanism to address [the use of the VIS without a victim's permission]. . . . [The VIS] was a very personal piece that I wrote, and I don't want anyone to have it. I don't want the [Parole Board of Canada] to have it. I don't want anyone to have it. I want to get it back. I want it expunged [anxious laughter].

\section{Discussion}

Traditional perceptions of the VIS have focused primarily on its instrumental and expressive purposes for victims (Roberts \& Erez, 2010), and little on its application and valuation by multiple actors within and beyond sentencing. In this article, I report the novel findings that the harms claims made by victims of sexual assault in the VIS were purposed, and repurposed, in multiple arenas by victims, criminal justice professionals, and adversaries.

Victims purposed harm details in keeping with the expressive and instrumental purposes of the VIS to successfully make claims beyond those typically associated with the criminal justice system's understandings of harms that flow from sexual assault. Victims successfully claimed sequelae as varied as environmental illnesses, juvenile delinquency, and social and economic harms experienced by partners and siblings. This finding positively supports victims' beliefs of their entitlements to claim harms, as well as the broader social 
and legal acceptance of the range of legitimate harms. It is an indication of an important development in the recognition and amelioration of harms by a justice system that has often been accused of inflicting a "second assault" on sexually victimized women (Campbell, Wasco, Ahrens, Sefl, \& Barnes, 2001).

In repurposing harms claims beyond simple expressions of harm, victims engaged in strategic disclosure to successfully effect behaviour and perception changes in offenders, family members, and the community at large. The purposefulness and strategy inherent in strategic disclosure is not captured by current understandings of communicative expressiveness (see for example Roberts \& Erez, 2010). The finding is suggestive of a new avenue for empirical research concerning the VIS. In this study, however, respondents indicated that the vast majority of offenders appeared not to have attended to the VIS, and some victims expressed significant disappointment even when disclosure targets responded. It is advised therefore that professionals caution victims to lower their expectations of emotional closure whenever the practice of strategic disclosure is observed.

Much has been made of the low rate of cross-examination on the VIS (Prairie Research Associates, 2005), which presumably limits its enormous emotional stress to the few victims whom experience it (Roberts \& Edgar, 2006). However, findings also demonstrate that harms claims struggles were often resolved well before the point of crossexamination, and often to the detriment of the original claim. Cooperative practices between prosecuting and defence attorneys that negatively impacted VIS submission were identified in earlier reports (Cunningham, 1994; Walberg-Hegan, 1997). Furthermore, an appellate court in Canada signalled in a recent decision that the persuasiveness of harm details contained in the VIS on the sentencing judge should not be allowed to overturn a joint submission between prosecuting and defence attorneys (Manikis \& Roberts, 2012). Together with the findings contained here, it is suggestive that valuations of victims' expressions of harms have placed a distant second behind organizational imperatives of efficiency for many legal professionals (see also Erez \& Laster, 1999).

Findings also demonstrated that some prosecutors' concerns regarding professional development and the tempering of their ongoing interactions with judges, rather than legal inadmissibility, hindered the submission of VIS harms claims. It is possible therefore that only those subjective harms claims perceived useful to, or inoffensive by, prosecuting and 
defence attorneys will continue to be permitted at sentencing. This suggests that the full utility of VIS harms claims for victims might lay beyond instrumentality or expressiveness, or indeed in other settings.

The finding here that a judge deliberately chose not to open and read a VIS, contrary to the Criminal Code of Canada (1985), had similarly been documented earlier. In 2006, it was determined that $21 \%$ and $8 \%$, respectively, of VISs filed with Provincial and Superior Trial Courts in Alberta, Canada, were not opened by judges (Alberta Justice, 2006). In another study, slightly less than half of Canadian judges reported that the VIS represented a source of unique information relevant to sentencing (Roberts \& Edgar, 2006). It is possible these findings were suggestive of judicial disinterest in harms claims outside of testimony. Paradoxically, however, findings from this study also demonstrate troublesome variation in whether judges believed the absence of a VIS constituted evidence of lack of harm.

The evidence presented here that a victim might have been legally disadvantaged for failing to seize a voluntary opportunity at sentencing to claim and narrate harms is alarming. It is possible this comprises a modern twist of the old common law requirement that a sexual assault victim raise an immediate "hue and cry" (Sheehy, 2000, p. 102) for the charge of rape to be heard. That is, without continued complaints or claims of harms through the VIS, some judges might not take seriously the full impacts of the crime on sexually assaulted women.

It is also possible, however, contra Rogers and Erez (1999), that the differing judicial reactions to the absence of a VIS reported in this article might be attributable to perceptions of the vulnerabilities associated with sex work. That is, a judge might have been more forgiving of the deliberate omission of subjective harms claims by a prostitute against a john than by a middle-class victim against a peer with no criminal history. Whereas this might positively echo the recent acknowledgment by courts in Canada of the seriousness and severity of harms suffered by sexually and physically assaulted sex workers (Bedford v. Canada, 2012), the findings reported here suggest such sensitivity has not been equally applied to other groups of women. Further qualitative exploration of judicial variability in interpretation of the VIS, and the discretionary coerciveness this might represent, is clearly required.

Contrary to Henley, Davis, and Smith (1994), no longer should sentencing judges be viewed as the exclusive "end users" of the VIS. The finding of the practice of harm peddling 
illuminates the novel, innovative uses that can be made of the VIS, and the new opportunities this has provided victims to legitimize claims of harms and the seeking of alternate and multiple forms of redress. The repurposing of harms claims accepted in a successful criminal trial permits multiple uses of the same claims in a manner that effectively neutralizes or circumvents possible critiques of women's violations of "sympathy etiquette" (Clark, 1987). Harm peddling might also be suggestive of the use of the VIS in the broader victim-led expansion of social control over sexual offenders (Leon, 2011).

It is of particular note that two victims in this study simultaneously engaged in harm peddling yet were distraught when their adversaries also did the same. The finding of harm peddling by adversaries highlights the very real legal danger and emotional distress that might potentially be experienced by victims when their disclosures of injury, sequelae, and coping mechanisms are decontextualized and used against them. Identification of the traumatic and tragic loss of child custody because of VIS participation by sexually assaulted women is an important and unique contribution made by this study, and urgently requires further examination.

Legal counsel for sexual assault victims while they complete the VIS had been previously advocated (Wilson, 2005). The demonstration here of the effective use of VIS harms claims by sex offenders and their allies supports that recommendation. In addition, the use of the VIS by nonsentencing authorities raises the sticky problem of ongoing informed consent for use. Many victims in Canada remain unaware of the purposes to which the VIS is put (Meredith \& Paquette, 2001; Prairie Research Associates, 2005), including that the Corrections and Conditional Release Act (1992) stipulates that correctional authorities are to take all practical steps to obtain it. Although this practice is not always followed (Alberta Justice, 2006; Cunningham, 1994), once the VIS becomes part of the official record it might be used by correctional or parole board authorities contrary to victims' wishes, as occurred in this study. Thus, although the practice of harm peddling cannot be discouraged wholesale because of its benefits to women in some extralegal settings, victims must be apprised of the potential for unwanted or negative consequences to submitting a VIS at all.

Two limitations of this study exist. First, I focused on the use of VISs undertaken by Canadian women who had been sexually assaulted. It is possible that the type of crime committed influenced the incidence or effectiveness of repurposed harms claims by victims 
and others. It is also possible that VIS use and experience might differ for women in other jurisdictions, or for sexually assaulted men. Second, all interviewed victims were White. The likelihood of experiences of racism during involvement in the criminal justice system might mean racialized women have alternate perspectives on the utility and expected payoffs of undertaking a VIS (Ruparelia, 2012). These perspectives are not presented here and would be a valuable next step in research.

\section{Author's Note}

This work is a component of the author's doctoral dissertation at the University of Toronto.

\section{Acknowledgments}

I am grateful to the victims who so generously shared their experiences. Victim services workers, advocates, and prosecutors prioritized interviews in spite of heavy caseloads: thank you. Ruth Croxford, Janice Du Mont, Pia Kontos, Susan McDonald, and Mariana Valverde provided insightful comments on earlier drafts.

\section{Declaration of Conflicting Interests}

The author declared no potential conflicts of interest with respect to the research, authorship, and/or publication of this article.

\section{Funding}

The author disclosed receipt of the following financial support for the research, authorship, and/or publication of this article: Support was received from the Frederick Banting and Charles Best Canada Graduate Scholarship of the Canadian Institutes of Health Research, and the Policy Centre for Victim Issues, Department of Justice Canada (Grant Number 615215-97). The views expressed do not necessarily reflect those of supporters or funders.

\section{References}

Alberta Justice. (2006). Court services statistics for victim impact statements filed with the Court but not considered. Edmonton, AB: Alberta Justice and Solicitor General. Bandes, S. (2009). Victims, "closure," and the sociology of emotion. Law and Contemporary Problems, 72, 2-25. 
Basile, K. C., \& Smith, S. G. (2011). Sexual violence victimization of women: Prevalence, characteristics, and the role of public health and prevention. American Journal of Lifestyle Medicine, 5, 407-417. doi:10.1177/1559827611409512

Bedford v. Canada (AG), 2012 ONCA 186, 109 OR (3d) 1.

Black, M. C., Basile, K. C., Breiding, M. J., Smith, S. G.,Walters, M. L., Merrick, M. T., . . . Stevens, M. R. (2011). The National Intimate Partner and Sexual Violence Survey (NISVS): 2010 summary report. Atlanta: National Center for Injury Prevention and Control, Centers for Disease Control and Prevention.

Burgess, A. W., Regehr, C., \& Roberts, A. R. (2010). Victimology: Theories and applications. Boston: Jones \& Bartlett.

Campbell, R., Wasco, S. M., Ahrens, C. E., Sefl, T., \& Barnes, H. E. (2001). Preventing the "second rape": Rape survivors' experiences with community service providers. Journal of Interpersonal Violence, 16, 1239-1259. doi:10.1177/088626001016012002

Caplan, J. M. (2010). Parole release decisions: Impact of victim input on a representative sample of inmates. Journal of Criminal Justice, 38, 291-300. doi:10.1016/j.jcrimjus.2010.02.012

Clark, C. (1987). Sympathy biography and sympathy margin. American Journal of Sociology, 93, 290-321.

Cole, M. A. (2003). Perceptions of the use of victim impact statements in Canada: A survey of Crown counsel in Ontario. (Master's thesis). University of Ottawa, Ontario.

Corrections and Conditional Release Act, SC 1992, c. 20.

Criminal Code, RSC 1985, c C-46 s 722.

Cunningham, A. H. (1994). Victims of crime and the justice system in Ontario: An issues paper. London, ON: Solicitor General Canada Secretariat Ontario Region.

Department of Justice Canada. (2013a). Use of victim impact statements at sentencing and parole. Ottawa, ON: Author. Retrieved from www.justice.gc.ca/eng.rp-pr/cj-jp/ victim/statem-declar/index.html

Department of Justice Canada. (2013b). Victim impact statement. Ottawa, ON: Author. Retrieved from www.justice.gc.ca/eng.rp-pr/cj-jp/victim/statem-declar/index.html

Du Mont, J., Miller, K.-L., \& Myhr, T. L. (2003). The role of "real rape" and "real victim" stereotypes in the police reporting practices of sexually assaulted women. Violence Against Women, 9, 466-486. doi:10.1177/1077801202250960

Du Mont, J., Miller, K.-L., \& White, D. (2008). Social workers' perspectives on the victim impact statements in cases of sexual assault in Canada. Women \& Criminal Justice, 18(3), 1-23. doi:10.1300/J012v18n03_01

Erez, E., \& Laster, K. (1999). Neutralizing victim reform: Legal professionals' perspectives on victims and impact statements. Crime \& Delinquency, 45, 530-553. doi:10.1177/0011128799045004008

Erez, E., Roeger, L., \& O'Connell, M. (1996). Victim impact statements in South Australia. In C. Sumner, M. Israel, M. O’Connell, \& R. Sarre (Eds.), International victimology: Selected papers from 8th International Symposium on Victimology (pp. 205-216). Canberra, Australia: Australian Institute of Criminology.

Erez, E., \& Tontodonato, P. (1990). The effect of victim participation in sentencing on sentence outcomes. Criminology, 28, 451-474. doi:10.1111/j.17459125.1990.tb01334.x 
Giliberti, C. (1990). Victim impact statements in Canada: Vol. 7. A summary of the findings. Ottawa, ON: Department of Justice Canada.

Henley, M., Davis, R. C., \& Smith, B. E. (1994). The reactions of prosecutors and judges to victim impact statements. International Review of Victimology, 3, 83-93. doi: $10.1177 / 026975809400300206$

Jewkes, R., Sen, P., \& Garcia-Moreno, C. (2002). Sexual violence. In E. G. Krug, L. L. Dahlberg, J. A. Mercy, A. B. Zwi, \& R. Lozano (Eds.), World report on violence and health (pp. 149-181). Geneva: World Health Organization.

Johnson, H. (2012). Limits of a criminal justice response: Trends in police and court processing of sexual assault. In E. Sheehy (Ed.), Sexual assault in Canada: Law, legal practice and women's activism (pp. 613-634). Ottawa, ON: University of Ottawa Press.

Jordan, J. (2011). Here we go round the review-go-round: Rape investigation and prosecution-Are things getting worse not better? Journal of Sexual Aggression, 17, 234-249. doi:10.1080/13552600.2011.613278

Konradi, A., \& Burger, T. (2000). Having the last word: An examination of rape survivors' participation in sentencing. Violence Against Women, 6, 351-395. doi:10.1177/10778010022181895

Koss, M. P., Bachar, K. J., Hopkins, C. Q., \& Carlson, C. (2004). Expanding a community's justice response to sex crimes through advocacy, prosecutorial, and public health collaboration: Introducing the RESTORE program. Journal of Interpersonal Violence, 19, 1435-1463. doi:10.1177/0886260504269703

Le Compte, M. D., \& Preissle, J. (1993). Ethnographic and qualitative design in educational research. San Diego: San Diego Academic Press.

Leon, C. S. (2011). Sex offender punishment and the persistence of penal harm in the U.S. International Journal of Law and Psychiatry, 34, 177-185. doi:10.1016/j. ijlp.2011.04.004

Leverick, F., Chalmers, J., \& Duff, P. (2007). An evaluation of the pilot victim statements schemes in Scotland. Aberdeen, UK: University of Aberdeen Law School.

Lincoln, Y. S., \& Guba, E. G. (1985). Naturalistic inquiry. Newbury Park, CA: Sage.

Manikis, M., \& Roberts, J. (2012). Victim impact statements: Recent guidance from the Courts of Appeal. Victims of Crime Research Digest, 5, 2-6.

Mays, N., \& Pope, C. (2000). Qualitative research in health care. Assessing quality in qualitative research. British Medical Journal, 320(7226), 50-52. doi:10.1136/bmj.320.7226.50

Meredith, C., \& Paquette, C. (2001). Summary report on victim impact statement focus groups. Ottawa, ON: Department of Justice Canada.

Miyata, H., \& Kai, I. (2009). Reconsidering evaluation criteria for scientific adequacy in health care research: An integrative framework of quantitative and qualitative criteria. International Journal of Qualitative Methods, 8, 64-75.

Palys, T., \& Lowman, J. (2000). Ethical and legal strategies for protecting confidential research information. Canadian Journal of Law and Society, 15, 39-80.

Parole Board of Canada. (2011). PBC QuickStats: Parole, pardons and clemency. Ottawa, ON: Author. Retrieved from http://pbc-clcc.gc.ca/infocntr/factsh/parole_stats-eng. shtml\#10 
Parole Board of Canada. (2012). The Safe Streets and Communities Act (Bill C-10): Changes that affect victims of crime. Ottawa, ON: Author.

Patton, M. Q. (1990). Qualitative evaluation and research methods. Newbury Park, CA: Sage.

Perreault, S., \& Brennan, S. (2010). Criminal victimization in Canada, 2009 (85-002-X). Ottawa, ON: Statistics Canada.

Prairie Research Associates. (2005). Multi-site survey of victims of crime and criminal justice professionals across Canada: Summary of Crown Attorney respondents. Ottawa, ON: Department of Justice Canada.

QSR International Pty Ltd. (2006). Nvivo qualitative data analysis software, Version 7, 2006 [Computer software]. Doncaster, Australia.

Rees, S., Silove, D., Chey, T., Ivancic, L., Steel, Z., Creamer, M., . . Forbes, D. (2011). Lifetime prevalence of gender-based violence in women and the relationship with mental disorders and psychosocial function. Journal of the American Medical Association, 306, 513-521. doi:10.1001/ jama.2011.1098

Regehr, C., \& Alaggia, R. (2006). Perspectives of justice for victims of sexual violence. Victims \& Offenders, 1, 33-46. doi:10.1080/15564880500498721

Roberts, J. (Ed.). (2009). Listening to the crime victim: Evaluating victim input at sentencing and parole (Vol. 38). Chicago: University of Chicago Press.

Roberts, J., \& Edgar, A. (2006). Victim impact statements at sentencing: Judicial experiences and perceptions. A survey of three jurisdictions. Ottawa, ON, Canada: Department of Justice Canada.

Roberts, J., \& Erez, E. (2010). Communication at sentencing: The expressive function of victim impact statements. In A. Bottoms \& J. V. Roberts (Eds.), Hearing the victim: Adversarial justice, crime victims and the state (pp. 232-254). Devon, UK: Willan.

Rogers, L., \& Erez, E. (1999). The contextuality of objectivity in sentencing among legal professionals in South Australia. International Journal of Sociology, 27, 267-286. doi:10.1006/ijsl.1999.0092

Ruparelia, R. (2012). All that glitters is not gold: The false promise of victim impact statements. In E. A. Sheehy (Ed.), Sexual assault in Canada: Law, legal practice and women's activism (pp. 665-700). Ottawa, ON: University of Ottawa Press.

Sanders, A. (1999) Taking account of victims in the criminal justice system: A review of the literature. Social Work Research Findings: Vol. 32. Edinburgh, UK: Scottish Office Central Research Unit.

Schuster, M. L., \& Propen, A. (2006). 2006 WATCH Victim Impact Statement study. Minneapolis: University of Minnesota.

Sheehy, E. (2000). From women's duty to resist to men's duty to ask: How far have we come? Canadian Woman Studies, 20, 98-104.

Smith, K., Coleman, K., Eder, S., \& Hall, P. (2011). Homicides, firearm offences and intimate violence 2009/10. London: Home Office Research, Development and Statistics.

Strauss, A. L. (1987). Qualitative analysis for social scientists. New York: Cambridge University Press.

Tracy, S. J. (2010). Qualitative quality: Eight "big-tent" criteria for excellent qualitative research. Qualitative Inquiry, 16, 837-851. doi:10.1177/1077800410383121 
Walberg-Hegan, L. M. (1997). Voices of victims: The experience of preparing a victim impact statement for use in court, as described by adolescent sexual abuse survivors (PhD thesis). Ontario Institute for Studies in Education of the University of Toronto.

Walsh, A. (1986). Placebo justice: Victim recommendations and offender sentences in sexual assault cases. Journal of Criminal Law and Criminology, 77, 1126-1141.

Warren, C. A. B. (2001). Qualitative interviewing. In J. F. Gubrium \& J. A. Holstein (Eds.), Handbook of interview research: Context and method (pp. 83-102). Thousand Oaks, CA: Sage.

Wemmers, J.-A. (2005). Victim policy transfer: Learning from each other. European Journal on Criminal Policy and Research, 11, 121-133. doi:10.1007/s10610-005-3624z

Wilson, L. C. (2005). Independent legal representation for victims of sexual assault: A model for delivery of legal services. Windsor Yearbook of Access to Justice, 23, 249-312.

Zhang, T. (2008). Costs of crime in Canada 2008. Ottawa, ON: Department of Justice Canada. 


\section{Chapter 9-Concluding Remarks}

\section{Summary}

Contrary to contemporary understandings that view the VIS as a rather straightforward account of harm and suffering written by the victim for purposes of communicating to the court (Gewirtz, 1996) and/or to the offender (Roberts, 2003), and that may have therapeutic or antitherapeutic effects on victims (Roberts \& Erez, 2010), the findings of this dissertation reveal a far more complex story. The VIS has a protean or mutable nature that is shaped by structural and relational factors, and that lends itself to versatile uses in multiple contexts.

In the Relational Caring chapter, it was described that victims' decision-making to complete a VIS, and determining the details that are to be provided in one, were implicated in a nurturing or caring ethic involving mothering, protecting future victims, or promoting the interests of abusive partners. Many of the decisions regarding the use of the VIS, and how and where it should be circulated, were strategic in nature. Victims purposed and repurposed the VIS, which was both in keeping with original legislative aims for sentencing involvement and went well beyond it. In the Relational Caring and Purposing Harms chapters, it was demonstrated that victims established harm claims in the VIS that were consistent with commonly expected sequelae (e.g., post-sexual assault nightmares) as well as personal harms not generally attributed to sexual assault (e.g., career and education limitations; environmental illnesses) and harms to others (e.g., children, either as direct witnesses of the assault or dependents who were harmed by victims' subsequent distress).

Victims' experiences of engaging with the VIS, and its effect on those in the courtroom who would attend to it, were unpredictable and inconstant. Some victims felt heard and validated by judges, and others believed their VISs had had an instrumental impact. Yet denial of VIS harm claims also occurred. For example, some prosecutors were reported not to seek a VIS based on belief that the sexual assault was too minor to warrant a VIS. Judges were also unpredictable in their responses to the presence, as well as absence, of a VIS. One judge was noted as claiming that a victim's failure to submit a VIS indicated a lack of harm had occurred, while another understood the absence of a VIS meant the victim was simply too traumatized to complete one. 
Nor can the effects of the VIS be predicted, or prevented, once a victim has put it in circulation. The title of this dissertation, You can't stop the bell from ringing, is taken from the whispered courtroom advice of a prosecutor to a victim to encourage her not to withdraw or modify her hotly contested VIS. The prosecutor implied that once a reader or audience was engaged with the VIS, in this case the judge, it would have a continuing effect. However, it is the unpredictability of the effects of the protean VIS upon readers or audience that is both promising, and troubling, for sexually assaulted women. Some victims were provided information that the allocution of their VIS or having its details reported in a local newspaper had influenced members of the public to the extent that other victims might be reporting to police. Others, however, were legally and socially harmed when family court adjudicators determined they were unfit to parent based on the details they had written in the VIS at criminal trial. The reported effects of VIS receipt on offenders also demonstrated that VIS effects upon readers were unpredictable and potentially harmful to sexually assaulted women. While respondents often criticized male offenders for showing no remorse when victims presented a VIS, sexually assaulted female offenders - including those who had murdered their abusive partners - were reported to display such exaggerated self-blame and consequent penitential receipt that they failed to protect their own legal interests.

ANT was the underpinning conceptual framework for this dissertation. It guided my methodological decisions, which included data sources and sampling breadth, as well as analytic decisions in determining which stories to follow. Because the analysis of "the flow of objects and concepts through the network of participating allies and social worlds" (Star \& Griesemer, 1989, pp. 389, original emphasis) is important to ANT, the overall study followed the human and nonhuman actors associated with the VIS network at multiple points from VIS development to usage(s), and its operation and evocation in multiple places and times.

ANT is "deeply empirical" (Clarke, 2009, p. 214), which is what makes it so ideally suited to structure and inform exploratory qualitative studies such as this one. At the same time, notwithstanding Latour's (1996b) identification of ANT's obsession with tracing relations, it does not prescribe methodological procedure (Mol, 2010). ANT is amenable to the broad use of multiple techniques. In his own work, Latour (2010) utilized a "carefully devised set of ethnographic devices" (p. ix) including case study, nonparticipant observation, interviews, and archival research. Of ANT methodology Latour (1996c) explained, "follow 
the actors themselves is the slogan of our sociology; indeed, but it is not said how to follow them" (p. 238, original emphasis). Nor indeed, does ANT describe how to report what is found. In this dissertation, the following and reporting of actors included the self-conscious and explicit use of ANT in the Obliging Detours paper. It also included a low level of theoretical visibility (Bradbury-Jones, Taylor, \& Herber, 2014) of ANT in the Relational Caring and Purposing and Repurposing Harms papers. Although ANT was not explicitly used as an organizing framework for the findings in the latter two papers, the theory nevertheless foregrounded the processes of data collection, analytic foci, and interpretations that led to the findings (Meyer \& Ward, 2014).

By utilizing ANT in both obvious and more covert ways, the three papers illuminated the character of the VIS in terms of its nature, agency, effects, and relationship(s) to human and to nonhuman actors. First, contrary to being a remonstration that originates solely from the victim and is directed exclusively to the sentencing judge, the VIS emerges from, and circulates throughout a network of actors within and outside the criminal justice system. The VIS has multiple (re)inventors, authors, and users, all of whom are relationally involved and located across multiple places and different temporal spaces. Interview and document analysis in this study revealed that when participants related experiences of VIS praxis, they linked the VIS to 85 different human and nonhuman actors. These included, for example, the Memoranda to Cabinet that facilitated federal and provincial cabinet approvals of VIS legislation, case law that altered VIS policy and victim practices, and proceeds from the victim surcharge that funded victim activities related to the VIS.

It was the ANT-inspired focus on the interactional and relational practices involving multiple actors, settings, and time points across an extended network (Latour, 1996b, 1996c) that enabled me to identify the VIS's implication in the strategic expression of victims' relational caring praxis. Here, the use of ANT illuminated the existence and influence of a previously unidentified ethical practice that underpins VIS practice in the context of female sexual assault. Relational caring bears resemblance to Gilligan's (1982) ethics of care and to Sevenhuijsen's (2003) caring citizenship. Like them, relational caring offers "radical political possibilities" (Sevenhuijsen, 2003, p. 194); in this case, for the exercise of private and public agency by sexually assaulted women through the VIS. 
In the past, ANT has been characterized as at best disinterested in, and at worst antithetical to, investigations into the practices of marginalized individuals, particularly those that might lend themselves to political or policy implications (Harding, 2008; Star, 1991; Wajcman, 2000). In fact, Bloor (1999) commented that ANT's vocabulary could not challenge power structures, only describe them. Yet as Quinlan (2014) smartly countered, “ANT's emphasis on description over analytical concepts does not necessarily need to halt a feminist analysis" (p. 203). Instead she proposed that

Both ANT and feminist methodologies have something to offer. . . . Without feminist methodologies, we may lose the voice of the survivor/victim and without ANT, we may lose the multitude of actors and messy practices within the network of the legal system. (p. 206)

I share Quinlan's (2014) assessment of the fit between feminist research and ANT. Because the use or attempted manipulation of victims' VISs by others - including offenders, offender's families, and state actors at the sentencing and parole level—has not been earlier identified in other VIS research, this new knowledge may be used to buffer victims from VIS-related secondary trauma by enabling a fuller assessment of the benefits and risks to completing a VIS.

Second, the VIS is not a static object. Following Latour (1992), the VIS is an actor with its own generative capabilities, and does things imperfectly and independently of the intentions of its inventors, authors, and users. The VIS first shapes - or attempts to shapestorytelling about the harms of sexual assault through the legal judgments and justice department policies that are embedded in its preprinted form and accompanying instructions, as was described by policy-makers and experienced by victims in the Relational Caring and Obliging Detours chapters. The form and its instructions structure and even require a particular shape or style of victim narrative that, for example, eschews expletives directed at the offender and is written under the spectre of cross-examination. Next, the practices that surround its writing, editing, and submission processes further structure how harms are recounted by involving and refashioning network negotiations and disputes. Participants quoted in the Purposing and Repurposing Harms chapter explained that harms claims struggles between victims and prosecutors work to ensure that the VIS details are compliant with other involved nonhuman actors such as the registered, often "pled down" convictions. 
Those practices, in turn, both shape and are shaped by obliging detours, which are secondarily instituted conditions of possibility and constraint across the network. These secondary conditions - those not part of legislators' initial design of the VIS - arise from VIS-related workarounds and use patterns, including those that become routinized or formalized into laws or procedures. Obliging detours permit the enrolment (Callon, 1986) in the VIS network of new actors such as the victims of offenders found not criminally responsible on account of mental disorder. Obliging detours also permit some but not other courses of actions and actors. For example, in the case of children of criminalized victims, obliging detours permit VIS network enrolment of those termed "recognized victims," while ensuring the exclusion of others.

Because its use and influence extends to ever more legal and popular contexts and populations, the VIS's protean nature means that it easily manages to bypass the design and restrictions originally placed upon it by legislators and the courts within the sentencing context. As study participants explained in the Purposing and Repurposing Harms and Obliging Detours chapters, when the VIS is reused or repurposed by third parties, including those strongly antagonistic to the well-being of sexual assault victims such as their offending ex-partners or their current in-laws, it can retraumatize the victim. Similarly, in its morphing to the VS, the VIS does not suffer the same restrictions as was placed on it earlier in the criminal justice process by legislators and sentence-makers. The multiplicity of the VIS, as I demonstrated in the Obliging Detours chapter, has both negative and positive effects on a range of actors in the VIS network.

Third, as demonstrated across all three papers, the VIS is a tool that can be used in innovative ways by various individuals with multiple agendas. Victims are not, in ANT terms, simply docile users of a technology (Akrich, 1992). In the Relational Caring and Purposing and Repurposing Harms chapters, I found that victims used the VIS to purposively message certain courtroom audience members of their own choosing (e.g., estranged family), and they also used the VIS outside of the sentencing hearing for their own ends (e.g., in small claims court). This latter innovation speaks to the performance of what I have called "harm peddling," which traditional understandings of both the "passive victim" or "empowered survivor" of sexual assault (see for example Doe, 2003; Dubber, 2002; Winkler, 2002) fail to perceive. As illustrated by the actions of participants described in the 
Purposing and Repurposing Harms chapter, harm peddling concerns the activity of strategically deploying VIS harm accounts in multiple settings for particular ends such as compensation or noncriminal court awards. The use of the VIS in this way also extends the time frame of active conflict/engagement between victims and offenders, and alone or in combination with relational caring practices, extends the spatio-temporal understandings of criminal harm and direct causality. This is particularly so, as noted in the Relational Caring chapter, when women write about the effects of sexual assaults that occurred when they were minors, and those for whom their VIS is used at parole board hearings. The Obliging Detours chapter similarly demonstrated the strategic use of the VIS by victims currently or previously intimately involved with the offender; this included those who used the VIS as a form of voluntary recanting, and a female offender who attempted to use the VIS to further her children's interests.

\section{Policy, Practice, and Research: Implications and Recommendations}

The findings of this dissertation cast a less than enthusiastic light on focus group research of Canadian victims that documented victims' positive endorsements about their VISs rarely being modified by anyone else once it was submitted, and their unconcern with the privacy aspects of completing a VIS (Department of Justice Canada, 2013c; Meredith \& Paquette, 2001). My findings demonstrated that what many victims would likely call the "editing" of the VIS, that is, the removal of harm information by prosecutors and judges that victims believe is pertinent to accurately narrate their experiences, could be accomplished through means other than rewording or striking. As I have shown in the Purposing and Repurposing Harms chapter, alternative means of restricting VIS content includes case law decisions and policies embedded in the procedural restrictions associated with VIS forms and guidelines, the strategic needs of prosecutors during plea arrangements that determine the parameters of permissible harms claims, and victims' own practices of self-censorship because of fear or coercion. The Purposing and Repurposing Harms chapter, like earlier VIS research (Du Mont et al., 2008; Schuster \& Propen, 2006), also demonstrated that people whom victims may turn to for support, including victim services workers and social workers, may subtly or directly discourage the inclusion of commentary that runs contrary to their own personally or professionally held beliefs about what judges will permit victims to say. Such 
discretionary actions may be equally effective, if not more so, at limiting or denying victims' narratives than what is traditionally viewed as the "editing" of troublesome or contested written commentary.

Victims' admissions of unconcern with privacy issues may reflect poor comprehension of the implications of the public use of personal information. Many victims remain unaware of the range of VIS use beyond sentencing, and its accessibility and utility to others beyond themselves and judges (Meredith \& Paquette, 2001). When sexual assault victims who were disillusioned with the criminal justice system were asked in a recent study commissioned by the Department of Justice Canada (Lindsay, 2014) what information they thought other victims should know to protect themselves, none mentioned the VIS. Certainly the Obliging Detours and Purposing and Repurposing Harms chapters demonstrated that policy-makers and victims had not expected offenders and others to re-use victims' VISs in nonsentencing domains. Many victims were reported by victim services workers and advocates to experience the third-party use of their VISs as traumatic. Yet existing protections associated with the due process, disclosure, and the principles of fundamental justice that underpin the Canada Evidence Act (1985), and the Canadian Charter of Rights and Freedoms (1982) make it unlikely that modifications could be made to the Criminal Code of Canada (1985) or to the Youth Criminal Justice Act (2002) that could prevent the use of the VIS in other contexts.

These findings suggest that practice remedies might be the first line of defence in terms of protecting victims from harms that flow as a result of VIS utilization in other settings. For example, a victim or her legal representative could argue that nonsentencing judges or adjudicators who have been provided a copy of her VIS by the offender or his supporters exercise discretion by "reading down" the VIS or placing less weight on it because of its origins in an earlier criminal proceeding. Victims or their legal representatives might additionally provide evidence of their own to counter the damaging arguments that the VIS details were meant to buttress. To illustrate, a victim who has had her VIS used against her in family court might introduce evidence to counter the characterization of her sleeping pill use to combat post-sexual assault insomnia as constituting a risk to the child. An affidavit from the family physician or attending emergency unit or specialized sexual assault care and treatment physician who had prescribed the medication could be used to demonstrate that the 
dosage would not impair the victim's ability to supervise, protect, and care for her child, or to respond in the case of a nighttime emergency.

Troubling evidence of the high numbers of self-represented civil litigants in Canada, particularly in family court (Access to Justice Committee, 2013), signals additional risks with VIS use. Lack of legal representation might additionally suggest that victims do not have the legal knowledge or resources with which to effectively defend against the reuse of their VIS in custody contests or other contexts by those antagonistic to their interests. Nevertheless, the inclusion of a statutory privilege in the Criminal Code to ensure that the VIS could be used only for the purpose of assisting the prosecutor at the sentencing phase of a criminal trial or during appeal would hamper victims' ability to "harm peddle" their own VISs. In the Purposing and Repurposing Harms chapter, it was reported that several victims undertook harm peddling as a key strategy in efforts to attain recognition as victims, or to obtain financial compensation or further social care services. Therefore, efforts to sideline the practice of harm peddling would not be helpful to some VIS authors. Attention to the implementation aspects of the VIS, rather than attempting to change or modify its legislative aspects, is likely the most effective route to ensuring its best use by, and on behalf of, sexual assault victims

Additional victim, advocate, and victim services worker education on the restrictions on openness that have successfully been used to protect the privacy rights of sexual assault victims in criminal court, such as publication bans (Cameron, 2003; Office of the Privacy Commissioner of Canada, 2011b), could also be used to limit the tertiary harms that arise from the disclosure and dissemination of personal information when harm peddling is undertaken, including by victims. In the Purposing and Repurposing Harms chapter, for example, it was reported that one victim had successfully "harm peddled" her VIS to a provincial human rights tribunal and was pleased by the successful outcome of her complaint. However, a later electronic search of decisions by the tribunal revealed troubling privacy practices that flowed from her use of the VIS at the tribunal, which could have been prevented by use of a publication ban (see also Miller, 2015).

Because the prosecutor at the criminal trial had not requested a publication ban on her name nor had the victim as a self-represented litigant initiated an application to protect her name or other sensitive information from being disclosed in the tribunal's reasons for 
decision, the electronic decision reported her identity and town of residence. Electronically searchable by her name, the decision also disclosed the range of post-sexual assault harms that she had detailed in her VIS and read aloud during the hearing. These details included her problematic use of alcohol, sexual difficulties with her husband, and weeping in front of her children. The printed decision also disclosed other highly sensitive information such as her prior sexual assault history by multiple offenders, which had not been permitted at criminal trial, and her poor credit history. The case name and awards reported in the judgment were then multiply republished on the Internet by various actors including the community newspaper in which both the victim and the offender lived, a civil liberties research centre that had produced a high-school education primer on the use of the newspaper to raise student awareness of human rights violations, and a human resources trade magazine commenting on the responsibility of employers in cases of sexual harassment (see also Miller, 2015). Given that the victim expressed during interview that she experienced significant emotional distress as well as shame and embarrassment when details of the trial were published, it is highly likely that these additional disclosures of such sensitive information were similarly antitherapeutic.

While making adjudicative tribunal decisions publicly available is related to the open court principle and is a key aspect of its public interest function (Sossin, 2013), the prejudice to public confidence of severing or masking personal information in these decisions "is likely to be more modest" (Saskatchewan Information and Privacy Commissioner, 2009, p. 27) than in criminal proceedings. Yet the consequences of failing to do so remains quite significant and long lasting for complainants (Office of the Privacy Commissioner of Canada, 2011a). Consequently, victims who intend to pursue further civil or adjudicative remedies should be advised by victim services workers or other criminal justice actors to investigate the Web publication practices of the organizations to which they intend to submit their VISs or read them into the record. Judicial and quasi-judicial decision-making bodies vary considerably in their privacy practices, and the tertiary harms flowing from VIS harm peddling by victims or others could well be mitigated by practices such as the removal of personal data identifiers in reasons for judgment, or the use of robot Web exclusion protocols when publishing results of inquiries on the Internet (Canadian Judicial Council, 2005; Office of the Privacy Commissioner of Canada, 2009, 2011b). Guidance to victims on these issues 
in relation to the VIS is critical to their well-being since understandings of privacy issues and adjudicative exceptions to the open court principle are generally restricted to legal professionals (Saskatchewan Information and Privacy Commissioner, 2009).

Several unique findings of this dissertation should be explored in further research. Aside from this study, it would appear that the VIS continues to be overlooked as a site of concern in cases involving simultaneous criminal and family law disputes (see for example Neilson, 2014). Yet consequences to the unexpected use of victims' VISs by abusive men to challenge child custody arrangements urgently requires further examination. There is additionally a paucity of research on intimate partner sexual assault (DeKeseredy, 2007), and this is acutely so in the context of the VIS. This dissertation demonstrated that victims of sexual assault by an intimate partner would sometimes write VISs that favoured or were supportive of the offender. VIS use for purposes of false recanting arose from a desire to protect offenders or because of coercion by in-laws or offenders. Both these situations trouble our understanding of victims' use of the VIS, and its possible exploitation by others, and warrant further exploration. Finally, the finding in this dissertation of the disproportionate gendered impact of the VIS on the due process interests of female offenders - that is, that prior sexual victimization experiences so negatively influenced the emotional processing of VIS harm descriptions that women who were in conflict in the law failed to protect their own legal interests - is a novel and disturbing finding that also requires further investigation.

\section{Conclusion}

This qualitative dissertation examines the use and consequences of the VIS in the context of sexually assaulted women. Interviews were conducted with 44 participants who sought or provided VIS-related services in Canada, and were analyzed using insights from actor-network theory. Findings are presented through three distinct but interrelated papers. Obliging Detours (Miller, submitted) describes the development of the VIS in Canada, and its multiple, innovative, and unauthorized pathways of use. Relational Caring (Miller, 2014) identifies an ethic of care that underpinned use of the VIS by sexually assaulted women. Purposing and Repurposing Harms (Miller, 2013) demonstrates how harm descriptions in 
the VIS were manipulated by victims and others in keeping with, and contrary to, legislators' design of the VIS. Taken together, the findings revealed that the VIS has a protean nature that is produced by structural and relational factors, and lends itself to multiple uses in multiple contexts. VIS-related outcomes and the effects on victims and others could neither be wholly predicted nor prevented, and involved interactions beyond the criminal court setting. The protean, unpredictable, and persisting positive and negative effects of the VIS hold promise - and danger - for sexual assault victims. 


\section{References}

\section{Cases and Acts Cited}

Bedford v. Canada (AG), 2012 ONCA 186, 109 OR (3d) 1

Fedirko v. Alberta, 2004 ABQB 11, 350 A.R. 139

R. v. Antler, 1982 CarswellBC 462, 29 C.R. (3d) 283, 69 C.C.C. (2d) 480 (B.C. S.C)

R. v. Bachmier, [2005] O.J. No. 496 (Ont. Ct. J.)

R. v. Bogart, 2002 O.J. No. 3039 (Ont. C.A.)

R. v. Bremner, 2000 BCCA 345, 2000 CarswellBC 1128, [2000] B.C.J. No. 1096, 146 C.C.C. (3d) 59, 138 B.C.A.C. 200, 226 W.A.C. 200 (B.C. C.A.)

R. v. Caporale, 2005 O.J. No. 1509 (Ont. Ct. J.)

R. v. Cook, 2009 QCCA 2423, 2009 CarswellQue 12692, 250 C.C.C. (3d) 248, 71 C.R. (6th) 369 (Que. C.A.)

R. v. Curtis, 1992 CarswellNB 5, 122 N.B.R. (2d) 194, 11 C.R. $\left(4^{\text {th }}\right)$ 92, 306 A.P.R. 194, C.C.C. (3d) 385 (N.B. C.A.)

R. v. G. (R.) 2003 NLCA 73, 2003 CarswellNfld 290, [2003] N.J. No. 336, 232 Nfld. \& P.E.I.R. 273 (N.L. C.A.)

R. v. Gabriel, 1999 No. 364, 2615

R. v. Greenhalgh, 2011 BCSC 511

R. v. Jackson, 2002 CanLII 41524 (ON CA)

R. v. McAnespie, [1993] 4 S.C.R. 501

R. v. Michael, 2014 ONCJ 360 (CanLII)

R. v. R. (S.) 1998 Carswell Ont 1761, [1998] O.J. No. 1439 (Prov. Div)

R. v. S. (T.), 1996 CarswellOnt 3956, [1996] O.J. No. 3761 (Ont. Prov. Div)

R. v. Shaban, 2004 ABQB 558

R. v. Shoendorfer 2004 ABQB (unreported - September 30, 2004, Court File No. 021226360Q1)

R. v. Talbot, 1985 O.J. No. 4304 (Ont. Ct. J.)

R. v. Tellier, [2000] A.J. No. 903, 2000 ABCA 219 (Alta. C.A.)

R. v. Truelove, [2002] A.J. No 1042 (Ont. Ct. J.)

R. v. W. [V.] 200889 O.R. (3d) 323 (Ont. C.A)

R. v. Walchuk, 2001 SKCA 36

R. v. Whiteman (2005), ABPC 74

Steeves v. R. (2010), 2010 NBCA 57, 2010 CarswellNB 378, 258 C.C.C. (3d) 506, 77 C.R. (6th) 341,360 N.B.R. (2d) 88, 930 A.P.R. 88 (N.B. C.A.)

An Act to amend the Criminal Code and the National Defence Act (mental disorder), SC 2014 c6

Canada Evidence Act, RSC 1985, c C-5

Canadian Charter of Rights and Freedoms, Part 1 of the Constitution Act, being Schedule B to the Canada Act 1982(UK) 1982 c 11

Corrections and Conditional Release Act, S.C. 1992

Criminal Code, R.S.C. 1985, c C-46

Strengthening Military Justice in the Defence of Canada Act, S.C. 2013 c24

Youth Criminal Justice Act, SC 2002, c 1 


\section{Bibliography}

Academy of Criminal Justice Sciences. (2000). Code of Ethics. Retrieved September 22, 2014, from http://www.acjs.org/pubs/167 671_2922.cfm

Access to Justice Committee. (2013). Reaching equal justice: An invitation to envision and act. Ottawa: The Canadian Bar Association.

Akrich, M. (1992). De-scription of technical objects. In W. E. Bijker \& J. Law (Eds.), Shaping technology/building society: Studies in sociological change (pp. 205-224). Cambridge: MIT Press.

Alberta Justice. (2004). Victim impact statement guidelines manual. Edmonton: Alberta Solicitor General.

Alberta Solicitor General and Public Security. (2006). Victims programs status report 200506. Edmonton: Author.

Alberta Solicitor General and Public Security. (2007). Victims of crime protocol: What victims can expect from the criminal justice system. (ISBN: 978-0-7785-6262-7). Edmonton: Author. Retrieved from http://www.victims.gov.ab.ca.

American Psychological Association. (2000). The behavioral health needs of rural women.

Arrigo, B. A., \& Williams, C. R. (2003). Victim vices, victim voices, and impact statements: On the place of emotion and the role of restorative justice in capital sentencing. Crime \& Delinquency, 49(4), 603-626. doi: 10.1177/0011128703252408

Ash, M. (1972). On witnesses: a radical critique of the criminal court procedures. Notre Dame Lawyer, 48.

Attorney-General's Department. (1999). Victims of crime review: Report one. Adelaide: Government of South Australia.

Baird, S., \& Jenkins, S. R. (2003). Vicarious traumatization, secondary traumatic stress, and burnout in sexual assault and domestic violence agency staff. Violence and Victims, 18(1), 71-86.

Bandes, S. (2009). Victims, "closure," and the sociology of emotion. Law \& Contemporary Problems, 72(1), 1-25.

Barrett, J. (2008). Expanding victims' rights in the Charter era and beyond. Supreme Court Law Review, 40, 627-653.

Basile, K. C., \& Smith, S. G. (2011). Sexual violence victimization of women: Prevalence, characteristics, and the role of public health and prevention. American Journal of Lifestyle Medicine, 5(5), 407-417. doi: 10.1177/1559827611409512

Bateman, A. L. (2002). Use of the victim impact statements: Alberta lawyers' perspectives. (Bachelor of Arts), University of Calgary, Calgary.

Bergen, R. K. (1993). Interviewing survivors of marital assault: Doing feminist research on sensitive topics. In C. Renzetti \& R. Lee (Eds.), Researching sensitive topics (pp. 197-211). Newbury Park: Sage.

Bergen, R. K. (1996). Wife rape: understanding the responses of survivors and service providers. Thousand Oakes: Sage.

Bergquist, M., Ihlstralm, C., Ljungberg, J., \& Kesson, M. A. (2008). Combing actor network theory and genre theory to understand the evolution of digital genres. Sprouts: Working Papers on Information Systems, 8(20). http://sprouts.aisnet.org/8-20 
Bernat, F., Parsonage, W. H., \& Helfgott, J. (1994). Victim impact laws and the parole process in the United States: Balancing victim and inmate rights and interests. International Review of Victimology, 3(1), 121-140.

Black, M. (2003). Victim submissions to parole boards: The agenda for research. Australian Institute of Criminology: Trends and issues in crime and criminal justice(May), 1-6.

Blumer, H. (1954). What is wrong with social theory? American Sociological Review, 18, 3 10.

Bowen, G. A. (2006). Grounded theory and sensitizing concepts. International Journal of Qualitative Methods, 5(3), 12-23.

Brabin, P. J., \& Berah, E. F. (1995). Dredging up past traumas: Harmful or helpful? Psychiatry, Psychology and Law, 2(2), 165-171.

Bradbury-Jones, C., Taylor, J., \& Herber, O. (2014). How theory is used and articulated in qualitative research: Development of a new typology. Social Science \& Medicine, 120, 135-141. doi: 10.1016/j.socscimed.2014.09.014

Braithwaite, J. (1993). Juvenile offending: New theory and practice. Paper presented at the National Conference on Juvenile Justice, Canberra.

Brennan, S. (2011). Violent victimization of Aboriginal women in the Canadian provinces, 2009. (85-002-X). Ottawa: Statistics Canada.

Breslau, N., Troost, J. P., Bohnert, K., \& Luo, Z. (2013). Influence of predispositions on post-traumatic stress disorder: Does it vary by trauma severity? Psychological Medicine, 43(2), 381-390. doi: 10.1017/S0033291712001195

Brewer, C. (2000). Recent developments in sentencing. Paper presented at the Spring Educational Conferences for Judges of the Ontario Court of Justice, Ottawa.

British Columbia Review Board. (2010). The British Columbia Review Board and victim impact statements. Vancouver: Author.

Burgess, A. W., Regehr, C., \& Roberts, A. R. (2010). Victimology: Theories and applications. Boston: Jones and Bartlett.

Callihan, J. M. (2003). Victim impact statements in capital trials: A selected bibliography. Cornell Law Review, 88, 569-581.

Callon, M. (1986). Some elements of a sociology of translation: Domestication of the scallops and the fishermen of St. Brieuc Bay. In J. Law (Ed.), Power, action, and belief: A new sociology of knowledge? (pp. 196-233). London: Routledge \& Kegan Paul.

Callon, M. (1991). Techno-economic networks and irreversibility. In J. Law (Ed.), $A$ sociology of monsters: Essays on power, technology and domination (pp. 132-164). London: Routledge.

Callon, M., \& Latour, B. (1981). Unscrewing the big Leviathan: How actors macro-structure reality and how sociologists help them to do so. In K. Knorr-Cetina \& A. V. Cicouvel (Eds.), Advances in social theory and methodology: Towards an integration of micro and macro-sociology. (pp. 277-303). Boston: Routledge.

Callon, M., \& Law, J. (1995). Agency and the hybrid collectif. South Atlantic Quarterly, 94, 481-507.

Cameron, J. (2003). Victim privacy and the open court principle. (rr03-VIC-1e). Ottawa:

Department of Justice Canada. Retrieved from http://www.justice.gc.ca/eng/rp-pr/cj$\mathrm{jp} /$ victim/rr03 vic1/rr03 vic1.pdf. 
Campbell, R. (2002). Emotionally involved: The impact of researching rape. New York: Routledge.

Campbell, R., Adams, A. E., Wasco, S. M., Ahrens, C. E., \& Sefl, T. (2009a). Training interviewers for research on sexual violence: A qualitative study of rape survivors' recommendations for interview practice. Violence Against Women, 15(5), 595-617.

Campbell, R., Adams, A. E., Wasco, S. M., Ahrens, C. E., \& Sefl, T. (2010). "What has it been like for you to talk with me today?": The impact of participating in interview research on rape survivors. Violence Against Women, 16(1), 60-83.

Campbell, R., Ahrens, C. E., Sefl, T., Wasco, S. M., \& Barnes, H. E. (2001). Social reactions to rape victims: Healing and hurtful effects on psychological and physical health outcomes. Violence and Victims, 16(3), 287-302.

Campbell, R., Dworkin, E., \& Cabral, G. (2009b). An ecological model of the impact of sexual assault on women's mental health. Trauma, Violence \& Abuse, 10(3), 225-246. doi: $10.1177 / 1524838009334456$

Canadian Bar Association. (2004). Bill C-10: Criminal Code Amendments (Mental Disorder). Ottawa: Author.

Canadian Judicial Council. (2005). Use of personal information in judgments and recommended protocol. Ottawa: Author.

Canadian Resource Centre for Victims of Crime. (2010). Navigating the Canadian criminal justice system: A guide for victims. Ottawa: Author.

Caplan, J. M. (2010). Parole release decisions: Impact of victim input on a representative sample of inmates. Journal of Criminal Justice, 38(3), 291-300. doi: 10.1016/j.jcrimjus.2010.02.012

Casavant, L., Morris, C., \& Nicol, J. (2014). Legislative Summary of Bill C-32: An Act to enact the Canadian Victims Bill of Rights and to amend certain Acts. (41-2-C32-E). Ottawa: Parliament of Canada, Retrieved from http://www.parl.gc.ca/About/Parliament/LegislativeSummaries/bills_1s.asp?Language $=\mathrm{E} \& 1 \mathrm{~s}=\mathrm{C} 32 \&$ Mode $=1 \& \operatorname{Parl}=41 \& \mathrm{Ses}=2 \&$ source $=$ library prb - txt77.

Cassell, P. G. (2009). In defense of victim impact statements. Ohio State Journal of Criminal Law, 6, 611-648.

Cassell, P. G., \& Erez, E. (2011). Victim impact statements and ancillary harm: The American perspective. Canadian Criminal Law Review, 15(2), 149.

Christie, N. (1977). Conflicts as property. The British Journal of Criminology, 17(1), 1-15.

Clarke, A. E. (2005). Situational analysis: Grounded theory after the postmodern turn. Thousand Oaks: Sage.

Clarke, A. E. (2009). From grounded theory to situational analysis. In J. M. Morse, P. N. Stern, J. Corbin, B. Bowers, K. Charmaz \& A. E. Clarke (Eds.), Developing grounded theory: The second generation (pp. 194-235). Walnut Creek: Left Coast Press Inc.

Cohen, S. (1998). Victims' rights: A voice, not a veto. (XC66-361/1-1-02). Ottawa: Standing Committee on Justice and Human Rights. Retrieved from http://publications.gc.ca/pub?id=115724\&sl=0.

Cole, M. A. (2003). Perceptions of the use of victim impact statements in Canada: A survey of Crown counsel in Ontario. (Master of Arts), University of Ottawa, Ottawa.

Collogan, L. K., Tuma, F., Dolan-Sewell, R., Borja, S., \& Fleischman, A. R. (2004). Ethical issues pertaining to research in the aftermath of disaster. Journal of Traumatic Stress, 17(5), 363-372. doi: 10.1023/B:JOTS.0000048949.43570.6a 
Cook, R. J., Dickens, B. M., \& Thapa, S. (2005). Caring for victims of sexual abuse. International Journal of Gynaecology and Obstetrics, 91(2), 194-199. doi: 10.1016/j.ijgo.2005.08.001

Correctional Service Canada. (2013). Victim statements. Retrieved December 27, 2013, from http://www.csc-scc.gc.ca/victims/003006-0003-eng.shtml

Cunningham, A. H. (1994). Victims of crime and the justice system in Ontario: An issues paper. London: Solicitor General Canada Secretariat Ontario Region.

Daly, K., \& Bouhours, B. (2010). Rape and attrition in the legal process: A comparative analysis of five countries. Crime and Justice: An annual review of research, 39, 565650. doi: 0192-3234/2010/0039-0009

Davis, R. C., \& Smith, B. E. (1994a). The effects of victim impact statements on sentencing decisions: A test in an urban setting. Justice Quarterly, 11(3), 453-512.

Davis, R. C., \& Smith, B. E. (1994b). Victim impact statements and victim satisfaction: An unfulfilled promise? Journal of Criminal Justice, 22(1), 1-12.

Dawson, M., \& Dinovitzer, R. (2001). Victim cooperation and the prosecution of domestic violence in a specialized court. Justice Quarterly, 18(3), 593-649.

de Laet, M., \& Mol, A. (2000). The Zimbabwe bush pump: Mechanics of a fluid technology. Social Studies of Science, 30(2), 225-263. doi: 10.1177/030631200030002002

Denzin, N. K., \& Lincoln, Y. S. (Eds.). (2000). Handbook of qualitative research (2nd ed.). Thousand Oakes: Sage.

Department of Justice Canada. (2003a, November 3-6, 2003). 2003 National Victims of Crime Conference. Paper presented at the National Victims of Crime Conference, Ottawa, Canada.

Department of Justice Canada. (2003b). Victims of crime initiative mid-term evaluation: Technical report. Ottawa: Author. Retrieved from http://www.justice.gc.ca/eng/rp$\mathrm{pr} / \mathrm{cp}-\mathrm{pm} / \mathrm{eval} / \mathrm{rep}-\mathrm{rap} / 08 / \mathrm{fvs}-\mathrm{vic} / \mathrm{p} 0 . \mathrm{html}$.

Department of Justice Canada. (2004). Summative evaluation of the Victims of Crime Initiative: Summary, recommendations and management response. Ottawa: Author.

Department of Justice Canada. (2006). Victim impact statement. Ottawa: Author. Retrieved from http://publications.gc.ca/collections/Collection/J2-285-1999E.pdf.

Department of Justice Canada. (2009). An overview of victim services in Canada. Retrieved March 7, 2015, from http://www.victimsweek.gc.ca/res/overview-survol.html

Department of Justice Canada. (2010). Age of consent to sexual activity. Retrieved March 7, 2015, from http://www.justice.gc.ca/eng/rp-pr/other-autre/clp/faq.html

Department of Justice Canada. (2011a). Backgrounder: White Collar Crime. Ottawa: Retrieved from http://www.justice.gc.ca/eng/news-nouv/nr-cp/2011/doc_32600.html.

Department of Justice Canada. (2011b). Federal victims strategy evaluation: Final Report. Ottawa: Author.

Department of Justice Canada. (2013a). Backgrounder: Victim surcharge. Retrieved November 10, 2013, from http://www.justice.gc.ca/eng/news-nouv/nr$\mathrm{cp} / 2012 /$ doc_32731.html

Department of Justice Canada. (2013b). Use of victim impact statements at sentencing and parole. Retrieved September 8, 2013, from http://www.victimsweek.gc.ca/res/r58.html

Department of Justice Canada. (2013c). Use of victim impact statements at sentencing and parole. Retrieved October 1, 2013, from http://www.victimsweek.gc.ca/res/r58.html 
Department of Justice Canada. (2014a). Criminal law policy function evaluation: Final report. (J2-396-/2014E-PDF). Ottawa: Author. Retrieved from

http://www.justice.gc.ca/eng/rp-pr/cp-pm/eval/rep-rap/14/clpf-fpdp/clpf-fpdp.pdf.

Department of Justice Canada. (2014b). Not Criminally Responsible Reform Act. Ottawa:

Government of Canada. Retrieved from http://news.gc.ca/web/article-

en.do?nid=838179.

Department of Justice Canada. (2014c). Victims Fund: Attending Parole Board of Canada hearings. Retrieved October 3, 2014, from http://www.justice.gc.ca/eng/fund-fina/cj$\mathrm{jp} /$ fund-fond/attend-audience.html

Derene, S., Walker, S., \& Stein, J. (2011). Chapter 2: History of the crime victims' movement in the United States (pp. 1-32). Fairfax: US Department of Justice, Office for Victims of Crime.

Dickson-Swift, V., James, E. L., Kippen, S., \& Liamputtong, P. (2006). Blurring boundaries in qualitative health research on sensitive topics. Qualitative Health Research, 16(6), 853-871. doi: 10.1177/1049732306287526

Dickson-Swift, V., James, E. L., Kippen, S., \& Liamputtong, P. (2009). Researching sensitive topics: qualitative research as emotion work. Qualitative Research, 9(1), 6179. doi: $10.1177 / 1468794108098031$

Diguilio, L., Roberts, J., \& Edgar, A. (2002). Seminar on the use of victim impact statements at sentencing. Ottawa: Policy Centre for Victim Issues, Department of Justice Canada.

Doe, J. (2003). The Story of Jane Doe. Toronto: Random House Canada.

Douglas, R., Laster, K., \& Inglis, N. (1994). Victims of efficiency: Tracking victim impact information through the system in Victoria, Australia. International Review of Victimology, 3, 95-110.

Drauker, C. B. (1999). The emotional impact of sexual violence research on participants. Archives of Psychiatric Nursing, 13(4), 161-191.

Du Mont, J. (2003). Charging and sentencing in sexual assault cases: An exploratory examination. Canadian Journal of Women and the Law, 15(2), 305-343.

Du Mont, J., Humphries, H., Leeke, T., Loutfy, M., Macdonald, S., Myhr, T., \& Rachlis, A. (2005). A prospective cohort study of HIV-1 post-exposure prophylaxis in Ontario sexual assault victims/survivors. Toronto: The Ontario Network of Sexual Assault/Domestic Violence Care \& Treatment Centres (SATC) and The Centre for Research in Women's Health (CRWH).

Du Mont, J., McGregor, M. J., Myhr, T. L., \& Miller, K.-L. (2000). Predicting legal outcomes from medicolegal findings: An examination of sexual assault in two jurisdictions. Journal of Women's Health and Law, 1(3), 219-233.

Du Mont, J., Miller, K.-L., \& Myhr, T. L. (2003). The role of "real rape" and "real victim" stereotypes in the police reporting practices of sexually assaulted women. Violence Against Women, 9(4), 466-486. doi: 10.1177/1077801202250960

Du Mont, J., Miller, K.-L., \& White, D. (2008). Social workers' perspectives on the victim impact statements in cases of sexual assault in Canada. Women \& Criminal Justice, 18(3), 1-23. doi: 10.1300/J012v18n03 01

Du Mont, J., \& Myhr, T. L. (2000). So few convictions: The role of client-related characteristics in the legal processing of sexual assaults. Violence Against Women, 6(10), 1109-1136. 
Du Mont, J., \& White, D. (2007). The uses and impacts of medico-legal evidence in sexual assault cases: A global review. Toronto: World Health Organization.

Dubber, M. (2002). Victims in the war on crime: The use and abuse of victims' rights. New York: New York University Press.

Eakin, J. M., \& Mykhalovskiy, E. (2003). Reframing the evaluation of qualitative health research: reflections on a review of appraisal guidelines in the health sciences. Journal of Evaluation in Clinical Practice, 9(2), 187-194.

Edwards, I. (2004). An ambiguous participant: The crime victim and criminal justice decision-making. British Journal of Criminology, 44(6), 967-982. doi: $10.1093 / \mathrm{bjc} / \mathrm{azh} 050$

Eisenstat, S. (2004). Revenge, justice and law: Recognizing the victim's desire for vengeance as a justification for punishment. Wayne Law Review, 50, 1115-1170.

Eisenstein, J., \& Jacob, H. (1977). Felony Justice: An organizational analysis of criminal courts. Boston: Little, Brown \& Company.

Englebrecht, C. M. (2008). The victim impact statement: An analysis of its content, function, and meaning within the criminal justice system. (PhD Dissertation), University at Albany, State University of New York, New York. (UMI: 3327473)

Erez, E. (1989). The impact of victimology on criminal justice policy. Criminal Justice Policy Review, 3, 236-256. doi: 10.1177/088740348900300302

Erez, E. (1994). Victim participation in sentencing: And the debate goes on... International Review of Victimology, 3, 17-32. doi: 10.1177/026975809400300202

Erez, E., Ibarra, P. R., \& Downs, D. M. (2011). Victim welfare and participation reforms in the United States: A therapeutic jurisprudence perspective. In E. Erez, M. Kichling \& J. Wemmers (Eds.), Therapeutic jurisprudenc and victim participation in justice: International perspectives (pp. 15-39). Durham: Carolina Academic Press.

Erez, E., \& Laster, K. (1999). Neutralizing victim reform: Legal professionals' perspectives on victims and impact statements. Crime \& Delinquency, 45(4), 530-553. doi: $10.1177 / 0011128799045004008$

Erez, E., \& Roberts, J. (2007). Victim participation in the criminal justice system. In R. C. Davies, A. J. Lurigio \& S. Herman (Eds.), Victims of Crime (pp. 277-297). Los Angeles: Sage.

Erez, E., \& Roeger, L. (1995). The effect of victim impact statements on sentencing patterns and outcomes: The Australian experience. Journal of Criminal Justice, 23(4), 363375.

Erez, E., Roeger, L., \& O'Connell, M. (1996). Victim impact statements in South Australia. In C. Sumner, M. Israel, M. O'Connell \& R. Sarre (Eds.), International victimology: Selected papers from the 8th International Symposium on Victimology (pp. 205-216). Canberra: Australian Institute of Criminology.

Erez, E., \& Rogers, L. (1999). Victim impact statements and sentencing outcomes and processes. British Journal of Criminology, 39(2), 216-238. doi: 10.1093/bjc/39.2.216

Erez, E., \& Tontodonato, P. (1990). The effect of victim participation in sentencing on sentence outcomes. Criminology, 28, 451-474. doi: 10.1111/j.17459125.1990.tb01334.x

Erez, E., \& Tontodonato, P. (1992). Victim participation in sentencing and satisfaction with justice. Justice Quarterly, 9(3), 393-418. 
Fergusson, D. M., McLeod, G. F. H., \& Horwood, J. (2013). Childhood sexual abuse and adult developmental outcomes: Findings from a 30-year longitudinal study in New Zealand. Child Abuse \& Neglect, 37(9), 664-674. doi: 10.1016/j.chiabu.2013.03.013

Finch, J. (1984). "It's great to have someone to talk to": The ethics and politics of interviewing women. In C. Bell \& H. Roberts (Eds.), Social Researching: Politics, problems and practice (pp. 70-87). London: Routledge and Kegan Paul.

Frost, N., Nolas, S. M., Brooks-Gordon, B., Esin, C., Holt, A., Mehdizadeh, L., \& Shinebourne, P. (2010). Pluralism in qualitative research: The impact of different researchers and qualitative approaches on the analysis of qualitative data. Qualitative Research, 10(4), 441-460. doi: 10.1177/1468794110366802

Fujimura, J. H. (1995). Ecologies of action: Recombining genes, molecularizing cancer, and transforming biology. In S. L. Star (Ed.), Ecologies in knowledge: Work and politics in science and technology (pp. 302-346). Albany: State University of New York Press.

Fujimura, J. H. (1997). Crafting science: A sociohistory of the quest for the genetics of cancer. Boston: Harvard University Press.

Galloway, A. R. (2004). Protocol: How control exists after decentralization. Cambridge: MIT Press.

Gardner, J. (2009). The ordering of medical things: Medical practices and complexity. (Master of Arts), Victoria University of Wellington, New Zealand. Retrieved from http://researcharchive.vuw.ac.nz/xmlui/bitstream/handle/10063/1178/thesis.pdf?seque nce $=1$

Gardner, J., Dew, K., Stubbe, M., Dowell, T., \& Macdonald, L. (2011). Patchwork diagnoses: the production of coherence, uncertainty, and manageable bodies. Social Science \& Medicine, 73(6), 843-850. doi: 10.1016/j.socscimed.2010.12.010

Gavey, N., \& Schmidt, J. (2011). "Trauma of rape" discourse: A double-edged template for everyday understandings of the impact of rape? Violence Against Women, 17(4), 433456. doi: $10.1177 / 1077801211404194$

Gewirtz, P. (1996). Victims and voyeurs at the criminal trial. Northwestern University Law Review, 90(3), 863-897.

Gherardi, S., \& Nicolini, D. (2005). Actor-networks: Ecology and entrepreneurs. In B. Czarniawska \& T. Hernes (Eds.), Actor-network theory and organizing (pp. 285-306). Copenhagen: Copenhagen Business School Press.

Giblin, M. J. (2014). Organization and management in the criminal justice system: A text/reader. Los Angeles: Sage.

Giliberti, C. (1990). Victim impact statements in Canada. Volume 7. A summary of the findings. Ottawa: Department of Justice Canada.

Giliberti, C. (1991). Evaluation of victim impact statement projects in Canada: A summary of the findings. In G. Kaiser, H. Kury \& H.-J. Albrecht (Eds.), Victims and criminal justice: Legal protection, restitution and support (pp. 703-718). Freiburg i. Br.: Eigenvergla Max-Planck-Institut fur Auslandisches und Internationales Stragrecht.

Gilligan, C. (1982). In a different voice: Psychological theory and women's development. Cambridge: Harvard University Press.

Glaser, B., \& Strauss, A. (1967). The discovery of grounded theory: Strategies for qualitative research. Chicago: Aldine. 
Goldkuhl, G., \& Cronholm, S. (2010). Adding theoretical grounding to grounded theory: Toward multi-grounded theory. International Journal of Qualitative Methods, 9(2), 187-205.

Government of Alberta. (2010). Victim impact statement. Criminal Code of Canada and Youth Justice Act. (VIC0016). Edmonton: Author. Retrieved from https://www.solgps.alberta.ca/programs_and_services/victim_services/help_for_victi ms/Publications/Victim Impact Statement.pdf.

Greaves, L., Hankivsky, O., \& Kingston-Riechers, J. (1995). Selected estimates of the costs of violence against women. London: Centre for Research on Violence Against Women and Children.

Harding, S. (2008). Sciences from below: Feminism, postcolonialities, and modernities. Durham: Duke University Press.

Hartt, C. M., Mills, A. J., Mills, J. H., \& Corrigan, L. T. (2014). Sense-making and actor networks: The non-corporeal actant and the making of an Air Canada history. Management \& Organizational History, 9(3), 288-304. doi: $10.1080 / 17449359.2014 .920260$

Haxell, A. (2008). Cn I jus txt, coz I don wan $2 b$ heard: Mobile technologies and youth counseling. Paper presented at the Ascilite 2008, Melbourne, Australia. http://www.ascilite.org.au/conferences/melbourne08/procs/haxell.pdf

Hendricks, R. (1997). On words and clocks: Temporal ordering in a ward for autistic youths. In K. Hetherington \& R. Munro (Eds.), Ideas of Difference (pp. 51-73). Oxford: Blackwell.

Henley, M., Davis, R. C., \& Smith, B. E. (1994). The reactions of prosecutors and judges to victim impact statements. International Review of Victimology, 3, 83-93. doi: $10.1177 / 026975809400300206$

Hoddenbagh, J., Zhang, T., \& McDonald, S. (2014). An estimation of the economic impact of violent victimization in Canada, 2009. (J4-34/2014E-PDF). Ottawa: Minister of Justice and Attorney General of Canada. Retrieved from http://semainedesvictimes.gc.ca/eng/rp-pr/cj-jp/victim/rr14 01/rr14 01.pdf.

Holmes, M., Resnick, H. S., Kilpatrick, D. G., \& Best, C. L. (1996). Rape-related pregnancy: Estimates and descriptive characteristics from a national sample of women. American Journal of Obstetrics and Gynecology, 175, 320-325.

Interagency Advisory Panel on Research Ethics. (2006). Reconsidering privacy and confidentiality in the TCPS: Social Sciences and Humanities Research Ethics Special Working Committee (SSHWC).

Interagency Advisory Panel on Research Ethics. (2009). Tri-Council Policy Statement: Ethical conduct for research involving humans (TCPS), Revised draft 2nd edition. Ottawa: Canadian Institutes of Health Research.

International Federation of Human Rights. (2010). Chapter 1: The evolution of victims' access to justice. Victims' rights before the International Criminal Court: A guide for victims, their legal representatives and NGOs. Paris: Author.

Irvine, A., Drew, P., \& Sainsbury, R. (2010). Mode effects in qualitative interviews: A comparison of semi-structured face-to-face and telephone interviews using conversation analysis. York: University of York.

Jackson, M., \& MacCrimmon, M. (1999). Research confidentiality and academic privilege: A legal opinion. Burnaby: Simon Fraser University. 
Jensen, T. E., \& Winthereik, B. R. (2005). The body multiple: Ontology in medical practice by Annemarie Mol. Acta Sociologica, 48(3), 266-268.

Jewkes, R., Sen, P., \& Garcia-Moreno, C. (2002). Sexual violence. In E. G. Krug, L. L. Dahlberg, J. A. Mercy, A. B. Zwi \& R. Lozano (Eds.), World report on violence and health (pp. 149-181). Geneva: World Health Organization.

Johnson, H. (2012). Limits of a criminal justice response: Trends in police and court processing of sexual assault. In E. Sheehy (Ed.), Sexual assault in Canada: Law, legal practice and women's activism (pp. 613-634). Ottawa: University of Ottawa Press.

Justice Solutions. (2003). James Rowland: biography \& interview summary. Available from University of Akron. Oral history of the crime victims assistance field video and audio archive. Retrieved November 13, 2014 http://vroh.uakron.edu/uakron.php

Katz, K. M. (2010). Opposing scales of justice: Victims' voices in the sentencing process. Canadian Criminal Law Review, 14(2), 181-230.

Kennard, K. (1989). The victim's veto: A way to increase victim impact on criminal case dispositions. California Law Review, 77(2), 417.

Kinnevy, S. C., \& Caplan, J. M. (2008). National surveys of state parole boards: Models of service delivery [Final report] Part 2 of 2. Philadephia: University of Pennsylvania School of Social Policy \& Practice.

Kirchengast, T. (2008). Sentencing law and the 'emotional catharsis' of victim's rights in NSW homicide cases. Sydney Law Review, 30(4), 615-637.

Konradi, A., \& Burger, T. (2000). Having the last word: An examination of rape survivors' participation in sentencing. Violence Against Women, 6(4), 351-395. doi: $10.1177 / 10778010022181895$

Kontos, P., Miller, K. L., Colantonio, A., \& Cott, C. (2014). Grief, anger, and relationality: The impact of a research-based theater intervention on emotion work practices in brain injury rehabilitation. Evaluation Review, 38(1), 29-67. doi: 10.1177/0193841X14531260

Koss, M. P., Bachar, K. J., Hopkins, C. Q., \& Carlson, C. (2004). Expanding a community's justice response to sex crimes through advocacy, prosecutorial, and public health collaboration: Introducing the RESTORE program. Journal of Interpersonal Violence, 19(12), 1435-1463. doi: 10.1177/0886260504269703

Langstraat, L. (2006). Emotion and community rhetorics: Victim impact statements as cultural pedagogy. In P. Bizzell (Ed.), Rhetorical agendas: Political, ethical, spiritual (pp. 267-274). Mahwah: Lawrence Erlbaum Associates.

Latour, B. (1986a). The powers of association. In J. Law (Ed.), Power, action and belief: A new sociology of knowledge? (pp. 264-280). London: Routledge \& Kegan Paul.

Latour, B. (1986b). Visualization and cognition: Thinking with eyes and hands. Knowledge and Society: Studies in the Sociology of Culture Past and Present, 6, 1-40.

Latour, B. (1987). Science in action: How to follow scientists and engineers through society. Cambridge: Harvard University Press.

Latour, B. (1992). Where are the missing masses? The sociology of a few mundane artifacts. In W. E. Bijker \& J. Law (Eds.), Shaping technology/building society: Studies in sociotechnical change (pp. 225-258). Cambridge: MIT Press.

Latour, B. (1993). We have never been modern (C. Porter, Trans.). Cambridge: Harvard University Press. 
Latour, B. (1996a). Aramis or the love of technology (C. Porter, Trans.). Cambridge: Harvard University Press.

Latour, B. (1996b). On actor-network theory. A few clarifications plus more than a few complications. Soziale Welt, 47, 369-381.

Latour, B. (1996c). On interobjectivity. Mind, Culture and Activity, 3(4), 228-245.

Latour, B. (1999). Pandora's hope: Essays on the reality of science studies. Cambridge: Harvard University Press.

Latour, B. (2005). Reassembling the social: An introduction to actor-network-theory. Oxford: Oxford University Press.

Latour, B. (2010). The making of law: An ethnography of the Conseil D'Etat (M. Brilman \& A. Pottage, Trans.). Cambridge: Polity Press.

Latour, B., \& Woolgar, S. (1986). Laboratory life: The construction of scientific facts. Princeton: Princeton University Press.

Law, J. (1992). Notes on the theory of the actor-network: Ordering, strategy, and heterogeneity. Systems Practice, 5(4), 379-393.

Law, J. (2009). Actor network theory and material semiotics. In B. S. Turner (Ed.), The new Blackwell companion to social theory (pp. 141-158). Oxford: Blackwell.

Law, J., \& Hassard, J. (1999). Actor network theory and after. Oxford: Blackwell.

Law, J., \& Mol, A. (2001). Situating technoscience: an inquiry into spatialities. Environment and Planning D: Society and Space, 19(5), 609-621. doi: 10.1068/d243t

Law, M. A., \& Sulllivan, S. M. (2006). Federal victim surcharge in New Brunswick: An operational review. Ottawa: Department of Justice Canada,.

Lawrence, E. (2010). Victim opinion statements: Providing justice for grieving families. Journal of Law and Family Studies, 12(2), 511-522.

Le Compte, M. D., \& Preissle, J. (1993). Ethnographic and qualitative design in educational research. San Diego: San Diego Academic Press.

Lehoux, P., Sicotte, C., \& Denis, J.-L. (1999). Assessment of a computerized medical record system: disclosing scripts of use. Evaluation and Program Planning, 22(4), 439-453. doi: 10.1016/S0149-7189(99)00034-8

Leichtentritt, R. D., \& Arad-Davidson, B. (2006). The impact of sexual abuse as portrayed by Israeli social workers through the victim impact statement. Families in Society, 87(1), 123-132. doi: 10.1606/1044-3894.3492

Leichtentritt, R. D., \& Davidson-Arad, B. (2002). Construction of the victim impact statement for sexually abused minors: A dramaturgy approach. British Journal of Social Work, 32(8), 1067-1087.

Leverick, F., Chalmers, J., \& Duff, P. (2007). An evaluation of the pilot victim statements schemes in Scotland. Aberdeen: University of Aberdeen Law School.

Levine, C. (2004). The concept of vulnerability in disaster research. Journal of Traumatic Stress, 17(5), 395-402.

Lincoln, Y. S., \& Guba, E. G. (1985a). Establishing trustworthiness. Naturalistic Inquiry (pp. 289-331). Newbury Park: Sage.

Lincoln, Y. S., \& Guba, E. G. (1985b). The only generalization is: There is no generalization Naturalistic Inquiry (pp. 110-128). Newbury Park: Sage.

Lindsay, M. (2014). A survey of survivors of sexual violence in three Canadian cities. (J2403/2014E-PDF). Ottawa: Department of Justice Canada. Retrieved from http://www.justice.gc.ca/eng/rp-pr/cj-jp/victim/rr13_19/rr13_19.pdf. 
Littlefield, D. (2004). Legislative history for victim impact statements. Toronto: Department of Justice Canada, Ontario Regional Office.

Lowman, J., \& Palys, T. (1999). Going the distance: Lessons for researchers from jurisprudence on privilege. A third submission to the SFU Research Ethics Policy Revision Task Force. Burnaby: Simon Fraser University.

Lynett, E., \& Rogers, R. (2000). Emotions overriding forensic opinions? The potentially biasing effects of victim statements. The Journal of Psychiatry and Law, 28, 449-457.

Maier, S. (2008). Are rape crisis centers feminist organizations? Feminist Criminology, 3(2), $82-100$.

Manikis, M. (2012). Recognizing victims' role and rights during plea bargaining: A fair deal for victims of crime. Criminal Law Quarterly, 58(3-4), 411-441.

Manikis, M. (2014). Victim impact statements: Past, present and future. Victim Justice Network: Webinar introduction: National Victims of Crime Awareness Week.

Manikis, M., \& Roberts, J. (2012). Victim impact statements: Recent guidance from the Courts of Appeal. Victims of Crime Research Digest, 5, 2-6. http://www.justice.gc.ca/eng/rp-pr/cj-jp/victim/rd5-rr5/p2.html

Manikis, M., \& Roberts, J. V. (2010). Recognizing ancillary harm at sentencing: A proportionate and balanced response. Canadian Criminal Law Review, 15, 132-144.

Manitoba Justice. (n.d.). Manitoba victim impact statement guidelines. Winnipeg: Author Retrieved from http://www.gov.mb.ca/justice/victims/pdf/guidelinesfactsheet.pdf.

Manson, A. (2001). Essentials of Canadian law: The law of sentencing. Toronto: Irwin Law.

Martin, P. Y. (2005). Rape work: victims, gender, and emotions in organization and community context. New York: Routledge.

Martsolf, D. S., Draucker, C. B., Cook, C. B., Ross, R., Stidham, A. W., \& Mweeba, P. (2010). A meta-summary of qualitative findings about professional services for survivors of sexual violence. The Qualitative Report, 15(3), 489-506.

Mays, N., \& Pope, C. (2000). Qualitative research in health care. Assessing quality in qualitative research. British Medical Journal, 320(7226), 50-52. doi: http://dx.doi.org/10.1136/bmj.320.7226.50

McGregor, M. J., Du Mont, J., \& Myhr, T. L. (2002). Sexual assault forensic medical examination: Is evidence related to successful prosecution? Annals of Emergency Medicine, 39(6), 639-647. doi: 10.1067/mem.2002.123694

McLeod, M. (1988). An examination of the victim's role at sentencing: Results of a survey of probation administrators. Judicature, 71, 162-168.

Meredith, C., \& Paquette, C. (2001). Summary report on victim impact statement focus groups. Ottawa: Department of Justice Canada. Retrieved from http://publications.gc.ca/collections/Collection/J3-3-2-2001E.pdf.

Meyer, S., \& Ward, P. (2014). 'How to' use social theory within and throughout qualitative research in healthcare contexts. Sociology Compass, 8(5), 525-539. doi: $10.1111 /$ soc4.12155

Miles, M. B., \& Huberman, A. M. (1994). Qualitative data analysis: An expanded sourcebook. (Second ed.). London: Thousand Oakes.

Miller, K.-L. (2007a). Empowering victims: The use of the victim impact statement in the case of sexual assault in Nova Scotia. The perspectives of victims and victim services staff. Ottawa: Department of Justice Canada. 
Miller, K.-L. (2007b). Investigating the use of the victim impact statement in the case of sexual assault in Nova Scotia: Notes on method and some preliminary observations. JustResearch, 14, 5-13.

Miller, K.-L. (2013). Purposing and re-purposing harms: The victim impact statement and sexual assault. Qualitative Health Research, 23(11), 1445-1458. doi: $10.1177 / 1049732313507753$

Miller, K.-L. (2014). Relational caring: The use of the victim impact statement by sexually assaulted women. Violence \& Victims, 28(5), 797-813. doi: 10.1891/0886-6708.VVD-13-00056

Miller, K.-L. (2015). Frenemies? The publication ban and the victim impact statement: Policy initiatives with positive benefits and unintended negative consequences for sexually assaulted women. Part II: The victim impact statement. Paper presented at the End Violence Against Women International Conference, New Orleans, Louisiana.

Miller, K.-L., \& Kontos, P. (2013). The intraprofessional and interprofessional relations of neurorehabilitation nurses: A negotiated order perspective. Journal of Advanced Nursing, 69(8), 1797-1807. doi: 0.1111/jan.12041

Miller, K.-L., Reeves, S., Zwarenstein, M., Beales, J. D., Kenaszchuk, C., \& Conn, L. G. (2008). Nursing emotion work and interprofessional collaboration in general internal medicine wards: A qualitative study. Journal of Advanced Nursing, 64(4), 332-343. doi: $10.1111 / \mathrm{j} .1365-2648.2008 .04768 . \mathrm{x}$

Ministry of the Attorney General of Ontario. (2004a). Practice Memorandum [2004] No. 3: Victims input re sentencing/victim impact statement/new order-in-council effective April 15, 2004. Toronto: Criminal Law Division, Ministry of the Attorney General of Ontario.

Ministry of the Attorney General of Ontario. (2004b). Victim impact statement. (PM [2004] No. 3 Attachment No. 3 EN). Toronto: Author.

Miyata, H., \& Kai, I. (2009). Reconsidering evaluation criteria for scientific adequacy in health care research: An integrative framework of quantitative and qualitative criteria. International Journal of Qualitative Methods, 8(1), 64-75.

Mol, A. (2002). The body multiple: Ontology in medical practice. London: Duke University Press.

Mol, A. (2010). Actor-network theory: Sensitive terms and enduring tensions. Kölner Zeitschrift für Soziologie und Sozialpsychologie, 50, 253-269.

Mol, A., \& Law, J. (1994). Regions, networks and fluids: Anaemia and social topography. Social Studies of Science, 24(4), 641-671.

Morgan, R., \& Sanders, A. (1999). The uses of victim statements. London: University of Bristol, Department of Law.

Morse, J. M., \& Coulehan, J. (2015). Maintaining confidentiality in qualitative publications. Qualitative Health Research, 18(3), 299-300. doi: 10.1177/1049732314563489

Moser, I. (2008). Making Alzheimer's disease matter: Enacting, interfering and doing politics of nature. Geoforum, 39(1), 98-110. doi: http://dx.doi.org/10.1016

Mosteller, R. P. (2003). Victim impact evidence: Hard to find the real rules. Cornell Law Review, 88, 543-554.

Munro, R. (2009). Actor-network theory. In S. R. Clegg \& M. Haugaard (Eds.), The Sage handbook of power (pp. 125-139). London: Sage. 
Myers, J. E. B. (2005). Myers on evidence in child, domestic, and elder abuse cases. New York: Aspen Publishers.

Navalta, C. P., Polcari, A., Webster, D. M., Boghassian, A., \& Telcher, M. H. (2006). Effects of childhood sexual abuse on neuropsychological and cognitive function in college women. The Journal of Neuropsychiatry \& Clinical Neurosciences, 18(1), 45-53.

Nova Scotia Department of Justice. (1998). Activity report April 1, 1997 - March 31, 1998. Halifax: Author.

Nova Scotia Department of Justice. (2005a). Victim impact statement form. Halifax: Author.

Nova Scotia Department of Justice. (2005b). Victim impact statement guidelines. Halifax: Author.

Nova Scotia Department of Justice. (2006). Victim impact statement program. Retrieved June 17, 2010, from http://www.gov.ns.ca/just/victim Services/programs.asp

O'Hear, M. (2006). Victims and criminal justice: What's next? Federal Sentencing Reporter, 19(2), 83-90.

Oakley, A. (2003). Interviewing women: A contradiction in terms. In Y. S. Lincoln \& N. K. Denzin (Eds.), Turning points in qualitative research: Tying knots in a handkerchief (pp. 243-264). Oxford: Altimira Press.

Office of Justice Programs. (2014). About victims' rights. Retrieved October 7, 2014, from https://www.victimlaw.org/victimlaw/pages/victimsRight.jsp

Office of the Federal Ombudsman for Victims of Crime. (2009). 2008-09 Annual Report. (J80-2009). Ottawa: Author.

Office of the Federal Ombudsman for Victims of Crime. (2010a). 2009-10 Annual Report. (J80-2010). Ottawa: Author.

Office of the Federal Ombudsman for Victims of Crime. (2010b). Towards a greater respect for victims in the Corrections and Conditional Release Act. (J84-2/2010E-PDF). Ottawa: Author Retrieved from Website: http://www.victimsfirst.gc.ca.

Office of the Federal Ombudsman for Victims of Crime. (2011). Shifting the conversation: A look at refocusing Canada's justice system to better meet the needs of victims of crime. (J84-3/2012). Ottawa: Author Retrieved from http://publications.gc.ca/collections/collection_2012/jus/J84-3-2012-eng.pdf.

Office of the Federal Ombudsman for Victims of Crime. (2014). A cornerstone for change: A response to Bill C-32, the Victims Bill of Rights Act, from the Federal Ombudsman for Victims of Crime. Retrieved October 5, 2014, from http://www.victimsfirst.gc.ca/vv/vbra-cdv.html

Office of the Privacy Commissioner of Canada. (2009). Balancing Transparency and Privacy in the Age of Google. Paper presented at the Advanced Administrative Law Conference, Ottawa, ON. http://www.priv.gc.ca/media/sp-d/2009/spd 20091028 cb e.asp

Office of the Privacy Commissioner of Canada. (2011a). The open court principle and privacy legislation in the digital age. Paper presented at the Lunch-and-Learn session on the de-identification of the decisions of labour tribunals and the protection of privacy in the 21st century organized by the Canadian Bar Association-Quebec Division, Employment and Labour Law Section, Montreal.

http://www.priv.gc.ca/media/sp-d/2011/sp-d_20110927_cb_e.asp 
Office of the Privacy Commissioner of Canada. (2011b). Open courts and privacy: Privacy law in Canada. Paper presented at the Supreme Court of British Columbia Education Seminar, Vancouver.

Ogrodnik, L. (2010). Child and youth victims of police-reported violent crime, 2008. Canadian Centre for Justice Statistics Profile Series. Ottawa: Statistics Canada.

Ontario Victim Services Secretariat. (2010). Victim services in Ontario: A report to the community, victims, survivors and service providers. Retrieved from http://www.attorneygeneral.jus.gov.on.ca/english/ovss/victims_week_2010/victim_se rvices report 2010.asp.

Openparliament.ca. (2015). Bill C-32 Victims Bill of Rights Act: An Act to enact the Canadian Victims Bill of Rights and to amend certain Acts. Retrieved June 11, 2015, from http://openparliament.ca/bills/41-2/C-32/

Palys, T., \& Lowman, J. (2000). Ethical and legal strategies for protecting confidential research information. Canadian Journal of Law and Society, 15(1), 39-80.

Parole Board of Canada. (2006). Contacts with victims - A review of Regional Practices April 2006. Ottawa: Author Retrieved from http://pbc-clcc.gc.ca/rprts/pmd-docs/c veng.shtml.

Parole Board of Canada. (2010a). Fact sheet \#1: Victims presenting oral statement. Ottawa: Author Retrieved from http://www.pbc-clcc.gc.ca/victims/factsheet-eng.shtml.

Parole Board of Canada. (2010b). Victims: Providing information. Ottawa: Author Retrieved from http://www.pbc-clcc.gc.ca/infocntr/factsh/pdf/provid-eng.pdf.

Parole Board of Canada. (2011a). Parole Board of Canada: Contributing to public safety. (PS94-5/2010E). Ottawa: Minister of Public Works and Government Services Canada.

Parole Board of Canada. (2011b). PBC QuickStats: Parole, pardons and clemency. Retrieved September 16, 2013, from http://pbc-clcc.gc.ca/infocntr/factsh/parole statseng.shtml - 10

Parole Board of Canada. (2012). Victims: Presenting a statement. Retrieved December 22, 2013, from http://www.pbc-clcc.gc.ca/infocntr/factsh/pas-pud-eng.shtml

Paternoster, R., \& Deise, J. (2011). A heavy thumb on the scale: The effect of victim impact evidence on capital decision making. Criminology, 49(1), 129-161. doi: 10.1111/j.1745-9125.2010.00220.x

Patton, M. Q. (1990). Qualitative evaluation and research methods. Newbury Park: Sage.

Pemberton, A., \& Reynaers, S. (2011). The controversial nature of victim participation: Therapeutic benefits in victim impact statements. In E. Erez, M. Kichling \& J. Wemmers (Eds.), Therapeutic jurisprudence and victim participation in justice (pp. 229-248). Durham: Carolina Academic Press.

Perrin, B. (2014). More than words: Enhancing the proposed Canadian Victims Bill of Rights (Bill C-32). Ottawa: Macdonald-Laurier Institute.

Pillai, M. (2008). Genital findings in prepubertal girls: What can be concluded from an examination? Journal of Pediatric and Adolescent Gynecology, 21(4), 177-185. doi: 10.1016/j.jpag.2007.08.005

Pilon, M. (1997). Murderers' parole eligibility: The evolution of judicial review. (BP-348E). Ottawa: Government of Canada, Depository Services Program Retrieved from http://dsp-psd.pwgsc.gc.ca/Collection-R/LoPBdP/BP/bp348-e.htm. 
Policy Centre for Victim Issues. (2008). A crime victim's guide to the criminal justice system. (ISBN 978-0-662-05503-7). Ottawa: Author.

Prairie Research Associates. (2005). Multi-site survey of victims of crime and criminal justice professionals across Canada: Summary of Crown Attorney respondents. (rr05vic-1sum5e 2005). Ottawa: Department of Justice Canada.

Project Victims in Europe. (2009). Implementation of the EU framework decision on the standing of victims in the criminal proceedings in the member states of the European Union. Lisboa: Associação Portuguesa de Apoio à Vítima.

Propen, A., \& Schuster, M. L. (2008). Making academic work advocacy work: Technologies of power in the public arena. Journal of Business and Technical Communication, 22(3), 299-329. doi: 10.1177/1050651908315980

Propen, A., \& Schuster, M. L. (2010). Understanding genre through the lens of advocacy: The rhetorical work of the victim impact statement. Written Communication, 27(1), 3 35. doi: $10.1177 / 0741088309351479$

Prout, A. (1996). Actor-network theory, technology and medical sociology: An illustrative analysis of the metered dose inhaler. Sociology of Health \& Illness, 18(2), 198-219.

Public Safety Canada. (2013). Information guide to assist victims: Federal corrections and conditional release ( 8 ed.). Ottawa: Author.

Punch, K. F. (1998). Introduction to social research: Quantitative and qualitative approaches. London: Sage.

QSR International Pty Ltd. (2006). Nvivo qualitative data analysis software, Version 7, 2006 [Computer software]. Doncaster: Author.

Quinlan, A. (2014). Studying DNA: Envisioning new intersections between feminist methodologies and the actor-network theory. In A. Tatnall (Ed.), Technological advancements and the impact of Actor-Network Theory (pp. 196-208). Australia: Victoria University.

Randall, M. (2010). Sexual assault law, credibility, and "ideal victims": Consent, resistance, and victim blaming. Canadian Journal of Women and the Law, 22(2), 397-433. doi: 10.3138/cjwl.22.2.397

Razack, S. H. (2002). Gendered racial violence and spatialized justice: The murder of Pamela George. In S. H. Razack (Ed.), Race, space and the law: Unmapping a white settler society (pp. 121-156). Toronto: Between the Lines.

Rees, S., Silove, D., Chey, T., Ivancic, L., Steel, Z., Creamer, M., . . Forbes, D. (2011). Lifetime prevalence of gender-based violence in women and the relationship with mental disorders and psychosocial function. JAMA: The Journal of the American Medical Association, 306(5), 513-521. doi: 10.1001/jama.2011.1098

Regehr, C., \& Alaggia, R. (2006). Perspectives of justice for victims of sexual violence. Victims \& Offenders, 1(1), 33-46. doi: 10.1080/15564880500498721

Regehr, C., Alaggia, R., Lambert, L., \& Saini, M. (2008). Victims of sexual violence in the Canadian criminal courts. Victims \& Offenders, 3(1), 99-113. doi: $10.1080 / 15564880701783699$

Ritter, N. (2011). The road ahead: Unanalyzed evidence in sexual assault cases. Washington: U.S. Department of Justice.

Roach, K. (1999). Due process and victims' rights. Toronto: University of Toronto Press.

Roberts, J. (2002). The use of victim impact statements in sentencing: A review of international research findings. Ottawa: Policy Centre for Victim Issues. 
Roberts, J. (2003). Victim impact statements and the sentencing process: Recent developments and research findings. Criminal Law Quarterly, 47, 365-396.

Roberts, J. (2008). Victim impact statements: Lessons learned and future priorities. Victims of Crime Research Digest, 3-15.

Roberts, J. (2009). Listening to the crime victim: Evaluating victim input at sentencing and parole. In M. Tonry (Ed.), Crime and Justice: A review of research (pp. 347-412). Chicago: University of Chicago Press.

Roberts, J., \& Edgar, A. (2003). Victim impact statements at sentencing: Perceptions of the judiciary in Canada. The International Journal of Victimology, 1(4), 1-11.

Roberts, J., \& Edgar, A. (2006). Victim impact statements at sentencing: Judicial experiences and perceptions. A survey of three jurisdictions. (rr06-vic3). Ottawa: Department of Justice Canada.

Roberts, J., \& Erez, E. (2004). Communication in sentencing: Exploring the expressive vs. impact model of victim impact statements. International Review of Victimology, $10(3), 223-244$.

Roberts, J., \& Erez, E. (2010). Communication at sentencing: The expressive function of victim impact statements. In A. Bottoms \& J. V. Roberts (Eds.), Hearing the victim: Adversarial justice, crime victims and the state (pp. 232-254). Devon: Willan Publishing.

Roberts, J., \& Grossman, M. G. (1992). Sexual assault legislation in Canada, an evaluation: Homicide and sexual assault. Ottawa: Department of Justice Canada.

Roberts, J. V., \& Manikis, M. (2011). Victim personal statements: A review of empirical research. Report for the Commissioner for Victims and Witnesses in England and Wales. Oxford: University of Oxford.

Roberts, T. (1992). Assessment of the victim impact statement program in British Columbia. Ottawa: Department of Justice Canada, Research and Development Directorate.

Rock, P. (1986). A view from the shadows: The Ministry of the Attorney General of Canada and the making of the Justice for Victims of Crime Initiative. Don Mills: Oxford University Press.

Rock, P. (1988). On the birth of organizations. The Canadian Journal of Sociology, 13(4), 359-384.

Rock, P. (2010). 'Hearing victims of crime': The delivery of impact statements as ritual behaviour in four London trials for murder and manslaughter. In A. Bottoms \& J. V. Roberts (Eds.), Hearing the victim: Adversarial justice, crime victims and the State (pp. 200-225). Devon: Willan Publishing.

Rodon, J., Pastor, J. A., Sesé, F., \& Christiaanse, E. (2008). Unravelling the dynamics of IOIS implementation: An actor-network study of an IOIS in the seaport of Barcelona. Journal of Information Technology, 23(2), 97-108. doi: 10.1057/palgrave.jit.2000131

Rogers, L., \& Erez, E. (1999). The contextuality of objectivity in sentencing among legal professionals in South Australia. International Journal of Sociology, 27, 267-286. doi: 10.1006/ijsl.1999.0092

Rosebury, B. (2011). The political logic of victim impact statements. Criminal Justice Ethics, 30(1), 39-67. doi: 10.1080/0731129x.2011.559061

Rowe, D. (2001). Update on the Pamela Jean George case. Jurisfemme, 20(1). http://www.nawl.ca/en/jurisfemme/entry/update-on-the-pamela-jean-george-case 
Ruparelia, R. (2012). All that glitters is not gold: The false promise of victim impact statements. In E. A. Sheehy (Ed.), Sexual assault in Canada: Law, legal practice and women's activism (pp. 665-700). Ottawa: University of Ottawa Press.

Sanders, A. (1999) Taking account of victims in the criminal justice system: A review of the literature. Social Work Research Findings: Vol. 32. Edinburgh: The Scottish Office Central Research Unit.

Saskatchewan Information and Privacy Commissioner. (2009). Administrative tribunals, privacy and the net. Paper presented at the Canadian Bar Association Legal Conference. http://www.oipc.sk.ca/Resources/Administrative Tribunals.pdf

Savarese, J. L. (2010). "Doing no violence to the sentence imposed": Racialized sex worker complainants, racialized offenders, and the feminization of the Homo Sacer in two sexual assault cases. Canadian Journal of Women and the Law, 22(2), 365-395. doi: 10.3138/cjwl.22.2.365

Schafer, S. (1977). Victimology: The victim and his criminal. Reston: Reston Publishing.

Scheurich, J. J. (1994). Policy archaeology: A new policy studies methodology. Journal of Education Policy, 9(4), 297-316. doi: 0268-0939/94

Schillmeier, M. (2007). Dis/abling practices: Rethinking disability. Human Affairs, 17(2), 195-208. doi: 10.2478/v10023-007-0017-6

Schuster, M. L., \& Propen, A. (2006). 2006 WATCH victim impact statement study. Minneapolis: University of Minnesota.

Schuster, M. L., \& Propen, A. (2010). Degrees of emotion: Judicial responses to victim impact statements. Law, Culture and the Humanities, 6(1), 75-104. doi: $10.1177 / 1743872109349104$

Sebba, L. (1996). Third parties: Victims and the criminal justice system. Columbus: Ohio State University Press.

Sevenhuijsen, S. (2003). The place of care: The relevance of the feminist ethic of care for social policy. Feminist Theory, 4(4), 179-197.

Seymour, A. K. (2001). The victim's role in offender reentry. Washington: U.S. Dept. of Justice, Office of Justice Programs, Office for Victims of Crime.

Shackel, R. (2011). Victim impact statements in child sexual assault cases: A restorative role or restrained rhetoric. University of New South Wales Law Journal, 34(1), 211-249.

Shaffer, M. (2012). The impact of the Charter on the law of sexual assault: Plus ça change, plus c'est la même chose. Supreme Court Law Review, 57(2), 337-354.

Sheley, E. L. (2012). Reverberations of the victim's "voice": Victim impact statements and the cultural project of punishment. Indiana Law Journal, 87(3), 1247-1286.

Silver, R. C., Wortman, C. B., \& Crofton, C. (1990). The role of coping in support provision: The self-presentation dilemma of victims of life crises. In B. Sarason, I. Sarason \& G. Pierce (Eds.), Social support: An interactional view (pp. 397-426). New York: Wiley.

Singleton, V., \& Michael, M. (1993). Actor-networks and ambivalence: General practitioners in the UK cervical screening programme. Social Studies of Science, 23(2), 227-264.

Smith, A. M. (2012). Victim impact statements: Past, present and a look to the future. Toronto: Thomson Reuters Canada Limited.

Sobieski, R. (1992). Victim impact statements: Do they increase victim satisfaction? Victims' response to MADD's criminal justice survey. MADDVOCATE, Winter 1992. 
Sossin, L. (2013). Access to administrative justice and other worries. In C. M. Flood \& L. Sossin (Eds.), Administrative law in context, 2nd edition. Toronto: Emond Montgomery.

Stalder, F. (1997). Actor-Network Theory and communication networks: Toward convergence. Retrieved November 30, 2014, from http://felix.openflows.com/html/Network_Theory.html

Stanbridge, K., \& Kenney, J. S. (2009). Emotions and the campaign for victims' rights in Canada. Canadian Journal of Criminology and Criminal Justice/La Revue canadienne de criminologie et de justice pénale, 51(4), 473-509. doi: $10.3138 /$ cjccj.51.4.473

Stanley, L., \& Wise, S. (1983). Breaking out: Feminist consciousness and feminist change. London: Routledge and Kegan Paul.

Stanley, L., \& Wise, S. (1993). Breaking out again: Feminist ontology and epistemology. London: Routledge.

Star, S. L. (1991). Power, technologies and the phenomenology of conventions: On being allergic to onions. In J. Law (Ed.), Sociology of monsters: Essays on power, technology and domination (pp. 26-56). London: Routledge.

Star, S. L., \& Griesemer, J. R. (1989). Institutional ecology, "translations" and boundary objects: Amateurs and professionals in Berkeley's Museum of Vertebrate Zoology, 1907-1939. Social Studies of Science, 19, 387-420.

Statistics Canada. (2006). Measuring violence against women. Stastical trends 2006. (85570-XIE). Ottawa: Author.

Strauss, A. L. (1987). Qualitative analysis for social scientists. Cambridge: Cambridge University Press.

Teasedale, P. (2003). Victim impact statements speech notes for November 03, 2003 panel discussion. Paper presented at the 2003 National Victims Conference, Ottawa.

Tilson, D. (2011). Bill C-21: Standing Up for Victims of White Collar Crime Act. Retrieved from http://www.davidtilson.ca/media/ottawa-journal/-bill-c-21--standing-up-forvictims-of-white-collar-crime-act

Ullman, S. (1996). Correlates and consequences of adult sexual assault disclosure. Journal of Interpersonal Violence, 11, 554-571.

Ullman, S. E. (1999). Social support and recovery from sexual assault: A review. Aggression and Violent Behavior, 4(3), 343-358.

Ullman, S. E., Starzynski, L. L., Long, S. M., Mason, G. E., \& Long, L. M. (2008).

Exploring the relationships of women's sexual assault disclosure, social reactions and problem drinking. Journal of Interpersonal Violence, 23(9), 1235-1257. doi: 10,1177/0886260508314298

Ullman, S. E., Townsend, S. M., Filipas, H. H., \& Starzynski, L. L. (2007). Structural models of the relations of assault severity, social support, avoidance coping, self-blame, and PTSD among sexual assault survivors. Psychology of Women Quarterly, 31(1), 23-37. doi: $10.1111 / \mathrm{j} .1471-6402.2007 .00328 . \mathrm{x}$

Usher, R., \& Edwards, R. (2007). Lifelong learning - signs, discourses, practices. Dordrecht: Springer.

Valverde, M. (2004). Authorizing the production of urban moral order: Appellate courts and their knowledge games. Paper presented at the Center for the Study of Law and 
Society Jurisprudence and Social Policy Program Bag Lunch Speaker Series, UC Berkeley.

van der Merwe, A., \& Skelton, A. (2014). Victims' mitigating views in sentencing decisions: A comparative analysis. Oxford Journal of Legal Studies. doi: 10.1093/ojls/gqu026

Verdun-Jones, S. N., \& Tijerino, A. A. (2002). Victim participation in the plea negotiation process in Canada: A review of the literature and four models of law reform. (rr20025e). Ottawa: Department of Justice Canada.

Vickers, D., \& Fox, S. (2005). Powers in a factory. In B. Czarniawska \& T. Hernes (Eds.), Actor-network theory and organizing (pp. 129-144). Copenhagen: Liber \& Copenhagen Business School Press.

Villmoare, E., \& Neto, V. V. (1987). Victim appearances at sentencing hearings under the California Victims' Bill of Rights - Final Report. Rockville: National Institute of Justice.

Wajcman, J. (2000). Reflections on gender and technology studies: In what state is the art? Social Studies of Science, 30(3), 447-464.

Walberg-Hegan, L. M. (1997). Voices of victims: The experience of preparing a victim impact statement for use in court, as described by adolescent sexual abuse survivors. (Doctor of Education), Ontario Institute for Studies in Education of the University of Toronto, Toronto. (ISBN: 9780612281332)

Walker, E. A., Newman, E., Koss, M. P., \& Bernstein, D. (1997). Does the study of victimization revictimize the victims? General Hospital Psychiatry, 19(6), 403-410.

Walklate, S. (2002). Victim impact statements: Voices to be heard in the criminal justice system? Reparation and victim-focused social work (pp. 146-159): Jessica Kingsley Publishers.

Walsh, A. (1986). Placebo justice: Victim recommendations and offender sentences in sexual assault cases. Journal of Criminal Law and Criminology, 77, 1126-1141.

Warner, M., \& Brown, J. (2014). The Not Criminally Responsible Reform Act: Reforms to the Mentally Disordered Accused Provisions of the Criminal Code. Retrieved October 3, 2014, from http://www.oba.org/Sections/Health-Law/Articles/Articles2014/June-2014/The-Not-Criminally-Responsible-Reform-Act-Reforms

Warrilow, L., \& McDonald, S. (2008). A summary of research into the Federal Victim Surcharge in New Brunswick and the Northwest Territories. Victims of Crime Research Digest, 1(1), 21-23.

Waterhouse-Watson, D. (2012). Framing the victim. Australian Feminist Studies, 27(71), 5570. doi: $10.1080 / 08164649.2012 .648260$

Wemmers, J. (2008). Victim participation and therapeutic jurisprudence. Victims and Offenders, 3, 165-191. doi: 10.1080/15564880801938318

Wemmers, J.-A., \& Cyr, K. (2004). Victims' perspectives on restorative justice: How much involvement are victims looking for? International Review of Victimology, 11, 259274.

Wemmers, J.-A., \& Cyr, K. (2006). Victims' needs within the context of the criminal justice system. Montreal: International Centre for Comparative Criminology, University of Montreal.

Wikipedia. (2014, October 22, 2014). Environmental impact statement. Retrieved November 13, 2014, from http://en.wikipedia.org/wiki/Environmental_impact_statement 
Williams-Jones, B., \& Graham, J. (2003). Actor-Network Theory: A tool to support ethical analysis of commercial genetic testing. New Genetics and Society, 22(3), 271-296. doi: $10.1080 / 1463677032000147225$

Winkel, F. W., \& Koppelaar, L. (1991). Rape victims' style of self-presentation and secondary victimization by the environment. Journal of Interpersonal Violence, 6 , 29-40.

Winkler, C. (1991). Rape as social murder. Anthropology Today, 7(3), 12-14.

Winkler, C. (2002). One night: Realities of rape. Oxford: Altamira Press.

Young, A. N. (2001). The role of the victim in the criminal process: A literature review 1989-1999. Ottawa: Policy Centre for Victim Issues, Research and Statistics Division. Retrieved from http://www.justice.gc.ca/eng/rp-pr/cj$\mathrm{jp} / \mathrm{victim} / \mathrm{rr} 00$ vic20/rr00 vic20.pdf.

Yuan, N. P., Koss, M. P., \& Stone, M. (2006). The psychological consequences of sexual trauma. Retrieved November 23, 2014

http://vawnet.org/Assoc_Files_VAWnet/AR_PsychConsequences.pdf 


\title{
Appendix A-Victim Recruitment Script (Victim Services Eastern Canada)
}

\author{
The Use of the Victim Impact Statement in the Context \\ of Adult Female Sexual Assault \\ Karen-Lee Miller, University of Toronto, PhD Candidate
}

Purpose: for use by Regional Supervisors in calling potential VS/VIS client interviewees and gaining verbal consent to forward their name and telephone number to Karen-Lee Miller.

\section{Script}

I am calling as a follow-up to the services provided to you by our office. In an effort to help identify ways the justice system can better protect and serve female victims of violence, we are asking your permission to give your name to Karen-Lee Miller from the University of Toronto.

Victim Services is assisting Karen-Lee to contact women who may wish to be involved in research that she is conducting as part of her $\mathrm{PhD}$ studies. The research is being conducted in two sites: [Anonymized for publication] and [Anonymized for publication].

The purpose of the research is to:

- describe the experiences and process of undertaking, writing, submitting, and presenting a victim impact statement in cases of sexual assault.

It is hoped that the findings of this study can be used to improve the experiences of women who choose to complete a victim impact statement.

Your help is completely voluntary. Our office will not provide your name and address to anyone without your agreement. If you decide that you do not want to be called, you will still be able to receive the services of Victim Services in the future.

If you decide that Karen-Lee may call you, she will arrange a time to meet with you. You will be asked to take part in one interview that will take up to one and a half hours to complete. In the interview, you will be asked to discuss:

- how you first heard about your right to complete a victim impact statement

- why you chose to complete a victim impact statement

- how you decided what to write about in your victim impact statement

- whether anyone assisted you in the writing, editing or presentation of the victim statement

- what you found helpful or supportive during the victim impact statement process

- problems or barriers you may have faced during the process

You will be able to decide the place and time of the interview. You don't have to answer any questions you don't want to, and, should you want to, you may stop the interview at any time. 
Thank you for considering this request. Your views are important and could help to improve the experience of women who choose to complete a VIS.

*Karen-Lee Miller is offering a $\$ 25.00$ honorarium to assist with any costs of participation, such as parking or child care.

For Regional Supervisors. Please:

- note in the client case notes that this script was read to the client;

- $\quad$ record the client's verbal consent or non-consent in the client case notes.

- $\quad$ place this script in the client file 


\section{Appendix B-Study Information Pamphlet for Victims}

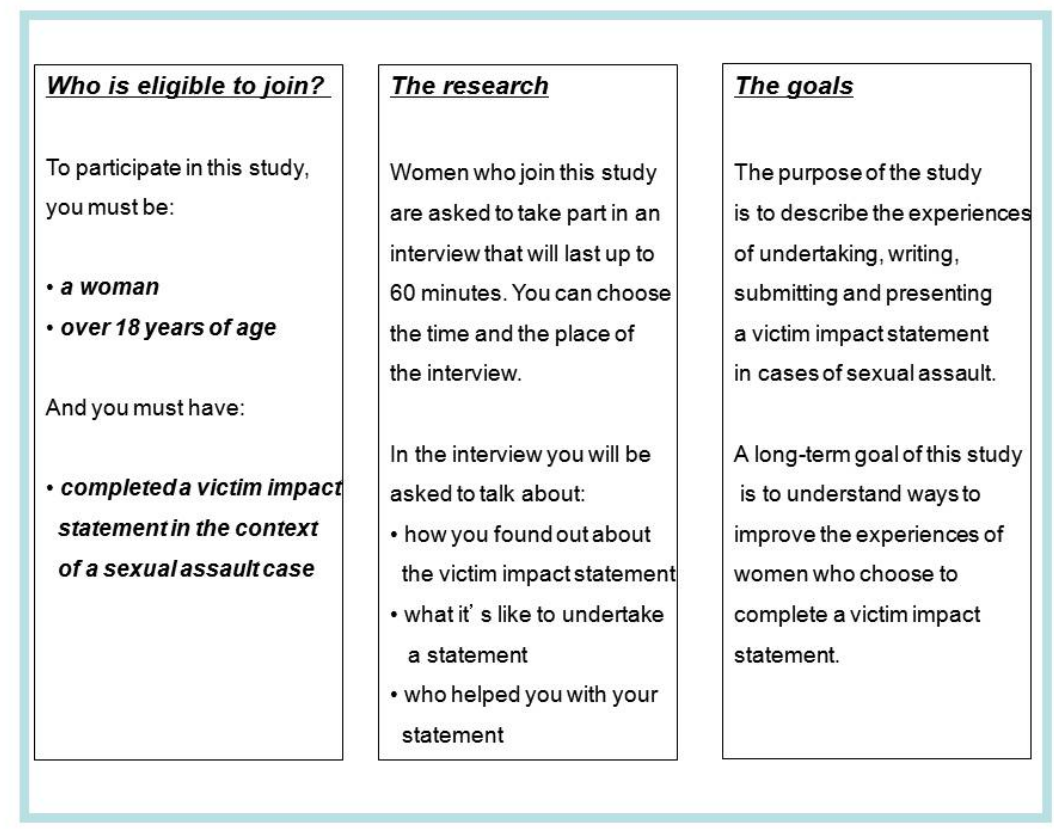
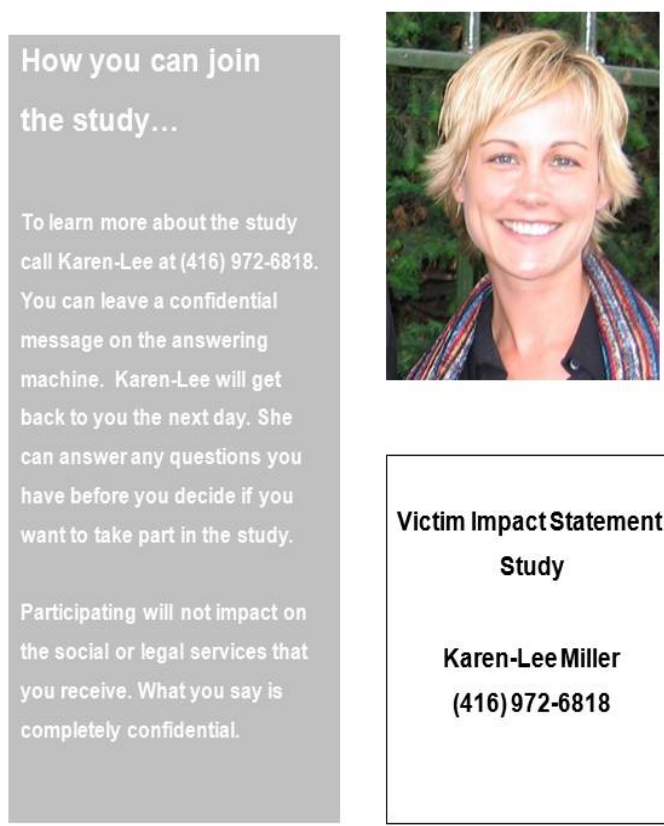

Have you ever

written a victim impact statement?

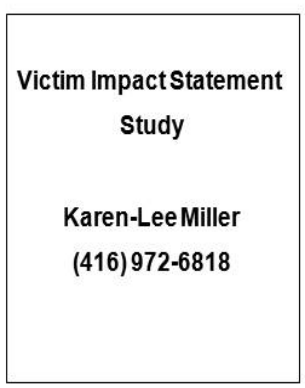

Would you like to join a research study and share your story?

To find out more, please call

(416) $972-6818$ 


\section{Appendix C-Study Information Pamphlet for Nonvictims}

\begin{tabular}{|c|c|c|}
\hline Who is eligible to join? & The research & The goals \\
\hline $\begin{array}{l}\text { To participate in this study, } \\
\text { you must help victims to } \\
\text { understand or complete } \\
\text { a victim impact statement } \\
\text { for court purposes. } \\
\text { And you must have assisted } \\
\text { with a victim impact statement } \\
\text { in the context of a sexual } \\
\text { assault case. }\end{array}$ & $\begin{array}{l}\text { Victim service workers who } \\
\text { join this study are asked to } \\
\text { take part in an interview that } \\
\text { will last up to } 60 \text { minutes. } \\
\text { You can choose the time } \\
\text { and the place of the interview. } \\
\text { In the interview you will be } \\
\text { asked to talk about: } \\
\text { - your role in helping with } \\
\text { the victim impact statement } \\
\text { - your work with other } \\
\text { professionals } \\
\text { - your opinion about the victim } \\
\text { impact statement }\end{array}$ & $\begin{array}{l}\text { A long-term goal of this study } \\
\text { is to understand ways to } \\
\text { improve the experiences of } \\
\text { women who choose to } \\
\text { complete a victim impact } \\
\text { statement. }\end{array}$ \\
\hline
\end{tabular}

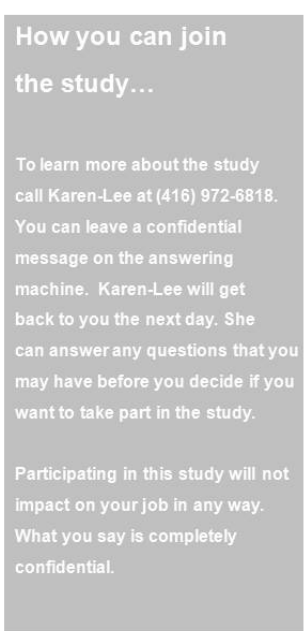

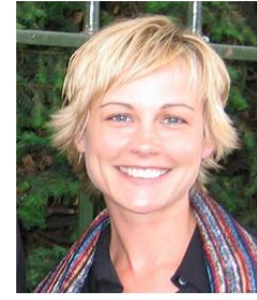

Karen-Lee

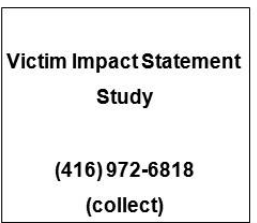

Have you ever

assisted a woman

who has been

sexually assaulted

in preparing a victim

impact statement?

Would you like to

join a research

study and share

your experiences?

To find out more,

please call

(416)972-6818 


\section{Appendix D-Information and Consent Form for Victims}

\section{A STUDY ABOUT THE VICTIM IMPACT STATEMENT}

The purpose of the study is to describe the experiences and process of undertaking, writing, submitting and presenting a victim impact statement in cases of female sexual assault. A long-term goal of this study is to understand ways to improve the experiences of women who choose to complete a victim impact statement. You have been asked to participate in this study because you have experience in completing a VIS in the context of a sexual assault case.

Before agreeing to participate in this study, it is important that you read and understand this information and consent form. This form provides information that you will need to know in order to decide whether you would like to participate, for example, the types of questions that you may be asked during the interview. If you have any questions after you read through this form, please ask the researcher (Karen-Lee). At the end of the form, you will be asked to give your verbal consent to participate. You should not agree to participate in the study until you are sure you are comfortable doing so.

Researcher: Karen-Lee Miller, MSW, PhD candidate in the Department of Public Health Sciences, Faculty of Medicine, University of Toronto

Supervisory Committee: Mariana Valverde, Centre for Criminology, University of Toronto; Peggy McDonough, Department of Public Health Sciences, University of Toronto; Adrienne Chambon, Faculty of Social Work, University of Toronto

Study Title: The use of the Victim Impact Statement in the context of Female Sexual Assault.

Sponsor: The Canadian Institutes of Health Research (CIHR) 
Review of the study: This study with this Information and Consent form have been reviewed and authorized by the Research Ethics Committee of the University of Toronto

Introduction: Before agreeing to participate in this study, it is important that you read and understand this information and consent form. This form provides information about the study that you will need to know in order to decide whether you would like to participate in the study. If you have any questions after your read through this form, please ask the researcher (Karen-Lee). At the end of the form, you will be asked to give your verbal consent to participate. You should not agree to participate in the study until you are sure you are comfortable doing so.

Purpose of the Research: The purpose of the study is to describe the experiences and process of undertaking, writing, submitting and presenting a victim impact statement in cases of sexual assault. A long-term goal of this study is to understand ways to improve the experiences of women who choose to complete a victim impact statement.

Eligibility: To participate in this study you must be female, over 18 years of age, and have completed a victim impact statement in the context of a sexual assault case.

Description of the Research: If you agree to participate in this study, you will be asked to take part in one interview that may take up to one and a half hours to complete. You will be able to decide on the place and time of the interview.

In the interview, you will be asked to discuss the following topics:

- how you first heard about your right to complete a victim impact statement

- why you chose to complete a victim impact statement

- how you decided what to write about in your victim impact statement

- whether anyone assisted you in the writing, editing or presentation of the victim statement

- what you found helpful or supportive during the victim impact statement process

- problems or barriers you may have faced during the process 
Potential Benefits, Harms and Inconveniences: You will not benefit immediately from participating in this study, but your contribution will increase awareness of what it is like for women who have been sexually assaulted to undertake a victim impact statement. In reports about the study, your contributions will be grouped with contributions from other participants to develop conclusions that could be used to improve the criminal justice supports available to women who complete victim impact statements.

Although there are no obvious harms associated with taking part in this study, participating will involve some of your time, and may inconvenience you. You may find it upsetting to discuss your experiences with undertaking a victim impact statement.

At the end of the interview, you will be provided with $\$ 25$ to assist with any costs of participation, such as parking or child care. You will also be provided with a list of local health and social services that provide services for women who have been sexually assaulted. A copy of this information and consent form will also be given to you.

Participation: Your participation in this study is entirely voluntary. It is important that you understand that if you change your mind and want to withdraw from the study at any time, you may simply inform the researcher (Karen-Lee). You do not need to provide any reasons for doing so. If you decide not to participate, it will not affect the legal or social care services you receive. You do not waive any legal rights by participating in the study. If you do decide to participate, you may refuse to answer any questions that you are not comfortable with.

Confidentiality: Everything you tell the researcher will be in confidence. The researcher or the study team will not share the information you provide. No information that could reveal your identity will be given to anyone. All information that is collected for the study, including audiotapes and transcripts, will be kept in a locked filing cabinet or on a password protected computer that can only be accessed by the researcher. Your name will not be recorded anywhere, and all identifying information such as names or dates that you may reveal during the interview will be replaced with pseudonyms. Your identity and any 
identifying characteristics will not be revealed in publications that report on the findings of this study.

Consent: You acknowledge that the research procedures described above have been explained to you and that any questions that you may have asked have been answered to your satisfaction. You have been informed of the alternatives to participation in this study, including the right not to participate and the right to withdraw without compromising the legal or social care that you may be receiving now, or at any time in the future. In addition, the potential harms and discomforts have been explained to you and you also understand the benefits of participating in the research study. You know that you may ask now, or in the future, any questions you have about the study or research procedures. You have been assured that all information pertaining to you will be kept strictly confidential and no information will be released or published that would disclose your personal identity.

You acknowledge that you have been provided with a copy of this consent form and description of the study. Having thoroughly read, understood and had full explanation of this consent form, you voluntarily consent to participate in this research study. Your consent will be recorded in the audiotape of the interview and recorded in field notes written by the researcher.

Further Questions: You understand that if you have any questions about this study, you can contact Karen-Lee Miller, who is responsible for the study, at (416) 603-5800 or at karenlee.miller@utoronto.ca, or her supervisor at the University of Toronto, Dr. Mariana Valverde, at (416) 978-6438 extension 229. If you have any questions or concerns about your rights as a participant in this study, you can call Jill Parsons, Ethics Review Officer, Ethics Review Office, University of Toronto, during working hours at (416) 946-5806 or by email: jc.parsons@utoronto.ca.

Please give Karen-Lee your verbal consent if you agree to participate in this study. 


\section{Appendix E-Information and Consent Form for Nonvictims}

\section{A STUDY ABOUT THE VICTIM IMPACT STATEMENT}

The purpose of the study is to describe the experiences and process of undertaking, writing, submitting and presenting a victim impact statement in cases of female sexual assault. Ultimately it is hoped that the findings of this study can be used to improve the experiences of women who choose to complete a victim impact statement (VIS). You have been asked to participate in this study because you have experience in directly assisting women in completing a VIS in the context of a sexual assault case, or providing VIS-related support in other contexts.

Before agreeing to participate in this study, it is important that you read and understand this information and consent form. This form provides information that you will need to know in order to decide whether you would like to participate, for example, the types of questions that you may be asked during the interview. If you have any questions after you read through this form, please ask the researcher (Karen-Lee). At the end of the form, you will be asked to give your verbal consent to participate. You should not agree to participate in the study until you are sure you are comfortable doing so.

The Study: The use of the Victim Impact Statement in the context of Adult Female Sexual Assault.

Researcher: Karen-Lee Miller, MA, MSW, PhD candidate in the Department of Public Health Sciences, Faculty of Medicine, University of Toronto

Supervisory Committee: Mariana Valverde, Centre for Criminology, University of Toronto; Peggy McDonough, Department of Public Health Sciences, University of Toronto; Adrienne Chambon, Faculty of Social Work, University of Toronto

Sponsor: The Canadian Institutes of Health Research (CIHR) 
Review of the study: This study with this Information and Consent form have been reviewed and approved by the Research Ethics Committee of the University of Toronto.

Purpose of the Research: The purpose of the study is to describe the experiences and process of undertaking, writing, submitting and presenting a victim impact statement in cases of female sexual assault. A goal of this study is to understand ways to improve the experiences of women who choose to submit a victim impact statement to court.

Eligibility: To participate in this study you must have (a) experience providing VIS-related assistance or information to adult females who had been sexually assaulted, or (b) knowledge of, or involvement in, VIS-related administrative practices, policy, and/or case law.

Description of the Research: This study will involve interviews with sexually assaulted VIS completers and criminal justice workers and other nonvictims who provide VIS-related support. If you agree to participate in this study, you will be asked to take part in one interview that will take up to one and a half hours to complete. You will be able to decide on the place and the time of the interview.

In the interview, you will be asked to discuss the following topics:

- guidelines and forms provided to a client who is eligible to complete a victim impact statement

- the ways in which you assist your client in the preparation or submission of a victim impact statement

- your work with other legal, paralegal or social care personnel who may be involved in assisting your client with a victim impact statement

- things that you find are helpful or supportive to undertaking your work in assisting a client during the victim impact statement process

- things that you find are problems or barriers to undertaking your work in assisting a client during the victim impact statement process

Potential Benefits, Harms and Inconveniences: You will not benefit immediately from participating in this study, but your contribution will increase awareness of facilitators and barriers to the completion of the victim impact statement in the context of sexual assault. In 
reports about the study, your contributions will be grouped with contributions from other participants to develop conclusions that could be used to improve the criminal justice supports available to women who complete victim impact statements.

Although there are no obvious harms associated with taking part in this study, participating will involve some of your time, and may inconvenience you.

At the end of the interview, a copy of this information and consent form will also be given to you.

Participation: Your participation in this study is entirely voluntary. Your employer will not be informed whether you have chosen to participate in this study, and participating or withdrawal from the study will not affect your employment. It is important that you understand that if you change your mind and want to withdraw from the study at any time, you may simply inform the researcher (Karen-Lee). You do not need to provide any reasons for doing so. You do not waive any legal rights by participating in the study. If you do decide to participate, you may refuse to answer any questions that you are not comfortable with.

Confidentiality: Everything you tell the researcher will be in confidence. The researcher or the study team will not share the information you provide. No information that could reveal your identity will be given to anyone. Information that you provide will not be shared with your employer. All information that is collected for the study, including audiotapes and transcripts, will be kept in a locked filing cabinet or on a password protected computer that can only be accessed by the researcher. Your name will not be recorded anywhere, and all identifying information such as names or dates that you may reveal during the interview will be replaced with pseudonyms. Your identity and any identifying characteristics will not be revealed in publications that report on the findings of this study.

Consent: You acknowledge that the research procedures described above have been explained to you and that any questions that you may have asked have been answered to your satisfaction. You have been informed of the alternatives to participation in this study, 
including the right not to participate and the right to withdraw. In addition, the potential harms and discomforts have been explained to you and you also understand the benefits of participating in the research study. You know that you may ask now, or in the future, any questions you may have about the study or research procedures. You have been assured that all information pertaining to you will be kept strictly confidential and no information will be released or published that would disclose your personal identity.

You acknowledge that you have been provided with a copy of this consent form and description of the study. Having thoroughly read, understood and had full explanation of this consent form, you voluntarily consent to participate in this research study. Your verbal consent will be recorded in the audiotape of the interview and recorded in field notes written by the researcher.

Further Questions: You understand that if you have any questions about this study, you may contact Karen-Lee Miller, who is responsible for the study, at (416) 972-6818 (collect) or through email at karenlee.miller@utoronto.ca, or her supervisor at the University of Toronto, Dr. Mariana Valverde, at (416) 978-6438 extension 229. If you have any questions or concerns about your rights as a participant in this study, you can call Jill Parsons, Ethics Review Officer, Ethics Review Office, University of Toronto, during working hours at (416) 946-5806 or by email: jc.parsons@utoronto.ca.

Please give Karen-Lee your verbal consent if you agree to participate in this study. 


\section{Appendix F-Interview Guide for Victims}

\section{Introduction}

We have gone through the "Information and Consent Form," you have agreed to participate and I have given you $\$ 25$ to cover transportation or child care expenses related to participating. Is this right? [Wait for verbal agreement]. Over the next hour, my questions will be about your experiences in writing, submitting, and/or presenting a victim impact statement in the context of a sexual assault case. Everything you say is absolutely confidential. You may skip questions that you do not feel comfortable answering, or you may ask me to come back to them later. At the end of the interview, I will be providing you with a list of social services in your area that provide information and support to women who have been sexually assaulted. Do you have any questions before we begin? [Wait for verbal consent to proceed]. Okay, let's start.

\section{Can you describe in your own words what a victim impact statement is?} Prompts: what do you think a VIS was designed to do e.g., affect sentence length or provide an opportunity for you to express how you are feeling? Do you think the VIS accomplished this in your particular case - why or why not?

2. How did you first find out about the victim impact statement? Prompts: who notified you, when did you find out, what forms were you provided

3. Why did you decide to write the victim impact statement? Prompts: what were your reasons? Did anyone help you decide?

4. Can you tell me a little bit about writing your victim impact statement? Prompts: who helped you and in what ways, what forms did you use, how long did it take

5. How did you decide what to write about? Prompts: were you given a list of appropriate topics, did someone coach you, did you just follow the form, did you ever have disagreements about what you should write and how did you resolve those disagreements, what would you have liked to write about that you didn't

6. In what ways was the VIS form helpful? In what ways was it not helpful? 
7. Once you had written your statement, was it modified or changed in any way? Prompt: Were you ever asked to write another version and if so, please describe. What changes did you have to make and why? How did it feel being asked to make changes? Did you think being told to make changes was helpful advice, and if so, why?

8. When it came time to submit your statement, who did you submit it to? Prompts: At what point was this in the case disposition? How did you know that you needed to submit it at this time? Was the timing convenient for you?

9. What happened to your statement after you submitted it? Prompt: who held it? Did they send it to anyone? Was it given to the defence?

10. Were you ever cross-examined by the defence on the contents of your VIS? Prompt: If so, please describe. If you had known that you would be cross-examined, would you still have completed a victim impact statement? If not, were you ever told this was a possibility (if so, by whom)? Were you prepared for the possibility of cross-examination (if so, did anyone help you prepare, what kinds of questions or comments were you prepared for)?

11. Did you verbally present your VIS in court? Prompt: if so, please describe. If not, can you tell me why you didn't present in court (e.g., not told you had the option, you don't like public speaking, you were afraid, you didn't go to the sentencing hearing, you were told that you would not be allowed)

12. Did the judge comment on your VIS in the judgment? Prompt: what did she/he say? How did those comments make you feel? How did you know those comments were a result of having read the VIS and not through other information (e.g., the trial)?

13. What impact or influence, if any, do you think the VIS made in your case?

14. When you think about all the people who may have been involved in helping you write, submit or present the victim impact statement (social worker, victim services workers, police, Crown), who do you think was the most helpful? The least helpful? Why? 
15. Do you have any suggestions for criminal justice personnel about how they can improve women's experiences of undertaking victim impact statements? Prompt: the forms; more court support; more or less assistance

16. Do you have any advice or suggestions to give a woman who has been sexually assaulted and thinking of completing a victim impact statement?

17. Is there anything that you would like to add about the victim impact statement that we have not discussed in the interview?

Thank you for your time. 


\section{Appendix G-Interview Guide for Nonvictims}

\section{Introduction}

We have gone through the "Information and Consent Form," and you have agreed to participate. Is this right? [Wait for verbal agreement]. Over the next hour, my questions will be about your experiences in assisting a client with the writing, submitting and/or presenting a victim impact statement in the context of a sexual assault case [Note: revise in case of policy-makers or those who do not undertake direct client service]. Everything you say is absolutely confidential. You may skip questions that you do not feel comfortable answering, or you may ask me to come back to them later. Do you have any questions before we begin? [Wait for verbal consent to proceed]. Okay, let's start.

\section{Can you tell me a little bit about what you do as a [insert role/position]?}

Prompts: daily practices; responsibilities; scope of practice

2. Please describe in your own words what is a victim impact statement (VIS). Prompts: what do you think a VIS was designed to do e.g., affect sentence length or provide a "steam valve" for the victim? Do you think the VIS accomplishes this-why or why not?

3. Can you take me through the kinds of things you do when you are involved with a client who is eligible to complete a victim impact statement? Prompts: do you inform clients of their right to complete a VIS, assist with the writing, transcribe their words, edit their submissions, prepare them for verbal presentation? [Revise as appropriate if respondent is not involved in direct VIS service]

4. How does the client decide what she is going to write about? Prompts: Do you ever offer suggestions on what she should write? What kinds of suggestions do you give? Where do you get the ideas about what should, or should not go into the victim impact statement? What are the steps that are taken if there is a disagreement about what goes into a VIS?

5. Do you work with other legal or social professionals who also assist with clients who are completing victim impact statements? Prompts: If so, whom? How does your role differ from theirs? Does it conflict with their roles? Does it complement their roles? Can you 
provide a recent example where you worked well with another professional around the VIS? Where you worked less well?

6. What differences, if any, are there between clients who complete a victim impact statement in the context of a sexual assault (SA) case and those who complete them for nonsexual offences? Prompts: Are SA client equally likely to attempt to complete a VIS? Are there some categories on the VIS form that SA VIS completers don't use with the same frequency as other crime victims? Are they more or less anxious about being cross-examined on the contents of their VIS?

7. What has been your impression about how VISs written by sexually assaulted clients are received by the court? Prompts: Do the judges include comments about the VIS in their judgments? What effect do you think that has on SA clients?

8. What are some changes that you think could be implemented to improve a client's experience of writing and presenting a victim impact statement in the context of a sexual assault case?

9. Is there anything that you would like to add about the victim impact statement that we have not discussed in the interview?

Thank you for your time. 